\title{
V. Befriedung und Stagnation: Die CSU in der Ära Ehard 1949-1955
}

\section{Mühsamer Start - die CSU nach Straubing}

\section{a) Das ungeliebte Amt: Hans Ehard als Parteichef}

Als Hans Ehard im Mai 1949 mehr nolens als volens die Führung der bayerischen Unionspartei übernahm, war er genau der Landesvorsitzende, den die von inneren Streitigkeiten zerrissene und zutiefst verunsicherte CSU brauchte - und er war es doch wieder nicht ${ }^{1}$. Ehard hatte sich, so gut es ging, aus den Führungs- und Flügelkämpfen herausgehalten, seine landesväterliche Autorität immer wieder geschickt ausgespielt und die Partei so auf seine Linie eingeschworen. Sein Amt hob Ehard gleichsam über das Parteivolk hinaus und machte ihn nahezu unangreifbar. Kein Wunder, daß es in einem Strategiepapier zur Vorbereitung der ersten Bundestagswahlen hieß, die CSU lebe „in den breitesten Massen der für sie in Frage kommenden Wähler ausschließlich von dem Prestige ihres Vorsitzenden “2. Es war jedoch nicht nur der Respekt, ja die Ehrfurcht vor dem Ministerpräsidentenamt, die Ehard zur großen Integrationsfigur seiner Partei werden ließ, sondern auch seine persönliche Integrität und seine ehrgeizlose, nüchterne Art, Probleme zu behandeln und dabei Sachfragen über persönliche Konflikte zu stellen. Ehard hatte sich nie nach einem Amt gedrängt, schon gar nicht nach dem des CSU-Vorsitzenden. Um so stärker war seine Position; schließlich hatte man ihn gerufen, ja fast genötigt, den Landesvorsitz zu übernehmen, um die Auseinandersetzungen zu beenden und die Partei wieder auf Erfolgskurs zu führen. Vielleicht war Ehard nicht der Mann der Mitte und der "Mann des Sammelns“" , als der er gefeiert wurde und als der er sich selbst gerne gab. Aber er war ein aufrechter und glaubwürdiger Anhänger des Unionsgedankens. Die politische Zusammenarbeit der beiden groBen christlichen Konfessionen als Erbe des gemeinsamen Kampfes gegen den Nationalsozialismus ${ }^{4}$ war für ihn das Urprinzip der Union, das es unter allen Umständen zu verteidigen galt 5 . Ehard ließ auch keinen Zweifel daran, daß er - obwohl vor 1933 selbst BVP-Mitglied - allen Gedanken an eine Revitalisierung der Bayerischen Volkspartei eine Absage erteilte. Die Union sei 1945 als völlig neue Partei mit dem festen Willen gegründet worden, die Demokratie aufzubauen und gegen alle Angriffe zu ver-

' Vgl. auch Gelberg, Hans Ehard, S. 275 ff., und Mintzel, Anatomie, S. 244-250.

2 BSB, NL Schwend 2, "Gedanken zur Vorbereitung des Wahlkampfes" vom 26. 6. 1949.

${ }^{3}$ ACSP, CSU-LTF II/1, 15-12/3, Rede Hans Ehards vor dem Landesausschuß der CSU am 14. 4. 1951 in Würzburg.

${ }^{4}$ ACSP, CSU-LL, Rechenschaftsbericht Hans Ehards vor dem Landesausschuß der CSU am 25. 10. 1952 in Dinkelsbühl.

${ }^{5}$ ACSP, CSU-LL, Rede Hans Ehards vor der Landesversammlung der CSU am 9. 10. 1954 in Nürnberg. 
teidigen, führte Ehard 1951 vor den Delegierten der Landesversammlung aus ${ }^{6}$. Man verkenne den Charakter der CSU, wenn man sie abschätzig „in die Kategorie der sogenannten alten Parteien“ einreihe. Die Union sei keine „Rückfälligkeit“, sondern bestehe zu dem Zweck, „die Entwicklung unseres politischen Lebens vor Rückfälligkeiten zu bewahren". Schon 1948 hatte sich Ehard ähnlich geäußert und sich dabei offen von den BVP-Traditionalisten distanziert:

„Die einstige Bayerische Volkspartei, die ein ansehnliches, festgefügtes und darum außerordentlich stabiles bayerisches Parteigebilde gewesen ist, war für die Erfüllung der Aufgaben, die sie sich gestellt hatte, doch zu schwach. Die Forderungen, die sie in der bayerischen Sache vertrat, standen sehr oft im Mißverhältnis zu ihren tatsächlichen machtmäßigen Möglichkeiten, sich durchzusetzen. Um wirklich bayerische Politik machen zu können, bedarf es einer Partei, die umfassender und universaler in ihrer Zusammensetzung, die kräftiger im Innern und überzeugender nach außen ist, als es die BVP in ihren besten Zeiten war. Gerade aus dieser Erkenntnis heraus haben die Männer, die zu einem großen Teil aus der ehemaligen Bayerischen Volkspartei kommen, nach dem Wiedererwachen des geknechteten demokratischen Lebens den Ruf der Christlich-Sozialen Union ergehen lassen zur Vereinigung aller bayerischen Kräfte ohne Unterschied des Standes und der Konfession, wenn sie sich nur durch die Wahl einer christlich fundierten Staats- und Gesellschaftsauffassung gebunden fühlen. Das bayerische Volk ist mit einem bemerkenswerten Verständnis diesem Ruf gefolgt, und es ist die Christlich-Soziale Union als eine der größten Hoffnungen eines neuen Bayern entstanden. "

Auch eine Annäherung an die Bayernpartei und die Aufgabe der Unionsidee zugunsten einer altbayerisch-katholischen Blockbildung war mit Ehard nicht zu machen ${ }^{8}$. Anders als Schäffer und Hundhammer stand der neue Landesvorsitzende der aufstrebenden landespolitischen Konkurrenz höchst skeptisch gegenüber und hielt insbesondere den Bayernpartei-Vorsitzenden Joseph Baumgartner für unberechenbar' ${ }^{9}$. Gerade dieses Festhalten an den grundlegenden Prinzipien der Union machte es vielen Anhängern der CSU in Franken möglich, die Entscheidung von Straubing zu akzeptieren und weiterhin in der Partei mitzuarbeiten.

Ehard bemühte sich redlich, die CSU aus der Krise zu führen, aber die Partei, deren Vorsitz er erst nach langem Zögern übernommen hatte ${ }^{10}$, blieb ihm stets fremd ${ }^{11}$. Für

${ }^{6}$ ACSP, CSU-LL, Rede Hans Ehards vor der Landesversammlung der CSU am 23. 6. 1951 in Bad Reichenhall.

7 Protokoll der Landesversammlung der CSU am 24./25. 1. 1948 in Marktredwitz, in: Protokolle und Materialien, S. 1492 f. Vor der Landtagsfraktion erklärte Ehard einige Monate später, man „könne nicht alles von 1919-1933 auf die heutigen Verhältnisse übertragen“. ACSP, CSU-LTF I, 15-14, Protokoll der Fraktionssitzung am 25. 8. 1948.

${ }^{8}$ ACSP, CSU-LL, Protokoll der Landesversammlung der CSU am 5./6. 7. 1952 in Regensburg, und Entwurf für den Rechenschaftsbericht Hans Ehards vor dem Landesausschuß der CSU am 25. 10. 1952 in Dinkelsbühl, sowie ACSP, CSU-LTF II/1, 15-14, Protokolle der Fraktionssitzungen am 12. 12.1950 und 19. 9. 1951.

9 BSB, NL Schwend 54, Aktennotiz über eine Besprechung zwischen Hans Ehard, Fritz Schäffer und Alois Hundhammer am 9.6. 1948. Am 30. 9. 1953 betonte Ehard während einer Sitzung der Landtagsfraktion, daß es "nach persönlichen Erfahrungen und Beobachtungen nicht möglich“ sei, mit den führenden Persönlichkeiten der Bayernpartei "in ein vernünftiges gemeinsames Verhältnis zu kommen“. ACSP, CSU-LTF II/1, 15-14.

10 IfZ-Archiv, RG 260, 7/29-1/13-16, Bericht des amerikanischen Generalkonsuls in München, Sam E. Woods, über die Straubinger Landesversammlung der CSU an das State Department vom 7.6. 1949. Darin heißt es: "The Minister President said that he was faced at Straubing with one of the most difficult decisions in his life and that he had never wanted to be party chairman, but that the alternative was to see the party fall apart."

11 BayHStA, NL Ehard 1039, undatierter Entwurf einer Erklärung Hans Ehards zu seiner Wahl als Landesvorsitzender. 
den Ministerpräsidenten waren die Prioritäten klar. Er fühlte sich in erster Linie dem bayerischen Staat und erst in zweiter Linie der CSU verpflichtet. Anders als Josef Müller, der in einer modernen Partei das Instrument der Politik gesehen hatte, wußte Ehard das Potential der CSU kaum zu nutzen. Ihm diente sie überwiegend zur parlamentarischen Absicherung der Regierungsarbeit und seiner föderalistischen Politik. Ehard machte auch keinen Hehl daraus, daß er sich aus Gründen der Staatsräson dazu entschlossen hatte, für das Amt des Parteivorsitzenden zu kandidieren:

„Ich bin seinerzeit durch das Vertrauen der Christlich-Sozialen Union an die Spitze der bayerischen Regierung gerufen worden, da es nach dem Wahlausgang dieser Partei oblag, für die politische Führung im Lande Sorge zu tragen. Ich streife diese Frage aus einem praktischen Anlaß, der mit meiner Person zusammenhängt. Es ergab sich nämlich in der CSU eine Lage, die mich kürzlich veranlaßte, auf den Wunsch meiner Parteifreunde selbst den Landesvorsitz zu übernehmen. Ich bin dadurch als Ministerpräsident kein anderer geworden! Daß der Regierungschef zugleich der Parteichef der Regierungspartei ist, ist in Ländern mit fester demokratischer Tradition sogar die natürliche Regelung. Trotzdem glaube ich, daß ich der Allgemeinheit ein paar Worte der Aufklärung schuldig bin, warum ich mich entschloß, auch noch diese Bürde auf mich zu nehmen. Ich habe es sicherlich nicht getan, weil mich etwa der Ehrgeiz plagte, ein führendes Parteiamt in die Hände zu bekommen. Selbstverständlich tat ich es in der Meinung, meiner Partei einen Dienst zu erweisen. Wenigstens glaubte ich, ihr den geforderten Dienst nicht mehr versagen zu können. Aber auch das war nicht der letzte und entscheidende Antrieb für meinen Entschluß, der mir wahrlich schwer genug fiel. Die ausschlaggebende Erwägung vollzog sich im Kopf des bayerischen Ministerpräsidenten und nicht im Herzen des Parteimannes! Was sich mir aufdrängte, war der drückende Gedanke, eine Pflicht gegenüber dem Lande zu verletzen, wenn ich mich versagte. Und so folgte ich der Pflicht und nahm die Last auf mich. Diese Überzeugung hängt mit der Überzeugung zusammen, daß die Zukunft der Christlich-Sozialen Union in Bayern eng mit der Zukunft Bayerns verbunden ist! Es handelt sich also hier um eine bayerische staatspolitische Frage ersten Ranges!“12

Folgerichtig versuchte der Ministerpräsident auch nicht, sich in der CSU eine Hausmacht aufzubauen, um seine Stellung dauerhaft zu sichern. Er, der bayerische Gouvernementale, fühlte sich in der Mitte seiner Ministerialbeamten in der Staatskanzlei wesentlich wohler als in der Gesellschaft von Parteifreunden. Ehard verstand es nicht, der CSU neue Impulse zu geben, und auch die Ansätze für eine dringend notwendige Reform von Parteiorganisation und -apparat verliefen immer wieder im Sande. Heinrich Aigner, der einige Zeit als Sekretär der Jungen Union in der Parteizentrale gearbeitet hatte, wußte 1957 sogar zu berichten, daß Ehard die Landesgeschäftsstelle kein einziges Mal betreten habe, solange er Landesvorsitzender gewesen sei ${ }^{13}$. Es wäre gewiß zu einfach, Ehard dafür und für manch andere Versäumnisse zu tadeln oder ihm allein die Schuld daran zu geben, daß die Partei unter seiner Regie mehr und mehr verkam. Aber er war zu führungsschwach, um eine grundlegende Reorganisation der Partei durchsetzen zu können, und er hatte zu wenig Charisma und zu wenig Kampfgeist ${ }^{14}$,

12 Unter der Überschrift „Zur bayerischen Situation 1949“ abgedruckt in: Bayerische Politik, S. 48-52. Ein Redemanuskript findet sich im ACSP, NL Seidel 35 a; ähnlich auch BayHStA, NL Ehard 1362, Hans Ehard an Konrad Adenauer vom 4. 6. 1949.

13 BayHStA, NL Ehard 407, Egon Klohn an Hans Ehard vom 28. 6. 1957

14 ACSP, CSU-LTF I, 15-14, Protokoll der Fraktionssitzung am 2. 10. 1950. Anton Besold, ein prominenter Bayernpartei-Politiker, nahm diese Schwäche Ehards am 23.7. 1952 in einer aggressiven Rundfunkrede aufs Korn: „Der Hauptfehler der Politik des bayer[ischen] Ministerpräsidenten Ehard ist, dass er sich von den Ereignissen treiben lässt, dass er bremst, bis sich etwas ereignet, und dass er nicht den Mut hat, selbst Ereignisse zu gestalten." BAK, NL Schäffer 27, Bl. 66-69 (hier Bl. 69). 
um die CSU aus ihrer lähmenden Lethargie zu befreien. Ehard erkannte solche Fehlentwicklungen durchaus, doch er war nur selten in der Lage, sie zu korrigieren ${ }^{15}$.

\section{b) Enttäuschte Hoffnungen}

Hans Ehard war sich der Tatsache bewußt, daß er mit dem Landesvorsitz eine wahre Sisyphos-Aufgabe übernommen hatte, und die Erwartungen, die nach seiner Wahl von den verschiedensten Seiten an ihn herangetragen wurden, waren groß. Ehard sollte vor allem den weiteren Zerfall der CSU aufhalten und den chaotischen Zuständen in der Partei ein Ende setzen. Müllers Gegner hatten in diesem Sinne mit dem Argument für den Ministerpräsidenten geworben, daß die Mitgliederzahlen wieder steigen und die versiegten Geldquellen wieder sprudeln würden, wenn die Lichtgestalt der CSU erst einmal zum Parteivorsitzenden gewählt sei ${ }^{16}$. Der konservative Flügel der bayerischen Unionspartei hoffte ferner, daß es nach dem Sturz Müllers endlich möglich sein würde, mit der Bayernpartei ins Gespräch und möglichst noch vor den Bundestagswahlen zu einem modus vivendi zu kommen ${ }^{17}$.

Ehard selbst interpretierte seine Wahl zum Landesvorsitzenden als Auftrag, die krisengeschüttelte CSU zu stärken und um der Zukunft des bayerischen Staates willen als "politisches Instrument ${ }^{\alpha}$ zu erhalten ${ }^{18}$. Der Ministerpräsident wurde immer wieder von stürmischem Beifall und Bravo-Rufen unterbrochen, als er die Delegierten in Straubing nach der Bekanntgabe des Wahlergebnisses eindringlich daran erinnerte, daß sich dieses Ziel nur nach dem Ende der Führungs- und Flügelkämpfe erreichen ließ:

„Eines allerdings, liebe Parteifreunde, muss aufhören: Es muss endlich einmal dieses persönliche Gegeneinander aufhören, [. . .] das persönliche Mißtrauen, dieser Untergrund, dieses - ich möchte fast sagen - Hassgefühl, [...] das gelegentlich aufflammt, wenn Meinungsverschiedenheiten auftauchen. Warum kann man nicht Meinungsverschiedenheiten so austragen, daß sie nicht ins Persönliche gehen? [...] Es muss das einmal aufhören, sei es nun Flüsterpropaganda, seien es nun alle möglichen anderen mehr oder weniger schönen Redensarten. [. . . Liebe Parteifreunde! Ich weiss und Sie wissen es alle: Unsere Parteifreunde draussen im Lande haben dafür wenig Verständnis. [...] Am allerwenigsten Verständnis haben unsere Heimatvertriebenen, die ganz andere Sorgen haben; [. . . ] haben auch unsere Frauen, die nicht verstehen, daß man einen Zank verewigt, [...] und für diese Art der Politik hat vor allen Dingen kein Verständnis unsere Jugend. [.. .] Wir müssen von dieser Art Politik wegkommen. Denn sie zerstört nicht nur die Partei, sie zerstört nicht nur das Zusammenleben und Zusammenarbeiten; sie zerstört die Demokratie, ehe sie überhaupt gewachsen ist."

Doch die Hoffnungen auf ein schnelles Ende der innerparteilichen Auseinandersetzungen wurden ebenso enttäuscht wie die Hoffnungen auf einen Aufbruch der CSU zu neuen Ufern. Vor allem bei den zahlreichen Gegnern Josef Müllers war die Meinung verbreitet gewesen, es würde sich alles von selbst regeln, wenn der Hydra erst einmal

15 ACDP, NL Ehlers 02/1, Protokoll der Sitzung des geschäftsführenden Ausschusses des EAK am 29. 9. 1952; ACSP, CSU-LL, Protokoll der Landesversammlung der CSU am 5./6. 7. 1952 in Regensburg.

16 Vgl. z. B. die Rede Hundhammers in Straubing; ACSP, NL Müller 16, Protokoll der Landesversammlung der CSU vom 27.-29. 5. 1949 in Straubing.

17 ACSP, CSU-LTF I, 15-14, Protokoll der Fraktionssitzung am 31. 5. 1949.

18 ACSP, NL Müller 16, Protokoll der Landesversammlung der CSU vom 27.-29. 5. 1949 in Straubing; das folgende Zitat ebenda. 
der letzte Kopf abgeschlagen sei ${ }^{19}$. Nun mußten aber auch sie erkennen, daß es nicht genügte, einfach den Parteivorsitzenden auszuwechseln, um die tiefgreifende Krise erfolgreich bekämpfen zu können. Die Wahl Hans Ehards setzte bei weitem nicht die Energien frei, die man erwartet hatte; wenn überhaupt, vermochte sie nur ein Strohfeuer zu entfachen, das hell aufflackerte und rasch verglomm. Die Zahl der CSU-Mitglieder verringerte sich auch nach der Straubinger Landesversammlung rasch und stetig ${ }^{20}$, und die Finanzlage der Partei blieb trotz Hundhammers vollmundiger Ankündigungen kritisch ${ }^{21}$. Nicht einmal die Reform der immer wieder heftig umstrittenen Satzungen konnte zügig zu Ende geführt werden. Auf Antrag des neuen Landesvorsitzenden wurden die noch unter Müller ausgearbeiteten Änderungsvorschläge von der Landesversammlung ohne Aussprache an den Landesausschuß verwiesen und damit auf unbestimmte Zeit vertagt ${ }^{22}$.

Daß die inneren Konflikte nicht abflauten, lag vor allem an Alois Hundhammer. Der "Sieger von Straubing“, der den Tag von Müllers Sturz als den schönsten seines Lebens bezeichnet haben soll ${ }^{23}$, ließ nun alle Rücksichten fahren; eine Koalition mit der Bayernpartei sei unter den neuen Gegebenheiten eher möglich als bisher, erklärte $\mathrm{er}^{24}$. Solche Äußerungen lösten bei den ohnehin tief verunsicherten Anhängern Josef Müllers helles Entsetzen aus. Noch am 30. Mai wandten sich mehr als dreißig prominente Mitglieder der CSU - darunter führende evangelische Persönlichkeiten aus Ober- und Mittelfranken wie August Haußleiter, Elisabeth Meyer-Spreckels, Alfred Euerl und Karl Sigmund Mayr - an den neuen Landesvorsitzenden ${ }^{25}$. „Uns alle bewegt die Frage“, hieß es in dem ernsten Brief, ob mit den Entscheidungen von Straubing der „Übergang zur alten Bayerischen Volkspartei oder zu einer wirklich neuen Entwicklung in der Christlich-Sozialen Union“ verbunden sei. Die Unterzeichneten machten keinen Hehl daraus, daß sie in Bayern und in Deutschland nichts so sehr fürchteten wie „den Rückfall in alte politische Methoden und damit auch in alte politische Fehlentwicklungen“. In diesem Sinne forderten sie Ehard nachdrücklich auf, allen Gerüchten über eine bevorstehende Fusion von CSU und Bayernpartei entgegenzutreten und es nicht länger zu dulden, daß Teile der eigenen Partei in Südbayern offensichtlich mit dem politischen Gegner fraternisierten. Der Hauptschuldige an dieser Entwicklung war für Haußleiter und seine Gesinnungsgenossen ohne Frage Alois Hundham-

19 BayHStA, NL Sedlmayr 22, Alois Hundhammer an Lorenz Sedlmayr vom 31. 12. 1948; ACSP, NL Müller 68, Protokoll der Bezirksversammlung der CSU München am 7. 4. 1949; BSB, NL Schwend 2, Notiz über die Bezirksversammlung der CSU München am 7. 4. 1949.

20 IfZ-Archiv, RG 260, 10/90-3/9, „Subject: CSU zum Wahlkampf“ vom 9.6. 1949; IfZ-Archiv, RG 260, 13/150-1/8, Politischer Tätigkeitsbericht der CSU für Juli 1949, und IfZ-Archiv, RG 260, 13/ 150-1/7, Politischer Tätigkeitsbericht der CSU für August 1949. Allein im August 1949 verlor die CSU 820 Mitglieder bei nur 70 Neuaufnahmen.

21 ACSP, CSU-LL, Protokolle der Sitzungen des geschäftsführenden Landesvorstands am 17. 6. und 28. 7. 1949. Am 28. Juli erklärte Ehard alarmiert, die Beitragszahlungen der Bezirks- und Kreisverbände wiesen einen "noch nie dagewesenen Tiefstand auf“.

22 ACSP, NL Müller 16, Protokoll der Landesversammlung der CSU vom 27.-29. 5. 1949 in Straubing.

23 BayHStA, NL Ehard 1046, Aktennotiz August Haußleiters über die Sitzung der CSU-Landtagsfraktion am 31.5. 1949. Hundhammer bestritt, diese Worte gebraucht zu haben. ACSP, CSU-LTF I, 15-14, Protokoll der Fraktionssitzung am 31. 5. 1949.

24 Telegraf vom 31. 5. 1949: „Ein Pyrrhussieg?“; Main-Echo vom 31. 5. 1949: „Der Sieger von Straubing. Wird die letzte Trumpfkarte der CSU stechen?"; SZ vom 31. 5. 1949: „Dr. Ehard zum Landesvorsitzenden der CSU gewählt“.

25 BayHStA, NL Ehard 1047, August Haußleiter und andere an Hans Ehard vom 30. 5. 1949; die folgenden Zitate ebenda. 
mer, den sie auch zu einem guten Teil für den unheilvollen Dualismus von Partei und Fraktion verantwortlich machten:

„Ein sehr grosser Teil unserer Freunde hat Sie gewählt, um einen inneren Ausgleich in der CSU zu erreichen. Dieser innere Ausgleich ist nur dann erreicht, wenn gleichzeitig auch die Fraktion der CSU im Landtag eine Führung der Mitte erhält. Sie wissen, dass die Partei sich als politisch machtlos gegenüber den Entscheidungen der Fraktion erwiesen hat. Die Regierung ist nicht durch die Partei, sondern durch die Fraktion gebildet worden, und Ihr erstes Kabinett sogar im ausgesprochenen Gegensatz zum Mehrheitswillen der Partei. Wenn die Partei eine Führung der Mitte hat, die Fraktion aber eindeutig von dem schärfsten Vertreter des rechten Flügels geführt wird, und wenn überdies die Regierung in ihrer überwiegenden Mehrheit aus Mitgliedern dieses rechten Flügels besteht, dann bedeutet die Ausschaltung des linken Flügels aus der an sich schon politisch sehr wenig bedeutsamen Parteileitung eine so eindeutige Option für einen klaren Rechtskurs der CSU, dass dadurch das erstrebte Gleichgewicht eher gestört als erreicht wird. Wir glauben deshalb, dass als Folge der Ausschaltung Dr. Josef Müller[s] vom Parteivorsitz ein Rücktritt Dr. Hundhammers vom Fraktionsvorsitz und eine Bildung einer ausgeglichenen und auch aktionsfähigen Fraktionsführung die unmittelbare Folge sein muss. Falls dieses Problem nicht gelöst wird, [wird] ohne Zweifel Ihre auf Vorschlag Dr. Hundhammer[s] erfolgte Wahl zum Parteivorsitzenden von einem sehr grossen Teil unserer Mitglieder und Wähler nicht als innerer Ausgleich, sondern als ein besonderer Erfolg Dr. Hundhammer[s] empfunden werden."

Der Gedanke, Hundhammer als Fraktionsvorsitzenden abzulösen und so wenigstens teilweise zu entmachten, war nicht neu. Schon im April 1947 hatten die Anhänger Müllers in der Landtagsfraktion ohne Erfolg einen Antrag eingebracht, der darauf abzielte, Fraktionsvorsitz und Ministeramt für unvereinbar zu erklären ${ }^{26}$. Im Vorfeld der Straubinger Landesversammlung war die Ablösung des Fraktionsvorsitzenden erneut diskutiert worden ${ }^{27}$, doch Hundhammer hatte sich lediglich zu der dehnbaren Erklärung durchringen können, keine führende Position in der neuen Parteileitung zu beanspruchen ${ }^{28}$. Das genügte den liberal-konservativen, interkonfessionell orientierten Anhängern Josef Müllers freilich nicht. Sie forderten gleichsam als Kompensation für ihr Entgegenkommen in der Frage des Parteivorsitzenden und als Garantie gegen einen Rechtsruck der CSU einen Wechsel an der Fraktionsspitze. Ein diesbezüglicher Antrag war für die Straubinger Landesversammlung vorbereitet und von Franz Xaver Butterhof, einem führenden Mitglied der Jungen Union aus Nürnberg, begründet worden. Doch dann hatten sich Butterhof und seine Freunde entschlossen, ihren Antrag als Zeichen des guten Willens zurückzuziehen ${ }^{29}$.

Damit war die Angelegenheit aber nicht erledigt. Schließlich hatte Ehard noch in Straubing angedeutet, daß man sich zu gegebener Zeit noch einmal über die Trennung von Fraktionsvorsitz und Ministeramt unterhalten könne. Der neue Landesvorsitzende hätte eine Ablösung Hundhammers wohl selbst nicht ungern gesehen, den er für unberechenbarer hielt als Müller und dessen Kontakte zu partikularistischen oder gar separatistischen Kreisen ihm ein Dorn im Auge waren ${ }^{30}$. Entsprechend erbost war Ehard

26 ACSP, CSU-LTF I, 15-14, Protokoll der Fraktionssitzung am 10. 4. 1947.

27 ACSP, NL Müller 55, Willi Hönekopp an Alois Hundhammer vom 25. 3. 1949, und NL Müller 144, Otto Kalbskopf an die Landesleitung der CSU vom 26. 3. 1949; SZ vom 16. 4. 1949: „Müller und Hundhammer sollen verzichten“.

28 IfZ-Archiv, ED 720 Smlg. Mintzel 45, Informations-Rundschreiben Nr. 1/49 des CSU-Bezirksverbands Oberfranken vom 15.3. 1949.

29 ACSP, NL Müller 16, Protokoll der Landesversammlung der CSU vom 27.-29. 5. 1949 in Straubing.

30 IfZ-Archiv, RG 260, 13/150-3/8, „Subject: Talk with Minister President Dr. Ehard about Landes Meeting of the CSU“ vom 31.5. 1949; das folgende nach dieser Aufzeichnung von J. P. Bradford. 
über die Statements seines Kultusministers bezüglich des Verhältnisses von CSU und Bayernpartei. Hundhammer sei eine große Belastung für ihn und seine Politik, teilte der Ministerpräsident unmittelbar nach der Straubinger Landesversammlung einem Vertreter der Militärregierung mit, der außerdem notierte, daß Ehard Hundhammer lieber heute als morgen loswerden würde, aber noch nicht wisse wie. Der erste Schritt müsse jedoch sein, Hundhammer als Fraktionsvorsitzenden zu stürzen.

Während Ehard auf eine günstige Gelegenheit warten wollte, suchte der hitzköpfige August Haußleiter, unterstützt von den Resten des Müller-Flügels, den schnellen, propagandistisch verwertbaren Erfolg. Gemeinsam mit den Landtagsabgeordneten Johann Brandner, Alfred Euerl und Ferdinand Neumann beantragte er am 8. Juni 1949, die "Entscheidung über die zukünftige Regelung des Fraktionsvorsitzes“ auf die Tagesordnung der nächsten Fraktionssitzung zu setzen, um die „innere Befriedung innerhalb der Christlich-Sozialen Union endlich zu verwirklichen “31. Doch Hundhammer dachte überhaupt nicht daran, seinen Sessel zu räumen ${ }^{32}$, und versuchte sogar, den Antrag Haußleiters ins Lächerliche zu ziehen, als dieser am 21. Juni in einer schwach besuchten Sitzung der Fraktion beraten wurde ${ }^{33}$. Der stellvertretende Landesvorsitzende begründete den Antrag selbst und forderte unmißverständlich Hundhammers Rücktritt, um das nach Müllers Sturz gestörte Gleichgewicht in der Partei wiederherzustellen und um den neuen „Kurs der Mitte“ auch nach außen zu dokumentieren.

Doch es zeigte sich schnell, daß diese Initiative nur wenig Aussicht auf Erfolg hatte; Haußleiter hatte seinen Antrag schlecht vorbereitet und konnte nicht einmal auf alle Abgeordneten zählen, die Hundhammers Politik bisher stets abgelehnt hatten. Zudem war die Forderung nach der Ablösung des Fraktionsvorsitzenden in der Öffentlichkeit bekannt und somit zu einer Prestigefrage geworden ${ }^{34}$, die jede sachliche Debatte überschatten mußte. Kein Wunder, daß die Auseinandersetzung mit harten Bandagen geführt wurde und letztlich sogar das Fundament der Union zu gefährden drohte. So schleuderte Josef Stürmann der in Straubing unterlegenen Minderheit am 21. Juni entgegen:

„Ich bin gewohnt, lange zuzuhören. Mir fällt auf, daß man grundsätzlich immer die unmöglichsten Argumente bringt. Wenn wir uns bewußt auseinander reden wollten, könnten wir es nicht besser machen. Ich bin in manchem nicht Hundhammers Meinung. Daß Minister und Fraktionsvorsitzender eine Person ist, ist auch nicht glücklich, wenn Sie das aber vor $11 / 2$ Jahren gegenüber dem Parteivorsitz von Dr. Müller geltend gemacht hätten, könnte ich Ihren Argumenten heute mehr Gehör schenken. Wir müssen endlich einmal die fortgesetzten Störer in der CSU el[i]minieren. Wird der Machtkampf bewußt von irgend einer Seite fortgesetzt, dann ist es unsere Pflicht zu überlegen, wie weit solche Persönlichkeiten noch Mitglieder unserer Fraktion sein können. [...] Verlangen Sie vom Fraktionsvorsitzenden keine Geste, was in Ihrem Herzen keine Geste, sondern eine fundamentale Änderung ist, oder seien Sie so mutig und sagen Sie, wir wollen die innere Änderung, da wir sie nicht durchsetzen, treten wir aus. Diese Alternative wäre die ehrlichere und würde der Partei im Sinne ihrer Ideologie am meisten helfen.“

31 ACSP, NL Seidel 35 c, Johann Brandner, Alfred Euerl, August Haußleiter und Ferdinand Neumann an Alois Hundhammer vom 8.6.1949.

32 IfZ-Archiv, RG 260, 10/90-3/9, „Subject: „Hundhammer-Anhänger und Hau[ß]leiter“ vom 16. 6. 1949.

33 ACSP, CSU-LTF I, 15-14, Protokoll der Fraktionssitzung am 21.6. 1949; das folgende - soweit nicht anders belegt - nach dem Protokoll dieser Sitzung.

${ }^{34}$ SZ vom 2. 6. 1949: „,Mittlerer Kurs‘ für die CSU. Haußleiter fordert: Keine Zusammenarbeit mit der Bayernpartei“; Telegraf vom 3. 6. 1949: „CSU ringt um ihre Linie“; SZ vom 16. 6. 1949: „Wechsel im CSU-Fraktionsvorstand gefordert“. 
Mit dieser Meinung stand Stürmann nicht allein. Schon wenige Tage zuvor hatte Ludwig Huber, ein Anhänger Hundhammers, einem Vertrauensmann der Militärregierung erklärt, Haußleiter und seine Gesinnungsgenossen hätten es noch immer nicht verwunden, „daß mit dem Sturze Dr. Müllers auch ihre Felle davon geschwommen“ seien, und sie bemühten sich nun verzweifelt, verlorenes Terrain zurückzugewinnen. Aber ihre Zeit in der Union sei nun um $^{35}$. So deutlich hatten die Vertreter des katholisch-konservativen Parteiflügels ihre liberalen und protestantischen Parteifreunde noch nie spüren lassen, daß man sie für einen Fremdkörper in der CSU hielt. Doch seit Straubing wehte ein anderer Wind. Der evangelische Abgeordnete Alfred Euerl aus Nürnberg konnte auf die offene Kampfansage Stürmanns nur fassungslos antworten, man dürfe ihn und seine Mitstreiter nicht als „Sprengpilze“ brandmarken, die man vor die Tür setzen müsse; schließlich seien in den innerparteilichen Konflikten vor allem sie mißbraucht worden.

Der Verlauf der Fraktionssitzung vom 21. Juni brachte Ehard in eine schwierige Situation. Einerseits wäre es auch in seinem Sinne gewesen, Hundhammer in die Schranken zu weisen, andererseits konnte er sich aber in der gegenwärtigen Situation keinesfalls auf eine Kraftprobe mit dem mächtigen Kultusminister einlassen. So entschied sich der neue Landesvorsitzende dafür, der Fraktion zu empfehlen, Haußleiters Antrag zurückzustellen und zu gegebener Zeit ohne alle persönlichen Ressentiments darüber zu diskutieren, ob die Verbindung von Fraktionsvorsitz und Ministeramt zweckmäßig $\operatorname{sei}^{36}$. Doch Hundhammer lehnte jeden Kompromißvorschlag ab und forderte eine offizielle Zurücknahme des von Haußleiter gestellten Antrages oder die sofortige Abstimmung; alles andere, so meinte er, müsse ihn als Fraktionschef desavouieren. Da der stellvertretende Landesvorsitzende und seine politischen Freunde an ihrem Antrag festhielten, kam es zur Abstimmung. Von den 68 Abgeordneten, die sich daran beteiligten, votierten 54 für Hundhammer, elf sprachen sich gegen ihn aus und drei enthielten sich der Stimme.

Einen Tag nach dieser Niederlage trat August Haußleiter von seinem Amt als stellvertretender Parteivorsitzender zurück. In einem Brief an Hans Ehard schrieb er tief enttäuscht über die Entwicklung der CSU:

„Ich bekenne mich zu den Zielen und Idealen, in deren Namen die Gründung der Christlich-Sozialen Union erfolgt ist. Als Stellvertreter des Parteivorsitzenden bin ich verpflichtet, Hüter dieses Programms und dieser Grundsätze zu sein. Wenn die Politik der Partei diese ihre Grundsätze verlässt, und wenn alle Versuche, sie wieder herzustellen, sich als unmöglich erweisen, wenn die neue Partei der Christlich-Sozialen Union sich wieder zurückverwandelt in die alte Partei der Bayerischen Volkspartei, deren Mitglieder aufrechte Demokraten und Christen waren, deren Führung aber schon einmal völlig versagt hat, dann wäre es gegen meine Pflicht und gegen mein Gewissen, wenn ich die Öffentlichkeit über diese Entwicklung täuschen und eine verantwortliche Stellung in der Partei weiterhin behalten würde. “37

35 IfZ-Archiv, RG 260, 10/90-3/9, „Subject: „Hundhammer-Anhänger und Hau[ß]leiter“ vom 16. 6. 1949.

36 In einer amerikanischen Quelle heißt es dazu treffend: „Ehard unsuccessfully attempted to have the issue postponed in the interest of party unity. [...] According to [Hanswolf] Haunhorst, one of Haussleiter's objects was to place Ehard on record concerning Hundhammer. Ehard refused to go on record." IfZ-Archiv, RG 260, 7/29-1/13-16, Bericht des amerikanischen Generalkonsuls in München, Sam E. Woods, über die Situation der CSU an das State Department vom 12. 7. 1949.

37 BayHStA, NL Ehard 1019, August Haußleiter an Hans Ehard vom 22. 6. 1949; in diesem Zusammenhang auch NL Ehard 1019, Hans Ehard an August Haußleiter vom 23. 6. 1949 und Hans Ehard an Anton Hergenröder vom 29.6. 1949. 
Haußleiters Rücktritt war ein Paukenschlag, auch wenn er nicht völlig unerwartet $\mathrm{kam}^{38}$. Die Öffentlichkeit hatte damit den Beweis, daß die Führungs- und Flügelkämpfe mit der Wahl Ehards nicht beendet waren. Wie sich das auf die bevorstehenden Bundestagswahlen auswirken sollte, war ungewiß. Gutes konnte man jedoch keinesfalls erwarten.

\section{Vor dem Sturz ins Nichts? Die ersten Bundestagswahlen}

\section{a) Wablkampf}

Es gab nur wenige Optimisten in den Reihen der CSU, die nach den Entscheidungen von Straubing darauf hofften, daß sich die Niederlage bei den Bundestagswahlen in Grenzen halten würde oder sogar ein Erfolg möglich sei ${ }^{39}$. In der bayerischen Unionspartei hatte sich vielmehr Resignation breit gemacht; man bereitete sich auf große Verluste vor und stellte Vermutungen darüber an, wie viele Prozentpunkte die CSU wohl verlieren würde ${ }^{40}$. Franz Heubl, der Kandidat der CSU für den Bundeswahlkreis München-West ${ }^{41}$, erklärte Anfang Juli einem Vertrauensmann der Militärregierung:

„Die Union wird [.. . ] einen gewaltigen Erdrutsch erleben. Wir haben keine zugkräftigen Parolen, haben unseren Kredit verbraucht durch die Regierungszeit und unsere persönlichen Händel. Was soll man da noch erwarten. Die Bayernpartei wird in Bayern mit der SPD wohl gleich auf gleich kommen und die Union wird zu einer im Vergleich zu früher kleinen Partei herabsinken. “42

Auch der neue Landesvorsitzende machte sich keine Illusionen über den Zustand seiner Partei und war tief besorgt über den Wahlausgang. Charlotte Fleischmann, die stellvertretende Vorsitzende des Bezirksverbands München, bemerkte, Ehard sehe „zerfallen“ aus und habe Sorgen, die er niemandem anvertrauen könne; er sei offensichtlich am Ende seiner $\mathrm{Kraft}^{43}$. Die zuständigen amerikanischen Behörden erwarteten ebenfalls eine klare Niederlage der CSU. Seit dem Sturz Josef Müllers habe die Partei kaum neue Aktivität entwickelt und gehe alles andere als einig in den Wahlkampf. Weiter hieß es in einer Analyse des Generalkonsulats in München:

38 Passauer Neue Presse vom 30. 5. 1949: „Dr. Ehard neuer Landesvorsitzender der CSU. Scharfe Auseinandersetzungen zwischen Dr. Josef Müller und Minister Dr. Hundhammer“.

39 IfZ-Archiv, RG 260, 10/90-3/9, „Subject: Zur Wahl für den Bundestag“ (Gespräch mit Karl Anzenhofer), undatiert; ACSP, CSU-LTF I, 15-14, Protokoll der Fraktionssitzung vom 31. 5. 1949 (Alois Hundhammer).

40 IfZ-Archiv, RG 260, 10/90-3/9, „Subject: Bayernpartei und Union“ (Gespräch mit Toni Böck) vom 23. 6. 1949, „Subject: CSU und Wahlkampf“ (Gespräch mit Charlotte Fleischmann) vom 29.6. 1949; „Subject: Katholische Junge Mannschaft und Wahlkampf“ (Gespräch mit Karl Anzenhofer) vom 30. 6. 1949; IfZ-Archiv, RG 260, 7/29-1/13-16, Bericht des amerikanischen Generalkonsuls in München, Sam E. Woods, über die Situation der bayerischen Parteien an das State Department vom 5. 8. 1949.

41 SZ vom 11. 8. 1949: "München-West und Bonn am Rhein“.

42 IfZ-Archiv, RG 260, 10/90-3/9, „Subject: Junge Union Münchens zur Bundestagswahl“ (Gespräch mit Franz Heubl) vom 6. 7. 1949.

43 IfZ-Archiv, RG 260, 10/90-3/9, „Subject: Dr. Ehard im Wahlkampf“ (Gespräch mit Charlotte Fleischmann) vom 22.6. 1949. Frau Fleischmann, die im Wahlkreis München-Nord selbst für den Bundestag kandidierte (SZ vom 4. 8. 1949: „Schwabings Auswahl für Bonn“), führte Ehards schlechten Zustand unter anderem auf die Kritik an seiner Tätigkeit als Richter während der NS-Zeit zurück, die im Wahlkampf wieder aufgeflammt war. Abendzeitung (München) vom 5. 7. 1949: Leserbrief Max Lions „Das Ärzte-Urteil“. 
"There is no doubt that the CSU will fail to obtain a majority of the Bavarian delegates to the federal [parliament]. With the best of luck the party may elect more candidates than the other parties, but even with fortunate circumstances the SPD and Bayernpartei are expected to be close behind, probably in that order." 44

Das größte Problem der CSU ergab sich zweifellos aus dem „trostlosen Zustand der Parteiorganisation “45. Wie sollte angesichts der desolaten Finanzlage und der weitgehend zusammengebrochenen Parteiverwaltung überhaupt ein Wahlkampf aufgezogen werden, der diesen Namen auch nur annähernd verdiente ${ }^{46}$ ? Der Geschäftsführer des Bezirksverbands München, Adolf Miller, war mehr als pessimistisch. Er wisse nicht, vertraute er einem Informanten der Militärregierung an, wie die CSU „auch nur eine schwache Wahlkampagne betreiben“ wolle; bisher seien keine Mittel dafür vorhanden. Wenn nicht noch Spenden „interessierter Kreise“ eingingen, würde seiner Partei „jede Propaganda fehlen“, da man nicht einmal in der Lage sei, die Mieten für größere Versammlungsräume zu bezahlen und den auswärtigen Rednern ihre Unkosten zu erstatten. „Ich sehe schwarz für den Wahlkampf“, schloß Miller, „und damit auch für den Ausgang der Wahl. ${ }^{\text {“7 }}$ In den anderen Bezirksverbänden sah es nicht besser aus. In Oberbayern, dem mitgliederstärksten Bezirk, betrugen die Einnahmen der Bezirksgeschäftsstelle im Juni 1949 ganze $51 \mathrm{DM}$ und im September etwa $1650 \mathrm{DM}^{48}$. Damit ließ sich kaum der normale Geschäftsbetrieb finanzieren, geschweige denn ein Bundestagswahlkampf. In dieser Situation blieb dem Bezirksgeschäftsführer und dem Bezirksschatzmeister nichts anderes übrig, als die Kandidaten der oberbayerischen Bundeswahlkreise selbst um eine Spende zu bitten. Leider habe die Bezirksgeschäftsstelle „weiter keine Mittel zur Verfügung als die höchst bescheidenen Mitgliederbeitragsanteile, die überdies von der Mehrzahl der Kreisverbände nur in verschwindend kleinen Bruchteilen und äußerst schleppend" bezahlt würden, hieß es in einem von Wilhelm Röhrl und Andreas Kurz gezeichneten Schreiben. Was Spenden betreffe, so scheine der Bezirksverband „diesmal überhaupt leer auszugehen“, da diese „ihren Weg meist direkt zur Landesleitung nehmen oder aber unten in den Kreisverbänden verbleiben“ würden ${ }^{49}$.

Wenn Bezirksgeschäftsführer Röhrl und Bezirksschatzmeister Kurz tatsächlich annahmen, die Parteizentrale stehe besser da als die Geschäftsstellen draußen im Land, so mußten sie sich bald eines Besseren belehren lassen. Die Landesgeschäftsstelle war selbst in den größten Schwierigkeiten und kaum arbeitsfähig. In der heißen Phase des Wahlkampfes gab es im Landessekretariat nur ein funktionierendes Telephon, die Büroeinrichtung war größtenteils gepfändet und Besuche von ungeduldigen Gläubigern waren an der Tagesordnung ${ }^{50}$. Woher sollte man das Geld für den Wahlkampf nehmen?

44 IfZ-Archiv, RG 260, 7/29-1/13-16, Bericht des amerikanischen Generalkonsuls in München, Sam E. Woods, über die Situation der CSU an das State Department vom 12. 7. 1949.

45 BayHStA, NL Ehard 1362, Hans Wutzlhofer an Hans Ehard vom 12. 7. 1949.

46 ACSP, CSU-LL, Protokolle der Sitzungen des geschäftsführenden Landesvorstands am 17.6. und 28. 7. 1949; IfZ-Archiv, RG 260, 10/90-3/9, „Subject: Dr. Ehard im Wahlkampf“ (Gespräch mit Charlotte Fleischmann) vom 22.6. 1949.

47 IfZ-Archiv, RG 260, 10/90-3/9, „Subject: CSU zum Wahlkampf“ (Gespräch mit Adolf Miller) vom 8. 6.1949.

48 IfZ-Archiv, RG 260, 13/100-1/10, Kassenberichte des CSU-Bezirksverbands Oberbayern für die Monate Juni und September 1949.

49 BayHStA, NL Pfeiffer 535, CSU-Bezirksverband Oberbayern, gez. Wilhelm Röhrl und Andreas Kurz, an Anton Pfeiffer vom 28. 7. 1949.

50 IfZ-Archiv, RG 260, 7/29-1/13-16, Bericht des amerikanischen Generalkonsuls in München, Sam E. Woods, über die Situation der CSU an das State Department vom 12. 7. 1949. 
Der Vorschlag Josef Müllers, von den Bezirks- und Kreisverbänden pro Mitglied eine DM als Wahlfondsumlage einzufordern ${ }^{51}$, war von vornherein illusorisch, da sich schon die normalen Mitgliederbeiträge nicht eintreiben ließen. Einen Staatskredit, wie ihn die CSU nach der Währungsreform schon einmal erhalten hatte, wollte der Ministerpräsident nicht beantragen ${ }^{52}$; er fürchtete wohl, seine politischen Gegner könnten ihm vorwerfen, aus seinem Staatsamt unzulässige Vorteile für die von ihm geführte Partei zu ziehen. So blieb nur die Hoffnung auf Spenden ${ }^{53}$. Franz Josef Strauß informierte die Mitglieder des geschäftsführenden Landesvorstands am 17. Juni 1949 darüber, daß die CSU 16 Prozent des vornehmlich aus Industriekreisen stammenden gemeinsamen Wahlfonds der Unionsparteien ${ }^{54}$ erhalten sollte. Darüber hinaus, so der Generalsekretär, gedenke man selbst kleinere Sammlungen bei Unternehmern durchzuführen, die der CSU nahestünden ${ }^{55}$.

Tatsächlich wurde der Wahlkampf der bayerischen Unionspartei überwiegend aus Spendengeldern finanziert ${ }^{56}$. Der Kassenbericht der Landesgeschäftsstelle für die Zeit vom 1. Juni bis zum 31. August 1949 weist unmittelbare Spenden in einer Höhe von fast 190600 DM auf. Das war ein großer Betrag, wenn man bedenkt, daß die Parteizentrale in diesen drei Monaten keine $4500 \mathrm{DM}$ an Mitgliederbeiträgen einnahm ${ }^{57}$. Aus diesen Mitteln erhielten die Kreisverbände insgesamt 31300 DM an zweckgebundenen Wahlkampfhilfen. Doch Geld allein reichte nicht aus, um einen effizienten Wahlkampf zu führen. Viele Kreisverbände waren schon aus organisatorischen Gründen nicht in der Lage, die in sie gesetzten Erwartungen zu erfüllen, und hofften vergeblich auf die ordnende Hand der Parteizentrale, die aber nicht einmal die korrekte Verwendung der Wahlkampfhilfen überprüfen konnte ${ }^{58}$.

Die Spenden versetzten die CSU immerhin in die Lage, mit der seit Juli 1949 erscheinenden Wochenzeitung Union in den entscheidenden Wochen des Wahlkampfes

51 ACSP, CSU-LL, Protokoll der Sitzung des geschäftsführenden Landesvorstands am 17. 6. 1949.

52 IfZ-Archiv, RG 260, 10/90-3/9, „Subject: Dr. Ehard im Wahlkampf“ (Gespräch mit Charlotte Fleischmann) vom 22.6. 1949.

53 ACSP, CSU-LL, Protokoll der Sitzung des geschäftsführenden Landesvorstands am 28. 7. 1949.

${ }^{54}$ Am 27. 5. 1949 trafen sich in Düsseldorf führende westdeutsche Industrielle, um über einen Wahlfonds zur Unterstützung der Parteien zu beraten, die die Wirtschaftspolitik Ludwig Erhards mittrugen. Über die Höhe dieses Fonds lassen sich keine genauen Angaben machen; in den Quellen ist von zwei oder von vier Millionen DM die Rede. Von diesem Geld sollte die Union 65 Prozent erhalten, die FDP 25 und die Deutsche Partei zehn. Vgl. dazu Udo Wengst, Die CDU/CSU im Bundestagswahlkampf 1949, in: VfZ 34 (1986), S. 1-52, hier S. $48 \mathrm{f}$.

55 ACSP, CSU-LL, Protokoll der Sitzung des geschäftsführenden Landesvorstands am 17. 6. 1949.

56 Woher die Spendengelder im einzelnen stammten und wie groß die Summe war, die aus dem Wahlfonds kam, ließ sich nicht klären. Charlotte Fleischmann teilte einem Vertrauensmann der Militärregierung im Juni 1949 mit, bisher habe die CSU „noch keinen Pfennig“ aus diesem Fonds erhalten (IfZ-A rchiv, RG 260, 10/90-3/9, „Subject: Wahlkampfsorgen der CSU “ vom 15. 6. 1949). Eine amerikanische Quelle enthält den Hinweis, daß die CSU bis zum 12. 7. 1949 20000 DM von der CDU erhaiten habe, mit denen die größten Löcher im Etat gestopft worden seien (IfZ-Archiv, RG 260, 7/29-1/13-16, Bericht des amerikanischen Generalkonsuls in München, Sam E. Woods, über die Situation der CSU an das State Department vom 12.7. 1949). Im Nachlaß Ehard (BayHStA, NL Ehard 131) findet sich ein Schreiben Willy Nubers, Direktor der Bayerischen Disconto-Bank, in dem von der Auszahlung von $90000 \mathrm{DM}$ an den Landesvorsitzenden die Rede ist, und eine handschriftliche Aufstellung Ehards über die Verwendung dieses Geldes.

57 BayHStA, NL Ehard 102, Kassenbericht der CSU-Landesgeschäftsstelle für die Zeit vom 1. 6.-31. 8. 1949.

58 IfZ-Archiv, RG 260, 10/90-3/9, „Subject: Wahlkampfsorgen der CSU “ (Gespräch mit Charlotte Fleischmann) vom 15. 6. 1949. 
wieder ein eigenes Parteiorgan herauszubringen ${ }^{59}$ und für die Funktionsträger der Partei einen Informations- und Rednerdienst zu erarbeiten ${ }^{60}$. Daneben wurden die obligatorischen Broschüren, Flugblätter und Plakate unter das Volk gebracht, die man zum Teil in modifizierter Form von der CDU übernehmen konnte ${ }^{61}$. Ansonsten ging die CSU jedoch im Wahlkampf eigene Wege ${ }^{62}$ und betrachtete alle Ansätze zu einer zentralen Wahlkampfführung, wie sie von der Arbeitsgemeinschaft der Unionsparteien und vom Frankfurter Generalsekretariat unter Bruno Dörpinghaus ausgingen, mit Mißtrauen $^{63}$. Es war allerdings auch nicht sonderlich schwierig, sich solchen unerwünschten Umarmungsversuchen zu entziehen. Das organisatorische Band der Arbeitsgemeinschaft war nur locker, die Kompetenzen der improvisierten Wahlkampfzentrale gering und der Egoismus der Landes- oder Zonenparteien groß ${ }^{64}$. Die CSU setzte sich nicht ohne Grund von der CDU ab. Die Existenz einer landespolitischen Konkurrenzpartei, die ihre Gefährlichkeit bei den letzten Kommunalwahlen unter Beweis gestellt hatte, zwang die neue Führung der CSU, der innerbayerischen Situation noch mehr Aufmerksamkeit zu schenken, als sie dies ohnehin schon getan hatte. Den Strategen in der Parteizentrale blieb im Grunde auch gar nichts anderes übrig, als auf die landespolitische Karte zu setzen. Die CSU mußte sich im Wahlkampf als selbständige Landespartei profilieren, um der Bayernpartei keine zusätzliche Munition zu liefern und jeden Anschein zu vermeiden, als sei sie nur ein Anhängsel der $\mathrm{CDU}^{65}$. In diesem Sinne lehnte die bayerische Unionspartei die von der CDU der britischen Besatzungszone erarbeiteten Düsseldorfer Leitsätze zur Wirtschafts-, Sozial- und Landwirtschaftspolitik ab, die als zentrale programmatische Grundlage für den Bundestagswahlkampf der Gesamt-Union gedacht waren ${ }^{66}$. Hans Ehard entschloß sich überdies, einem Presseempfang fernzubleiben, zu dem Konrad Adenauer für den 15. Juli 1949

59 ACSP, CSU-LTF I, 15-20/2, Entwurf einer Notiz über die Wochenzeitung Union vom 26.8. 1949.

${ }^{60}$ Die Wochenzeitung Union erschien in einer Auflage von zeitweise mehr als 40000 Exemplaren; der Informations- und Rednerdienst startete versuchsweise mit einer Auflage von 450 bzw. 350 Stück, scheint sich aber bewährt zu haben, da von den Nummern 3 bis 62000 Exemplare hergestellt wurden. IfZ-Archiv, RG 260, 13/150-1/8, Politischer Tätigkeitsbericht der CSU für Juli 1949, und IfZArchiv, RG 260, 13/150-1/7, Politischer Tätigkeitsbericht der CSU für August 1949. Zu den Materialien für die Funktionsträger vgl. auch ACSP, CSU-LTF I, 15-20/2, Rundschreiben der CSU-Landesgeschäftsstelle, gez. Franz Josef Strauß, vom 23. 7. 1949.

61 ACSP, CSU-LL, Protokoll der Sitzung des geschäftsführenden Landesvorstands am 17. 6. 1949; vgl. auch Wengst, CDU/CSU im Bundestagswahlkampf, S. $10 \mathrm{f}$.

${ }^{62}$ Müchler, CDU/CSU, S. 54 und S. 87, kommt dagegen zu dem unzutreffenden Ergebnis, die Unionsparteien hätten den Bundestagswahlkampf "gemeinsam" und "geschlossen" geführt.

${ }^{63}$ Als sich das Frankfurter Generalsekretariat der Arbeitsgemeinschaft mit einem Rundschreiben an die einzelnen Kreisverbände wandte und zum Bezug des Informationsdienstes Union im Wahlkampf aufforderte, reagierte man bei der CSU stellenweise ungehalten. So hieß es etwa im Oberbayerischen Informationsbrief 9/49 vom 29. 3. 1949 (BAK, NL Schäffer 26, Bl. 36): „Der Bezirksverband Oberbayern hegt gegen diese Art einer zentralen Wahlkampfsteuerung Bedenken und empfiehlt Zurückhaltung. Tatsache ist doch, dass der Wahlkampf gerade zu den Bundestagswahlen in Bayern mit ganz anderen Argumenten geführt werden muss als in Nord- oder Westdeutschland. [...] Auch Herr Generalsekretär Strauß hält, wie eine Anfrage ergab, diese zentrale Wahlkampfsteuerung für unzweckmässig [...]".

${ }^{64} \mathrm{Vgl}$. Wengst, CDU/CSU im Bundestagswahlkampf, S. 2-10.

${ }^{65}$ Grundlegende Überlegungen zur Wahlkampfstrategie der CSU in: BSB, NL Schwend 2, „Gedanken zur Vorbereitung des Wahlkampfes“" vom 26.6. 1949; dieses Dokument ist ungezeichnet und wurde vermutlich nicht in der Landesgeschäftsstelle der CSU, sondern in der Staatskanzlei erarbeitet.

66 BayHStA, NL Ehard 102, Notizen aus der Besprechung beim Herrn Landesvorsitzenden am 11. 7. 1949; zu den Düsseldorfer Leitsätzen vgl. Wengst, CDU/CSU im Bundestagswahlkampf, S. 27-31. 
in den Sitzungssaal des Düsseldorfer Landtags eingeladen hatte ${ }^{67}$; diese Veranstaltung sollte nicht nur dazu dienen, der Öffentlichkeit das Wahlprogramm der CDU vorzustellen, sondern war allgemein als Auftakt für die heiße Phase des Wahlkampfes der CDU/CSU gedacht. Dementsprechend legte die CSU auch keinen gesteigerten Wert auf die Unterstützung von Rednern aus den Reihen der Schwesterpartei. Anfang Juli 1949 waren von Bayern lediglich drei CDU-Politiker als Redner angefordert worden: Ludwig Erhard, Anton Storch und Theodor Blank ${ }^{68}$. In einer Notiz über eine Besprechung mit Hans Ehard am 11. Juli finden sich überdies die Namen von Jakob Kaiser, Alfred Hartmann und Heinrich von Brentano; ein Wahlkampfauftritt von Konrad Adenauer verstand sich ohnehin von selbst ${ }^{69}$. Blank und Storch, der als Gewerkschafter vor allem im oberbayerischen Pechkohlerevier um Peißenberg und Penzberg sprechen sollte, lehnten jedoch einen Wahlkampfauftritt in Bayern $a^{70}$. So blieb es hauptsächlich Konrad Adenauer und Ludwig Erhard vorbehalten, bei ihren Kundgebungen in Bayern die Verbundenheit der Unionsparteien zu betonen ${ }^{71}$.

Auch inhaltlich setzte man in der CSU andere Schwerpunkte als die CDU, wo die Frage „Planwirtschaft oder soziale Marktwirtschaft" und die Auseinandersetzung mit der SPD eine „überragende Rolle" spielte ${ }^{72}$. Im Freistaat waren dagegen die Frage der Stellung Bayerns in der Bundesrepublik und das Problem der föderalistischen Ausgestaltung des Grundgesetzes von zentraler Bedeutung ${ }^{73}$. Die CSU mußte diese Themen besetzen, um nicht der Bayernpartei das Feld zu überlassen, die auf ihrer Landesversammlung am 18. und 19. Juni 1949 zu einem „Kreuzzug für Bayern ${ }^{\text {“74 aufgerufen }}$ und führenden Politikern der CSU vorgeworfen hatte, "wesentlich dazu beigetragen“ zu haben, daß mit dem Grundgesetz „das Fundament zu einem neuen Zentralismus gelegt werden konnte" 75 . Hermann Etzel, der stellvertretende Vorsitzende, diffamierte Ministerpräsident Ehard in seiner Rede gar als "politisch schwache[n] Mann" und "Anhänger des preußisch-deutschen Bundesstaates", der alles andere sei als ein Föderalist. Der Ministerpräsident, so Etzel, sei „eine der verhängnisvollsten Figuren der

67 BayHStA, NL Ehard 102, Notizen aus der Besprechung beim Herrn Landesvorsitzenden am 11. 7. 1949; zum Wahlkampfauftakt der CDU vgl. Wengst, CDU/CSU im Bundestagswahlkampf, S. 37-40. Ehard nahm dafür an der Großkundgebung der Unionsparteien am 21. 7. 1949 in Heidelberg teil. Seine Rede ist unter der Überschrift "An der Schwelle eines neuen Deutschlands“ abgedruckt in: Bayerische Politik, S. 53-61.

${ }^{68} \mathrm{Vgl}$. Wengst, CDU/CSU im Bundestagswahlkampf, S. $14 \mathrm{f}$.

69 BayHStA, NL Ehard 102, Notizen aus der Besprechung beim Herrn Landesvorsitzenden am 11. 7. 1949.

70 Vgl. Wengst, CDU/CSU im Bundestagswahlkampf, S. 15.

7 Udo Wengst unterstreicht besonders die Rolle Ludwig Erhards bei der Festigung der Bindungen zwischen den Unionsparteien; ebenda, S. 27.

72 So Konrad Adenauer in seiner ersten Regierungserklärung am 20.9. 1949; abgedruckt in: Konrad Adenauer. Reden 1917-1967. Eine Auswahl, hrsg. von Hans-Peter Schwarz, Stuttgart 1975, S. 153-169.

73 ACSP, CSU-LTF I, 15-20/4, Manuskript der Rede Hans Ehards am 17. 7. 1949 im Kongreß-Saal des Deutschen Museums in München; ACSP, NL Seidel $35 \mathrm{c}$, Rundfunkrede Alois Hundhammers am 22. 6. 1949; Mitteilungen der CSU Nr. 1 vom 18. 7. 1949; Informations- und Rednerdienst der CSU Nr. $1 / 49$ vom Juli 1949.

${ }^{74}$ SZ vom 21. 6. 1949: „Bayernpartei begann ,Kreuzzug für Bayern`. Die Passauer Landesversammlung wählt Baumgartner, Donhauser und Etzel zu Vorsitzenden“.

75 Stadtarchiv Bamberg, NL Etzel 17, Manuskript der Rede Hermann Etzels „Die geschichtliche Schuld der CSU und des Ministerpräsidenten Dr. Ehard" vor den Delegierten der Landesversammlung der Bayernpartei am 18./19.6. 1949 in Passau; das folgende Zitat nach diesem Redemanuskript. 
neuesten bayerischen Geschichte“ und müsse wegen Verfassungsbruchs vor dem bayerischen Verfassungsgerichtshof angeklagt werden ${ }^{76}$.

Während die Bayernpartei nichts unversucht ließ, um der angeschlagenen Regierungspartei vielleicht noch vor den Wahlen den entscheidenden Schlag zu versetzen, konnte man sich in der CSU nicht auf einen einheitlichen Kurs gegenüber der landespolitischen Konkurrentin einigen. Prononciert konservative und extrem föderalistische Kräfte um Alois Hundhammer forderten ein Bündnis mit der Bayernpartei, und Fritz Schäffer, der keine Gelegenheit ausließ, um gegen den „Zerfall der bodenständigen Bevölkerung Bayerns in zwei Parteien“ zu wettern" ${ }^{77}$, warnte CSU und Bayernpartei öffentlich vor dem „Wahnsinn eines Parteihaders"78. Führende Vertreter der CSU in Franken forderten dagegen eine klare Abgrenzung von der Bayernpartei ${ }^{79}$. Die „Voraussetzung fuer einen erfolgreichen Kampf gegen die SPD und FDP in Nordbayern“, erklärte August Haußleiter im geschäftsführenden Landesvorstand, sei „ein entschieden gefuehrter Kampf gegen die Bayernpartei in Südbayern" ${ }^{80}$. Die neue Parteiführung war sich durchaus über das Dilemma im klaren, in dem sich die CSU befand. So hieß es in einem Strategiepapier für Hans Ehard:

"Die Auseinandersetzung mit der Bayernpartei ist das schwierigste Moment in diesem Wahlkampf, da sie nicht in ideologischer Gegnerschaft zu uns steht, mehr oder weniger aus unseren Reihen hervorgegangen ist und sich an die gleichen Wählerschichten wenden muß, die ureigentlich nur für uns in Frage kämen. Diese Tatsachen in Verbindung mit der ohne jeden Zweifel bestehenden Notwendigkeit, nach den Wahlen in irgendeiner Form mit ihr zusammenarbeiten zu müssen, machen hinsichtlich ihrer Bekämpfung ein besonderes Fingerspitzengefühl und aussergewöhnliche Selbstdisziplin notwendig. " ${ }^{81}$

Auch Hans Ehard wußte, daß der richtige Umgang mit der Bayernpartei für den Wahlausgang von entscheidender Bedeutung sein konnte, und befürchtete einen Wahlsieg der SPD, wenn sich CSU, Bayernpartei und FDP im Kampf um das nichtsozialistische Wählerpotential aufrieben ${ }^{82}$. Andererseits hielt er die Bayernpartei für unberechenbar und lehnte ein Wahlbündnis oder gar eine Fusion $a^{83}$, wenn er auch öffentlich selten eindeutig Stellung bezog ${ }^{84}$. Dabei befürworteten nicht wenige Politiker innerhalb und außerhalb der CSU ein Wahlabkommen der nichtsozialistischen Parteien, um einen Erfolg der SPD zu verhindern ${ }^{85}$.

76 Daß Ehard von diesen Vorwürfen tief getroffen war, zeigte seine Rede am 17. 7. 1949 im KongreßSaal des Deutschen Museums in München. ACSP, CSU-LTF I, 15-20/4.

77 ACSP, CSU-LTF I, 15-12/4 und 5, Fritz Schäffer an Hans Kraus vom 11. 6. 1949.

78 SZ vom 18. 6. 1949: „West-Deutschland im Spiegel der Parteien“.

79 IfZ-Archiv, RG 260, 7/29-1/13-16, Bericht des amerikanischen Generalkonsuls in München, Sam E. Woods, über die Situation der CSU an das State Department vom 12. 7. 1949.

80 ACSP, CSU-LL, Protokoll der Sitzung des geschäftsführenden Landesvorstands am 17. 6. 1949.

${ }^{81}$ BSB, NL Schwend 2, "Gedanken zur Vorbereitung des Wahlkampfes“ vom 26. 6. 1949.

82 ACSP, CSU-LL, Protokoll der Sitzung des geschäftsführenden Landesvorstands am 28. 6. 1949.

83 ACSP, CSU-LL, Protokoll der Sitzung des geschäftsführenden Landesvorstands am 17. 6. 1949.

${ }^{84}$ IfZ-Archiv, RG 260, 10/90-3/9, „Subject: CSU und Wahlkampf/Fleischmann“ vom 29.6. 1949 und „Subject: Bayernpartei und Union“ (Gespräch mit Toni Böck) vom 23. 6. 1949; ACSP, CSU-LTF I, 15-12/4 und 5, Fritz Schäffer an Hans Kraus vom 11. 6. 1949; SZ vom 18. 6. 1949: „West-Deutschland im Spiegel der Parteien“.

${ }^{85}$ So hoffte beispielsweise Konrad Adenauer auf ein Wahlabkommen zwischen CSU und BP, da für ihn der Wahlsieg der Union wesentlich vom Ausgang der Wahlen in Bayern abhing; vgl. Wengst, CDU/CSU im Bundestagswahlkampf, S. $11 \mathrm{f}$. Zu verschiedenen Initiativen, ein Wahlabkommen zwischen CSU und BP zustandezubringen, vgl. Archiv der CSU-Landesgruppe, Protokoll der Landesgruppensitzung am 7. 9. 1949; Franz Josef Strauß nannte Konrad Adenauer, Anton Pfeiffer, Alois 
Der geschäftsführende Landesvorstand beriet am 28. Juni 1949 gemeinsam mit führenden Mitgliedern des Wirtschaftsbeirats der Union über dieses umstrittene Thema ${ }^{86}$. Nach grundsätzlichen Ausführungen von Hans Ehard und Josef Müller wurde schließlich beschlossen, "von sich aus keinerlei Schritte“ in Richtung eines Wahlabkommens zu unternehmen. Überdies hielten Ehard und die anwesenden Vorstandsmitglieder ${ }^{87}$ „eine Klärung der Stellung des Kultusministers Dr. Hundhammer zur Bayernpartei noch vor Beginn des Wahlkampfes für unbedingt erforderlich“, und sie waren sich darüber einig, daß Wahlbündnisse „für die CSU keinerlei Vorteile, wohl aber erhebliche Nachteile bringen würden und aus sachlichen wie aus personellen und psychologischen Gründen abzulehnen seien“.

Nichtsdestotrotz trafen sich wiederholt Vertreter von CSU, FDP und Bayernpartei in der Staatskanzlei, um sich auf eine sachliche und faire Wahlkampfführung zu verständigen $^{88}$, die Ministerpräsident Ehard besonders am Herzen $\operatorname{lag}^{89}$. Vielleicht sondierte man dabei auch die Möglichkeiten für ein stillschweigendes Wahlabkommen gegen die SPD, von dem der Parteichef am 28. Juni andeutungsweise gesprochen hatte ${ }^{90}$. Besonders erfolgreich waren diese „Burgfriedens-Gespräche“91 jedoch nicht. Der Bayernpartei-Vorsitzende Joseph Baumgartner hatte schon sein Desinteresse bekundet, ehe die Verhandlungen richtig begonnen hatten. Siegessicher kommentierte er den Wunsch des jungen stellvertretenden Vorsitzenden der oberbayerischen CSU, Ludwig Huber, nach einem Wahlbündnis zwischen CSU und BP mit den Worten, man könne sich nicht mit einer Leiche verheiraten ${ }^{92}$. Die Gespräche zwischen CSU und Bayernpartei verliefen ebenso im Sande wie die Gespräche mit der FDP. Pressemeldungen, man sei zu einem Wahlabkommen für die mittelfränkischen Bundeswahlkreise Ansbach und Erlangen gelangt, dementierte die Landesgeschäftsstelle der bayerischen FDP umgehend als „Versuchsballon der CSU“93.

Auch die Auseinandersetzung mit der SPD hatte einen spezifisch bayerischen Charakter und war nicht ganz so scharf wie im übrigen Bundesgebiet ${ }^{94}$. Insbesondere Hans Ehard sah den Konflikt primär unter föderalistischen Vorzeichen, und da war

Hundhammer, aber auch Thomas Dehler als Befürworter oder gar Drahtzieher eines Wahlabkommens.

${ }^{86}$ ACSP, CSU-LL, Protokoll der Sitzung des geschäftsführenden Landesvorstands am 28. 6. 1949; die folgenden Zitate finden sich ebenda.

87 Die Anwesenheitsliste des Protokolls der Sitzung des geschäftsführenden Landesvorstands am 28. 6. 1949 führt unter dem Stichwort „Vorstandsmitglieder" neben Ehard und Müller mit Heinrich Emmert, Richard Schachtner, Emil Muhler, Elisabeth Meyer-Spreckels, Franz Josef Strauß, Charlotte Fleischmann und Hans Schwägerl überwiegend Personen auf, die bisher stets den Ochsensepp unterstützt und eine Annäherung an die Bayernpartei strikt abgelehnt hatten.

${ }^{88} \mathrm{Vgl}$. Wengst, CDU/CSU im Bundestagswahlkampf, S. $20 \mathrm{f}$.

${ }^{89} \mathrm{BSB}, \mathrm{NL}$ Schwend 2, "Gedanken zur Vorbereitung des Wahlkampfes“ vom 26. 6. 1949; IfZ-Archiv, RG 260, 10/90-3/9, „Subject: Versammlung der CSU München“ vom 30. 6. 1949; ACSP, CSU-LTF I, 15-20/4, Manuskript der Rede Hans Ehards am 17. 7. 1949 im Kongreß-Saal des Deutschen Museums in München.

90 ACSP, CSU-LL, Protokoll der Sitzung des geschäftsführenden Landesvorstands am 28. 6. 1949.

91 SZ vom 7. 7. 1949: „Burgfriedens-Gespräche in der Staatskanzlei. Bayerische Parteien erörtern sachliche Führung des Wahlkampfes".

92 IfZ-Archiv, RG 260, 10/90-3/9, „Subject: CSU und Wahlkampf/Fleischmann“ vom 29. 6. 1949; IfZArchiv, RG 260, 7/29-1/13-16, Bericht des amerikanischen Generalkonsuls in München, Sam E. Woods, über die Situation der CSU an das State Department vom 12. 7. 1949.

${ }^{93}$ SZ vom 12. 7. 1949: „Bayern im Spiegel der Parteien. Gerüchte um Wahlbündnisse“.

$94 \mathrm{Vgl}$. Wengst, CDU/CSU im Bundestagswahlkampf, S. 41. 
es nicht opportun, den Hoegner-Flügel der bayerischen SPD, den man vielleicht noch einmal als Bundesgenossen gebrauchen konnte, mehr als nötig zu attackieren ${ }^{95}$. Folgerichtig betonte Ehard in seiner Rede zum Auftakt der heißen Phase des Wahlkampfes am 17. Juli 1949 im Kongreß-Saal des Deutschen Museums:

„Da ergibt sich zunächst die Notwendigkeit einer klaren Grenzziehung gegenüber den sozialistischen Parteien. Wir wollen gegen die Sozialdemokratische Partei so wenig wie gegen andere Parteien einen wüsten, die politische Atmosphäre vergiftenden Wahlkampf führen. Wir wollen nicht vergessen, daß wir alle zusammen in einer Schicksals-Gemeinschaft eingespannt sind, in der wir miteinander leben müssen. Aber zwischen dem sozialistischen Weltbild, das durch die materialistisch-marxistische Weltanschauung geformt ist, und zwischen dem Bild vom Menschen und der Gesellschaft, wie wir es auf Grund unseres christlichen Glaubens in uns tragen, besteht ein unüberwindbarer Unterschied. [. . . ] Man stelle sich vor, die Sozialdemokratie würde in Bayern einen maßgebenden Einfluss gewinnen und die bayerische Politik erhielte ihre entscheidenden Inspirationen dann von der Partei-Zentrale in Hannover. Es würde sehr bald genau so wie im dritten Reich überhaupt keine bayerische Politik mehr geben. Denn Dr. Schumacher ist ein Zentralist vom reinsten Wasser! Er müsste dann Sozialist mit diktatorischen Allüren sein. Er hat alle [...] Mienen springen lassen, um die Bonner Verfassung in punkto Föderalismus möglichst zu denaturalisieren! Er hat hierzu auch alle ihm zu Gebote stehenden internationalen Hilfsstellungen ausgenützt. Seinem Eingreifen ist es in erster Linie zuzuschreiben, dass sich die bayerische CSU und die bayerische Staatsregierung veranlasst sahen, zu Bonn Nein zu sagen! Herr Dr. Schumacher wird ohne Scheu und ohne Rücksicht auf Bayern und auf Süddeutschland, wenn er nur die Möglichkeit hiezu haben würde, das neue Verfassungs-Instrument so anwenden, dass die Entwicklung rücksichtslos nach der zentralistischen Seite getrieben wird."96

\section{b) Kandidatenaufstellung}

Wichtiger als alle Strategien und Programme waren aber die Personen, die die CSU ins Rennen schicken sollte. Allerdings konnten sich die Führungsgremien der Partei lange nicht einigen, und der Wahlkampf war bereits in vollem Gange, als man noch immer mit der Kandidatenaufstellung beschäftigt war. Die Auswahl und Nominierung der Bewerber für einen Sitz im Bundestag war nicht zuletzt angesichts des erst wenige Wochen zurückliegenden Wechsels an der Parteispitze problematisch. Wie würde sich der Sturz des Ochsensepp auswirken? Wie würden Müller und seine verbliebenen Gefolgsleute taktieren? Mußten sie sich endgültig der Koalition aus katholisch-konservativen und gemäßigten Kräften beugen, die Hans Ehard in den Sattel gehoben hatte, oder reichte ihr Einfluß noch so weit, um wenigstens einigen liberalen, sozial progressiven und/oder protestantischen Kandidaten zu einem Sitz im Bundestag zu verhelfen?

Die Parteiführung hatte sich seit Mitte Juni 1949 wiederholt mit der Frage beschäftigt, welche Personen für die bevorstehenden Wahlen nominiert werden sollten ${ }^{97}$, und

95 In den für Ehard bestimmten "Gedanken zur Vorbereitung des Wahlkampfes" vom 26. 6. 1949 (BSB, NL Schwend 2) heißt es: „Die bereits jetzt [gegen Kurt Schumacher] feststellbare Opposition im bayerischen Lager der Sozialdemokratie [...] muß für unsere eigene bayerische Tendenz ausgenützt werden." Vgl. auch Informations- und Rednerdienst der CSU Nr. 1/49 vom Juli 1949 („Hat auch die SPD Flügel?" $)$.

96 ACSP, CSU-LTF I, 15-20/4, Manuskript der Rede Hans Ehards am 17. 7. 1949 im Kongreß-Saal des Deutschen Museums in München.

97 BayHStA, NL Ehard 102, Tagesordnung für die Sitzung der Bezirksvorsitzenden am 15.6. 1949, handschriftliche Stichworte Hans Ehards für die Sitzung der Bezirksvorsitzenden am 15.6. 1949, Notizen über die Sitzung der Bezirksvorsitzenden am 12.7. 1949, Tagesordnung für die Sitzung des geschäftsführenden Landesvorstands am 13. 7. 1949; ACSP, CSU-LL, Protokolle der Sitzungen des geschäftsführenden Landesvorstands am 17. 6. und 28. 6. 1949. 
am 29. Juni gab die Landesleitung diesbezügliche Richtlinien heraus, die zuvor die Billigung der Bezirksvorsitzenden gefunden hatten ${ }^{98}$. Die Kandidaten der CSU dürften „nicht Vertreter irgendwelcher Gruppen“ sein, hieß es in diesem von Ehard gezeichneten Dokument, sondern im „öffentlichen Leben bekannte und angesehene Persönlichkeiten“, die politisch „auf dem Boden der christlichen und föderalistischen Grundsätze der Union stehen und die ausserdem in persönlicher Hinsicht die geistigen und charakterlichen Qualitäten besitzen, um vollwertige Abgeordnete im Bundesparlament darzustellen“. Man vergaß auch nicht zu betonen, daß sich jeder Kandidat verpflichten müsse, sich „mit dem Aufgebot aller Kräfte, unter Inkaufnahme aller Opfer an Zeit und Arbeitskraft und dem Aufgebot der ihm zur Verfügung stehenden finanziellen Mittel [.. .] für den Wahlkampf restlos einzusetzen" ${ }^{\text {99 }}$.

Die Realität sah jedoch anders aus und hatte nur wenig mit den Vorstellungen Hans Ehards und seiner Strategen zu tun. Besonders begrenzt war der Handlungsspielraum des Parteichefs offensichtlich bei der Nominierung der Kandidaten in den 47 bayerischen Bundeswahlkreisen. Interessenverbände, allen voran der Bayerische Bauernverband, versuchten ebenso wie die tonangebenden Zirkel und Gruppierungen in der CSU, die Nominierung bestimmter Personen hinter den Kulissen zu forcieren oder zu verhindern, um die Zusammensetzung der künftigen CSU-Bundestagsfraktion in ihrem Sinne zu beeinflussen. Die Chancen dafür standen nicht schlecht. Hans Ehard mußte sich in seinem neuen Amt erst zurechtfinden und verfügte überdies nicht über den notwendigen Apparat, um die Nominierung der Kandidaten wirkungsvoll steuern zu können ${ }^{100}$. Dem Landesvorsitzenden gelang es nicht einmal, die Kandidatur des ungeliebten Fritz Schäffer zu verhindern, der nach Müllers Sturz wieder mit Macht auf die politische Bühne drängte. Der geschäftsführende Landesvorstand und führende Mitglieder des Wirtschaftsbeirats der Union hatten in einer gemeinsamen Sitzung am 28. Juni 1946 „allgemein aus verschiedenen Erwägungen" gegen den ehemaligen BVP-Vorsitzenden Stellung genommen ${ }^{101}$; dennoch wurde Schäffer im Bundeswahlkreis Passau nominiert ${ }^{102}$.

Wie hart hinter den Kulissen um die Kandidatenaufstellung gerungen wurde, zeigte sich besonders deutlich im Bezirksverband Oberpfalz, wo Alois Hundhammer nichts unversucht ließ, um die Nominierung Müller-treuer Bewerber zu verhindern. Als Karl Kahn, ein Gesinnungsgenosse des Kultusministers, der vor 1933 eine führende Rolle in der Jugendorganisation der BVP gespielt hatte, mit der Bitte an den einflußreichen Parteifreund herantrat, doch seine Bemühungen um einen sicheren Wahlkreis zu unterstützen, zögerte dieser nicht lange. Schließlich wußte Kahn zu berichten, daß mit Otto Schedl und Franz Xaver Butterhof zwei enge Vertraute des Ochsensepp für den Bundestag kandidieren wollten. Weiter führte Kahn aus: „Ich stehe auf dem Stand-

$98 \mathrm{BSB}, \mathrm{NL}$ Schwend 2, „Richtlinien für die Aufstellung von Kandidaten für den Bundestag“, gez. Hans Ehard, vom 29. 6. 1949; die folgenden Zitate ebenda.

99 Gerade die letzte Forderung war angesichts der organisatorischen und finanziellen Schwäche der CSU nur allzu berechtigt und durchaus wörtlich zu nehmen. Wahlkampfhilfe in großem Stil konnte keiner der Kandidaten von der Landesleitung erwarten.

100 Zum Verfahren der Kandidatenaufstellung vgl. BayHStA, NL Ehard 102, Notizen aus der Besprechung beim Herrn Landesvorsitzenden am 11.7. 1949; BSB, NL Schwend 2, "Richtlinien für die Aufstellung von Kandidaten für den Bundestag“, gez. Hans Ehard, vom 29. 6. 1949.

101 ACSP, CSU-LL, Protokoll der Sitzung des geschäftsführenden Landesvorstands am 28. 6. 1949.

102 Vgl. dazu Henzler, Fritz Schäffer, S. 282-286; zur skeptischen Haltung der CSU-Landesleitung gegenüber Schäffer vgl. ebenda. 
punkt, dass in der Oberpfalz unbedingt ein Mann der kath. konservativen Richtung, der ich unbedingt angehöre, zum Zug kommen muss. Wir dürfen uns auf gar keinen Fall hier von der anderen Richtung überfahren lassen. " 103 Derselben Meinung war auch Alois Hundhammer, der in diesem Sinne mit Erfolg bei Fritz Dengler, dem zuständigen Bezirksvorsitzenden, intervenierte ${ }^{104}$. Die Nominierung von Otto Schedl im Wahlkreis Burglengenfeld, die bereits in der Presse gemeldet worden war ${ }^{105}$, wurde rückgängig gemacht. Der neue Kandidat hieß Karl Kahn ${ }^{106}$.

Die Kandidatenaufstellung wurde aber auch durch einige exogene Faktoren erschwert, auf die die CSU nur geringen Einfluß nehmen konnte. So blieb eine so wichtige Frage wie der genaue Wahltermin lange Zeit ebenso unklar wie das genaue Wahlverfahren und die Zahl und der Zuschnitt der Bundeswahlkreise, da sich die Ministerpräsidenten und der Parlamentarische Rat erst am 15. Juni 1949 auf ein Wahlgesetz einigen konnten ${ }^{107}$. Auch Gerüchte, die Militärregierung bestehe auf einer strikten Trennung der Legislative von der Exekutive und denke an eine Einschränkung des passiven Wahlrechts für Beamte, machten der CSU zu schaffen. Durch solche Sonderregelungen, da war man sich im geschäftsführenden Landesvorstand einig, würde „die Nominierung der fuer den grossen Rahmen von Bonn geeignete[n] Kandidaten wesentlich erschwert" ${ }^{108}$. Immerhin war der Anteil von Bürgermeistern, Landräten und Ministerialbeamten, die für einen Sitz im Bundestag in Frage kamen, in der bayerischen Unionspartei besonders hoch, und die Süddeutsche Zeitung zitierte am 14. Juni einen Sprecher der CSU mit den Worten, man rechne damit, „daß in den 1. westdeutschen Bundestag eine Anzahl von CSU-Kandidaten gewählt werden, die in staatspolitischer Hinsicht bisher noch nicht hervorgetreten sind“109.

Es war nicht zuletzt auf solche Probleme und Unsicherheiten zurückzuführen, daß die Delegierten des Landesausschusses erst am 16. Juli 1949 zusammenkamen, um über die Besetzung der Landesliste zu entscheiden ${ }^{110}$. Der Vorsitzende und Wahlleiter Hans Ehard überließ nichts dem Zufall, denn es konnte keinesfalls im Interesse der neuen Parteiführung sein, aufwühlende Streitereien entstehen zu lassen und die mühsam ausgehandelten Kompromisse zu gefährden ${ }^{111}$, auf die man sich wohl zuvor im

103 ACSP, CSU-LTF I, 2-30, Karl Kahn und Alois Hundhammer vom 7. 6. 1949.

104 ACSP, CSU-LTF I, 2-30, Alois Hundhammer an Fritz Dengler und Alois Hundhammer an Karl Kahn vom 9.6. 1949.

105 SZ vom 30. 7. 1949: „Kandidaten der bayerischen Parteien zum Bundestag“.

$106 \mathrm{BSB}, \mathrm{NL}$ Schwend 2, Liste der Kandidaten in den Bundeswahlkreisen, undatiert.

107 SZ vom 16.6. 1949: "Wahlgesetz wurde unterzeichnet. ,Auf Anordnung der Militärregierung\%/ 14. August endgültiger Wahltermin“; zur Wahlrechtsfrage allgemein vgl. Wengst, CDU/CSU im Bundestagswahlkampf, S. $16 \mathrm{ff}$.

108 ACSP, CSU-LL, Protokoll der Sitzung des geschäftsführenden Landesvorstands am 17. 6. 1949.

109 SZ vom 14. 6. 1949: „Der Wahlkampf hat begonnen. Gehen CSU und Bayernpartei zusammen?/Persönliche Angriffe der SPD“. Das Wahlgesetz sah schließlich vor, daß die Beamten des Bundes, öffentlicher Körperschaften oder von Anstalten des öffentlichen Rechts einen Antrag auf Versetzung in den Wartestand stellen mußten, ehe sie ihren Sitz im Bundestag einnahmen. Wartegeld sollte ihnen nicht zustehen, wohl aber das Recht auf Wiedereinstellung nach Erlöschen des Mandats. Die erste Bundestagswahl in Bayern am 14. August 1949, hrsg. vom Bayerischen Statistischen Landesamt, München 1950, S. 5.

110 BayHStA, NL Ehard 102, Rundschreiben Franz Josef Strauß` an die Mitglieder des Landesausschusses der CSU vom 5. 7. 1949. Ein Protokoll dieser Landesausschußsitzung ließ sich nicht ermitteln. SZ vom 19. 7. 1949: „Westdeutschland im Spiegel der Parteien. Dr. Seidel CSU-Spitzenkandidat“.

11 Jede „Besprechung über die Aufstellung von Landeskandidaturen“, so erklärte Ehard nach den Wahlen mit „einiger Bitterkeit“, habe „sofort zu Indiskretionen und nachfolgendem Druck der Berufsor- 
Landesvorstand geeinigt hatte ${ }^{112}$. Aus diesem Grund wurden die Listenplätze unabhängig von der Zahl der Stimmen vergeben, die auf die einzelnen Kandidaten entfallen waren. Der Parteivorsitzende hielt es zudem erst gegen Ende des Wahlvorgangs für nötig, die Delegierten auf diese zweifelhafte Praxis hinzuweisen ${ }^{113}$. Das Resultat sah schließlich folgendermaßen aus: Hanns Seidel, der allseits geschätzte Wirtschaftsminister, führte die Landesliste an; ihm folgten Hans Schütz, Walter Rinke und Baron Georg von Manteuffel-Szoege, zwei katholische und ein evangelischer Flüchtlingsvertre$\operatorname{ter}^{114}$. Daß gleich drei Flüchtlinge auf der Landesliste so weit oben standen, überrascht nur auf den ersten Blick. $\mathrm{Da}$ in den Bundeswahlkreisen nur vier Flüchtlingskandidaten aufgestellt worden waren, von denen Gerhard Wacher ${ }^{15}$ in Hof und Hans Bartel in Nürnberg/Fürth überdies keine echte Siegchance hatten und Karl Graf Spreti, der in Kempten kandidierte, kein Flüchtling im eigentlichen Sinne war ${ }^{116}$, mußte die Parteiführung über die Landesliste den Eindruck zu verwischen suchen, als hätten die Flüchtlinge in der CSU keine Vertretung. Dies war um so dringender, als sich die CSU mit dem Wahlbündnis von WAV und Neubürgerbund einer verdeckten Flüchtlingspartei gegenübersah ${ }^{117}$, die gute Aussichten hatte, der bayerischen Unionspartei einen großen Teil ihrer bisherigen Wähler aus dem Flüchtlingsmilieu abspenstig zu machen.

Auf Platz fünf der Landesliste rangierte Anton Pfeiffer ${ }^{18}$, gefolgt von Heinrich Seiler, einem evangelischen Pfarrer aus Ansbach, um dessen Kandidatur es im Vorfeld ein unerfreuliches Tauziehen gegeben hatte ${ }^{119}$; auf den Plätzen sieben und acht waren die

ganisationen geführt“. BayHStA, NL Ehard 102, Protokoll der Tagung der Bezirksvorsitzenden am 28. 10. 1949.

112 SZ vom 16./17. 7. 1949: „Landesausschußsitzung der CSU“; BayHStA, NL Ehard 102, Tagesordnung für die Sitzung des geschäftsführenden Landesvorstands am 13. 7. 1949.

$113 \mathrm{Vgl}$. Kühnel, Fränkischer Protestantismus, S. $26 \mathrm{f}$.

114 Hans Schütz vertrat die Flüchtlinge aus dem Sudetenland, Walter Rinke dic aus Schlesien und Georg von Manteuffel die Baltendeutschen; Schütz und Rinke, die bekanntesten Flüchtlingsvertreter in der CSU, gehörten beide dem Landesvorstand an.

115 Gerhard Wacher, geb. 29.11. 1916 in Wien, gest. 27. 10. 1990, ev., Studium der Agrarwissenschaft in Prag, 1939 zweite Staatsprüfung, Teilnahme am Zweiten Weltkrieg, 1948 Eintritt in den bayerischen Staatsdienst (zuletzt Oberlandwirtschaftsrat), seit 1951 Vorsitzender des CSU-Kreisverbands Hof, seit 1952 Mitglied des Landesvorstands, 1955-1963 und 1967-1974 Mitglied des geschäftsführenden Landesvorstands der CSU (1967/1968 kooptiert), Mitglied des Landesvorstands des EAK der CSU, 1953-1963 MdB (CSU), 1956-1962 Parlamentarischer Geschäftsführer der CSU-Landesgruppe, 1966-1974 MdL (CSU), 1962-1966 Staatssekretär im bayerischen Staatsministerium für Wirtschaft und Verkehr, seit 1967 Mitglied des Vorstands der Bayerischen Berg-, Hütten- und Salzwerke.

$116 \mathrm{Karl}$ Graf Spreti wurde in Kapfing bei Landshut geboren; bei Kriegsende 1945 befand sich seine Familie in Böhmen und wurde von dort ausgewiesen. Handbuch des Deutschen Bundestags, 1. W. P., S. $241 \mathrm{f}$. Von der Führung der CSU wurde Spreti zwar trotz seiner nur mittelbaren Erfahrungen als Flüchtlingskandidat geführt (ACSP, NL Müller 325, Aufstellung über die „Kandidaten in den Mehrheitswahlkreisen“, undatiert), von den Flüchtlingen selbst wurde Spreti jedoch „nicht als wirklicher Heimatvertriebener anerkannt" (BayHStA, NL Ehard 102, Protokoll der Tagung der Bezirksvorsitzenden am 28. 10. 1949).

117 Zum Wahlabkommen von WAV und Neubürgerbund vgl. Woller, Loritz-Partei, S. 118-122.

118 Am 7. 7. 1949 hatte die Süddeutsche Zeitung noch gemeldet, Anton Pfeiffer solle die Landesliste der CSU anführen.

119 Vgl. Kühnel, Fränkischer Protestantismus, S. 27-37; Renner, Nachkriegsprotestantismus, S. 34-39; Anzeneder/Götz, 50 Jahre CSU in Erlangen, S. 81-89. Ursprünglich sollte mit Emil Muhler auch ein katholischer Priester auf der Landesliste kandidieren, Kardinal Faulhaber gab hierzu jedoch nicht seine Zustimmung. BayHStA, NL Ehard 1362, Rundschreiben Kardinal Faulhabers an die bayerischen Bischöfe vom 25. 7. 1949; vgl. auch Kühnel, Fränkischer Protestantismus, S. 27. 
beiden Frauenvertreterinnen ${ }^{120}$ Agnes Gennerwein (kath.) und Eva Schleip ${ }^{121}$ (ev.) zu finden, auf Platz neun Michael Horlacher und auf Platz zehn Franz Josef Strauß; Adolf Konrad, Fritz Flörl, Karl Greib, Johannes Semler und Fritz Höhenberger komplettierten das Vorderfeld der Landesliste, die aus insgesamt 29 Personen bestand ${ }^{122}$.

Mit dem Ergebnis der Landesausschußsitzung war kaum jemand zufrieden. Alois Hundhammer äußerte offen sein Mißfallen darüber, daß die Landesliste fast ausschließlich mit Anhängern Josef Müllers besetzt sei ${ }^{123}$, aber auch Elisabeth MeyerSpreckels, eine der einflußreichsten Sprecherinnen der Protestanten in der CSU, ließ ihren Unmut erkennen. Sie beklagte sich bei Hans Ehard darüber, daß evangelische Kandidaten auf der Landesliste hinter katholischen Parteifreunden plaziert worden seien, obwohl sie mehr Stimmen erhalten hätten, und schloß auch die Möglichkeit einer Wahlanfechtung nicht aus ${ }^{124}$. Aber war der Unmut von Alois Hundhammer und Elisabeth Meyer-Spreckels wirklich gerechtfertigt? War die eine Seite zu kurz gekommen und von der anderen überspielt worden? Wie sah das politische und soziale Profil der Kandidaten auf der Landesliste und in den Bundeswahlkreisen überhaupt aus?

Betrachtet man die konfessionelle Zusammensetzung der Kandidaten ${ }^{125}$, so zeigt sich, daß die evangelischen Christen in der bayerischen Unionspartei nicht gerade bevorzugt behandelt worden waren. Soweit sich feststellen läßt ${ }^{126}$, waren von den $\mathrm{Kandi}$ daten in den 47 Bundeswahlkreisen Bayerns lediglich sieben evangelisch, von denen Elisabeth Meyer-Spreckels in Nürnberg, Charlotte Fleischmann in München-Nord und Gerhard Wacher in Hof überdies in Wahlkreisen kandidierten, die aller Voraussicht nach nicht zu gewinnen waren. Lediglich Friedrich Bauereisen in Ansbach, Friedrich Jakob Funk ${ }^{127}$ in Schweinfurt, Heinrich Seiler in Erlangen und Karl Sigmund Mayr in Schwabach konnten sich Siegchancen ausrechnen. In den aussichtsreichen Wahlkreisen Schwabens und der Oberpfalz hatten sich die Delegierten dagegen nicht

120 Unter den Direktkandidaten waren mit Charlotte Fleischmann in München-Nord, Elisabeth MeyerSpreckels in Nürnberg und Maria Probst in Hammelburg drei Frauen; allerdings hatte nur Maria Probst eine realistische Chance, ihren Wahlkreis zu gewinnen. Zu Maria Probst vgl. Männle, Maria Probst, in: Aretz/Morsey/Rauscher (Hrsg.), Zeitgeschichte in Lebensbildern, Bd. 7, S. 113-127, und Ursula Männle, Mit Mütterlichkeit verbundene Energie: Maria Probst (1902-1967), in: Renate Hellwig (Hrsg.), Unterwegs zur Partnerschaft. Die Christdemokratinnen, Stuttgart 1984, S. 194-203.

121 Eva Schleip, ev., 1923-1932 Leiterin des Büros der DVP-Reichstagsfraktion, seit 1939 verheiratet mit dem Landgerichtspräsidenten Dr. Josef Schleip (seit 1950 Vorsitzender des Landesschiedgerichts der CSU), Mitbegründerin der CSU in Ansbach, Mitglied des Vorstands des CSU-Bezirksverbands Mittelfranken, seit 1949 Mitglied des Landesausschusses der CSU, bis 1961 Mitglied des Landesvorstands und 1949-1951 Mitglied des geschäftsführenden Landesvorstands der CSU, Laienrichterin am Verwaltungsgericht Ansbach.

122 SZ vom 28. 7. 1949: „Kandidaten der bayerischen Parteien für den Bundestag“.

123 Erlanger Nachrichten vom 18. 7. 1949; zit. nach Kühnel, Fränkischer Protestantismus, S. 26.

124 Elisabeth Meyer-Spreckels an Hans Ehard vom 18. 7. und 13. 8. 1949; zit. nach ebenda, S. $26 \mathrm{f}$.

125 Zur Datenbasis vgl. S. 70. Die Angaben zu den Listenkandidaten beziehen sich nur auf die ersten 15 Bewerber; da die hinteren Listenplätze von untergeordneter politischer Bedeutung waren, erschien diese Einschränkung sinnvoll.

126 Von den 47 Kandidaten in den Bundeswahlkreisen konnte die Konfession bei 36 ermittelt werden; die Konfessionszugehörigkeit der ersten 15 Listenkandidaten ließ sich dagegen bei allen feststellen.

127 Friedrich J. Funk, geb. 3. 10. 1900 in Neuses am Sand/Ufr., gest. 5. 8. 1963, ev., nach Schulbesuch und Militärdienst Studium an den landwirtschaftlichen Hochschulen in Hohenheim und München, Abschluß als Diplomlandwirt, anschließend Gutsverwalter und Sachverständiger bei der Mainkanalisierung, seit 1927 auf dem elterlichen Pachthof tätig, seit 1932 selbständiger Pächter, 1936 Erwerb des Pachthofes, seit 1948 Kreisrat (parteilos, seit 1949 CSU) in Gerolzhofen, 1949-1963 MdB (CSU), 1953-1957 stellvertretender Vorsitzender der CSU-Landesgruppe. 
entschließen können, einen protestantischen Kandidaten aufzustellen und so Bedeutung und Tragfähigkeit des Unionsgedankens zu unterstreichen. Die Parteiführung war sich dieser offenen Flanke wohl bewußt und versuchte, diese Disparität über die Landesliste auszugleichen. Auf den ersten fünfzehn Listenplätzen kandidierten elf $\mathrm{Ka}$ tholiken und vier Protestanten; da diese Relation in etwa der konfessionellen Struktur der bayerischen Bevölkerung entsprach ${ }^{128}$, war zumindest der Optik genüge getan, obwohl die Protestanten nicht gerade an exponierter Stelle zu finden waren. Mit Baron von Manteuffel rangierte der erste evangelische Kandidat erst auf Platz vier; Manteuffel war jedoch mehr ein Vertreter der Flüchtlinge aus dem Baltikum als ein Repräsentant der Protestanten in Franken. Alles in allem konnten die Protestanten in der CSU mit dem Ergebnis der Kandidatenaufstellung nicht zufrieden sein. Etwas mehr Entgegenkommen der katholischen Seite wäre für die Protestanten im Wahlkampf sicherlich hilfreich gewesen, zumal die Verunsicherung unter den evangelischen CSU-Anhängern nach dem Sturz Josef Müllers groß war ${ }^{129}$.

\section{Altersstruktur der CSU-Kandidaten für die ersten Bundestagswablen}

$\begin{array}{lr}\text { Wahlkreiskandidaten } \\ 1 & 2,13 \text { Prozent } \\ 6 & 12,77 \text { Prozent } \\ 15 & 31,91 \text { Prozent } \\ 7 & 14,89 \text { Prozent } \\ 11 & 23,40 \text { Prozent } \\ 1 & 2,13 \text { Prozent } \\ 6 & 12,77 \text { Prozent }\end{array}$

\begin{tabular}{lll} 
Alter & \multicolumn{2}{l}{ Listenkandidaten } \\
21-30 Jahre & & $\ldots . .$. \\
31-40 Jahre & 2 & 13,33 Prozent \\
41-50 Jahre & 5 & 33,33 Prozent \\
51-60 Jahre & 2 & 13,33 Prozent \\
61-70 Jahre & 4 & 26,67 Prozent \\
71-80 Jahre & & $\ldots . .-$ \\
unbekannt & 2 & 13,33 Prozent
\end{tabular}

Das Durchschnittsalter der Direktkandidaten lag bei 50,34 Jahren, das der Kandidaten auf der Landesliste mit 52,62 Jahren etwas darüber ${ }^{130}$. Signifikant ist vor allem zweierlei: Zum einen lassen sich klare Spitzen bei den 41-50 jährigen und den 61-70 jährigen ausmachen. Die erste Gruppe rekrutierte sich zumeist aus Personen, die $1945 \mathrm{zu}$ den jüngeren Mitbegründern der CSU gehört hatten und sich nun langsam zu Entscheidungsträgern mauserten, die zweite Gruppe bestand vor allem aus Politikern, die bereits in der Weimarer Republik aktiv gewesen waren und zum Teil bereits auf eine beachtliche Karriere zurückblicken konnten. Zum anderen fällt auf, daß sich eine Reihe jüngerer Kandidaten hatte durchsetzen können, und das, obwohl die Förderung des politischen Nachwuchses nicht gerade gängige Praxis war, namentlich nicht mehr, seitdem Müller den Sessel des Parteichefs hatte räumen müssen ${ }^{131}$. So war beispielsweise der 25jährige Franz Heubl in einem Münchner Wahlkreis nominiert worden, der 32jährige Richard Stücklen in Weißenburg ${ }^{132}$, der gleichaltrige Gerhard Wacher in

\footnotetext{
128 Vgl. dazu S. $74 \mathrm{f}$.

129 Vgl. dazu S. 335-338 und S. $412 \mathrm{f}$.

130 Von den 47 Kandidaten in den Bundeswahlkreisen konnten Alter und Geburtsdatum bei 41 ermittelt werden, bei den hier untersuchten 15 Listenkandidaten bei 13 .

131 Josef Müller war stets für die Verjüngung der CSU eingetreten; vgl. S. 123 und S. 149.

132 Wie diffizil die Kandidatenaufstellung sein konnte und von welchen Unwägbarkeiten sie manchmal abhängig war, beschreibt Richard Stücklen in einem Erinnerungsinterview, in: Geschichte einer Volkspartei, S. 581-603, hier S. 590ff.
} 
Hof und der ein Jahr ältere Franz Josef Strauß in Weilheim. Daß diese Nachwuchspolitiker zum Zuge gekommen waren, war nicht zuletzt darauf zurückzuführen, daß sich viele ältere und prominentere Parteifreunde bei der Kandidatenaufstellung auffällig zurückgehalten hatten. Nicht alle Kandidaten, die jünger als 40 Jahre waren, hatten bei den ersten Bundestagswahlen Erfolg, es bildete sich aber schon hier der Kern einer schlagkräftigen Mannschaft heraus - genannt seien neben Strauß, Stücklen und Wacher auch Richard Jaeger und Emil Kemmer -, die das Gesicht der CSU in Bonn für ein Jahrzehnt und länger prägen sollten.

\begin{tabular}{rrllr}
$\begin{array}{r}\text { Berufsgruppenschichtung der } \\
\text { Wahlkreiskandidaten }\end{array}$ & Berufsgruppe & \multicolumn{3}{l}{ Listenkandidaten } \\
& & & \\
11 & 23,40 Prozent & Landwirtschaft & 1 & 6,67 Prozent \\
6 & 12,77 Prozent & öffentlicher Dienst & 1 & 6,67 Prozent \\
7 & 14,89 Prozent & Berufspolitiker & 4 & 26,67 Prozent \\
$8^{133}$ & 17,02 Prozent & freie Berufe & 3 & 20,0 Prozent \\
4 & 8,51 Prozent & selbst. Mittelstand & 2 & 13,33 Prozent \\
5 & 12,77 Prozent & Angestellte & 1 & 6,67 Prozent \\
1 & 2,12 Prozent & Pfarrer & 1 & 6,67 Prozent \\
5 & 10,64 Prozent & Sonstige & 2 & 13,33 Prozent
\end{tabular}

Vergleicht man die Berufsgruppenschichtung der Wahlkreiskandidaten mit der der ersten 15 Kandidaten auf der Landesliste, so zeigen sich einige auffällige Unterschiede und Gemeinsamkeiten. Die Landwirte stellten unter den Direktkandidaten die mit Abstand größte Gruppe, während auf der Landesliste mit dem Flüchtlingsvertreter Georg von Manteuffel nur ein Bauer kandidierte. Vor allem in den ländlichen Bundeswahlkreisen vertrauten die Delegierten, die oft genug selbst aus der Landwirtschaft kamen, ausgewiesenen Vertretern agrarischer Interessen ${ }^{134}$, in einigen Fällen auch ohne Rücksicht darauf, ob diese aufgrund ihrer Vorbildung und wirtschaftlichen Situation in der Lage waren, ein Bundestagsmandat auszufüllen. Wenn die Delegierten in vorwiegend agrarisch strukturierten Wahlkreisen nicht von sich aus einen Landwirt nominierten, half in einigen Fällen der mächtige Bayerische Bauernverband nach. Karl Greib, der Vorsitzende des Bezirksverbands Unterfranken, beschwerte sich nach den Bundestagswahlen über die einseitige Standespolitik des BBV, der kategorisch darauf gedrängt habe, daß in den fünf unterfränkischen Bundeswahlkreisen mindestens zwei Bauernvertreter aufgestellt würden; damit sei die unhaltbare Situation entstanden, daß sich unter 22 unterfränkischen Land- und Bundestagsabgeordneten sage und schreibe 20 Landwirte befänden ${ }^{135}$ ! Da bei der Aufstellung der Landesliste übergeordnete parteipolitische Notwendigkeiten ausschlaggebend waren und die Parteiführung bemüht sein mußte, einen Ausgleich zwischen den verschiedenen Interessen herbeizuführen, fand der Anteil bäuerlicher Kandidaten keine Entsprechung auf der Landesliste, auf der neben Manteuffel vor allem Michael Horlacher den Bauernstand repräsentierte.

\footnotetext{
133 Von den acht Direktkandidaten, die freien Berufen zuzurechnen sind, waren fünf Rechtsanwälte.

$134 \mathrm{Zu}$ den Vertretern agrarischer Interessen zählen auch drei hier als Berufspolitiker eingestufte Kandidaten, die entweder selbst aus der Landwirtschaft kamen oder im Bayerischen Bauernverband aktiv waren.

135 BayHStA, NL Ehard 102, Protokoll der Tagung der Bezirksvorsitzenden am 28. 10. 1949.
} 
Überraschend ist der vergleichsweise geringe Anteil an Berufspolitikern ${ }^{136}$ unter den Wahlkreiskandidaten: Mit Anton Pfeiffer bewarb sich lediglich ein Mitglied der bayerischen Staatsregierung um ein Direktmandat, auch Landtagspräsident Horlacher und Generalsekretär Franz Josef Strauß waren unter den Kandidaten; die übrigen waren Landräte und Oberbürgermeister. Auch auf der Landesliste fanden sich nur vier Berufspolitiker auf den ersten fünfzehn Listenplätzen: die Staatsminister Seidel und Pfeiffer, Landtagspräsident Horlacher und Franz Josef Strauß.

Signifikant unterrepräsentiert war ohne Zweifel die Arbeiterschaft; kein einziger Kandidat läßt sich dieser Berufsgruppe zurechnen, so daß die abhängig Beschäftigten nur durch Angestellte und Beamte repräsentiert wurden. Immerhin kandidierte aber der Gewerkschaftssekretär Hugo Karpf im Bundeswahlkreis Aschaffenburg, und Adolf Konrad, vor 1933 ein Spitzenfunktionär der Christlichen Gewerkschaften in Bayern, stand auf dem elften Platz der Landesliste. Ob dies jedoch ausreichte, um die CSU für die Arbeiterschaft attraktiv zu machen, war zweifelhaft.

Unter den Kandidaten der CSU war auch nur ein Geistlicher, der evangelische Pfarrer Heinrich Seiler, der sowohl im Wahlkreis Erlangen als auch auf der Landesliste kandidierte; ein katholischer Priester stellte sich nicht zur Wahl. Das ist angesichts der Tatsache, daß 1946 noch drei katholische Geistliche und ein evangelischer Theologe für die CSU in den Landtag gewählt worden waren ${ }^{137}$, auf den ersten Blick ebenso erstaunlich wie angesichts der Tradition von Zentrum und BVP, in deren Parlamentsfraktionen Prälaten stets eine führende Rolle gespielt hatten. Aber auch hier hatten sich nach 1945 die Zeiten geändert. In der CSU gab es seit ihrer Gründung Stimmen, die Geistliche als Parlamentarier ablehnten, und vor allem bei den Verantwortlichen auf katholischer Seite war die Einsicht gewachsen, daß es nicht unbedingt wünschenswert war, Geistliche in die Parlamente zu entsenden ${ }^{138}$.

Das politische Profil der Kandidaten, die sich in einem Bundeswahlkreis um ein Mandat bewarben, war geprägt durch den hohen Anteil ehemaliger BVP-Mitglieder. Von den 47 Direktkandidaten hatten mindestens 15 (31,91 Prozent) vor 1933 der Bayerischen Volkspartei angehört, zum Teil als einfache Mitglieder oder Funktions- und Mandatsträger auf unterer Ebene, zum Teil aber auch in führenden Positionen ${ }^{139}$. So kandidierte Fritz Schäffer, der letzte BVP-Vorsitzende, im Bundeswahlkreis Passau, sein damaliger Generalsekretär Anton Pfeiffer und dessen Stellvertreter Josef Oesterle in den Wahlkreisen München-Land und Augsburg-Land. Mit Michael Horlacher, Hugo Karpf und Joseph Sturm versuchten überdies drei frühere Reichstagsabgeordnete der BVP, an ihre parlamentarische Karriere anzuknüpfen, die 1933 so plötzlich unterbrochen worden war. Die Kandidaten aus den Reihen der untergegangenen BVP er-

136 Zur Definition dieses Begriffs vgl. S. 82.

137 Vgl. S. 162.

138 Vgl. dazu allgemein Rudolf Morsey, Prälaten auf der politischen Bühne. Zur Rolle geistlicher Parlamentarier im 19. und 20. Jahrhundert, in: Winfried Becker, Werner Chrobak (Hrsg.), Staat, Kultur, Politik. Beiträge zur Geschichte Bayerns und des Katholizismus. Festschrift zum 65. Geburtstag von Dieter Albrecht, Kallmünz 1992, S. 313-323; zur Diskussion innerhalb der Evangelischen Landeskirche Bayerns vgl. Renner, Nachkriegsprotestantismus, S. 34-39.

139 Von den ersten 15 Bewerbern auf der Landesliste hatten - soweit feststellbar - nur vier vor 1933 der BVP angehört (26,67 Prozent). Außer Michael Horlacher und Anton Pfeiffer, die sich auch direkt zur Wahl stellten, waren dies Hanns Seidel und Adolf Konrad, der die BVP zwischen 1919 und 1933 auch im Landtag vertreten hatte. 
wiesen sich als erstaunlich durchsetzungsfähig, so daß der Anteil der ehemaligen BVPMitglieder an den 24 Bundestagsabgeordneten der bayerischen Unionspartei mehr als 40 Prozent ausmachte. Damit konnte auch die Landesgruppe der CSU im ersten deutschen Bundestag das Erbe der Bayerischen Volkspartei nicht verleugnen.

Auffällig ist weiterhin, daß die Namen vieler bekannter CSU-Politiker auf den Kandidatenlisten fehlten, ja es drängt sich fast der Eindruck auf, als hätte sich nur die zweite Garde der bayerischen Unionspartei um ein Bundestagsmandat bemüht, während die Parteiprominenz ihre Ämter und Mandate in Bayern für wichtiger erachtete. Von den 47 Wahlkreiskandidaten läßt sich für 29 kein Parteiamt nachweisen ${ }^{140}$; Friedrich Jakob Funk, der die Fahne der CSU im Wahlkreis Schweinfurt hochhalten sollte, war der Union sogar erst im Juni 1949 beigetreten ${ }^{141}$. Von den mehr als 50 Mitgliedern des Parteivorstands kandidierten insgesamt nur zehn ${ }^{142}$, von den zehn Bezirksvorsitzenden stellten sich nur Karl Sigmund Mayr und Karl Greib zur Wahl. Auch die Landtagsabgeordneten der CSU rissen sich nicht darum, ihr Betätigungsfeld ins ferne Bonn zu verlegen. Lediglich Michael Horlacher, Wilhelm Laforet, Anton Pfeiffer und Maria Probst wagten den Sprung in den Bundestag; Hanns Seidel führte zwar die Landesliste an, aber ob seine Liebe zur Bundespolitik groß genug war, daß er - im Ernstfall - sein Amt als bayerischer Wirtschaftsminister aufgegeben hätte, ist zweifelhaft ${ }^{143}$. Hans Ehard war nicht einmal bereit, wenigstens pro forma als Spitzenkandidat seiner Partei anzutreten. Er wolle den Eindruck vermeiden, erklärte der Landesvorsitzende auf einer Pressekonferenz, als habe er sich vorsorglich ein Bundestagsmandat „auf Eis gelegt ${ }^{\text {"144 }}$. Josef Müller zeigte sich unentschlossen ${ }^{145}$. Er überlege ernsthaft, vertraute er einem Mitarbeiter des amerikanischen Generalkonsulats an, auf einem Spitzenplatz der Landesliste für den Bundestag zu kandidieren. Es seien jedoch so viele Kandidaten aus dem Umfeld Hundhammers aufgestellt worden, daß er Bedenken habe, einer solchen Fraktion anzugehören ${ }^{146}$. Müller nahm schließlich von einer Kandidatur ebenso Abstand wie Friedrich Wilhelm von Prittwitz und Gaffron und August Haußleiter. Offiziell begründeten sie ihren Verzicht damit, daß sie durch ihre Ämter ohnehin ausgelastet seien und überdies "den Uebergangscharakter Bonns" dokumentieren wollten $^{147}$. Vielleicht erschien es ihnen angesichts der veränderten innerparteilichen Mehrheitsverhältnisse aber auch zu unsicher, ihren Hut in den Ring zu werfen.

Müßte man die Kandidaten der CSU für die ersten Bundestagswahlen kurz charakterisieren, so ließe sich vor allem folgendes feststellen: Die Kandidatenliste zeichnete sich durch einen bemerkenswerten Mangel an prominenten Namen aus, statt dessen

140 Von den ersten $15 \mathrm{Kandidaten}$ der Landesliste läßt sich für sechs kein Parteiamt nachweisen. Es sei jedoch einschränkend betont, daß sich Parteiämter auf Orts- und Kreisebene in den Quellen nur schwer nachweisen lassen.

141 Darüber beklagte sich nach der Wahl der unterfränkische Bezirksvorsitzende Greib bitter; BayHStA, NL Ehard 102, Protokoll der Tagung der Bezirksvorsitzenden am 28. 10. 1949.

142 Davon traten drei nur auf der Landesliste an.

143 Vgl. Groß, Hanns Seidel, S. 111.

144 SZ vom 19. 7. 1949: „Westdeutschland im Spiegel der Parteien. Dr. Seidel CSU-Spitzenkandidat“.

145 SZ vom 5. 7. 1949: „Dr. Müllers Kandidatur noch ungewiß“. Die Aufforderung Otto Grafs, auf die Kandidatenaufstellung in Unterfranken Einfluß zu nehmen, ließ Müller offensichtlich ungerührt. ACSP, NL Müller 325, Otto Graf an Josef Müller und Otto Graf an Alfons Goppel vom 11. 7. 1949.

146 IfZ-Archiv, RG 260, 7/29-1/13-16, Bericht des amerikanischen Generalkonsuls in München, Sam E. Woods, über die Situation der CSU an das State Department vom 12. 7. 1949.

147 SZ vom 19. 7. 1949: „Westdeutschland im Spiegel der Parteien. Dr. Seidel CSU-Spitzenkandidat“. 
trat eine ganze Reihe von Bewerbern an, die wohl in ihren Wahlkreisen bekannt waren, ansonsten in der CSU aber kaum hervorgetreten waren. Auch ehemalige Reichspolitiker der BVP zog es wieder über die bayerischen Grenzen, ebenso viele Abgeordnete, die die CSU im Frankfurter Wirtschaftsrat und im Parlamentarischen Rat vertreten hatten ${ }^{148}$. Andere Kandidaten - beispielsweise Fritz Schäffer - hatten sich in den Führungs- und Flügelkämpfen zu sehr exponiert und versuchten nun einen Neuanfang auf Bundesebene. Auch eine Reihe von Nachwuchspolitikern rechnete sich in Bonn offensichtlich größere Aufstiegschancen aus als in München, wo die wichtigen Positionen längst mit erfahrenen Fachleuten oder verdienten Parteifreunden besetzt waren.

\section{c) Wablergebnis}

Am 14. August kam für die CSU der Tag der Wahrheit - und er endete in einem Desaster. Da konnte Alois Hundhammer in der Fraktion noch so geschickt versuchen, das Wahlergebnis schönzureden ${ }^{149}$, aber es ließ sich nicht wegdiskutieren, daß es in Bayern einen politischen Erdrutsch gegeben hatte. Die Regierungspartei, die im Landtag nach wie vor über die absolute Mehrheit verfügte, kam lediglich auf 29,2 Prozent der Stimmen. Damit konnte sich die CSU zwar vor der SPD und der Bayernpartei als stärkste Partei behaupten, verlor aber gegenüber dem schon schlechten Ergebnis der Land- und Stadtkreiswahlen im Frühjahr 1948 noch einmal 8,6 Prozent und war meilenweit von den Wahlergebnissen entfernt, die sie 1946 zur bayerischen Mehrheitspartei gemacht hatten.

Im neuen Bundestag waren 78 Abgeordnete aus Bayern vertreten. Davon gehörten 24 der CSU, 18 der SPD, 17 der BP, 12 der WAV und sieben der FDP an. Die Abgeordneten der CSU waren alle direkt gewählt worden; anders als bei den Konkurrenzparteien gelangte keiner ihrer Kandidaten über die Landesliste in den Bundestag, da die CSU nicht genügend Stimmen erhalten hatte, um neben den erfolgreichen Wahlkreiskandidaten auch noch dem einen oder anderen Listenbewerber zu einem Mandat zu verhelfen ${ }^{150}$. Die Versuche der Parteiführung, die Disparitäten der Kandidatenaufstellung in den Wahlkreisen über die Landesliste zumindest teilweise auszugleichen, hatten sich damit als vergeblich erwiesen ${ }^{151}$.

Als der geschäftsführende Landesvorstand am 3. Oktober 1949 zusammenkam, um über das Wahlergebnis und die Regierungsbildung zu beraten, konstatierte Elisabeth Meyer-Spreckels eine „Verlagerung des Schwerpunktes der Partei durch das Ergebnis der Bundeswahlen nach Franken [.. .], während gleichzeitig Franken, der protestantische Bevölkerungsteil und die evangelischen Frauen [...] vernachlässigt worden sei-

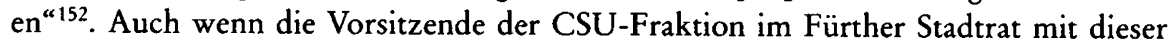

148 Von den 15 Vertretern der CSU in Frankfurt kandidierten acht (Franz Elsen, Fritz Flörl, Kurt-Wilhelm Fromm, Hugo Karpf, Ernst Rattenhuber, Hans Schütz, Franz Josef Strauß und Johannes Semler), von den acht Abgeordneten in Bonn vier (Ferdinand Kleindinst, Wilhelm Laforet, Karl Sigmund Mayr und Anton Pfeiffer).

149 ACSP, CSU-LTF I, 15-14, Protokoll der Fraktionssitzung am 19. 8. 1949.

$150 \mathrm{Vgl}$. Richard Schachtner, Die Wahl zum ersten Bundestag. Vorläufiges Ergebnis der Wahl vom 14. August 1949, in: Bayern in Zahlen. Monatshefte des Bayerischen Statistischen Landesamts 3 (1949), S. 189-195, hier S. 190.

151 BayHStA, NL Ehard 102, Protokoll der Tagung der Bezirksvorsitzenden am 28. 10. 1949.

152 BayHStA, NL Ehard 102, Protokoll der Sitzung des geschäftsführenden Landesvorstands am 3. 10. 1949. 
Aussage übertrieb, hatte sie richtig erkannt, daß sich die Gewichte in der bayerischen Union vom Süden und Südosten nach Westen und Nordosten verschoben hatten. In Ober- und Niederbayern, den alten Hochburgen der CSU, waren mit Franz Josef Strauß, Richard Jaeger und Fritz Schäffer nur drei Kandidaten durchgekommen; mit Ausnahme der vier Münchner Bundeswahlkreise, die ausnahmslos von der SPD erobert worden waren, gingen alle anderen ober- und niederbayerischen Wahlkreise an die Bayernpartei ${ }^{153}$. Dagegen blieb die CSU in allen Wahlkreisen Schwabens, Unterfrankens und der Oberpfalz siegreich. In Ober- und Mittelfranken war die CSU immerhin noch stark genug, um die Wahlkreise Bamberg, Forchheim, Ansbach und Weißenburg zu gewinnen. Damit standen neun Abgeordneten, die in fränkischen Bundeswahlkreisen gewählt worden waren, nur drei Vertreter aus Ober- und Niederbayern gegenüber!

Ergebnisse der Bundestagswablen vom 14. August 1949 in den bayerischen Regierungsbezirken ${ }^{154}$

$\begin{array}{lllllrl} & \text { CSU } & \text { SPD } & \text { BP } & \text { WAV } & \text { FDP } & \text { KPD } \\ \text { Oberbayern } & 23,0 & 22,0 & 26,9 & 14,7 & 7,9 & 5,5 \\ \text { Niederbayern } & 26,8 & 14,2 & 33,9 & 19,5 & 3,4 & 2,2 \\ \text { Oberpfalz } & 35,1 & 23,3 & 22,7 & 11,0 & 4,5 & 3,4 \\ \text { Oberfranken } & 23,2 & 29,3 & 18,8 & 12,0 & 12,7 & 4,0 \\ \text { Mittelfranken } & 24,0 & 30,1 & 6,9 & 15,7 & 16,6 & 6,2 \\ \text { Unterfranken } & 44,9 & 20,1 & 13,7 & 12,3 & 6,1 & 2,9 \\ \text { Schwaben } & 36,5 & 20,0 & 18,8 & 14,7 & 7,2 & 2,8 \\ \text { Gesamt } & \mathbf{2 9 , 2} & \mathbf{2 2 , 8} & \mathbf{2 0 , 9} & \mathbf{1 4 , 4} & \mathbf{8 , 5} & \mathbf{4 , 1}\end{array}$

In diesen beiden Regierungsbezirken war die CSU auch gemessen an den Stimmenanteilen deutlich hinter die Bayernpartei zurückgefallen. Im Vergleich zu den Landund Stadtkreiswahlen des Jahres 1948 hatte die CSU in Oberbayern noch einmal 7,1 Prozent und in Niederbayern sogar 18 Prozent verloren. Stärkste Partei war die Union nur noch in Schwaben, in Unterfranken und in der Oberpfalz, wo sich ihr Stimmenanteil im Vergleich zu den Land- und Stadtkreiswahlen des Jahres 1948 jedoch um 14,8 Prozent reduziert hatte. Trotz dieser gravierenden Verluste und trotz ihrer offensichtlichen Schwäche in Teilen Mittel- und Oberfrankens ${ }^{155}$ war die CSU nach wie vor in allen bayerischen Regierungsbezirken verankert. Sie fiel als einzige Partei in keinem Wahlkreis unter die Marke von 15 Prozent ${ }^{156}$, während sich die SPD in weiten Teilen Niederbayerns mit Stimmenanteilen von 10-15 Prozent zufriedengeben mußte und die Bayernpartei in fünf von sechs mittelfränkischen Wahlkreisen nicht über 10 Prozent hinauskam.

153 Zur regionalen Verteilung und Parteizugehörigkeit der direkt gewählten Kandidaten vgl. das Schaubild „Dic erste Bundestagswahl in Bayern am 14. August 1949“. Für die Führung der BP, die sich weit mehr ausgerechnet hatte, war dieses Ergebnis eine große Enttäuschung. Vgl. Unger, Bayernpartei, S. 33.

154 Zahlen nach Erste Bundestagswahl in Bayern, S. 24-33; alle Angaben in Prozent.

155 Vor allem in den nordost-oberfränkischen Wahlkreisen Coburg, Kulmbach, Bayreuth und Hof sowie in den mittelfränkischen Wahlkreisen Erlangen, Schwabach, Nürnberg und Nürnberg-Fürth.

156 Vgl. das Schaubild „Stimmenanteile der Parteien an der Gesamtzahl der gültigen Stimmen“. 
Doch die Union schnitt nicht nur in Bayern schlecht ab. Im Vergleich zu den ersten Landtagswahlen mußten CDU und CSU in neun von elf Bundesländern Verluste hinnehmen - von 0,7 Prozent in Nordrhein-Westfalen bis zu 9,7 Prozent in Hessen und 23,1 Prozent in Bayern. Im Durchschnitt büßte die Union 7,1 Prozent ihrer Stimmen ein. Es gab 1949 so etwas wie einen Trend gegen die Unionsparteien, so daß Verluste für die CSU an und für sich nicht ungewöhnlich waren. Was jedoch überraschte, auf den ersten Blick vielleicht sogar sensationell wirkte, war das Ausmaß der Wahlniederlage, die die CSU 1949 erlitt. Einige Ursachen für diese erdrutschartige Niederlage liegen auf der Hand, beispielsweise die ständigen innerparteilichen Streitereien und die daraus resultierende Unzufriedenheit vieler CSU-Anhänger, die finanzielle und organisatorische Schwäche der Partei oder die zunehmende Zersplitterung des nichtsoziali-

\section{Die epste Bundestagswahl in Bayern am 14. August 1949} Parteizugehörigkeit der in den Wahlkreisen mit Mehrheit gewählten Abgeordneten

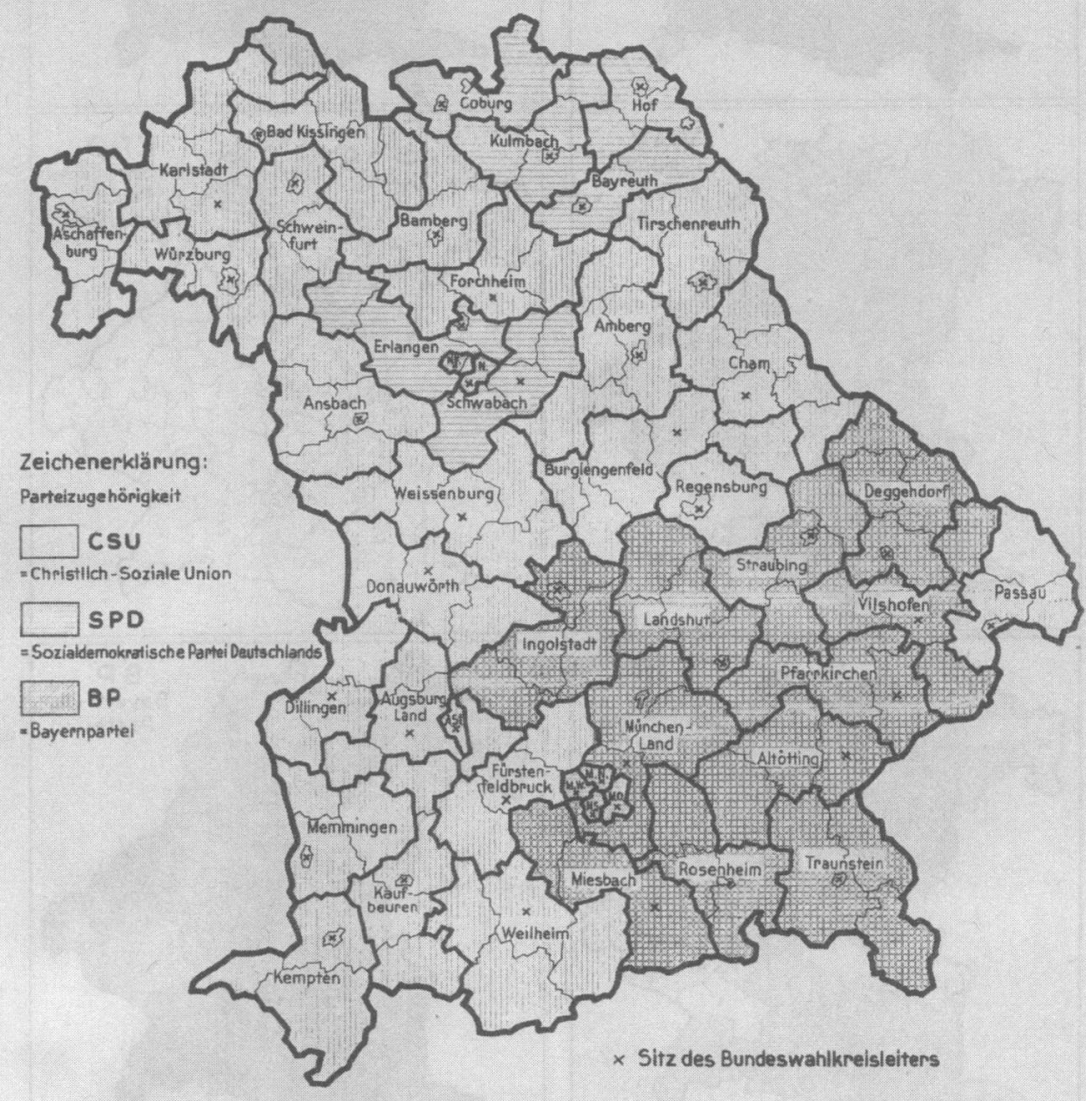




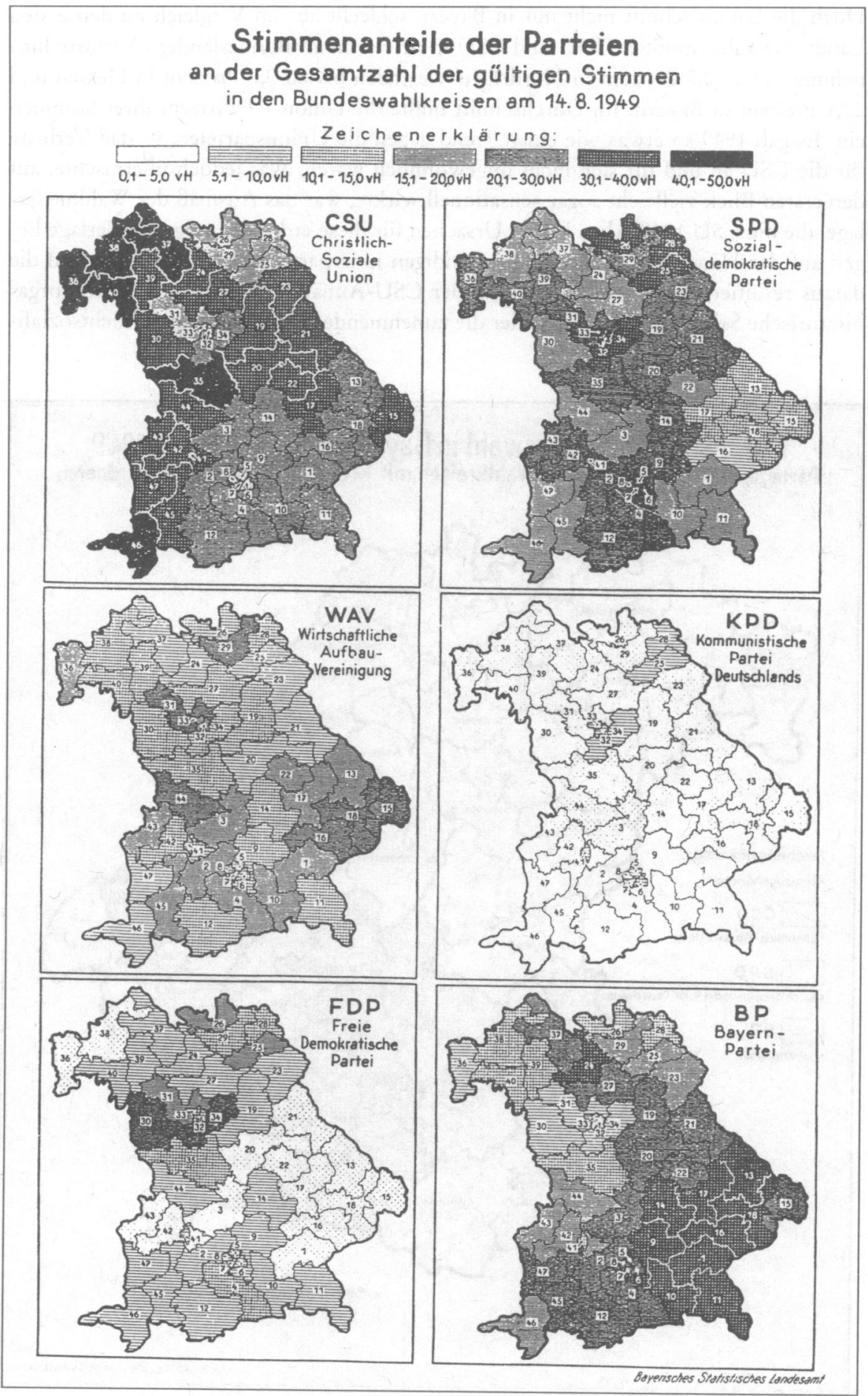


Verzeichnis der bayerischen Bundeswablkreise

$\begin{array}{llll}1 \text { Altötting } & \text { 13 Deggendorf } & 25 \text { Bayreuth } & 37 \text { Bad Kissingen } \\ 2 \text { Fürstenfeldbruck } & \text { 14 Landshut } & 26 \text { Coburg } & 38 \text { Karlstadt } \\ 3 \text { Ingolstadt } & \text { 15 Passau } & 27 \text { Forchheim } & 39 \text { Schweinfurt } \\ 4 \text { Miesbach } & \text { 16 Pfarrkirchen } & 28 \text { Hof } & 40 \text { Würzburg } \\ 5 \text { München-Nord } & \text { 17 Straubing } & 29 \text { Kulmbach } & 41 \text { Augsburg-Stadt } \\ 6 \text { München-Ost } & 18 \text { Vilshofen } & 30 \text { Ansbach } & 42 \text { Augsburg-Land } \\ 7 \text { München-Süd } & 19 \text { Amberg } & 31 \text { Erlangen } & 43 \text { Dillingen } \\ 8 \text { München-West } & \text { 20 Burglengenfeld } & 32 \text { Nürnberg } & 44 \text { Donauwörth } \\ 9 \text { München-Land } & \text { 21 Cham } & 33 \text { Nürnberg-Fürth } & 45 \text { Kaufbeuren } \\ 10 \text { Rosenheim } & \text { 22 Regensburg } & 34 \text { Schwabach } & 46 \text { Kempten } \\ 11 \text { Traunstein } & 23 \text { Tirschenreuth } & 35 \text { Weißenburg i. Bay. } & 47 \text { Memmingen } \\ 12 \text { Weilheim } & 24 \text { Bamberg } & 36 \text { Aschaffenburg } & \end{array}$

stisch-bürgerlichen Lagers am Ende der Besatzungszeit ${ }^{157}$. Andere Gründe lassen sich erst erkennen, wenn man die Situation der CSU in Bayern mit der Situation der CDU in anderen Bundesländern vergleicht. Wie schnitt die Union z. B. in SchleswigHolstein, Hessen, Niedersachsen oder Nordrhein-Westfalen ab? Um es vorwegzunehmen: Die CSU bekam bei den Bundestagswahlen im August 1949 nicht nur die Quittung für die andauernden Führungs- und Flügelkämpfe präsentiert, sondern sie wurde auch das Opfer bestimmter besatzungspolitisch bedingter Entwicklungen, auf die die Partei keinen Einfluß nehmen konnte.

\section{Wablergebnisse der Union in den Ländern der Westzonen und der späteren Bundesrepublik ${ }^{158}$}

\begin{tabular}{|c|c|c|c|}
\hline & $\begin{array}{l}\text { Landtagswahlen } \\
1946 / 47\end{array}$ & $\begin{array}{l}\text { Bundestagswahlen } \\
1949\end{array}$ & $\begin{array}{l}\text { Gewinne und } \\
\text { Verluste }\end{array}$ \\
\hline Bayern & 52,3 & 29,2 & $-23,1$ \\
\hline Baden & 55,9 & 51,1 & $-4,8$ \\
\hline Bremen $^{160}$ & 22,0 & 16,9 & $-5,1$ \\
\hline Hamburg & 26,7 & 19,8 & $-6,9$ \\
\hline Hessen & 31,0 & 21,3 & $-9,7$ \\
\hline Niedersachsen & 19,9 & 17,6 & $-2,3$ \\
\hline Nordrhein-Westfalen & 37,6 & 36,9 & $-0,7$ \\
\hline Rheinland-Pfalz & 47,2 & 49,1 & $+1,9$ \\
\hline Schleswig-Holstein & 34,1 & 30,7 & $-3,4$ \\
\hline Württemberg-Baden & 38,4 & 31,0 & $-7,4$ \\
\hline Württemberg-Hohenzollern & 54,2 & 59,1 & $+4,9$ \\
\hline (Bundes)durchschnitt ${ }^{161}$ & 38,1 & 31,0 & $-7,1$ \\
\hline
\end{tabular}

So hatte die amerikanische Militärregierung in Bayern im Frühjahr 1946 nur wenige Parteien lizenziert, um eine Zersplitterung der Parteienlandschaft zu verhindern; die Bayerische Heimat- und Königspartei, die zu einer ernsten Gefahr für die CSU hätte

157 Erste Bundestagswahl in Bayern, S. 11.

158 Prozentangaben nach Ritter/Niehuss, Wahlen in Deutschland, S. 113-121 und S. 147, sowie Erste Bundestagswahl in Bayern, S. 7. West-Berlin wurde nicht berücksichtigt.

159 Eigene Berechnung.

160 Bürgerschaftswahlen vom 12. 10. 1947.

161 Eigene Berechnung. 
werden können, war im Mai 1946 sogar verboten worden ${ }^{162}$. In den Ländern der britischen Besatzungszone dagegen erhielten mit der Niedersächsischen Landespartei, der späteren DP, und dem Zentrum auch Parteien eine Lizenz, die in direkter Konkurrenz zur CDU standen ${ }^{163}$. Während sich die CSU damit zunächst unter einer Art besatzungspolitischem Schutzschirm entwickeln konnte, blies der Schwesterpartei in der britischen Zone schon bei den ersten Landtagswahlen im April 1947 der Wind scharf ins Gesicht ${ }^{164}$. In Niedersachsen gewann die CDU 19,9 Prozent der Stimmen und lag nur knapp vor der DP, die 17,9 Prozent erringen konnte; das Zentrum erreichte mit 4,1 Prozent immerhin einen Achtungserfolg. Bei den ersten Bundestagswahlen änderte sich das Bild kaum: Die CDU verlor 2,3 Prozent und fiel mit 17,6 Prozent der Stimmen knapp hinter die DP zurück, deren Stimmenanteil mit 17,8 Prozent nahezu konstant blieb; das Zentrum verlor ebenfalls leicht und verpaßte mit 3,4 Prozent den Sprung über die 5-Prozent-Hürde. In Nordrhein-Westfalen spielte zwar die DP keine Rolle, aber hier mußte sich die CDU mit dem Zentrum herumschlagen, das mit der Union um die Stimmen aus dem katholischen Lager rang und an eine lange, erfolgreiche Tradition anzuknüpfen vermochte ${ }^{165}$. Bei den Landtagswahlen von 1947 wurde die CDU mit 37,6 Prozent zwar stärkste Partei, das Zentrum konnte jedoch immerhin 9,8 Prozent der Stimmen auf sich vereinigen, die sonst vermutlich der Union zugute gekommen wären. Auch hier hatte sich 1949 nur wenig verändert. Die CDU blieb bei den Bundestagswahlen mit 36,9 Prozent nur knapp hinter ihrem Ergebnis von 1947 zurück, und auch das Zentrum erwies sich mit 8,9 Prozent als weitgehend stabil.

In Niedersachsen und Nordrhein-Westfalen bestand somit schon 1947 eine Situation, die in Bayern erst 1948 mit der landesweiten Lizenzierung der Bayernpartei eintrat und die 1949 entscheidend zur Niederlage der CSU beitrug. Hätte die BP oder eine ähnlich strukturierte Partei schon 1946 bei den Landtagswahlen kandidieren können wie das Zentrum und die DP in der britischen Zone, dann wären sowohl der Wahlsieg vom Dezember 1946 als auch die Schlappe vom August 1949 nicht so hoch ausgefallen.

Hinzu kam, daß die CSU bei den Bundestagswahlen nicht nur durch die Bayernpartei bedroht wurde, die sich erstmals einer Wahl auf Landesebene stellen konnte. Die Stellung der CSU war auch durch eine verdeckte Flüchtlingspartei gefährdet, die es in den anderen Bundesländern nicht gab oder die dort nur auf geringe Resonanz stieß ${ }^{166}$.

${ }^{162} \mathrm{Vgl}$. dazu zusammenfassend Schlemmer, Amerikaner in Bayern, in: Oberreuter/Weber (Hrsg.), Freundliche Feinde, S. $87 \mathrm{ff}$.

163 Vgl. Schmollinger, Deutsche Partei, in: Stöss (Hrsg.), Parteien-Handbuch, Bd. 2, S. 1028-1031; Ute Schmidt, Zentrum oder CDU. Politischer Katholizismus zwischen Tradition und Anpassung, Opladen 1987, S. 154-287.

$164 \mathrm{Zu}$ den ersten Wahlen in der britischen Zone vgl. Horstwalter Heitzer, Die CDU in der britischen Zone 1945-1949. Gründung, Organisation, Programm und Politik, Düsseldorf 1988, S. 610-638.

165 Vgl. Karl Rohe, Vom Revier zum Ruhrgebiet. Wahlen, Parteien, politische Kultur, Essen 1986, S. 19-24, S. 95-99 und S. 106-114.

166 In Baden und Württemberg-Hohenzollern trat ein Wahlbündnis an, das aus der von der französischen Militärregierung lizenzierten Sammlung zur Tat und den Notgemeinschaften der Vertriebenen und Fliegergeschädigten bestand, deren soziale Basis jedoch in der französischen Besatzungszone weitaus schwächer war als beispielsweise in der amerikanischen. So kam die Sammlung zur Tat in Württemberg-Hohenzollern bei den Bundestagswahlen über 1,5 Prozent der Stimmen nicht hinaus und scheiterte auch in Baden, wo das Bündnis unter dem Namen Europäische Volksbewegung Deutschlands antrat, mit 3,6 Prozent an der landesweiten 5-Prozent Sperrklausel. Vgl. Erste Bundes- 
Ansätze zu einer parteipolitischen Vertretung der besonderen Interessen von Flüchtlingen und Heimatvertriebenen hatte es schon bald nach Kriegsende gegeben, aber keine der vier Besatzungsmächte genehmigte die Gründung einer Flüchtlingspartei ${ }^{167}$. Bei den bayerischen Kommunalwahlen im Frühjahr 1946 konnten zwar noch einige selbständige Flüchtlingsgruppen antreten, in den folgenden Monaten unterband die amerikanische Militärregierung jedoch konsequent alle „auf Parteigründungen ausgerichteten Organisationsversuche“. Schließlich sollten sich die Flüchtlinge und Vertriebenen vollständig in die deutsche Gesellschaft integrieren, auch in politischer und parteipolitischer Hinsicht. Die Besatzungsbehörden fürchteten nicht zuletzt eine Radikalisierung der Flüchtlinge und die Entstehung einer unkalkulierbaren revanchistischen Irredenta; in den etablierten Parteien, so hoffte man, würde die brisante Mixtur aus sozialem Elend und politischer Radikalität neutralisiert.

1948 wurden bestehende Bestimmungen langsam gelockert, neue Gruppierungen entstanden oder wurden von den Besatzungsbehörden genehmigt, nachdem sie sich längere Zeit nur eingeschränkt oder gar nicht hatten betätigen können. Politische Parteien waren nach wie vor verboten, aber es bildeten sich verschiedene Organisationen heraus, die man als "Flüchtlingsparteien in Wartestellung“ bezeichnet hat. Für Bayern war der von Günter Goetzendorff gegründete Neubürgerbund von besonderer Bedeutung, der Anfang 1948 auf Landesebene zugelassen wurde und wenige Wochen später erfolgreich mit eigenen Listen an den Kommunalwahlen teilnahm ${ }^{168}$. Mit seinen ungefähr 200000 Mitgliedern war der Neubürgerbund, der seine Hochburgen in Niederbayern und Franken hatte, die größte Flüchtlings- und Vertriebenenorganisation Bayerns, und es war im Vorfeld der Bundestagswahlen naheliegend, aus der Sicht Goetzendorffs vielleicht sogar zwingend, allen Hindernissen zum Trotz endlich eine eigene Flüchtlingspartei aus der Taufe zu heben. In diesem Sinne beschloß die Landesversammlung des Neubürgerbundes im Juni 1949, unter dem Namen Block der Heimatvertriebenen mit einer überparteilichen Liste bei den bevorstehenden Wahlen anzutreten. Doch wieder setzte die Militärregierung durch ihr Veto allen Hoffnungen ein Ende. Dem überaus ehrgeizigen Goetzendorff und seiner Klientel blieb nur ein erfolgversprechender Ausweg: Ein Wahlabkommen mit einer lizenzierten Partei, die bereit war, Kandidaten des Neubürgerbundes in aussichtsreichen Wahlkreisen oder auf erfolgversprechenden Listenplätzen aufzustellen. Doch Verhandlungen mit der SPD und der FDP scheiterten an den überzogenen Forderungen Goetzendorffs, der daraufhin an die durch heftige innere Konflikte und Skandale fast in die Bedeutungslosigkeit versunkene - aber von der Militärregierung lizenzierte! - WAV von Alfred Loritz herantrat. Der verschlagene Demagoge witterte sofort die Chance, mit Hilfe der Vertriebenen die Talfahrt seiner Partei aufhalten zu können, und er war schnell bereit, Goetzendorff die paritätische Besetzung der Landesliste und den Kandidaten des Neubürgerbundes volle Handlungsfreiheit zuzusichern. Trotz vereinzelter Proteste segnete die Landesversammlung der WAV diese Vereinba-

tagswahl in Bayern, S. 7; Richard Stöss, Die Deutsch-Soziale Union, in: ders. (Hrsg.), ParteienHandbuch, Bd. 2, S. 1243-1278, hier S. 1262; Richard Stöss, Der Gesamtdeutsche Block/BHE, in: ders. (Hrsg.), Parteien-Handbuch, Bd. 3: EAP-KSP, S. 1424-1478, hier S. 1427.

$167 \mathrm{Vgl}$. dazu Woller, Loritz-Partei, S. 116-123; das folgende - soweit nicht anders belegt - nach ebenda; Zitate auf S. $117 \mathrm{f}$.

$168 \mathrm{Vgl}$. Schachtner, Wahlen in den Gemeinden und Kreisen Bayerns, passim. 
rung ab. Die Führungsriege der CSU erkannte zwar die Bedrohung, die von diesem Abkommen zwischen WAV und Neubürgerbund ausging, doch all ihre Gegenmaßnahmen liefen ins Leere ${ }^{169}$.

Ergebnisse bürgerlich-demokratischer Parteien in ausgewäblten Ländern der Westzonen und der späteren Bundesrepublik bei den Bundestagswablen 1949 und den folgenden Landtagswablen ${ }^{170}$

\begin{tabular}{|c|c|c|c|c|c|c|c|c|}
\hline & \multicolumn{2}{|c|}{ Bayern } & \multicolumn{2}{|c|}{ Bremen } & \multicolumn{2}{|c|}{ Hamburg } & \multicolumn{2}{|c|}{ Hessen } \\
\hline & 1949 & 1950 & 1949 & 1951 & 1949 & 1949 & 1949 & 1950 \\
\hline $\mathrm{CDU} / \mathrm{CSU}$ & 29,2 & 27,4 & 16,9 & 9 & 19,8 & $34,5^{171}$ & 21,3 & 18,8 \\
\hline Zentrum & -- & $\cdots$ & --- & -- & --- & $\cdots$ & $-\cdot-$ & $\cdots$ \\
\hline $\mathrm{BP}$ & 20,9 & 17,9 & -- & --- & -- & -- & $\cdots$ & $\cdots$ \\
\hline FDP & 8,5 & 7,1 & 12,9 & 11,8 & 15,8 & -- & 28 & $31,8^{17}$ \\
\hline DP & -- & $\cdots$ & 18 & 14,7 & 13,1 & 13,3 & -- & $\cdots$ \\
\hline WAV & 14,4 & 2,8 & -- & -- & $\cdots$ & -- & $\cdots$ & -- \\
\hline \multirow[t]{3}{*}{ BHE/GB BHE/DG } & -- & 12,3 & -- & 5,6 & -- & $-\cdot$ & $\cdots$ & $\cdots$ \\
\hline & \multicolumn{2}{|c|}{ Niedersachsen } & \multicolumn{2}{|c|}{$\begin{array}{l}\text { Rheinland- } \\
\text { Pfalz }\end{array}$} & \multicolumn{2}{|c|}{$\begin{array}{l}\text { Schleswig- } \\
\text { Holstein }\end{array}$} & \multicolumn{2}{|c|}{$\begin{array}{l}\text { Württem.- } \\
\text { Baden }\end{array}$} \\
\hline & 1949 & 1951 & 1949 & 1951 & 1949 & 1950 & 1949 & 1950 \\
\hline CDU/CSU & 17,6 & $23,7^{173}$ & 49,1 & 39,2 & 30,7 & $19,8^{174}$ & 31 & 26,3 \\
\hline Zentrum & 3,4 & 3,3 & -- & 2,1 & 0,9 & -- & $\cdots$ & $\cdots$ \\
\hline $\mathrm{BP}$ & -- & $\cdots$ & -- & -- & -- & -- & -- & $\cdots$ \\
\hline FDP & 7,5 & 8,3 & 15,8 & 16,7 & 7,4 & 7,1 & 18,2 & 21,1 \\
\hline DP & 17,8 & -- & --- & $\cdots$ & 12,1 & 9,6 & $\cdots$ & $\cdots$ \\
\hline WAV & -- & $\cdots$ & -- & $\cdots$ & -- & -- & $-\cdot$ & $\cdots$ \\
\hline BHE/GB BHE/DG & $\cdots$ & 14,9 & $\cdots$ & 1,9 & -- & 23,4 & -. & 14,7 \\
\hline
\end{tabular}

In anderen Ländern gab es ähnliche Initiativen von Flüchtlings- und Vertriebenenorganisationen, von denen jedoch die meisten, und vor allem diejenigen, die Erfolg versprachen, scheiterten ${ }^{175}$. Somit gab es durch das Bündnis von WAV und Neubürgerbund

169 So versuchten Josef Müller und Hans Ehard anscheinend, Alfred Loritz keine drei Wochen vor dem Wahltermin vor Gericht zu bringen. Die Militärregierung verhinderte diese in ihren Augen parteitaktische und undemokratische Aktion, was zu einem vielbeachteten Konflikt zwischen Landtag und Staatsregierung auf der einen und OMGBY auf der anderen Seite führte; vgl. Woller, Loritz-Partei, S. 105-115.

170 Prozentangaben nach Ritter/Niehuss, Wahlen in Deutschland, S. 113-121 und S. 147, und Erste Bundestagswahl in Bayern, S. 7; die Angaben zum Ergebnis der Landtagswahlen in WürttembergBaden vom 19.11. 1950 nach Neue Zeitung vom 21. 11. 1950. West-Berlin und Nordrhein-Westfalen wurden nicht berücksichtigt. In Baden und Württemberg-Hohenzollern fanden die anstehenden Landtagswahlen wegen der Verhandlungen über den Zusammenschluß der drei südwestdeutschen Länder nicht mehr statt. Der Bundestag verlängerte am 15.3. 1951 die Wahlperioden der Landtage von Baden und Württemberg-Hohenzollern. Vgl. Paul-Ludwig Weinacht, Der Weg in den Südweststaat, in: Der Weg zum Südweststaat, hrsg. von der Landeszentrale für politische Bildung BadenWürttemberg, Karlsruhe 1991, S. 310-323.

171 CDU, FDP und Deutschkonservative Partei traten gemeinsam unter dem Namen Vaterstädtischer Bund Hamburg an.

172 FDP, BHE und DP gingen eine Listenverbindung ein.

173 CDU und DP traten gemeinsam unter dem Namen Niederdeutsche Union an.

174 CDU, FDP und DP bildeten für die Landtagswahlen am 9.7. 1950 einen Wahlblock; dabei trat - mit Unterstützung der anderen Parteien - jeweils nur eine Partei gegen den Kandidaten der SPD an.

175 So formierte sich in Hessen eine gemeinsame Liste von Demokratischer Wirtschafts- und Aufbaugemeinschaft und der Arbeitsgemeinschaft Unabhängiger Kandidaten. Die Besatzungsbehörden ver- 
1949 nur in Bayern die erfolgreiche Vorform einer Flüchtlingspartei, die bei den Bundestagswahlen immerhin 14,4 Prozent der Stimmen gewann und als viertstärkste bayerische Partei zwölf Abgeordnete nach Bonn entsenden konnte.

Daß vor allem Flüchtlinge und Vertriebene die WAV gewählt hatten, zeigt ein Blick auf ihre Wahlergebnisse in ländlichen Regionen mit einem überdurchschnittlich hohen Flüchtlingsanteil. Im niederbayerischen Landkreis Wegscheid beispielsweise, wo die Flüchtlinge circa 20 Prozent der Bevölkerung ausmachten, hatte die WAV bei den ersten Landtagswahlen nur 3,3 Prozent der Stimmen verbuchen können; im August 1949 stimmten dort 19,4 Prozent für die Allianz von Loritz und Goetzendorff ${ }^{176}$. Die Stimmengewinne der WAV gingen sicherlich nicht ausschließlich, aber doch zu einem guten Teil auf Kosten der CSU, der es offensichtlich nicht einmal gelang, die katholischen Wähler aus Oberschlesien oder dem Sudetenland an sich zu binden.

In den anderen Bundesländern gab es - von Ausnahmen abgesehen ${ }^{177}$ - kein Ventil für die Flüchtlingswähler, die sich von den etablierten Parteien nicht vertreten fühlten und denen damit nichts anderes übrigblieb, als für unabhängige, aber chancenlose Wahlkreiskandidaten ihrer Richtung zu stimmen. So votierten in Hessen 11,9 Prozent der Wähler für parteilose (Flüchtlings-)Kandidaten, in Niedersachsen 8,1 Prozent und in Württemberg-Baden sogar 18,0 Prozent ${ }^{178}$. Es gelang jedoch lediglich dem katholischen Flüchtlingspfarrer Franz Ott im württembergischen Wahlkreis Eßlingen, die Mehrheit der Stimmen auf sich zu vereinigen. Das Potential für eine Flüchtlingspartei war im August 1949 zweifellos vorhanden, es kam jedoch aus rechtlichen und besatzungspolitischen Gründen nur in Bayern zum Tragen. Bei den Landtagswahlen der Jahre 1950 und 1951 bekam die Union auch in anderen Bundesländern die Konkurrenz der Flüchtlingsparteien zu spüren, die sich mittlerweile frei entfalten konnten ${ }^{179}$. Während die CSU bei den Landtagswahlen vom November 1950 nur geringe Verluste zu verzeichnen hatte, erlitt die CDU in einigen Bundesländern schmerzhafte, ja zum Teil katastrophale Niederlagen. So kamen DP und CDU, die 1951 bei den niedersächsischen Landtagswahlen gemeinsam unter dem Namen Niederdeutsche Union antraten, gerade noch auf 23,7 Prozent der Stimmen; 1949 waren die beiden Parteien noch auf 35,4 Prozent gekommen, damals hatte aber auch der BHE noch nicht kandidiert, für

sagten diesem Bündnis aus einheimischen und vertriebenen Kriegsgeschädigten jedoch ebenso ihre Zustimmung wie der Tatgemeinschaft Freier Deutscher, einer Organisation aus Opfern des Bombenkriegs und Heimatvertriebenen, die sich in Nordrhein-Westfalen vergeblich um eine Lizenz bemühte. Die Notgemeinschaften der Fliegergeschädigten und Vertriebenen in Württemberg-Baden wurden ebenfalls nicht zu den Bundestagswahlen zugelassen (vgl. Stöss, Gesamtdeutscher Block/BHE, in: ders. (Hrsg.), Parteien-Handbuch, Bd. 3, S. 1427f.). In Baden und Württemberg-Hohenzollern einigten sich die Notgemeinschaften dagegen am 15. 7. 1949 auf ein Wahlabkommen mit der Sammlung zur Tat, einer von der französischen Militärregierung lizenzierten Splitterpartei (vgl. Stöss, Deutsch-Soziale Union, in: ders. (Hrsg.), Parteien-Handbuch, Bd. 2, S. 1261 f.). Dadurch ergab sich die paradoxe Situation, daß die Notgemeinschaften in Baden und Württemberg-Hohenzollern bei den Bundestagswahlen antreten konnten, dort aber nur eine ungenügende soziale Basis hatten, während sie im benachbarten Württemberg-Baden zwar zahlenmäßig stark waren, aber eben nicht an den Wahlen teilnehmen konnten.

176 Vgl. Woller, Loritz-Partei, S. 125; dort auch weitere Beispiele.

177 Diese Ausnahme war die erfolglose Sammlung zur Tat/Europäische Volksbewegung Deutschlands in Baden und Württemberg-Hohenzollern.

178 Erste Bundestagswahl in Bayern, S. 7.

179 Vgl. Franz Neumann, Der Block der Heimatvertriebenen und Entrechteten 1950-1960. Ein Beitrag zur Geschichte und Struktur einer politischen Interessenpartei, Meisenheim am Glan 1968, S. 20-64. 
den 1951 14,9 Prozent der Wähler stimmten. Ähnlich sah das Ergebnis der Landtagswahlen aus, die 1950 in Schleswig-Holstein abgehalten wurden. Die CDU verlor gegenüber den Wahlen vom August 1949 fast 11 Prozent der Stimmen, und das, obwohl es ein Wahlabkommen mit der DP und der FDP gab; der BHE, der auch hier erstmals antrat, gewann dagegen 23,4 Prozent der Stimmen.

\section{Neue Frontlinien und alte Konflikte}

\section{a) Trügerische Rube: Die Eindämmung der Führungs- und Flügelkämpfe}

Die Delegierten der Straubinger Landesversammlung hatten Ehard vor allem deshalb zum Parteivorsitzenden gewählt, weil sie davon überzeugt waren, daß er als einziger in der Lage sein würde, die CSU noch vor den Bundestagswahlen aus der Krise zu führen, die Flügelkämpfe zu beenden und so ein weithin sichtbares Zeichen für einen Neuanfang zu setzen ${ }^{180}$. Die Hoffnung, mit dem Ministerpräsidenten an der Spitze ließe sich eine Wahlniederlage in Grenzen halten oder gar ein Sieg erringen, erwies sich jedoch als trügerisch, und auch ein Ende der innerparteilichen Auseinandersetzungen war zunächst nicht abzusehen. Immerhin gelang es dem neuen Landesvorsitzenden aber, die Einheit der CSU zu wahren und den Zerfall seiner Partei zu verhindern, mit dem nach Müllers Sturz vielfach gerechnet worden war. Einflußreiche CSU-Mitglieder aus den protestantischen Teilen Frankens wie Karl Sigmund Mayr und Alfred Euerl liebäugelten zwar mit der Gründung einer bayerischen $C D U^{181}$ oder führten Sondierungsgespräche mit der FDP ${ }^{182}$, die sich als politische Heimat der evangelischen Christen zu profilieren suchte, hielten ihrer Partei aber letztlich doch die Treue. Auch die CSU-Fraktion im bayerischen Landtag, die sich wahrlich nicht durch besondere Disziplin und Geschlossenheit ausgezeichnet hatte, bewies genügend Stehvermögen, um die Forderung nach einer Auflösung des Landtags und Neuwahlen abzublocken ${ }^{183}$, die nach den Bundestagswahlen wiederholt laut geworden war ${ }^{184}$. Selbst als August Haußleiter am 20. September 1949 aus der CSU austrat, weil er nicht in den Verdacht kommen wollte, „eine wirklichkeitsfremde Besitzbürgerpolitik“ zu unterstützen oder "Bundesgenossenschaft zu primitiven partikularistischen Tendenzen“ zu pflegen ${ }^{185}$, folgten nur wenige seinem Beispiel. Verunsicherte evangelische CSU-Mitglieder um

180 ACSP, NL Müller 16, Protokoll der Landesversammlung der CSU vom 27.-29. 5. 1949 in Straubing; ACSP, NL Seidel 35 c, Rundfunkrede Alois Hundhammers am 22. 6. 1949.

181 IfZ-Archiv, RG 260, 13/150-3/10, Notiz von Donald T. Shea zum Thema „Franconian CSU“ vom 17. 6. 1949. Prominente evangelische CSU-Politiker aus Franken drohten auch in der Folgezeit wiederholt mit der Gründung einer bayerischen CDU; BSB, NL Schwend 3, Richard Jaeger an Karl Schwend vom 20. 3. 1951, und ACDP, NL Ehlers 02/1, Protokoll der Sitzung des geschäftsführenden Ausschusses des EAK am 29. 9. 1952.

182 IfZ-Archiv, RG 260, 7/29-1/13-16, Bericht des amerikanischen Generalkonsuls in München, Sam E. Woods, über die Situation der CSU an das State Department vom 12. 7. 1949.

183 ACSP, CSU-LTF I, 15-14, Protokoll der Fraktionssitzung am 19. 8. 1949; ACSP, CSU-LL, „Besprechungsprotokoll für die Sitzung des geschäftsführenden Vorstandes unserer Partei“ am 5. 12. 1949 vom 3. 12. 1949.

${ }^{184}$ SZ vom 18. 8. 1949: „Für und wider Auflösung des Landtages. Eine Umfrage der SZ/Dr. Ehard für stabile Verhältnisse/Oppositionsparteien fordern Neuwahlen“, und vom 20. 8. 1949: „Keine CSUDebatte über Landtagsauflösung“.

185 BayHStA, NL Ehard 1019, August Haußleiter an Hans Ehard vom 20. 9. 1949. 
Alfred Euerl beschlossen im Gegenteil, ,an der CSU festzuhalten und einzutreten für den Zusammenhalt der christlichen Konfessionen "186. Aber trotz dieser positiven Signale gelang es nicht, die Gräben zwischen den zerstrittenen Flügeln wirklich zu überwinden, obwohl eine gewisse Beruhigung der Situation einsetzte, die nach und nach in einen innerparteilichen Burgfrieden mündete.

Im wesentlichen waren drei Faktoren für diese Entwicklung verantwortlich. Zum einen lag es selbstverständlich an der ausgleichenden Persönlichkeit des Ministerpräsidenten und seiner "landesväterliche[n] Autorität ${ }^{\alpha 187}$, daß die Auseinandersetzungen abflauten; Josef Müller war als Parteivorsitzender dagegen stets eine Reizfigur gewesen, an der sich die Geister geschieden hatten. Zum zweiten versuchte die neue Führung, keine Interna mehr nach außen dringen zu lassen und Streitigkeiten nur noch hinter verschlossenen Türen auszutragen ${ }^{188}$. Entscheidungen verlagerten sich $\mathrm{Zug}$ um Zug in kleine, oft informelle Zirkel, offene Diskussionen, die bis zum Sturz Müllers die Tagungen der Parteigremien beherrscht hatten, wurden soweit wie möglich unterbunden ${ }^{189}$. Zum dritten veränderte die CSU mehr und mehr ihr Gesicht und degenerierte zu einer Honoratiorenpartei klassischen Typs, ohne aber den Anspruch aufzugeben, Volkspartei zu sein ${ }^{190}$. Zwischen 1948 und 1955 verlor die bayerische Unionspartei circa 60 Prozent ihrer Mitglieder, darunter viele Gefolgsleute Josef Müllers, die sich nach der Abwahl ihres Mentors enttäuscht von der CSU abwandten, aus der Partei austraten oder ihre Mitgliedschaft einfach erlöschen ließen. Mit dem Ausscheiden liberaler, protestantischer, sozial progressiver, aber auch nationalkonservativer Mitglieder lösten sich viele Konflikte praktisch von selbst, weil einfach die Reibungspunkte wegfielen, an denen sich zwischen 1945 und 1949 immer wieder heftige Kontroversen entzündet hatten. Doch der Preis für das größere Maß an Homogenität war hoch. Die CSU, die als klassen- und konfessionenübergreifende Sammlungspartei angetreten war, hatte damit erst einmal keine Chance mehr, die verlorene absolute Mehrheit zurückzugewinnen. In der Ära Ehard trug die bayerische Unionspartei deutlich konservativere und konfessionellere Züge als vor 1949. Sie erinnerte in vielem an die untergegangene Bayerische Volkspartei, „obgleich die Kräfte zu deren ,inneren“ Überwindung nicht erloschen waren " ${ }^{191}$. Nach dem Sturz des Ochsensepp wichen die Turbulenzen der ersten Jahre einer trügerischen Stille, die zeitweise an eine Art Friedhofsruhe, zeitweise aber auch an die Ruhe vor dem Sturm erinnerte.

Hans Ehard wurde nicht müde, auf die „fortschreitende Beruhigung und Befriedung innerhalb der Partei“ hinzuweisen und die „innere Konsolidierung" der CSU zu betonen ${ }^{192}$. Auf der Landesversammlung in Kempten, wo sich Ehard am 17. und 18. Juni

186 ACSP, CSU-LTF I, 15-14, Protokoll der Fraktionssitzung am 12. 10. 1949.

187 Mintzel, Geschichte der CSU, S. 66.

188 ACSP, CSU-LL, Protokoll der Sitzung des Landesausschusses der CSU am 10.6. 1950 in München oder Protokoll der Landesversammlung der CSU am 17./18. 6. 1950 in Kempten.

189 Beispielsweise ACSP, CSU-LL, Protokoll der Sitzung des Landesvorstands der CSU am 8. 10. 1954.

190 Vgl. Mintzel, Anatomie, S. 249.

191 Mintzel, Geschichte der CSU, S. 67.

192 ACSP, CSU-LL, Protokoll der Landesversammlung der CSU am 17./18. 6. 1950 in Kempten. Schon im Besprechungsprotokoll für die Sitzung des geschäftsführenden Landesvorstands am 5. 12. 1949 (ACSP, CSU-LL) wird der Parteivorsitzende mit den Worten zitiert: „Es ist erfreulich festzustellen, daß die innere Festigung der Partei und ihre Aktivität seit den Bundestagswahlen fortschreitet. Das Bestreben der Landesleitung, durch Betonung der mittleren Linie die Spannung zwischen den Flügeln zu vermindern, war erfolgreich und hat seinen erfreulichsten Ausdruck in der Tatsache gefun- 
1950 erstmals zur Wiederwahl stellte, wurde die neue Einmütigkeit geradezu feierlich inszeniert. Schon vor Beginn des Parteitags erklärte Generalsekretär Strauß, die „Sonne der Einheit" werde über Kempten leuchten ${ }^{193}$, und die von der Landtagsfraktion herausgegebene CSU-Correspondenz berichtete in einer Sondernummer:

„Die Landesversammlung der CSU 1950 unterschied sich von den vier vorhergehenden Landesparteitagen durch die volle Einmütigkeit der Delegierten in allen grundsätzlichen Fragen. Die Tatsache, dass die CSU damit endgültig die umfassende, von allen Teilen der Union bejahte Grundlage gefunden hat, wird für die innenpolitische Entwicklung in Bayern sehr bedeutsam sein. Die Einmütigkeit der CSU in Kempten als Ausdruck gemeinsam[en] politischen Wollens ist dabei alles andere als eine geistige Uniformität; die Männer der CSU haben in den vergangenen Jahren bewiesen, dass sie Gegensätze nicht totschweigen. Wenn in Kempten keine im wesentlichen differenzierten Meinungen auftraten, dann war das nicht das Ergebnis einer tüchtigen Regie, sondern des Umstandes, dass nach 5 Jahren die christliche Sammelpartei Bayerns ihr Gesicht und ihre Aufgabe gefunden hat. [...] Die Einheit der CSU ist die erste Voraussetzung für die erfolgreiche Behauptung im Wahlkampf. Auch der kritischste Besucher von Kempten wird anerkennen müssen, dass die Einmütigkeit einer ehrlichen Gesinnung entspricht. Noch immer aber war Einmütigkeit die beste Gewähr für die erfolgreiche Verteidigung einer guten Sache. “194

Tatsächlich kam es in Kempten zu keinen nennenswerten Kontroversen. Vor lauter Grundsatzreferaten und Rechenschaftsberichten blieb einfach keine Zeit für Diskussionen ${ }^{195}$. Man müsse sich daran gewöhnen, „daß auf Parteitagen keine Politik mehr gemacht werde“, erklärte ein Delegierter zufrieden den leicht enttäuschten Pressevertretern ${ }^{196}$. Nichts dokumentierte die viel beschworene neue Einigkeit stärker als das Wahlergebnis für Hans Ehard. Der Parteivorsitzende wurde mit 97,79 Prozent der Stimmen in seinem Amt bestätigt und konnte sich damit auf ein Maß an Zustimmung stützen, von dem sein Vorgänger nur hatte träumen können ${ }^{197}$.

Josef Müller, der noch ein Jahr zuvor so zäh um den Parteivorsitz gekämpft hatte, hielt sich im Hintergrund. Er hatte im Vorfeld der Kemptener Landesversammlung nicht die Werbetrommel für seine Person gerührt und offensichtlich kein Interesse daran, kaum verheilte Wunden in aller Öffentlichkeit erneut aufzureißen. Als der Ochsensepp am Ende des ersten Sitzungstages aus der Bundeshauptstadt kommend den Saal

den, daß die solange üblichen Auseinandersetzungen über interne Parteiangelegenheiten in der Öffentlichkeit aufgehört haben. Im gleichen Maß steigt das Vertrauen zur Partei.“ Auch in der Parteipresse war man um eine solche Darstellung bemüht: Bayern-Kurier vom 17.6. 1950: „Straubing und Kempten“ oder vom 21.4. 1951: „Im richtigen Ton. Landesausschuß in Würzburg/Was wächst, macht keinen Lärm“.

193 SZ vom 17./18. 6. 1950: „,Sonne der Einheit' über der CSU. Die Landesversammlung der bayerischen Regierungspartei tagt in Kempten".

194 CSU-Correspondenz Nr. 84 a vom 18.6. 1950: „Kempten - Beispiel und Auftrag“. Ähnlich auch Bayern-Kurier vom 17.6. 1950: „Straubing und Kempten“.

195 Als nach dem Bericht des stellvertretenden Generalsekretärs Josef Brunner über die Lage der Parteiorganisation eine Aussprache gewünscht wurde, verwies Ehard auf die Möglichkeit zur Diskussion nach den Rechenschaftsberichten. Als am Ende des ersten Tages der Landesversammlung dann endlich Zeit dafür gewesen wäre, zogen vier von fünf gemeldeten Rednern erschöpft oder resigniert ihre Wortmeldungen zurück. ACSP, CSU-LL, Protokoll der Landesversammlung der CSU am 17./18. 6. 1950 in Kempten.

196 SZ vom 19.6. 1950: „In Einigkeit, ganz ohne Sensationen. Randnotizen von der Landesversammlung der Christlich-Sozialen Union in Kempten“.

197 Von 452 abgegebenen Stimmen entfielen 442 auf Hans Ehard, zwei auf Josef Müller, eine auf Franz Josef Strauß, eine auf Karl Sigmund Mayr und eine auf Josef Stürmann; eine Stimme war ungültig, vier Delegierte enthielten sich der Stimmen. ACSP, CSU-LL, Protokoll der Landesversammlung der CSU am 17./18.6. 1950 in Kempten. 
betrat, in dem die Delegierten tagten, nahm kaum jemand von dem ehemaligen Parteichef Notiz, der unauffällig in der vorletzten Reihe Platz nahm ${ }^{198}$.

Die alten Frontlinien bestanden jedoch weiter, auch wenn die Auseinandersetzungen zwischen Katholiken und Protestanten, Liberalen und Konservativen oder gemäßigten und radikalen Föderalisten zunehmend von neuen Konflikten überlagert wurden. So entzweiten sich die führenden CSU-Politiker immer wieder über der Frage nach dem richtigen Kurs gegenüber der Bayernpartei, und auch das schwierige Verhältnis von Bundes- und Landespolitik erwies sich als ständige Quelle kleinerer und größerer Streitigkeiten, seitdem sich mit der CSU-Landesgruppe in Bonn ein neuer Machtfaktor im organisatorischen Gefüge der Partei herausgebildet hatte.

\section{b) Kabale und Liebe: CSU, Bayernpartei und das Scheitern der kleinen Koalition im Dezember 1950}

Hans Ehard hatte viele Vorzüge, die ihn zu einem allseits geachteten Ministerpräsidenten machten und zumindest zeitweise zu einer für die CSU unverzichtbaren Persönlichkeit werden ließen. Es überstieg jedoch auch seine Fähigkeiten, dem Gerangel zwischen den diversen Zirkeln und Gruppierungen wirklich ein Ende zu setzen oder verfeindete Flügelmänner wie Hundhammer und Müller dazu zu bewegen, das Kriegsbeil zu begraben und im Interesse der gesamten CSU zu einem gedeihlichen Zusammenwirken zu kommen. So mußte sich Ehard damit begnügen, die immer wiederkehrenden Konflikte möglichst geräuschlos auszubalancieren, den status quo zu sichern und damit den Kern der Union zusammenzuhalten. Anders als für Alois Hundhammer standen die Grundprinzipien der Union für den Parteivorsitzenden und Ministerpräsidenten nie zur Disposition ${ }^{199}$. Hundhammer hatte im Oktober 1949 erklärt, „der Name CSU sei nicht populär genug “200, und übte noch im Januar 1952 Kritik am Sammlungskonzept der Gründungsphase, als man versucht habe, „den links stehenden Sozialisten und den rechts stehenden Arbeitgeber unter einen Regenschirm zu bringen“. Der „Bogen der CSU“ sei 1945 „zu weit gespannt worden, deshalb seien Abwanderungen notwendig gewesen “201. Hundhammer machte auch keinen Hehl daraus, daß für ihn die Wiedervereinigung der aufgespaltenen christlich-bayerischen Kräfte oberste Priorität hatte. Vor der Arbeitsgemeinschaft der Katholischen Publizisten führte er aus:

„Wenn es uns gelingen würde, die Kräfte der christlichen Staatsidee wieder zusammenzuführen, vielleicht unter Abstossung mancher Einzelner, die nicht ganz in diesen Gedankenbereich hineinpassen und in der CSU und in der BP noch mitschwimmen, dann würden wir in Bayern ein poli-

${ }^{198}$ SZ vom 19. 6. 1950: „In Einigkeit, ganz ohne Sensationen. Randnotizen von der Landesversammlung der Christlich-Sozialen Union in Kempten".

199 Dafür gibt es eine Fülle von Belegen; vgl. z. B. ACSP, CSU-LL, Protokoll der Landesversammlung der CSU am 17./18.6. 1950 in Kempten, Rede Hans Ehards vor der Landesversammlung der CSU am 23. 6. 1951 in Bad Reichenhall und Rechenschaftsbericht Hans Ehards vor dem Landesausschuß der CSU am 25./26. 10. 1952 in Dinkelsbühl; IfZ-Archiv, ED 720 Smlg. Mintzel 20, Rede Hans Ehards vor der Landesversammlung der CSU am 9./10. 10. 1954 in Nürnberg. Vgl. auch Gelberg, Hans Ehard, S. $346 \mathrm{ff}$.

200 BayHStA, NL Ehard 102, Protokoll der Tagung der Bezirksvorsitzenden am 28. 10. 1949.

201 BSB, NL Schwend 48, Notiz über eine Grundsatzrede Alois Hundhammers vor der Arbeitsgemeinschaft Katholischer Publizisten, undatiert (vermutlich am 19. 1. 1952). 
tisches Instrument schaffen, das die CSU beträchtlich weiter vorwärtsbringen und ihre Schlagkraft wesentlich wirkungsvoller als es heute der Fall ist, gestalten könnte. “202

Es war vielleicht Ehards größte Leistung als Parteivorsitzender, daß er nicht bereit war, eine wie auch immer geartete Arbeitsgemeinschaft von CSU und Bayernpartei um den Preis der Abkehr von den Grundprinzipien der Union zuzulassen. Als „Vereinigung all derer, die auf dem Boden der christlichen Auffassung stehen“, so erklärte der Landesvorsitzende nach seiner Wiederwahl in Kempten, sei „die Union eine absolut neue Erscheinung in unserer Parteikonstellation“, deren Grundsätze so entwicklungsfähig seien, daß sie sich „trotz allem und trotz aller Widerstände und Gegensätzlichkeiten, trotz aller Bekämpfungen von anderer Seite durchsetzen“ werde ${ }^{203}$. „Wenn sie sich nicht durchsetzen könnte“, fuhr Ehard fort, „dann könnten wir [. . . zugleich den Gedanken an eine vernünftige, brauchbare und dauernde Demokratie [. . . ein für allemal abschreiben." In diesem Sinne hielt der Ministerpräsident die Kluft zwischen CSU und Bayernpartei nur im Geiste der Unionsidee für überwindbar, nicht aber durch irgendwelche Kompromisse oder organisatorische Arrangements. Im Juni 1951 betonte er dies nachdrücklich vor der Landesversammlung, die diesmal in Bad Reichenhall zusammengetreten war:

„Die Heilung [des Bruches zwischen CSU und Bayernpartei] kann nur erfolgen dadurch, dass sich die Unions-Idee als die grosse Sammlungs-Idee aller christlich-sozialen, aller föderalistischen und christlich-demokratischen Kräfte immer stärker manifestiert. Uns dafür stark zu machen, dafür die Herzen der Jungen und Alten warm zu machen, dafür Opfer zu bringen und dafür zu arbeiten, das ist unsere Unions-Aufgabe, die wir nicht um der Union willen, sondern um ernster Dinge willen erfüllen müssen, von denen die politische Zukunft unseres Volkes und die Gestaltung der politischen Verhältnisse in Deutschland sehr wesentlich abhängt. Diese Arbeit muss im Zeichen einer die Arme weit ausgebreitet haltenden Union geschehen, in der für [a]lle Platz ist, die nur einen Funken christlicher Gesinnung, föderalistischer Anschauungen, demokratischer Überzeugung und sozialen Geistes in sich tragen. Wir sind keine exklusive, keine intransigente, sondern eine umfassende Partei. “204

Die Bayernpartei blieb die ganzen fünfziger Jahre hindurch ein „Krisenfaktor“ für die $\mathrm{CSU}^{205}$, aber die führenden Exponenten der bayerischen Unionspartei konnten sich lange nicht auf eine gemeinsame Strategie im Umgang mit der gefährlichen landespolitischen Konkurrentin einigen. Vereinfacht gesagt, sah man in der CSU drei Möglich-

202 BSB, NL Schwend 48, „Niederschrift über Dr. Hundhammers Erklärungen vor der Arbeitsgemeinschaft der Katholischen Publizisten in München (19. Januar 1952)“. Hundhammers Bayernparteifreundlicher Kurs stieß auch in Altbayern auf Widerspruch. So hatte der Geschäftsführer der von Schäffer eingerichteten Bundeswahlkreisgeschäftsstelle in Passau schon am 27. 2. 1950 an den Bundesfinanzminister geschrieben (BAK, NL Schäffer 27, Bl. 268f.), es sei „unter allen Umständen notwendig, dass endlich eine klare Abgrenzung zur Bayernpartei vollzogen“" werde, ,auch bei unserem sehr verehrten Herrn Staatsminister Dr. Dr. Hundhammer".

${ }^{203}$ ACSP, CSU-LL, Protokoll der Landesversammlung der CSU am 17./18. 6. 1950 in Kempten.

204 ACSP, CSU-LL, Rede Hans Ehards vor der Landesversammlung der CSU am 23.6. 1951 in Bad Reichenhall. Vgl. auch Gelberg, Hans Ehard, S. 360. Ähnlich hatte sich Ehard bereits im März 1950 vor der Bonner Landesgruppe geäußert: „Wir müßten unbedingt an der klaren Linie der Union festhalten, und schar[f] gegen die Bayernpartei und alle anderen Parteien abgrenzen. Jede Konzession kommt immer nur den anderen zugute. [. . .] Unsere Stellung ist nur zu halten, wenn wir uns auf unsere eigene Kraft und die Stärke des Unionsgedankens besinnen [. . . ] Der Gedanke der Union ist so groß und einmalig, daß er unbedingt festgehalten werden muß. Der Gedanke des praktischen Christentums ist auch der Gedanke der Union. [...] Wir müssen die stärkste Partei in Bayern werden, sonst können wir keine Politik mehr in Bayern machen." Archiv der CSU-Landesgruppe, Protokolle der Landesgruppensitzungen am 1.3. und 3. 3. 1950 (Zitat).

${ }^{205}$ Mintzel, CSU, in: Stöss (Hrsg.), Parteien-Handbuch, Bd. 2, S. 687. 
keiten, um mit der Bayernpartei zu einem modus vivendi zu kommen - oder ihr Zug um Zug den Garaus zu machen ${ }^{206}$. Diejenigen, die wie Alois Hundhammer und Fritz Schäffer in der BP eine wesensverwandte Partei, ja einen abtrünnigen Teil der CSU sahen, versuchten immer wieder, auf eine Annäherung hinzuarbeiten ${ }^{207}$. Wer jedoch die Auffassung Josef Müllers und Hans Ehards teilte und jede auf Wiedervereinigung angelegte Politik gegenüber der BP strikt ablehnte, für den kam nur die Strategie der Abgrenzung in Frage, die keine Rücksichtnahme und keine bevorzugte Behandlung der Bayernpartei zuließ. Von dieser Position war es nur ein kleiner Schritt zu offenen und verdeckten Initiativen, die zu einer "Aufreibung und Aufsaugung " 208 der lästigen Konkurrenz führen sollten, also mit anderen Worten darauf abzielten, die Bayernpartei zu spalten, ihre christlich-konservativen Teile in die CSU zu überführen und den Rest in die politische Bedeutungslosigkeit zu drängen. Diese drei Konzeptionen standen nicht als streng getrennte Alternativen nebeneinander, die sich gegenseitig ausschlossen. Die Protagonisten der Abgrenzungsstrategie waren durchaus bereit, mit der Bayernpartei zusammenzuarbeiten, wenn es ihren Interessen dienlich schien ${ }^{209}$, andererseits gab es auch eine Reihe von CSU-Politikern, die zwar einer einheitlichen „christlichen Front ${ }^{\text {“ }} 10$ in Bayern das Wort redeten, aber nicht zögerten, sich an Intrigen gegen die Bayernpartei oder ihre Führung zu beteiligen.

Im August und September 1949 hatten führende Politiker der CSU die Einbeziehung der Bayernpartei in Adenauers Regierungskoalition verhindert ${ }^{211}$, obwohl der

${ }^{206}$ Vgl. Wolf, CSU und BP, S. 155-205. Auch Zeitgenossen wußten um die beiden wichtigsten Alternativen. So wurde Alois Hundhammer mit den Worten zitiert: „Das grösste gegenwärtige Übel sei die Zerreissung des Lagers der probayerisch-christlichen Wähler. [...] Es gäbe zwei Wege für eine Lösung: a) eine Partei versuche, die andere an die Wand zu drücken, und b) der Versuch, einen Weg zueinander zu finden. $\mathrm{Er}, \mathrm{Hu}$ [ndhammer], sei für eine Überbrückung. [...] Mein Bemühen ist, aus den 2 Parteien eine herauszuschälen, geht das nicht, dann muss die eine die andere bezwingen." BSB, NL Schwend 53, Bericht über eine Rede Alois Hundhammers am 23.1.1951 im Münchner Kreuzbräu.

${ }^{207}$ Vgl. Gelberg, Hans Ehard, S. $346 \mathrm{f}$.

208 Wolf, CSU und BP, S. 179.

209 Als Beispiel sei nur das Wahlabkommen zwischen CSU und Bayernpartei in München für die Bundestagswahlen von 1953 genannt, zu dessen maßgeblichen Architekten Josef Müller gehörte. Vgl. dazu Unger, Bayernpartei, S. 167f., und Wolf, CSU und BP, S. 175-178. Eine Abschrift des Wahlabkommens nebst Anhang findet sich im ACSP, CSU-LTF II/2, 5-30. Müller wandte sich nach dem Wahlsieg der CSU vom September 1953 auch dagegen, Teilen der Bayernpartei Avancen zu machen, da er es für gefährlich hielt, die gemäßigten Kräfte, die zur CSU neigten, aus der BP herauszubrechen. ACSP, NL Müller 394, Protokoll eines Telephongesprächs zwischen Josef Müller und Alois Hundhammer vom 7. 9. 1953, und BayHStA, NL Ehard 73, Ferdinand Kerber an Hans Ehard vom 12. 9. 1953.

210 Dieser Ausdruck fiel häufig, wenn von der parteipolitischen Konstellation in Bayern und dem Verhältnis von CSU und BP die Rede war; z. B. Archiv der CSU-Landesgruppe, Protokoll der Landesgruppensitzung am 27.4. 1950.

211 Generalsekretär Franz Josef Strauß forderte am 21. 8. 1949 in Rhöndorf eine „Isolierung der Bayern-

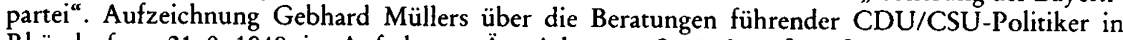
Rhöndorf am 21. 8. 1949, in: Auftakt zur Ära Adenauer, S. 39. Strauß wußte sich dabei ausnahmsweise einig mit Alois Hundhammer, der zwei Tage zuvor festgestellt hatte: „Bayernpartei ist in sehr schwieriger Situation. Entweder sie geht mit, dann ist sie in Bayern unten durch, oder sie tut nicht mit in Bonn, dann wird man [vor der bayerischen Landtagswahl Ende 1950] sagen, ihr seid ein Jahr in Bonn und habt nichts getan." Aufzeichnung Karl Schwends über eine Sitzung des Ellwanger Kreises am 19./20. 8. 1949, in: ebenda, S. 26. Auch Fritz Schäffer warnte trotz der knappen Mehrheitsverhältnisse im Namen seiner bayerischen Freunde davor, der BP Gelegenheit zu geben, einen guten "Kaufpreis“ auszuhandeln. Protokoll der Sitzung der CDU/CSU-Bundestagsfraktion am 14. 9. 1949, in: ebenda, S. 380. Und Michael Horlacher erklärte für die CSU: „Ich bitte, unter keinen Umständen derartige Fühler [zur Bayernpartei] auszustrecken. Die Mehrzahl der Arbeitsgruppen der CSU stehen im scharfen Kampf gegen die Bayernpartei. Es ist für uns ganz unmöglich, daß Verhandlungen mit der Bayernpartei aufgenommen werden. Wir können keinerlei Beziehungen zur 
designierte Bundeskanzler dafür plädiert hatte ${ }^{212}$. Nur wenige Wochen später eröffneten Generalsekretär Strauß und der inzwischen zum Bundesfinanzminister avancierte Fritz Schäffer eine Offensive gegen den Bayernpartei-Vorsitzenden Joseph Baumgartner und seinen engsten Vertrauten Ernst Falkner, die den CSU-feindlichen Flügel der BP anführten ${ }^{213}$. Strauß und Schäffer, beide in solchen Dingen nicht gerade zimperlich, versuchten, gemäßigte Gruppen in der chronisch finanzschwachen Bayernpartei um den stellvertretenden Landesvorsitzenden Anton Donhauser und den Bundestagsabgeordneten Hermann Aumer durch finanzielle Zuwendungen ${ }^{214}$ in die Lage zu versetzen, eine Palastrevolution gegen die Parteiführung anzuzetteln und die Bayernpartei auf einen Kurs zu bringen, der eine Annäherung von CSU und BP erleichtert hätte. Doch die Bemühungen des Kreises um Donhauser scheiterten, als Baumgartner von seinen Aktivitäten Wind bekam. Donhauser und seine Mitverschwörer wurden aus der Partei ausgeschlossen oder kamen einem Ausschlußverfahren durch Austritt zuvor.

Die unverhohlenen Versuche von Schäffer und Strauß, sich zum Vorteil der CSU in die innerparteilichen Auseinandersetzungen einzumischen, die die Bayernpartei 1949/ 1950 vor schwere Zerreißproben stellten ${ }^{215}$, vergifteten die ohnehin gespannte Atmosphäre im Vorfeld der Landtagswahlen zusätzlich ${ }^{216}$. Dennoch hielten sich hartnäckig Gerüchte über eine Koalition aus CSU und BP, die Bayern nach den für den 26. November 1950 anberaumten Landtagswahlen regieren sollte ${ }^{217}$, und die Spekulationen über die Zusammensetzung der neuen Regierung häuften sich, je näher der Wahltermin rückte. Nur eines stand fest: Dieses Kabinett würde im Landtag von einer Koalition getragen werden müssen, denn nach dem Ergebnis der Bundestagswahlen rechnete niemand ernsthaft damit, daß die CSU ihre absolute Mehrheit würde verteidigen können, die sie 1946 errungen hatte ${ }^{218}$.

Bayernpartei aufnehmen. Das würde bedeuten, daß die Bayernpartei das sofort agitatorisch gegen uns ausnützen würde.“" Protokoll der Sitzung der CDU/CSU-Bundestagsfraktion am 15. 9. 1949, in: ebenda, S. 415. Zu den Bedenken aus der CSU, die BP an der Regierungskoalition zu beteiligen, vgl. auch Strauß, Erinnerungen, S. $107 \mathrm{ff}$.

${ }^{212}$ Protokoll der Sitzung der CDU/CSU-Bundestagsfraktion am 14. 9. 1949, in: Auftakt zur Ära Adenauer, S. 369.

213 Vgl. dazu Vossen, Joseph Baumgartner, S. 94-104. Aufschlußreiches und bisher nicht oder nur ansatzweise ausgewertetes Material zum Verhältnis von CSU und BP in dieser kritischen Phase findet sich in: ACSP, NL Müller 394, und ACSP, CSU-LTF II/1, 3-70/5.

214 Bundesfinanzminister Schäffer vermittelte der Gruppe Donhauser Spenden aus der Industrie; vgl. Vossen, Joseph Baumgartner, S. 100.

215 Offiziell gab Ehard die Parole aus, die CSU dürfe sich durch die Krise der Bayernpartei nicht von ihrem Kurs abbringen lassen. ACSP, CSU-LL, Rede Hans Ehards vor der Landesversammlung der CSU am 17.6. 1950 in Kempten. Intern wurden aber durchaus Überlegungen angestellt, wie sich die Auseinandersetzungen in der BP, an denen die CSU nicht ganz schuldlos war, auswirken würden. So erklärte Franz Josef Strauß am 12. 9. 1950 vor dem Landesvorstand (ACSP, CSU-LL): „In der Bayernpartei spiele sich eine Scheidung der Geister zwischen Separatisten und Föderalisten ab. Der vernünftige Teil, die Föderalisten, müsse zu uns zurückgeholt werden. [. . . ] Der Zerfall der Bayernpartei sei im vollen Gange." Und Fritz Schäffer ergänzte, es bedeute bereits „einen grossen Erfolg“" daß "die Spaltung in der Bayernpartei deutlich in Erscheinung trete“.

$216 \mathrm{Vgl}$. Müller, Schulpolitik, S. 281.

217 Vgl. Gelberg, Hans Ehard, S. 346. Alois Hundhammer hatte schon im Sommer 1949 erklärt, daß man nach den nächsten Landtagswahlen „an der Bayernpartei nicht vorübergehen“ könne. ACSP, CSU-LTF I, 15-14, Protokoll der Fraktionssitzung am 19. 8. 1949. Zum Wahlkampf der CSU vgl. die Materialien im IfZ-Archiv, ED 145 NL Sattler 24; vgl. auch die letzte Wahlkampf-Nummer des Bayern-Kurier vom 25.11. 1950.

${ }^{218}$ SZ vom 18./19. 11. 1950: "Wählen ist schwer - Regierung bilden noch mehr. Bayerns Innenpolitik voll Ungewißheit und Gefahren". 
So gesehen, war das Resultat der Landtagswahlen keine Überraschung ${ }^{219}$. Die SPD konnte ihr Ergebnis von 1949 um mehr als fünf Prozent verbessern und erreichte 28,0 Prozent der Stimmen; die CSU fiel mit 27,4 Prozent hinter die Sozialdemokratie zurück, hatte aber gegenüber der erdrutschartigen Niederlage, die sie bei den ersten Bundestagswahlen erlitten hatte, kaum mehr Stimmen verloren ${ }^{220}$. Die Bayernpartei zog mit 17,9 Prozent als drittstärkste Kraft in den Landtag ein, gefolgt von der Listenverbindung DG/BHE mit 12,3 Prozent und der FDP mit 7,1 Prozent. Doch die CSU hatte noch einmal Glück im Unglück. Zwar hatte sie ihre Stellung als stärkste Partei an die SPD verloren, entsandte aufgrund zweier Überhangmandate im Wahlkreis Schwaben mit 64 Abgeordneten - unter denen sich so prominente Neulinge wie Otto von Feury $^{221}$, Otto Schedl oder Wenzel Weigel ${ }^{222}$ befanden - aber erneut die stärkste Fraktion in den Landtag ${ }^{223}$. Damit lag die Initiative zur Regierungsbildung zunächst bei Hans Ehard, und es stand außer Zweifel, daß die CSU alle Hebel in Bewegung setzen würde, um erneut das Ministerpräsidentenamt zu besetzen. Der Rückzug auf die Oppositionsbänke, um die Wunden zu kurieren, die die innerparteilichen Auseinandersetzungen und die herben Wahlschlappen der letzten Monate geschlagen hatten, war für die bayerische „Staatspartei und Ordnungspartei“ kein Thema ${ }^{224}$.

Am sichersten erschien eine große Koalition aus SPD und CSU, die im Landtag über 127 von 204 Sitzen verfügt hätte ${ }^{225}$. Auch Hans Ehard hielt eine Regierungsbildung mit den Sozialdemokraten für die beste Lösung. Schließlich hatte er schon einmal Erfahrungen mit einer solchen Koalition sammeln können, und Wilhelm Hoegner ${ }^{226}$

219 Angaben nach Ritter/Niehuss, Wahlen in Deutschland, S. $174 \mathrm{f}$.

220 Das Wahlergebnis war für die Parteiführung aber dennoch enttäuschend, da man die eigene Stärke überschätzt und bessere Resultate als bei den Bundestagswahlen erwartet hatte. ACSP, CSU-LL, Protokoll der Sitzung des Landesvorstands am 12. 9. 1950.

221 Otto Freiberr von Feury, geb. 27. 12. 1906 in München, kath., 1926-1931 Studium der Rechtswissenschaften und Nationalökonomie, 1931-1935 Angestellter der Auslandsabteilung der Bayerischen Vereinsbank in München, 1933 Übernahme des Gutshofs Thailing bei Steinhöring, seit 1946 Kreisrat (CSU) in Ebersberg, seit 1949 Mitglied des Landesausschusses der CSU, seit 1950 Mitglied des Ernährungsausschusses des Wirtschaftsbeirats der Union, seit 1952 Mitglied des Landesvorstands und des geschäftsführenden Landesvorstands der CSU, 1952-1961, 1963-1968 und seit 1970 1. Landesschriftführer der CSU, 1961-1963 und 1968-1970 2. Landesschriftführer der CSU, 1950-1978 MdL (CSU), 1957 MdB (CSU), seit 1946 Bezirksobmann des BBV in Ebersberg, seit 1949 stellvertretender Präsident des BBV in Oberbayern, 1955-1977 Präsident des BBV, seit 1956 Mitglied des Präsidiums des DBV.

222 Wenzel Weigel, geb. 6. 11. 1888 in Tschentschitz/Böhmen, gest. 2. 4. 1979, Konfession nicht ermittelt, Besuch einer deutschen Lehrerbildungsanstalt und eines humanistischen Gymnasiums in Prag, Lehrer an Volks- und Bürgerschulen, anschließend Studium in Prag, Teilnahme am Ersten Weltkrieg, 1920 Examen für das höhere Lehramt und Promotion zum Dr. phil., 1922-1927 Lehrauftrag an der Universität Hamburg, seit 1927 Dozent an der Universität Prag, Mitbegründer und später wissenschaftlicher Direktor der Deutschen Pädagogischen Hochschule in Prag, 1945 ausgewiesen, 1950-1954 MdL (CSU), 1950-1954 Mitglied des Fraktionsvorstands, 1950-1952 Mitglied des Landesvorstands der CSU.

223 SZ vom 29. 11. 1950: „Parlamentssitze unter dem Rechenstift. Warum die stärkste Partei nicht die meisten Abgeordneten erhält".

${ }^{224}$ Muhler, Ideologische Grundlagen, S. 25. In der konstituierenden Sitzung der neugewählten Landtagsfraktion erklärte Hans Ehard: „Eine Partei wie die CSU geht nicht in die Opposition, wenn sie die Möglichkeit hat zu arbeiten." ACSP, CSU-LTF II/1, 15-14, Protokoll der Fraktionssitzung am 4. 12.1950.

${ }_{225} \mathrm{Zu}$ den verschiedenen Optionen und ihrer Bewertung durch Hans Ehard vgl. ACSP, CSU-LTF II/1, 15-14, Protokoll der Fraktionssitzung am 12.12. 1950.

${ }^{226}$ Zum Verhältnis von Ehard und Hoegner vgl. Ritter, Wilhelm Hoegner, in: Seibt (Hrsg.), Gesellschaftsgeschichte, S. 350 . 
war für ihn allemal ein kalkulierbarerer Partner als der polternde Joseph Baumgartner ${ }^{227}$, der das Steuer der BP auch nicht fest in der Hand zu haben schien. Außerdem fürchtete Ehard, daß ihn ein Bündnis von CSU und BP unter dem bestimmenden Einfluß von Hundhammer und Schäffer „um die Früchte seiner langfristig angelegten föderalistischen Politik gebracht“, wenn es nicht gar das Ende seiner Ministerpräsidentschaft bedeutet hätte ${ }^{228}$. Ehard entschied aber nicht allein. Jene CSU-Abgeordneten, denen ein Bündnis mit der Bayernpartei natürlicher zu sein schien als eine Koalition mit der Sozialdemokratie, mit der man sich im Wahlkampf ${ }^{229}$ scharfe Gefechte geliefert hatte, übten Druck auf ihn aus. Auch Konrad Adenauer versuchte, seinen Einfluß geltend zu machen, um eine Regierung aus CSU und Bayernpartei zustandezubringen und so eine Einbeziehung der BP in die Bonner Koalition vorzubereiten ${ }^{230}$. Ein Bündnis dieser beiden Parteien barg jedoch gewisse Risiken. Nicht nur, daß CSU und Bayernpartei mit 103 von 204 Sitzen nur über eine hauchdünne Mehrheit verfügt hätten, aufgrund des vergifteten Klimas war es auch fraglich, ob sich alle Abgeordneten von CSU und BP auf eine solche Koalition würden einschwören lassen. Oder wie es Alois Hundhammer am 12. Dezember in seiner Fraktion ausdrückte: „Der BP müssen wir sagen, dass Voraussetzung für eine Koalition ist, dass wir uns auf eine geschlossene Fraktion verlassen können; die Rückfrage an uns wird freilich peinlich sein. " ${ }^{231}$ Allein aus diesem Grund war es notwendig, über die Erweiterung eines solchen Bündnisses nachzudenken. Dafür kamen nur der BHE oder die FDP in Frage, in beiden Fällen gab es aber gravierende Schwierigkeiten. Eine Zusammenarbeit zwischen einer ausgesprochenen Flüchtlingspartei wie dem BHE und der Bayernpartei, die überwiegend die Interessen der alteingesessenen Bevölkerung vertrat, war ebenso schwer vorstellbar wie eine Koalition von CSU und FDP, zwischen denen krasse Gegensätze in kulturund schulpolitischen Fragen bestanden ${ }^{232}$.

Für Zündstoff war also gesorgt, und es stellte sich schnell heraus, daß die bevorstehende Grundsatzentscheidung das mühsam eingedämmte Feuer der Führungs- und Flügelkämpfe wieder hell auflodern ließ. Schon in den ersten Fraktionssitzungen prallten die Fronten hart aufeinander ${ }^{233}$. Der mit großer Mehrheit wieder zum Fraktionschef gewählte Hundhammer forderte ${ }^{234}$, „dass man alle Möglichkeiten ausschöpfen soll, um mit der BP zu einer Koalition zu kommen“. Weiter führte er aus:

227 Zur Konstellation im Vorfeld der Landtagswahlen, insbesondere zu den Positionen von Ehard, Schäffer und Hundhammer vgl. Gelberg, Hans Ehard, S. 345-348; BAK, NL Schäffer 27, Bl. 131, Fritz Schäffer an Hans Ehard vom 15. 8. 1950, Bl. $186 \mathrm{f}$., Hans Ehard an Fritz Schäffer vom 6. 5. 1950, Bl. 190 ff., Fritz Schäffer an Hans Ehard vom 8. 5. 1950, Bl. 275 f., Fritz Schäffer an Domkapitular Johann Zinkl vom 27. 2. 1950, Bl. 281, Fritz Schäffer an Domkapitular Johann Zinkl vom 22. 2. 1950, Bl. 430-433, Fritz Schäffer an Karl Donderer vom 20. 12. 1950.

228 Gelberg, Hans Ehard, S. 347.

229 Zum Landtagswahlkampf der CSU vgl. BSB, NL Schwend 4, „Richtlinien für die Landtagswahlen 1950“, gez. Josef Brunner, vom 9. 10. 1950.

230 Vgl. Gelberg, Hans Ehard, S. $348 \mathrm{ff}$.

231 ACSP, CSU-LTF II/1, 15-14, Protokoll der Fraktionssitzung am 12. 12. 1950.

232 Vgl. Müller, Schulpolitik, S. 280; ACSP, CSU-LTF II/1, 15-14, Protokoll der Fraktionssitzung am 12. 12. 1950.

${ }^{233}$ Zur Diskussion über die Regierungsbildung in der CSU-Fraktion: ACSP, CSU-LTF II/1, 15-14, Protokolle der Fraktionssitzungen am 4.12., 12. 12., 14. 12., 15. 12., 16. 12., 18. 12., 19. 12. 1950 und 3. 1. 1951; im folgenden werden nur Zitate einzeln belegt.

234 Hundhammer erhielt 50 von 59 Stimmen; zum stellvertetenden Fraktionschef wurde mit 54 von 61 Stimmen der evangelische Abgeordnete Friedrich Wilhelm von Prittwitz-Gaffron gewählt. Außerdem gehörten Georg Bachmann, Heinrich Junker, Andreas Kurz, Wenzel Weigel, Zita Zehner und 
„Was mir eine Koalition mit der SPD unerwünscht erscheinen lässt und was mir Hemmungen bereitet, ist folgendes: Kulturpolitisch: Unsere Wähler bekommen einen Schock; zuerst waren wir gegen die SPD, jetzt gehen wir mit der SPD [...]. Die kirchlichen Kreise werden sich dann nur sehr schwer mehr für uns einsetzen können. Wirtschaftspolitisch: Die BP und die FDP stehen uns etwas näher als die SPD; ausgerechnet die Näherstehenden sollen wir beiseite lassen und die sozialisierungsfreundliche SPD hereinnehmen? Staatspolitisch: Die Bayernpartei vertritt, wenn auch überspitzt, den Föderalismus. Sie soll man draussen lassen, die Zentralisten der SPD [aber] hereinnehmen? Dazu kommt die Bonner Situation: Wenn dort die SPD [. . . zur Regierungsbildung kommt, dann haben wir von Bayern aus keinen Gegenkurs mehr. Noch etwas: Wir kommen in Bayern aus der üblen Lage der Zerrissenheit nur dann heraus, wenn es uns einmal gelingen würde, den Graben zur BP zu überbrücken. Wenn die BP aber gegen uns in die Opposition getrieben wird, dann wird dort der radikale Ton aufflackern, es wird dann noch schwerer, die Familienmitglieder wieder zusammenzubringen. Eine Zusammenarbeit in der Regierung wäre ein Weg dazu. ${ }^{* 235}$

Dagegen warnte Ehard davor, sich zu früh auf einen Partner festzulegen. Wenn man jetzt einseitig mit der BP verhandle, könne es passieren, daß die CSU mit der Regierungsbildung überhaupt scheitere. Der Ministerpräsident stand mit seinen Bedenken nicht allein. Das Häuflein der evangelischen CSU-Abgeordneten teilte sie ebenso wie Josef Müller ${ }^{236}$ und Franz Josef Strauß, der wie Fritz Schäffer nach München geeilt war, um die Regierungsbildung in seinem Sinne zu beeinflussen. Der Ochsensepp fand wie immer deutliche Worte:

„Die Bayernpartei sei ein Sauhaufen, wenn man mit der Bayernpartei zusammengehe, lege man sich zu einem Sauhaufen ins Bett und mache sich schmutzig damit. Komme die Bayernpartei jetzt nicht an die Futterkrippe, dann würden ihre inneren und finanziellen Schwierigkeiten nur größer. Während die SPD kalkulierbar sei, sei es die Bayernpartei nicht. Es müßten zuerst also sämtliche Möglichkeiten mit der SPD erschöpft werden. Eine Koalition mit der Bayernpartei ohne BHE sei überhaupt und völlig ausgeschlossen." 237

Max Zillibiller dem Fraktionsvorstand an. ACSP, CSU-LTF II/1, 15-14, Protokoll der Fraktionssitzung am 4. 12. 1950. Max Zillibiller, geb. 7. 12. 1896 in Aschau bei Prien/Obb., gest. 17. 11. 1970, kath., seit 1914 Teilnahme am Ersten Weltkrieg als Kriegsfreiwilliger, anschließend Beginn eines Jurastudiums, 1921 Erwerb eines Bauernhofes in Oberbayern, Übernahme des elterlichen Betriebs (Käsefabrikation und Großhandel mit Landwirtschaft) in Hindelang, seit 1946 CSU-Mitglied, stellvertretender Vorsitzender des CSU-Kreisverbands Sonthofen, 1950-1954 Mitglied des Landesvorstands der CSU, 1946 MdVLV (CSU), 1946-1966 MdL (CSU), 1950-1958 Mitglied des Fraktionsvorstands, Bürgermeister von Hindelang.

235 ACSP, CSU-LTF II/1, 15-14, Protokoll der Fraktionssitzung am 12. 12. 1950; Hervorhebungen im Original; die folgende Warnung Ehards findet sich ebenda.

236 Der Ochsensepp wurde schon lange verdächtigt, hinter den Kulissen eine große Koalition vorzubereiten. So schrieb am 8.5. 1950 Fritz Schäffer an Hans Ehard (BAK, NL Schäffer 27, Bl. 190ff.): "Ich würde dringend bitten, einen Gedanken gar nicht anklingen zu lassen, daß die CSU an die Möglichkeit dächte, mit der SPD eine Koalition zu machen. Das wäre meiner Überzeugung nach für uns in Bonn unmöglich und würde auch die geschlossene Einheit der Partei nicht fördern. [...] Mag sein, daß der Kreis um Dr. Josef Müller herum anderer Meinung ist. Dieser Kreis ist [aber] auch eine Belastung und keine Stärkung.“ In „Erinnerung an die beschämenden Vorgänge des Jahres 1946 bei der Regierungsbildung " formulierte Schäffer eine vom Landesausschuß zu verabschiedende Resolution, die gegen die „Gruppe Dr. Müller - Prittwitz-Gaffron“ in der Fraktion gerichtet war. Es sei unerträglich, "dass eine solche Minderheit die gesamte Landespolitik stört“. BSB, NL Schwend 54, Fritz Schäffer an Hans Ehard vom 10.12. 1950.

237 ACSP, CSU-LTF II/1, 15-14, Protokoll der Fraktionssitzung am 4. 12. 1950. Auch Eduard Maier, der ehemalige Schatzmeister der BP, hielt die Strategie des Aushungerns für erfolgversprechend. Am 14. 12. 1950 schrieb er an Josef Müller (ACSP, NL Müller 394): „Gelingt Dr. Baumgartner heute der Eintritt in die Regierung nicht, dann ist es nur eine Frage der Zeit, wann er vor den Toren verhungern wird. Gelingt er ihm aber infolge der Sturheit von Dr. Hundhammer, dann wird die CSU in spätestens 2 Jahren ihre blauen Wunder erleben.“ 
Die Unionsfraktion war also wieder einmal gespalten, und wie früher war es auch jetzt schwer, wenn nicht gar unmöglich, einen gemeinsamen Nenner zu finden. Wie zwei geheime Probeabstimmungen ergaben, tendierte die eine Hälfte der Fraktion zu einem Bündnis mit der Bayernpartei, während die andere eine große Koalition mit der SPD befürwortete. Einige Abgeordnete machten jedoch auch klar, daß sie nicht bereit waren, sich der Fraktionsdisziplin zu unterwerfen und für eine Koalition zu stimmen, die sie strikt ablehnten ${ }^{238}$. Angesichts der knappen Mehrheitsverhältnisse konnte dies bei der Wahl des Ministerpräsidenten von entscheidender Bedeutung sein. Am Ende der Fraktionssitzung vom 12. Dezember 1950 faßte Ehard die mehrstündige Diskussion zusammen, die ohne konkretes Ergebnis geblieben war:

„Neuwahlen wären eine Katastrophe. Eine Koalition CSU, BP, FDP hat zwei Unsicherheitsfaktoren, in der BP und bei uns. So kann der CSU der Ministerpräsident überhaupt verloren gehen. Diese Koalition ist also eine Basis, die unter den heutigen Verhältnissen viel zu knapp ist. Mit dem BHE zusammen wäre die Sache glatt, den müssten wir unbedingt haben. Zur SPD-Koalition: Hier kommt die Frage des Kultusministers. Für uns ist es eine absolute Notwendigkeit, an Kultusminister Hundhammer festzuhalten. Wie die Sache dann weitergeht, ist eine andere Frage. Alles steht und fällt dann mit dem Entschluss, den Dr. Hundhammer selbst zu fassen hat."

Damit spielte Ehard auf eine zentrale Wahlkampfaussage der SPD an. Führende bayerische Sozialdemokraten, allen voran Waldemar von Knoeringen, hatten im Wahlkampf wiederholt und nachdrücklich betont, Hundhammer sei als kulturpolitischer Reaktionär und unverbesserlicher Klerikaler im Amt des Kultusministers nicht länger tragbar ${ }^{239}$. Die potentiellen Koalitionspartner BHE und FDP hatten sich ebenfalls klar gegen Hundhammer ausgesprochen, für den es somit nicht nur darum ging, die "aufgespaltene bayerisch-christliche Front wieder zusammenzuführen “240, sondern seine Stellung als bayerischer Kultusminister zu behaupten, was offensichtlich nur durch ein Regierungsbündnis von CSU und Bayernpartei möglich war. Die Verknüpfung der Koalitionsfrage mit dieser entscheidenden Personalfrage machte die Verhandlungen mit den anderen Parteien außerordentlich schwierig und beherrschte zeitweise auch die Diskussion in der Unionsfraktion, die immer dann außer Kontrolle zu geraten drohte, wenn es um die Person Hundhammers ging. So protestierte Alfred Euerl, der nach dem Ausscheiden August Haußleiters zum Sprecher der evangelischen Abgeordneten avanciert war, vehement gegen Hundhammers Versuch, die Fraktion noch vor den ersten Probeabstimmungen auf seine Linie einzuschwören:

„Es ist falsch, wenn wir bei dieser Abstimmung schon personelle Angelegenheiten hereinnehmen. Es steht nicht in der Verfassung, dass der einzelne Ministerposten ein Erbrecht ist. Man kann auch ein anderes Ministerium übernehmen, wenn sonst die Koalitionsverhandlungen scheitern würden. Wir kennen die Widerstände gegen die Person des Kultusministers, so dass wir diese Frage nicht zur Prestigefrage machen dürfen. In einer solchen Probeabstimmung dürfen wir uns nicht von vornherein auf eine Person festlegen und eine Garantie übernehmen. Es geht um den Bestand der Partei. “241

Bevor der Konflikt über die Regierungsbildung und die Person des Kultusministers jedoch weiter eskalieren konnte, unterlief Joseph Baumgartner ein schwerer Fehler, der die Koalitionsverhandlungen maßgeblich beeinflußte. Der Bayernpartei-Vorsitzende

${ }^{238}$ ACSP, CSU-LTF II/1, 15-14, Protokolle der Fraktionssitzungen am 4. 12. und 12. 12. 1950; das folgende Zitat ebenda.

239 Vgl. Müller, Schulpolitik, S. 280-286.

${ }^{240}$ ACSP, CSU-LTF II/1, 15-14, Protokoll der Fraktionssitzung am 17. 1. 1951.

${ }^{2+1}$ ACSP, CSU-LTF II/1, 15-14, Protokoll der Fraktionssitzung am 12. 12. 1950. 
hatte sich am 13. Dezember 1950 in einer Bundestagsdebatte über einen Gesetzentwurf zur Umsiedlung von Heimatvertriebenen zu dem Zwischenruf hinreißen lassen „Das gibt es ja in keinem Kulturstaat der Welt, daß Leute mitwählen, die nicht hingehören“, und war wegen dieser „Beleidigung aller Flüchtlinge Westdeutschlands“ von Bundestagspräsident Ehlers zur Ordnung gerufen worden ${ }^{242}$. Die Vertreter des bayerischen BHE nahmen diesen Zwischenfall zum Anlaß, eine Koalition mit der Bayernpartei für unmöglich zu erklären ${ }^{243}$. Daraufhin kippte auch in der CSU-Fraktion die Stimmung. Baumgartners Politik sei doppelzüngig und unaufrichtig, hieß es, und Josef Müller erklärte, die Union wäre „würde- und charakterlos, wenn sie jetzt diese Koalition noch einginge “244. Damit war der zunächst von der Fraktionsmehrheit favorisierte Plan zur Bildung einer Koalition mit der BP obsolet geworden. Als die Unionsfraktion über die Frage „Bist Du für die kleine Koalition“ abstimmte, votierten nur noch 13 Abgeordnete für ein Bündnis von CSU und Bayernpartei, das durch die FDP erweitert werden sollte; 44 stimmten dagegen, ein Abgeordneter enthielt sich der Stimme.

Damit waren zwar die Weichen für die große Koalition gestell $\mathrm{t}^{245}$, aber bevor die Regierungsbildung erfolgreich abgeschlossen werden konnte, galt es noch, das überaus sperrige Hindernis Hundhammer aus dem Weg zu räumen, der als selbsternannter „Eckpfeiler“ einer christlichen Kulturpolitik zäh an seinem Amt festhielt und so die Verhandlungen zum Scheitern zu bringen drohte ${ }^{246}$. Die Argumente, mit denen Hundhammer seine unnachgiebige Haltung vor der Fraktion begründete, werfen ein bezeichnendes Licht auf sein von starren Grundsätzen geprägtes Politikverständnis:

"Ich hoffe, dass niemand hier im Raum von mir die Meinung hat, ich würde um eines Ministersessels willen eine solche harte Stellung einnehmen. Ich habe 1933 gelernt, eisern zu Grundsätzen zu stehen. Nie werde ich darauf Rücksicht nehmen, welche Konsequenz eine Entscheidung für mich hat. Ich habe in der Nazizeit eine andere Haltung durchziehen müssen als andere Leute. Auf diesem Gebiet muss jede persönliche eigennützige Haltung ausscheiden. Es ist die Verantwortung, die man für das Geschick des ganzen Volkes trägt und an der ich vielleicht in einem besonders starken Maße heute in Bayern mittrage."

Hundhammer verfügte in der Fraktion allerdings nicht mehr über den Rückhalt, den er sich erhofft hatte. Es waren nicht nur einige evangelische Abgeordnete, die seit langem mit dem kulturpolitischen Kurs Hundhammers haderten ${ }^{247}$, und alte Widersacher wie Josef Müller $^{248}$, die endlich eine Chance sahen, den ungeliebten Minister aus dem

${ }^{242}$ Zit. nach BSB, NL Schwend 15, „Die CSU Fraktion berichtet (1950-1954)“; vgl. auch Vossen, Joseph Baumgartner, S. $87 \mathrm{ff}$. und S. $110 \mathrm{ff}$.

${ }^{243}$ Vgl. Gelberg, Hans Ehard, S. $351 \mathrm{f}$.

${ }^{244}$ ACSP, CSU-LTF II/1, 15-14, Protokoll der Fraktionssitzung am 14. 12. 1950; das folgende nach dem Protokoll dieser Sitzung.

${ }^{245}$ CSU und Bayernpartei warfen sich in den folgenden Jahren immer wieder gegenseitig vor, für das Scheitern der kleinen Koalition verantwortlich zu sein; diese Kontroverse trug viel dazu bei, das Klima zwischen den beiden Parteien weiter zu vergiften. Vgl. ACSP, CSU-LTF II/2, 5-30, Joseph Baumgartner an Josef Brunner vom 11. 3. 1953; BayHStA, NL Ehard 170, offener Brief Joseph Baumgartners an Fritz Schäffer vom 31. 3. 1953 und Fritz Schäffer an Joseph Baumgartner vom 2. 4. 1953.

246 ACSP, CSU-LTF II/1, 15-14, Protokoll der Fraktionssitzung am 12. 12. 1950; das folgende nach dem Protokoll dieser Sitzung.

$247 \mathrm{Zu}$ den von Hundhammer mitverschuldeten konfessionellen Irritationen im Vorfeld der Landtagswahlen vgl. Müller, Schulpolitik, S. $281 \mathrm{ff}$.

${ }^{248}$ Josef Müller erklärte in der Fraktionssitzung am 12.12. 1950: „[H]eute müssen wir uns entscheiden zwischen SPD und BP. Ich bitte Dr. Hundhammer, die Person zurücktreten zu lassen. (Zwischenruf Dr. Hundhammer: Man darf nicht Plätze räumen, auf die man gestellt ist.) Hundhammer darf nicht 
Amt zu kippen. Auch ein Teil der Abgeordneten, die der Linie ihres Fraktionsvorsitzenden an und für sich positiv gegenüberstanden, war nicht bereit, die Regierungsbeteiligung der CSU wegen einer Personalfrage aufs Spiel zu setzen, und ihr Unmut wuchs, als Hundhammer sich weigerte, ein anderes Ministerium zu übernehmen ${ }^{249}$. Als die Diskussion am 15. Dezember in ihr entscheidendes Stadium trat, drängten immer mehr Abgeordnete den Fraktionschef, auf das Kultusministerium zu verzichten, um über seiner Person keine „bayerische Staatskrise“ entstehen zu lassen ${ }^{250}$. Doch Hundhammer blieb hart, und so sah sich der Ministerpräsident schließlich gezwungen, eine Entscheidung herbeizuführen. Ehard hatte es bislang soweit wie möglich vermieden, sich offen gegen Hundhammer zu stellen, aber diesmal stand für ihn zuviel auf dem Spiel. So griff er zur ultima ratio und drohte wiederholt damit, den Auftrag zur Regierungsbildung an die Fraktion zurückzugeben, sollte sie nicht bereit sein, für eine Koalitionsregierung mit der SPD zu stimmen, in der der Kultusminister nicht Alois Hundhammer heißen würde ${ }^{251}$. Ehard war sich seiner Sache offensichtlich sicher, und es gab tatsächlich keinen Abgeordneten, der sich offen gegen den Ministerpräsidenten und Parteivorsitzenden ausgesprochen hätte. Um zu retten, was nicht mehr zu retten war, plädierten Hundhammer und Schäffer dafür, die endgültige Entscheidung über die Koalitionsfrage dem Landesausschuß zu überlassen ${ }^{252}$, der am Nachmittag des 15. Dezember zusammentreten sollte ${ }^{253}$. Doch die Hoffnung, die Delegierten könnten sich gegen ein Regierungsbündnis mit der SPD entscheiden, erfüllte sich nicht. Zwar taten Hundhammer und Schäffer alles, um den Landesausschuß davon zu überzeugen, daß eine Koalition mit der Bayernpartei - mit Hundhammer als Kultus-

davon ausgehen, dass von seiner Person die christliche Linie abhängt. [...] Wir wollen nun in den kulturellen Sektor Ruhe bringen, ohne nach der Seite der Labilität Konzessionen machen zu müssen. [. . .] Durch den Namen Hundhammer haben wir Stimmen verloren, sicher stehen auch viele Stimmen hinter ih[m], diese Stimmen haben wir aber auch dann, wenn ein anderer Katholik als Kultusminister dasteht. Wenn wir wegen Dr. Hundhammer in einen neuen Wahlgang gehen müssten, würden wir noch mehr von den fluktuierenden Stimmen verlieren." ACSP, CSU-LTF II/1, 15-14.

249 Hundhammer wäre höchstens bereit gewesen, das strategisch wichtige Innenministerium zu übernehmen, das jedoch die SPD für Wilhelm Hoegner beanspruchte. Das Angebot, Landwirtschaftsminister zu werden, lehnte der Fraktionschef als demütigend ab, da Waldemar von Knoeringen mit den Worten zitiert worden war, Hundhammer sei höchstens noch in diesem Amt tragbar. Ehard dementierte später, daß sich Verteter der SPD in den Koalitionsverhandlungen abwertend über das Landwirtschaftsministerium geäußert hätten. Der gestürzte Kultusminister warf Ehard dagegen vor, nicht genug dafür getan zu haben, das Innenministerium für ihn zu erkämpfen. BayHStA, NL Ehard 242, Alois Hundhammer an Hans Ehard vom 26. 12. 1950 und Hans Ehard an Alois Hundhammer vom 22. 2. 1951. ACSP, CSU-LTF II/1, 15-14, Protokolle der Fraktionssitzungen am 14. 12. und 18. 12. 1950. Der Vorschlag, Hundhammer mit der Leitung des Innenministeriums zu beauftragen, stammte von Georg Meixner und war vermutlich zwischen den beiden abgesprochen.

250 ACSP, CSU-LTF II/1, 15-14, Protokoll der Fraktionssitzung am 15. 12. 1950 (Fritz von HanielNiethammer).

$25 !$ Zu Ehards Rolle bei der Durchsetzung der großen Koalition vgl. Gelberg, Hans Ehard, S. 348-354. Als die Diskussion in der Fraktion am Tag nach Baumgartners Lapsus an einen toten Punkt zu kommen drohte, schlug Ehard den Abgeordneten vor, die Sitzung zu unterbrechen und andere Verhandlungsführer zu wählen. Hundhammer antwortete nur ungläubig: „Ist der Vorschlag ernst gemeint?" In den folgenden Tagen sah sich Ehard nicht nur einmal gezwungen, mit seinem Rücktritt zu drohen, um seine Positionen durchzusetzen. ACSP, CSU-LTF II/1, 15-14, Protokolle der Fraktionssitzungen am 14. 12. und 15. 12. 1950 sowie am 3.1. 1951.

252 Schäffer hatte schon Tage vorher beabsichtigt, die Landtagsfraktion durch eine Resolution des Landesausschusses auf seine Linie einzuschwören und eventuelle Abweichler unter den Abgeordneten durch die Androhung von Sanktionen abzuschrecken. BSB, NL Schwend 54, Entwurf Fritz Schäffers für einen Antrag an den Landesausschuß, undatiert (10.12. 1950).

253 ACSP, CSU-LTF II/1, 15-14, Protokoll der Fraktionssitzung am 15. 12. 1950. 
minister - trotz allem die beste Lösung sei, auf Antrag von Franz Josef Strauß ${ }^{254}$ gaben die Delegierten Ehard aber freie Hand zur Bildung einer Regierung mit der SPD ${ }^{255}$. Noch am selben Abend folgte die Fraktion dem Votum des Landesausschusses. Bei einer Enthaltung und elf Gegenstimmen beschlossen die Abgeordneten, Ehard den „endgültigen Auftrag zur Regierungsbildung“ zu erteilen; dieser Beschluß wurde explizit „dahingehend interpretiert, dass Ministerpräsident Ehard auch bevollmächtigt ist, ein Kabinett Ehard ohne Dr. Hundhammer als Kultusminister zu bilden " ${ }^{256}$.

Wie so oft waren mit dieser definitiven Entscheidung die Auseinandersetzungen nicht beendet. Der Konflikt in der Fraktion drohte sogar zu eskalieren, und es zeigte sich einmal mehr, daß die Führungs- und Flügelkämpfe der vergangenen Jahre noch längst nicht beigelegt waren. Die Diskussion über die anstehenden Sach- und Personalentscheidungen nahm sogar Formen an, die den unterfränkischen Abgeordneten Engelbert Kraus zu dem ebenso verzweifelten wie resignierten Ausruf veranlaßten: „Ich komme mir vor wie [19]46 in der Fraktion bei der Regierungsbildung. “257 Wie lebendig die Erinnerung an die Schlachten der Vergangenheit noch war, bekam vor allem der von Hans Ehard erneut für das Amt des Justizministers vorgeschlagene Josef Müller zu spüren. Fritz von Haniel-Niethammer ${ }^{258}$, der Vorsitzende des CSU-Bezirksver-

${ }^{254}$ Franz Josef Strauß galt wie Josef Müller seit langem als Hindernis für eine Einigung von CSU und BP; BAK, NL Schäffer 27, Bl. 263, Hans Limmer an Fritz Schäffer vom 6. 3. 1950. Strauß hatte aus seiner Skepsis gegenüber der Bayernpartei auch nie einen Hehl gemacht. So hatte er schon im März 1950 vor der Landesgruppe zum bevorstehenden Landtagswahlkampf und zum Verhältnis von CSU und BP erklärt: „In den kommenden Landtagswahlen wird sich unsere Partei nur dann behaupten und weiterhin an der Verantwortung teilnehmen können, wenn wir unsere Front gegenüber der Bayernpartei klar abgrenzen. Dazu müssen wir uns sehr aktiv und aggres[s]iv zur Wehr setzen. Bei einzelnen Regierungsmitgliedern scheint es hier an der notwendigen Klarheit und Selbstdisziplin zu fehlen, um diesen Kampf durchzusetzen. Es entwürdigt sich eine Parteifraktion selbst, wenn sie auf die gegen ihre von Parteifreunden gebildete Regierung erhobenen Vorwürfe nicht in der gebührenden Weise antwortet. Der Kampf muß mit aller Kraft aufgenommen werden." Archiv der CSULandesgruppe, Protokoll der Landesgruppensitzung am 1. 3. 1950.

25564 Delegierte stimmten für den von Strauß eingebrachten Antrag, zwölf enthielten sich der Stimme. Hans Ehard verband diese Abstimmung mit der Vertrauensfrage, wie Fritz Schäffer am 20. 12. 1950 erbost an seinen Passauer Parteifreund Karl Donderer schrieb (BAK, NL Schäffer 27, Bl. 430-433): „In der letzten Minute wurde jedoch in einer Art Geschäftsordnungsdebatte über die Art und Weise der Abstimmung von dem Herrn Vorsitzenden die Frage plötzlich auf das Gebiet Vertrauensvotum oder Mißtrauensvotum geschoben, was selbstverständlich zu einer großen Mehrheit für den Herrn Vorsitzenden führte, aber auch die sachliche Erörterung unmöglich machte." Alois Hundhammer erstattete der Fraktion noch am selben Abend Bericht; ACSP, CSU-LTF 11/1, 15-14, Protokoll der Fraktionssitzung am 15.12. 1950 (irrtümlich auf den 16.12. datiert); vgl. auch BSB, NL Schwend 15, „Die CSU Fraktion berichtet (1950-1954)“.

256 ACSP, CSU-LTF II/1, 15-14, Protokoll der Fraktionssitzung am 15. 12. 1950 (irrtümlich auf den 16. 12. datiert), und die diesem Protokoll beigefügte Notiz „Beschlüsse der CSU-Landtagsfraktion vom 14. 12. 50 u. 15. 12.50“. Hans Ehard wurde am 18. 12. 1950 vom bayerischen Landtag mit 131 Stimmen bei 68 Enthaltungen erneut zum Ministerpräsidenten gewählt. Dem dritten Kabinett Ehard gehörten acht Vertreter der CSU, sechs der SPD und zwei des BHE an, der ebenfalls in die Koalition einbezogen worden war. Neben Ministerpräsident Ehard und Justizminister Müller stellte die CSU den Wirtschaftsminister (Hanns Seidel), den Landwirtschaftsminister (Alois Schlögl), den Kultusminister (Josef Schwalber) sowie die Staatssekretäre im Finanzministerium (Richard Ringelmann), im Innenministerium (Paul Nerreter) und im Arbeitsministerium (Heinrich Krehle). Eine Aufstellung aller bayerischen Kabinette nach 1945 findet sich in: Geschichte einer Volkspartei, S. 718-740, hier S. $722 \mathrm{f}$. Zur CSU-offiziellen Version der Regierungsbildung vgl. die Weihnachts- und Neujahrsausgabe des Bayern-Kurier vom Dezember 1951: „Kabinett sachlicher Arbeit. Voraussetzung für den Bestand der großen Koalition“.

257 ACSP, CSU-LTF II/1, 15-14, Protokoll der Fraktionssitzung am 17. 1. 1951.

${ }^{258}$ Fritz von Haniel-Niethammer, geb. 20. 7. 1895 in Köln, gest. 24. 5. 1977 in Tunzenberg/Ndb., kath., 1914-1920 Teilnahme am Ersten Weltkrieg und Kriegsgefangenschaft, landwirtschaftliches Lehrjahr 
bands Niederbayern, sprach aus, was viele dachten: „Ich bitte Dr. Müller, an diesem Kabinett nicht als Minister teilzunehmen, nachdem auch Dr. Hundhammer nicht drinnen ist. “259 Weiter führte von Haniel aus:

„Die beiden Herren gelten nun einmal als Flügelexponenten. Die neue Koalition wird draußen als linkes Kabinett bezeichnet, und wir müssen versuchen, diesen Dingen die Spitze abzubrechen. Wir müssen Müller bitten, jetzt auf seinen Sitz im Kabinett zu verzichten. [...] Es ist nicht nur wegen der propagandistischen Wirkung, wir müssen auch bedenken, daß wir einer Zeit entgegengehen, wo die Rehabilitierung des deutschen Soldaten wieder kommt; ich halte es nicht für glücklich, wenn ein Mann im Kabinett ist, der seinerzeit im Vatikan mit den Feindmächten verhandelt hat, [i]ch halte auch einen Mann nicht für glücklich, der gegenüber der Ostregierung eine Politik betreiben würde, die ich nicht billigen könnte."

Müller konnte auf diese Attacke nur fassungslos erwidern, er sehe sich gezwungen, aus der CSU auszutreten, wenn man seine Rolle im Widerstand gegen das NS-Regime so beurteile, und obwohl Hans Ehard für ihn Partei ergriff, nominierte die Fraktion den Ochsensepp nur widerstrebend und mit einem miserablen Ergebnis für den Posten des Justizministers ${ }^{260}$. Aber immerhin: Müller konnte sich behaupten, während Hundhammer sein Ministeramt verloren hatte - und eine solche Niederlage vergaß der Fraktionsvorsitzende nicht. Schon vierzehn Tage später gerieten Müller und Hundhammer in der Fraktion lautstark aneinander ${ }^{261}$. Der gestürzte Kultusminister wartete nur auf eine Gelegenheit, um Revanche zu nehmen, und diese Gelegenheit kam bald.

Schwerer als der wieder aufgeflammte Konflikt zwischen den beiden alten Streithähnen Müller und Hundhammer wog aber das Zerwürfnis zwischen Ehard und dem noch immer einflußreichen Vorsitzenden der CSU-Fraktion. Wie tief der Bruch zwischen den beiden ging, zeigt ein Briefwechsel aus den letzten Tagen des Jahres 1950. Am 23. Dezember richtete der Ministerpräsident ein persönliches Schreiben an Hundhammer, in dem er um Verständnis für seine Haltung in der umstrittenen Koalitionsfrage warb und den Fraktionschef darum bat, im Interesse von Staat und Partei aufrichtig und vertrauensvoll mit ihm, dem Ministerpräsidenten, zusammenzuarbeiten ${ }^{262}$. Doch Hundhammer war zu tief getroffen, um sich von Ehards versöhnlichen Worten beschwichtigen zu lassen. Am 26. Dezember antwortete er:

„Der Ernst und die Schwere der Entscheidung, die in diesem Monat gefallen ist, bleiben als ein wesentliches und gewichtiges Glied in der Kette der von mir mitzuverantwortenden Ereignisse

und Studium der Volkswirtschaft, 1923 Promotion zum Dr. rer. pol., anschließend bei einer Handelskammer, bei Banken und im Verlagswesen tätig, 1939-1945 Teilnahme am Zweiten Weltkrieg (zuletzt Major), nach 1945 Bewirtschaftung des Familienbesitzes, Kreisrat (CSU) und stellvertretender Landrat in Dingolfing, 1949-1965 Vorsitzender des CSU-Bezirksverbands Niederbayern, 1951-1965 Mitglied des Landesvorstands der CSU, 1950-1954 MdL (CSU), 1957-1965 MdB (CSU).

259 ACSP, CSU-LTF II/1, 15-14, Protokoll der Fraktionssitzung am 18. 12. 1950; das folgende nach dem Protokoll dieser Sitzung.

260 Für Müller stimmten nur 41 Fraktionsmitglieder, 20 stimmten gegen ihn, zwei Abgeordnete enthielten sich der Stimme. Alois Schlögl, Hanns Seidel und Heinrich Krehle wurden bei wenigen Enthaltungen ohne Gegenstimme nominiert; selbst auf die nicht unumstrittenen Richard Ringelmann, Paul Nerreter und Josef Schwalber entfielen erheblich mehr Stimmen als auf den Ochsensepp. ACSP, CSU-LTF II/1, 15-14, Protokolle der Fraktionssitzungen am 18. 12. 1950 und 3. 1. 1951.

261 ACSP, CSU-LTF II/1, 15-14, Protokoll der Fraktionssitzung am 17. 1. 1951. Müller warf Hundhammer erregt vor, er betreibe gezielt den Sturz der Regierung und bereite in konspirativen Gesprächen ein Bündnis von CSU und Bayernpartei vor. Hundhammer nannte den Justizminister einen "hundsgemeine[n] Verleumder“, und beschuldigte Müller, ihn illegal bespitzeln zu lassen.

262 BayHStA, NL Ehard 242, Hans Ehard an Alois Hundhammer vom 23. 12. 1950. 
bis an meine letzten Tage auf mir lasten. Ich kann mich der Erkenntnis nicht entziehen, dass die Ereignisse logisch und mit dramatischer Folgerichtigkeit sich abgewickelt haben durch die Schuld, das Versagen und die Unzulänglichkeit der Menschen. Das Endergebnis, das vor uns liegt, ist nicht gut. Es hätte nicht so sein müssen. Es ist widernatürlich, dass in Bayern eine Regierung zustande kam zwischen CSU und SPD, wo CSU und Bayernpartei eine Mehrheit gehabt hätten. [...] Du hast die Entscheidung für links gefällt. Motive und Umstände hast Du berührt. Ich will sie nicht weiter erörtern. Nur den Ablauf der Tatsachen halte ich fest. Erinnerst Du Dich an das Gespräch unter vier Augen auf Deinem Büro in der entscheidenden Zeit? Du hast mir dabei erklärt: ,Wenn ich meine, ich könnte eine kleine Koalition mit der Bayernpartei bilden, dann soll ich es versuchen. Du würdest Dein Mandat niederlegen. Die Partei solle einen anderen Vorsitzenden wählen und Du würdest Dir eine andere Beschäftigung suchen.' Mit dieser Haltung war die kleine Koalition unmöglich gemacht. Keim und Wurzel der jetzigen Wendung liegen in der Geschichte der CSU von deren Anfängen her. Ich habe mich redlich bemüht - angefangen von der Zeit, in der einige das Wort ,christlich' aus unserem Parteinamen streichen wollten und das Wort ,bayerisch' tatsächlich von unseren Briefköpfen entfernt wurde, über die Entscheidung bezüglich der Person des Ministerpräsidenten und den Kurs der Staatsregierung im Jahre 1946 bis zur Rettung der CSU vor dem buchstäblichen finanziellen wie dem politischen und moralischen Konkurs durch die Wendung auf dem Straubinger Parteitag -, die Anhänger der Union zusammenzuhalten und die Rücksichtnahme auf verhängnisvolle Kräfte und ihren Einfluss auf den Kurs der Partei auszuschalten. Die Aufsplitterung des bürgerlichen christlichen bayerischen Lagers in CSU und Bayernpartei ist der Herd des Übels. Die Beseitigung der Spaltung ist der Weg zur Abhilfe und Wiedergesundung unseres staatspolitischen Zustandes. Bayern darf nicht die Verantwortung auf sich laden, dass durch sein Versagen als Flügelmann in der entscheidenden Schlüsselstellung der föderalistischen Kräfte in den Bundesländern die Führung Deutschlands in die Hände sozialdemokratischer Kräfte gespielt worden ist. [...] Du bittest mich um der Sache unseres Landes und der Partei willen, es nicht zuzulassen, einen Graben zwischen uns beiden zu ziehen. Ich meine, wir hätten in den vergangenen vier Jahren Kameraden werden können. Ich habe Dich selber ein zweitesmal zum Ministerpräsidenten vorgeschlagen und gewählt. Ich werde Dich loyal unterstützen bis zu der Stunde, in welcher diese Koalition zerbricht. [...] Ich bin in meinem Leben einen harten Weg gegangen, nicht eiskalt, aber unter Hinnahme von Opfern, an denen meine Familie zeitweise schwer mittragen musste und bis heute noch trägt. Aber es war der rechte Weg. Die Erfahrung hat es erwiesen. Fehlgegangen bin ich dann, wenn ich weich war. ${ }^{\text {“263 }}$

Hans Ehard wird diese Zeilen mit sorgenvoller Miene gelesen haben, wußte er doch nur allzu gut, wie hart, kompromißlos und nachtragend Hundhammer sein konnte ${ }^{264}$. Wie berechtigt solche Sorgen waren, zeigte sich rasch. So kursierte Ende Januar 1951 das Gerücht, Joseph Baumgartner werde als Bayernpartei-Vorsitzender abtreten und Alois Hundhammer Platz machen ${ }^{265}$. Der gestürzte Kultusminister dementierte solche Meldungen zwar umgehend ${ }^{266}$, ließ aber andererseits keine Gelegenheit verstreichen, um gegen die große Koalition Front zu machen und nachdrücklich für eine Annäherung von CSU und Bayernpartei zu plädieren ${ }^{267}$. Ein erster Schritt auf diesem Weg war im Januar 1951 die Gründung der Bayerischen Volksaktion durch den Regensburger Journalisten und Verleger Josef Held, einen Sohn des ehemaligen Ministerpräsiden-

263 BayHStA, NL Ehard 242, Alois Hundhammer an Hans Ehard vom 26. 12. 1950.

${ }^{26+}$ BayHStA, NL Ehard 242, Hans Ehard an Alois Hundhammer vom 22. 2. 1951, Alois Hundhammer an Hans Ehard vom 4. 3. 1951, und NL Ehard 298, Alois Endrich an die Landesgeschäftsstelle der CSU vom 11.5. 1951; BAK, NL Schäffer 27, Bl. 365, Fritz Schäffer an Karl Schwend vom 2. 3. 1951, und Bl. 397 f., Alois Endrich an Alois Hundhammer vom 12. 1. 1951.

265 BayHStA, NL Ehard 242, Franz Josef Strauß an Alois Hundhammer vom 25. 1. 1951.

266 ACSP, CSU-LTF II/1, 15-19/2, Alois Hundhammer an Franz Josef Strauß vom 26. 1. 1951. Hundhammer beendete sein kurzes Schreiben mit dem Satz: „Für die Bayernpartei würde ein solches Geschäft gar nicht schlecht sein."

267 ACSP, CSU-LTF II/1, 15-14, Protokoll der Fraktionssitzung am 17. 1. 1951; BSB, NL Schwend 53, Bericht über eine Rede Alois Hundhammers am 23.1.1951 im Münchner Kreuzbräu. 
ten Heinrich $\mathrm{Held}^{268}$. Als eigentliche Drahtzieher dieser überparteilichen „Arbeits$\mathrm{u}[$ nd] Gesinnungsgemeinschaft christl[ich-] konservativer Kräfte “269 galten freilich Alois Hundhammer und Fritz Schäffer ${ }^{270}$, die damit „die Unzufriedenheit über die Ehardsche Koalitionsbildung “ kanalisieren ${ }^{271}$ und ihrem erklärten Ziel, der Wiedervereinigung der aufgespaltenen bayerisch-christlichen Kräfte, ein Stück näherkommen wollten. Zunächst schien sich diese Initiative durchaus erfolgversprechend anzulassen. Am 31. März 1951 sprachen sich der Landesausschuß der Bayernpartei und der von Hundhammer geführte CSU-Bezirksverband Oberbayern dafür aus, die Bayerische Volksaktion zu unterstützen. Es war aber einmal mehr Hans Ehard, der sich offen gegen alle Pläne zur Verschmelzung von CSU und BP stellte und die Parole ausgab: „Sammelt Euch in der Union“!'272 Damit nahm er der Bayerischen Volksaktion einen großen Teil ihrer Attraktivität und Stoßkraft, denn gegen den Willen des CSU-Vorsitzenden und Ministerpräsidenten war eine Annäherung oder gar eine Fusion von CSU und BP kaum denkbar. So führte die Bayerische Volksaktion noch eine Zeitlang ein Schattendasein, bevor sie schließlich ganz von der Bildfläche verschwand.

Weniger erfolgreich war Ehards vorsichtiger Versuch, auf elegante Weise den unbequemen Alois Hundhammer loszuwerden, der nicht nur die große Koalition ablehnte, sondern ihm selbst auch skeptisch, ja fast feindselig gegenüberstand und so eine ständige Bedrohung für seine politische Linie darstellte. Da lag es nahe, daß der Ministerpräsident den einflußreichen Vorsitzenden der CSU-Fraktion bei Konrad Adenauer für das Amt des Vertreters der Bundesrepublik beim Heiligen Stuhl ins Gespräch brachte, als dieses im März 1951 zur Besetzung anstand ${ }^{273}$. Allerdings gelang es Ehard nicht, seinen Gegenspieler aus München wegzuloben, und so mußte er sich auf weitere unerwünschte Querschüsse aus der Hundhammer-Ecke gefaßt machen ${ }^{274}$.

Ehard war nicht zu beneiden. Mit der Entscheidung für eine große Koalition unter Ausschluß von Alois Hundhammer war die Lage in der CSU noch unübersichtlicher geworden. Wie sich vor allem in der Fraktion gezeigt hatte, bestanden die alten Gegensätze zwischen den katholisch-konservativen Kräften und den Resten des Müller-Flügels weiter, ganz zu schweigen von der unüberbrückbaren persönlichen Feindschaft zwischen Hundhammer und dem Justizminister, wenn die beiden Streithähne auch

${ }^{268}$ Vgl. dazu Unger, Bayernpartei, S. 164 f., sowie Wolf, CSU und BP, S. 169 ff., und Gelberg, Hans Ehard, S. $359 \mathrm{f}$.

${ }^{269}$ Zit. nach Unger, Bayernpartei, S. 164.

270 BayHStA, NL Ehard 242, Fritz Schäffer an Hans Ehard vom 22. 1. 1951; BSB, NL Schwend 53, Bericht über eine Rede Alois Hundhammers am 23. 1. 1951 im Münchner Kreuzbräu; BAK, NL Schäffer 27, Bl. 331 f., Josef Held an Fritz Schäffer vom 6. 6. 1952, Bl. 358 ff., Fritz Schäffer an Hans Ehard vom 20. 2. 1951, Bl. 373 ff., Josef Held an Fritz Schäffer vom 23. 1. 1951, Bl. 389 ff., Fritz Schäffer an Josef Held vom 23. 1. 1951, Bl. 406, Josef Held an Fritz Schäffer vom 14. 1. 1951, Bl. 409, Josef Held an Fritz Schäffer vom 16. 1. 1951. Wie Henzler, Fritz Schäffer, S. 367, zu der Einschätzung kommt, der Bundesfinanzminister hätte sich im Frühjahr 1951 von der Bayerischen Volksaktion scharf distanziert, bleibt unverständlich.

271 Gelberg, Hans Ehard, S. 359.

${ }^{272}$ BSB, NL Schwend 55, Hans Ehard an Fritz Schäffer vom 3. 3. 1951; ähnlich auch ACSP, CSU-LTF II/1, 15-12/3, Rede Hans Ehards vor dem Landesausschuß der CSU am 14. 4. 1951 in Würzburg.

${ }^{273}$ BSB, NL Schwend 3, Hans Ehard an Konrad Adenauer vom 17. 3. 1951.

274 Vgl. z. B. Rheinischer Merkur vom 2. 3. 1951: Der schwarze Mann. Dr. Aloys Hundhammer wartet auf seine Chance"; weitere diesbezügliche Zeitungsausschnitte in: ACSP, CSU-LTF II/1, 15-12/1, und BSB, NL Schwend 55; Hundhammer machte aus seiner Skepsis gegenüber der großen Koalition und aus seiner Reserve gegen Ehard keinen Hehl: ACSP, CSU-LTF II/1, 15-20/40, Rede Alois Hundhammers vor der Landesversammlung der CSU am 24. 6. 1951 in Bad Reichenhall. 
sichtlich an Einfluß verloren hatten. Mit dem Bruch zwischen Ehard und Hundhammer wurde jedoch ein neuer Graben aufgerissen, und im Frühjahr 1951 konnte niemand sagen, welche Auswirkungen dieser neue Konfliktherd auf die CSU haben würde. Eines war jedoch klar: Ehard war in seiner Partei nicht mehr so unangefochten wie bisher. Da kam es dem CSU-Vorsitzenden besonders ungelegen, daß sich zwischen den Landespolitikern und der immer selbstbewußter auftretenden Landesgruppe der CSU in Bonn eine neue Frontlinie herauszubilden begann.

\section{c) Landespolitik versus Bundespolitik}

Als die CSU 1945 gegründet wurde, stand keineswegs fest, daß sie sich zu einer autonomen Landespartei entwickeln würde. Immerhin gab es prominente Mitbegründer wie Josef Müller und Adam Stegerwald, die nicht an die Tradition der selbständigen bayerischen Parteien anzuknüpfen gedachten, sondern in der CSU den bayerischen Landesverband einer künftigen Reichsunion sahen, welche Form diese auch immer haben mochte. Es zeigte sich jedoch schon 1946, daß sich diese Kräfte nicht würden durchsetzen können und die Weichen mehr und mehr in Richtung auf eine organisatorisch-politische Eigenständigkeit der CSU gestellt würden. Damit stand aber auch die Frage auf der Tagesordnung, wie die Partei in Gremien wie dem Frankfurter Wirtschaftsrat und dem Parlamentarischen Rat oder seit August 1949 im Bundestag auftreten sollte ${ }^{275}$. Schließlich hatte die „Betonung einer parlamentarischen Sonderstellung auf nationaler Ebene“ ebenso tiefe historische Wurzeln ${ }^{276}$ wie die autonomen bayerischen Landesparteien selbst.

Nach den ersten Bundestagswahlen standen den verantwortlichen CSU-Politikern im Prinzip drei strategische Optionen offen: die Bildung einer eigenen Fraktion, eine Fraktionsgemeinschaft mit der CDU oder eine Arbeitsgemeinschaft mit anderen föderalistischen Parteien wie der DP oder der Bayernpartei. Doch welche von diesen Möglichkeiten sollte man wählen ${ }^{277}$ ? Eine eigene Fraktion hätte sicherlich die größtmögliche Bewegungsfreiheit geboten und der CSU die besten Chancen eröffnet, sich gemäß ihrem Selbstverständnis als eigenständige Partei zu präsentieren. Zudem gab es für eine solche Lösung namhafte historische Vorbilder. So hatte die Bayerische Patriotenpartei nach 1871 im Reichstag eine eigene Fraktion gebildet ${ }^{278}$, und auch die Bayerische Volkspartei hatte sich 1920 entschlossen, die Fraktionsgemeinschaft mit dem Zentrum aufzulösen und eigene Wege zu gehen ${ }^{279}$. Mit dieser Entscheidung hatte sich die BVP im

275 ACSP, NL Müller 16, Protokoll der Landesversammlung der CSU vom 27.-29. 5. 1949 in Straubing (Anton Pfeiffer).

${ }^{276}$ Alf Mintzel, Franz Josef Strauß und die CSU-Landesgruppe im Deutschen Bundestag, in: Friedrich Zimmermann (Hrsg.), Anspruch und Leistung. Widmungen für Franz Josef Strauß, Stuttgart 1980, S. 281-307, hier S. 287.

277 Zu den möglichen Optionen vgl. BSB, NL Schwend 2, „Brief aus dem 1. Deutschen Bundestag“" vom 14. 9. 1949; ACSP, CSU-LTF I, 15-14, Protokolle der Fraktionssitzungen am 19. 8. und 14. 9. 1949; Archiv der CSU-Landesgruppe, Protokoll der Landesgruppensitzung am 7. 9. 1949; ACSP, CSULL, Protokoll der Landesversammlung der CSU am 17./18. 6. 1950 in Kempten (Franz Josef Strauß, Hans Ehard, Fritz Schäffer).

${ }^{278}$ Zum Verhältnis von Patriotenpartei und Zentrum vgl. Albrecht, Von der Reichsgründung bis zum Ende des Ersten Weltkrieges, in: Spindler (Hrsg.), Handbuch der bayerischen Geschichte, Bd. IV/1, S. 298-307.

279 Vgl. Schönhoven, BVP, S. 35-42, und Christian Maga, Prälat Johann Leicht (1868-1940). Konservativer Demokrat in der Krise der Zwischenkriegszeit, Diss., Würzburg 1990, S. 69-77. 
Reichstag allerdings selbst isoliert und das verlorene Häuflein ihrer Abgeordneten mehr oder weniger zur Bedeutungslosigkeit verdammt. Diese bittere Erfahrung, die frischgebackene Bundestagsabgeordnete wie Michael Horlacher und Hugo Karpf selbst hatten machen müssen, sprach für eine Fraktionsgemeinschaft mit der CDU. Schließlich verstand sich die CSU trotz mancher Vorbehalte als Teil der Union, und man hatte bereits im Frankfurter Wirtschaftsrat und im Parlamentarischen Rat Erfahrungen mit einer solchen Fraktionsgemeinschaft sammeln können. Dennoch wurden auf seiten der konservativen BVP-Traditionalisten immer wieder Stimmen laut, die für die Bildung einer eigenen Fraktion plädierten ${ }^{280}$. Tatsächlich durfte man eines nicht übersehen: Es war durchaus möglich, daß die 24 Abgeordneten der CSU bei einem Zusammenschluß mit der großen CDU-Fraktion einfach aufgesogen würden und die Partei so ihre Handlungsfähigkeit auf der politischen Bühne Bonns verlieren könnte. Außerdem bedeutete eine Fraktionsgemeinschaft einen geradezu strukturellen Zwang zum Kompromiß, und diese Kompromisse mußten nicht immer im Sinne der Münchner Parteiführung ausfallen. Als dritte Option bot sich eine Arbeitsgemeinschaft aller föderalistischen Kräfte unter Führung der CSU an. Das vergiftete Verhältnis von CSU und Bayernpartei ${ }^{281}$, die neben der $\mathrm{DP}^{282}$ der wichtigste Partner in einem solchen Bündnis gewesen wäre, machte die Verwirklichung dieser Idee jedoch von vornherein mehr als schwierig.

Überraschenderweise wählten die Abgeordneten der CSU jedoch keine von diesen Möglichkeiten, sondern entschieden sich für eine Kompromißlösung, die die Vorteile einer eigenen Fraktion mit den Vorteilen einer Fraktionsgemeinschaft von CDU und CSU verbinden sollte ${ }^{283}$. In diesem Sinne beschlossen die neugewählten Parlamentarier der bayerischen Unionspartei, wie im Frankfurter Wirtschaftsrat und im Parlamentarischen Rat eine Fraktionsgemeinschaft mit der CDU einzugehen, aber zugleich einen eigenen Vorstand zu wählen, eigene Sitzungen abzuhalten und sich so als organisatorisch weitgehend unabhängige Landesgruppe innerhalb der gemeinsamen Bundestagsfraktion zu konstituieren ${ }^{284}$. Eine verdeckte Vorform dieser speziellen CSU-Lösung hatte es schon im Wirtschaftsrat und im Parlamentarischen Rat gegeben. In Frankfurt war es Franz Josef Strauß gewesen, der die Zügel in die Hand genommen und eine eigene Sitzordnung für die Abgeordneten der CSU durchgesetzt hatte ${ }^{285}$, und die Repräsentanten der bayerischen Unionspartei im Parlamentarischen Rat waren darauf bedacht gewesen, trotz ihrer Mitgliedschaft in der gemeinsamen Fraktion eine gewisse

${ }^{280}$ Vgl. Müchler, CDU/CSU, S. 45.

${ }^{281} \mathrm{Zu}$ einer - allerdings kurzlebigen - Arbeitsgemeinschaft von CSU und BP kam es erst 1951; vgl. Unger, Bayernpartei, S. 165; Archiv der CSU-Landesgruppe, Protokoll der Landesgruppensitzung am 12.4. 1951 und Protokoll der Sitzung der Arbeitsgemeinschaft von CSU und BP am 5. 6. 1951.

${ }^{282} \mathrm{Zu}$ Kontakten Fritz Schäffers mit der DP-Führung vgl. Auftakt zur Ära Adenauer, S. XXV, und Fritz Schäffer an Heinrich Hellwege vom 17. 8. 1949, in: ebenda, S. $19 \mathrm{f}$.

283 Müchler, CDU/CSU, S. 63, stellt mit Recht fest: „Die Organisationsform der Landesgruppe stellte einen Kompromiß dar. Einerseits bedeutete sie weniger als eine eigene Fraktion; andererseits manifestierte sie die herausgehobene Stellung der CSU in der F[raktionsgemeinschaft].

${ }^{284}$ Der Landtagsabgeordnete Anton Maier, der seinen Fraktionskollegen über die Vorgänge in Bonn Bericht erstattete, zitierte Fritz Schäffer mit den Worten: „Wir haben in Bonn eine eigene Landesgruppe, eine eigene Vorstandschaft und halten eigene Sitzungen ab, um geschlossen und umso stärker in der grossen CDU-CSU-Fraktion auftreten zu können." ACSP, CSU-LTF I, 15-14, Protokoll der Fraktionssitzung am 14. 9. 1949.

285 Protokoll der Sitzung des Landesausschusses der CSU am 28./29. 2. 1948 in Regensburg, in: Protokolle und Materialien, S. 1635. Strauß erklärte auch, er habe die Abgeordneten der CSU in Frankfurt "zu einer Gruppe zusammengefaßt". 
Eigenständigkeit zu wahren ${ }^{286}$. Robert Lehr, in der CSU als Zentralist verschrien und entsprechend unbeliebt ${ }^{287}$, hatte schon Ende Oktober 1948 vor dem Zonenausschuß der CDU in der britischen Besatzungszone festgestellt: „Die Bayern haben sich von Anfang an als eine Fraktion innerhalb der Fraktion gefühlt und so auch uns gegenüber verhalten.“288

Zum vielleicht wichtigsten Fürsprecher des Landesgruppenmodells, ja überhaupt zur treibenden Kraft der CSU auf Bundesebene, avancierte Fritz Schäffer. Vom ehemaligen BVP-Vorsitzenden hatte man das nicht unbedingt erwarten können, schließlich galt der Staatsrat als Erzföderalist ${ }^{289}$ und als Verfechter einer eigenständigen bayerischen Politik. Außerdem war er ohne jedes Parteiamt, nachdem er im September 1948 aus der CSU ausgetreten war. Wenn Schäffer in den Überlegungen der Parteiführung um Hans Ehard überhaupt eine Rolle spielte, dann keine besonders erfreuliche ${ }^{290}$. Man hatte nicht vergessen, daß Schäffer die Flügelkämpfe mit der oberbayerischen Rebellion auf die Spitze getrieben hatte und war auch von seiner Kandidatur für den Bundestag nicht gerade begeistert gewesen. Als Führungsfigur der CSU in Bonn kam er jedenfalls für Ehard nicht in Frage. Der Landesvorsitzende setzte vielmehr auf seinen bewährten Parteifreund Anton Pfeiffer, der schon im Parlamentarischen Rat sein Statthalter gewesen war $^{291}$. Der Chef der Staatskanzlei, immerhin einer der prominentesten CSU-Politiker überhaupt, fiel jedoch in seinem Wahlkreis München-Land gegen Anton Besold von der Bayernpartei glatt durch, und auch seine Absicherung über die Landesliste erwies sich als erfolglos. Das Scheitern Pfeiffers eröffnete Schäffer die Chance für ein erneutes Comeback, und er packte die Gelegenheit beim Schopf, sich „als neue Führungspersönlichkeit der CSU in Bonn zu etablieren“292.

Nur zwei Tage nach der Wahl ergriff Schäffer die Initiative und lud die frischgebackenen Bundestagsabgeordneten seiner Partei für den 19. August 1949 zu einer Besprechung nach München ein ${ }^{293}$. Für den Staatsrat war es keine Frage, daß die CSU im Bundestag in irgendeiner Form als selbständige Partei auftreten mußte. Sollten die Abgeordneten der bayerischen Unionspartei keine eigene Organisationsform finden, schrieb er an seinen Regensburger Kollegen Max Solleder ${ }^{294}$, „fallen unsere Freunde sicherlich auseinander". Sie seien „fast alle neu gewählt", würden sich noch nicht kennen

${ }^{286}$ So hatten die Vertreter der bayerischen Unionspartei am 7. 1. 1949 beschlossen, künftig regelmäßige Gruppenbesprechungen abzuhalten, allerdings unter Ausschluß von Karl Sigmund Mayr, den man der Komplizenschaft mit den zentralistischen Kräften in der CDU verdächtigte. Sogar ein Ausscheiden der CSU aus der gemeinsamen Fraktion war erwogen worden. Vgl. Gelberg, Hans Ehard, S. $198 \mathrm{f}$.

${ }^{287} \mathrm{Zu}$ den Bedenken gegen Lehr, die im August 1949 nach einem föderalistischen Canossa-Gang des früheren Oberbürgermeisters von Düsseldorf zumindest vorübergehend zurückgestellt wurden, vgl. Archiv der CSU-Landesgruppe, Protokoll der Landesgruppensitzung am 7. 9. 1949, sowie Fritz Schäffer an Hans Ehard vom 16. 9. 1949 und Protokoll der Sitzung der CDU/CSU-Bundestagsfraktion am 17. 9. 1949, in: Auftakt zur Ära Adenauer, S. 438f. bzw. S. 448 f.

${ }^{288}$ Zit. nach Müchler, CDU/CSU, S. 49.

${ }^{289}$ SZ vom 3. 9. 1949: „Wo bleiben die Länder?“".

290 Vgl. Gelberg, Hans Ehard, S. 289 f.

${ }^{291} \mathrm{Zu}$ dem nicht ganz reibungsfreien Verhältnis von Ministerpräsident Ehard und seinem Staatsminister, der im Parlamentarischen Rat die CDU/CSU-Fraktion führte, vgl. Reuter, Anton Pfeiffer, S. $182-206$.

292 Auftakt zur Ära Adenauer, S. XXV.

${ }^{293}$ Vgl. Henzler, Fritz Schäffer, S. $290 \mathrm{ff}$.

294 Maximilian Solleder, geb. 8. 3. 1894 in Schierling/Opf., gest. 23. 1. 1966, kath., Jurastudium und Promotion, seit 1922 Rechtsanwalt in Regensburg, vor 1933 BVP-Mitglied und Geschäftsführer der 
und seien aufgrund ihrer Unerfahrenheit "den gewiegten Parlamentariern der CDU völlig ausgeliefert". Es bestehe die Gefahr, so Schäffer weiter, daß die CSU im Bundestag überhaupt nicht zu Wort komme und von der Öffentlichkeit völlig unbeachtet bliebe. Außerdem müsse man auf die schwierigen innerbayerischen Verhältnisse Rücksicht nehmen und dürfe der Bayernpartei keine zusätzliche Munition liefern ${ }^{295}$. Andererseits war Schäffer klug genug, um zu erkennen, daß die 24 Abgeordneten der CSU ohne Unterstützung im Bundestag nur wenig würden ausrichten können. Er schlug deshalb seinen Kollegen vor, eine Fraktionsgemeinschaft mit der CDU einzugehen, aber zugleich eine eigene Landesgruppe zu bilden ${ }^{296}$. Auch wenn es durchaus Stimmen gab, die sich für eine eigene Fraktion aussprachen ${ }^{297}$, folgte die Mehrheit der CSUBundestagsabgeordneten Schäffers Empfehlung.

Am 30. August 1949 konstituierte sich die CSU-Mannschaft "mit Nachdruck als eigenständige Gruppierung" und wählte Fritz Schäffer und Franz Josef Strauß zu ihren Vorsitzenden. Zugleich entschieden sie sich für eine Fraktionsgemeinschaft mit der $\mathrm{CDU}^{298}$, allerdings nicht ohne Bedingungen. Tatsächlich konnte die CSU einiges fordern, da ihre Ausgangsposition nicht so schlecht war, wie es auf den ersten Blick scheinen mochte 299 . Immerhin waren es ihre 24 Mandate, die der Union im Bundestag das Übergewicht über die SPD sicherten ${ }^{300}$. In dieser Konstellation war es der CSU trotz ihres miserablen Wahlergebnisses möglich, Ansprüche zu stellen, die ihrer numerischen Stärke nicht unbedingt entsprachen ${ }^{301}$. So wurde etwa die Forderung erhoben, das Innen- und das Finanzministerium nur mit prinzipientreuen Föderalisten zu beset$z^{302}$ und den Gedanken an eine große Koalition mit der SPD aufzugeben ${ }^{303}$. Eine gemeinsame Fraktion, so hieß es weiter, sei nur unter der Voraussetzung möglich, „daß

BVP in der Oberpfalz, seit 1945 CSU-Mitglied, 1949-1953 MdB (CSU), stellvertretender Vorsitzender der CSU-Landesgruppe, 1952/1953 Mitglied des Landesvorstands der CSU.

295 Zit. nach Henzler, Fritz Schäffer, S. 291 Anm. 98.

296 Archiv der CSU-Landesgruppe, Fritz Schäffer an Franz Josef Strauß vom 20. 8. 1949; auch abgedruckt in: Geschichte einer Volkspartei, S. 465.

297 Archiv der CSU-Landesgruppe, Protokoll der Landesgruppensitzung am 7. 9. 1949.

${ }^{298}$ Henzler, Fritz Schäffer, S. 296 f.; auch Hans Ehard sprach sich für das Landesgruppenmodell aus: SZ vom 1. 9. 1949: „Erneute Besprechung Adenauer - Ehard“.

${ }^{299}$ So zu Recht Reuter, Anton Pfeiffer, S. 213 f. Anders dagegen Gelberg, Hans Ehard, S. 282, und Auftakt zur Ära Adenauer, S. XXIV.

300 Nach Pressemeldungen, die bayerische CSU würde sich in Bonn mit dem Postministerium zufriedengeben, betonte Ehard am 26. 8. 1949 vor der Landtagsfraktion: „Ihnen hier erkläre ich, daß damit, daß die CSU die CDU/CSU zur stärksten Partei macht, wir ganz andere Wünsche anzumelden haben." Und zwei Wochen später führte der Ministerpräsident aus: „Ohne Zweifel ist gegenwärtig der Einfluss der CSU-Gruppe in Bonn sehr gross, weil durch die CSU-Gruppe die CDU ja stärkste Partei ist und vor der SPD dominiert. Dass wir aus dieser Position heraus ständig mit der Faust auf den Tisch schlagen, kommt natürlich nicht in Frage; aber wir bleiben aktiv!“ ACSP, CSU-LTF I, 15-14, Protokolle der Fraktionssitzungen am 26. 8. und 14. 9. 1949.

$301 \mathrm{Zu}$ den Forderungen der CSU vgl. Müchler, CDU/CSU, S. 99-105, und Henzler, Fritz Schäffer, S. 295-303.

302 SZ vom 1. 9. 1949: „Föderalistischer Innenminister gefordert".

${ }^{303}$ Zur diesbezüglichen Diskussion vgl. ACSP, CSU-LTF I, 15-14, Protokolle der Fraktionssitzungen am 19. 8., 26. 8. und 14. 9. 1949; Protokoll der Sitzung der CDU/CSU-Bundestagsfraktion am 1.9. 1949, in: Auftakt zur Ära Adenauer, S. 162 (Fritz Schäffer); Archiv der CSU-Landesgruppe, Protokoll der Landesgruppensitzung am 7. 9. 1949. An einer deutlichen Präferenz der CSU für eine Koalition unter Ausschluß der SPD kann kein Zweifel bestehen; es steht jedoch ebenfalls fest, daß Konrad Adenauer das Nein der CSU als Waffe zur Durchsetzung der kleinen Koalition in der CDU benutzte. Vgl. z. B. Protokoll der Sitzung der CDU/CSU-Bundestagsfraktion am 1. 9. 1949, in: Auftakt zur Ära Adenauer, S. 145. 
die Interessen der Länder in finanzwirtschaftlichen und auch in kulturpolitischen Fragen auf keinen Fall majorisiert werden" dürften ${ }^{304}$. Diese Forderungen lagen der Erklärung zugrunde, die Fritz Schäffer am 1. September 1949 zu Beginn der konstituierenden Sitzung der Unionsfraktion abgab:

„Meine sehr verehrten Damen und Herren! Die Abgeordneten, die auf den Namen der bayerischen Landespartei CSU gewählt sind, haben in einer Vorbesprechung sich darauf geeinigt, Ihnen vorzuschlagen, daß sie als Mitglieder der vereinigten Fraktion CDU/CSU von Ihnen anerkannt werden und an Ihren Beratungen in dieser Eigenschaft teilnehmen wollen, damit wir auch in der Lage sind, dem Büro des Bundestages mitzuteilen, daß die CDU/CSU mit 139 Mitgliedern die stärkste Fraktion dieses Hauses ist. (Lebhafter Beifall) Sie wissen, daß die bayerische Landespartei der CSU unter besonderen Verhältnissen kämpft und unter diesen besonderen Verhältnissen den föderativen Gedanken vertreten wird. Wir stellen uns in dieser Situation vor, daß wir auch in die Fraktion ein Stück föderativer Gedanken hineintragen dürfen. Wir haben uns deshalb entschlossen, Sie zu bitten, daß wir eine bayerische Landesgruppe in Ihrem Kreise bilden, wir aber als Mitglieder der Fraktion gelten sollen. " ${ }^{305}$

Diese Erklärung wurde von den Abgeordneten der CDU mit Beifall aufgenommen, und damit war die Fraktionsgemeinschaft beschlossene Sache ${ }^{306}$. Das erneuerte Bündnis der Unionsparteien ließ sich für die CSU nicht schlecht an. Noch am 1. September wählte die Fraktion Fritz Schäffer zu einem ihrer stellvertretenden Vorsitzenden und delegierte Franz Josef Strauß als zweites Mitglied der CSU in den Fraktionsvorstand $^{307}$. In Bayern gab es jedoch nicht geringe Widerstände gegen diese Lösung, und diejenigen, die von vornherein auf Eigenständigkeit bedacht gewesen waren, konnten sich bestätigt fühlen, als Karl Arnold und nicht der von der CSU vorgeschlagene Hans Ehard zum Präsidenten des Bundesrats gewählt wurde ${ }^{308}$. Ehard, der wie kein

304 SZ vom 27. 8. 1949: „Sonderbesprechung CDU/CSU auf dem Rittersturz“.

305 Protokoll der Sitzung der CDU/CSU-Bundestagsfraktion am 1.9. 1949, in: Auftakt zur Ära Adenauer, S. $140 \mathrm{f}$.

306 Allerdings waren nicht alle CDU-Abgeordneten erfreut über diese Lösung. Heinrich Krone vermerkte am 18. September in seinem Tagebuch: „Die Bayern haben dem Grundgesetz nicht zugestimmt, sind aber froh, daß die anderen es angenommen haben. Als in der Fraktionssitzung Staatsrat Fritz Schäffer feierlich erklärte, daß die bayerische CSU sich entschlossen habe, mit der CDU eine Fraktion zu bilden, gab es für diese wohlwollende bayerische Geneigtheit lautes Beifallklatschen. Ich klatschte nicht." Krone, Tagebücher, Bd. 1, S. 76.

307 Protokoll der Sitzung der CDU/CSU-Bundestagsfraktion am 1. 9. 1949, in: Auftakt zur Ära Adenauer, S. 184 und S. 186.

${ }^{308}$ Die führenden Repräsentanten der Landesgruppe wußten um das Mißtrauen gegen eine allzu enge Zusammenarbeit mit der CDU und versuchten daher so schnell wie möglich, ihre Entscheidung zu rechtfertigen. In einem vermutlich von Fritz Schäffer selbst verfaßten „Brief aus dem 1. Deutschen Bundestag“ vom 14.9. 1949 (BSB, NL Schwend 2) hieß es: „Für die CSU war es von vornherein klar, dass sie versuchen müsse, sich an der Verantwortung einer Regierungsbildung und Regierungsführung zu beteiligen und [. . . ] das bayerische Gewicht dabei möglichst zur Geltung zu bringen. Sie musste sich daher schon am Anfange entscheiden, sollte sie eine eigene Fraktion, getrennt von der ihr gesinnungsverwandten Christlich Demokratischen Union, im Bundestag bilden und allein im Bundestag mit 24 unter 403 Stimmen stehen, oder sollte sie sich mit der Christlich Demokratischen Union verschmelzen, um sich dem Stimmengewicht der auf den Namen dieser Partei gewählten 115 Abgeordneten anzuschliessen, aber unter Aufgabe der eigenen Selbständigkeit? Die Abgeordneten der Christlich [Sozialen] Union wählten einen dritten Weg, den wirklich föderalistischen. Sie beschlossen einstimmig, eine eigene Landesgruppe der CSU zu bilden, da sie auch auf den Namen einer eigenen Landespartei gewählt sind. Die CSU ist eine bayerische Landespartei und will es bleiben. Die CSU weiss aber auch, dass sie sich in der Bundespolitik nur geltend machen kann, wenn sie zusammenwirkt mit allen den Kräften im Bunde, die dieselben föderalistischen Ziele vertreten wie sie. Solche sind am zahlreichsten und stärksten vertreten in der Christlich Demokratischen Union; es galt daher, diese zu stärken und sich mit ihnen zu verbinden. “ Hervorhebungen im Original. 
anderer um die Verankerung dieses Verfassungsorgans im Grundgesetz gekämpft hatte, war der geborene Kandidat dafür und hatte im Zuge der Koalitionsverhandlungen von Konrad Adenauer auch entsprechende Zusagen erhalten ${ }^{309}$. Der designierte Bundeskanzler hatte jedoch nicht damit gerechnet, daß eine Reihe von Politikern aus seiner eigenen Partei den Versuch unternehmen würden, die Wahl Ehards zum Bundesratspräsidenten zu verhindern und damit die Bildung einer Regierung ohne die SPD überhaupt zu torpedieren. So wurde am 7. September 1949 nicht der bayerische Ministerpräsident, sondern sein nordrhein-westfälischer Kollege Arnold, der anders als Adenauer für eine große Koalition von Union und SPD eintrat, zum Präsidenten des Bundesrats gewählt. Dieser Tag gehörte zu den schwärzesten in Ehards bisheriger politischer Karriere; er war tief enttäuscht und zieh Adenauer und die CDU des Vertrauensbruch $s^{310}$. Der Ministerpräsident, der es stets vermieden hatte, an die defensive, ja streckenweise destruktive Politik Bayerns nach 1918 anzuknüpfen und statt dessen für eine positive Mitwirkung am Aufbau des neuen Staates eingetreten war ${ }^{311}$, erwog sogar, sich von der bundespolitischen Bühne zurückzuziehen und nur dann zu „erscheinen, wenn es notwendig ist, die bayerischen Interessen energisch zu wahren “312.

Auch die Stimmung unter den Bundestagsabgeordneten der CSU war äußerst gereizt. Als die Landesgruppe wenige Stunden nach der Wahl Arnolds den Bericht Ehards entgegennahm, hatten Schäffer und Strauß alle Mühe, ihre Kollegen von übereilten Schritten abzuhalten ${ }^{313}$. Die jüngsten Vorfälle waren selbstverständlich Wasser auf die Mühlen derer, die über die Fraktionsgemeinschaft alles andere als glücklich waren. Max Solleder, ein Rechtsanwalt aus Regensburg, der vor 1933 in der BVP aktiv gewesen war, kritisierte die Vertrauensseligkeit bei den Absprachen mit der CDU und erklärte unmißverständlich:

„Die bisherigen Stellungnahmen sind durch die heutigen Ereignisse überholt. [...] Bayern ist überspielt, schwere[r] Prestigeverlust. Ich war von Anfang an dagegen, dass wir in der Fraktion aufgehen. Ich bin mir klar, dass wir eine Fraktion haben müssen, aber taktisch wäre es richtiger gewesen, wenn wir vorher gewisse Bedingungen gestellt und uns gesichert hätten. Man ist über uns zur Tagesordnung übergegangen. Wie stellen wir uns in der Zukunft: Nur ein Anhängsel bleiben gegen[ü]ber den anderen, Bayern ist kein Eckstein im neuen Deutschland. Wenn wir ein zentralistisches Deutschland aufbauen, haben wir den Zerfall unserer Partei in Bayern."

Der Amberger Abgeordnete Josef Schatz ergänzte: „Wir haben damals gesagt, wir gehen keine Ehe ein. Leider ist es eine Ehe geworden, und den ersten Ehebruch haben wir jetzt." Hugo Karpf, Franz Josef Strauß und Fritz Schäffer, die erkannt hatten, was auf dem Spiel stand, schlugen jedoch einen Ausweg aus der Misere vor, der es der CSU erlaubte, die Fraktionsgemeinschaft aufrechtzuerhalten und zugleich das durch die Niederlage Ehards schwer geschädigte Ansehen der Partei wiederherzustellen. Sie

${ }^{309}$ Vgl. Auftakt zur Ära Adenauer, S. XLVI f., und - insbesondere zum Stellenwert der Bundesratspräsidentschaft für den bayerischen Ministerpräsidenten - Gelberg, Hans Ehard, S. 280-289; vgl. auch Karl-Ulrich Gelberg, Hans Ehard und Karl Arnold. Stationen eines wechselvollen Verhältnisses 1948-1952, in: ZfBLG 55 (1992), S. 625-646, insbesondere S. 632-637.

310 Archiv der CSU-Landesgruppe, Protokoll der Landesgruppensitzung am 7. 9. 1949; ACSP, CSULTF I, 15-14, Protokoll der Fraktionssitzung am 14. 9. 1949.

311 Vgl. Gelberg, Hans Ehard, S. $23 \mathrm{f}$.

312 Archiv der CSU-Landesgruppe, Protokoll der Landesgruppensitzung am 7. 9. 1949; das foigende nach dem Protokoll dieser Sitzung.

${ }^{313}$ Vgl. dazu auch das Protokoll der Sitzung der CDU/CSU-Bundestagsfraktion am 8. 9. 1949, in: Auftakt zur Ära Adenauer, S. 287-298. 
verlangten eine stärkere Berücksichtigung der CSU bei der Verteilung der Kabinettssitze, und da Adenauer auf die Stimmen der Landesgruppe angewiesen war, blieb ihm nichts anderes übrig, als diese Forderung zu erfüllen. Die CSU erhielt mit dem Finanzministerium (Fritz Schäffer) ein Schlüsselressort ${ }^{314}$ und konnte das Postministerium (Hans Schuberth) und das Landwirtschaftsministerium (Wilhelm Niklas) besetzen; mit Hans Ritter von Lex wurde zudem ein CSU-Mitglied und überzeugter Föderalist Staatssekretär im Innenministerium ${ }^{315}$. Damit hatte man weitaus mehr erreicht, als man hatte erwarten können. Bei einem Mandatsanteil von knapp sechs Prozent konnte die CSU drei von 13 Bundesministerien erobern! Von einer Auflösung der Fraktionsgemeinschaft sprach nun niemand mehr. Es hatte sich trotz mancher Rückschläge offensichtlich bewährt, unter Wahrung der Eigenständigkeit das Bündnis mit der CDU zu suchen. Als die Landesversammlung der CSU im Juni 1950 in Kempten zusammentrat, begründete Franz Josef Strauß in seinem ersten Rechenschaftsbericht als Obmann der Landesgruppe ${ }^{316}$ noch einmal die im Sommer 1949 getroffenen Entscheidungen:

„Der Auftrag, den der bayerische Wähler der Landesgruppe der CSU in Bonn erteilt hat, bestand nicht darin, Kritik zu üben und dort bayerische Wünsche einseitig zu vertreten, sondern darin, das bayerische Volk mit seinen über 9 Millionen Einwohnern in Bonn seiner Bedeutung entsprechend in Würde und Anstand zu vertreten. Demgemäss bestand, nachdem der Bundestag $402 \mathrm{Ab}$ geordnete umfasst, zu denen wir von der CSU aus 24 beigetragen haben, unsere Aufgabe von vornherein darin: Wie bekommen wir trotz dieser kleinen Zahl [...] einen grösstmöglichen Einfluss auf die Gestaltung der Bundesrepublik. Diesen grösstmöglichen Einfluss auf die Gestaltung der Bundesrepublik haben wir [. . . ] damit gewonnen, dass wir unter bestimmten, ganz klar umrissenen Bedingungen unsere Mitarbeit angeboten haben. Es geht nicht an, dass man in Bonn mit einer Gruppe, die insgesamt 5-6\% des Bundestages umfasst, oder im Falle eines Zusammenschlusses mit der Bayernpartei $10 \%$, in einer hoffnungslosen Minderheit bei der Vertretung bayerischer Wünsche immer einer [...] starken Mehrheit gegenübersteht, sondern es kommt darauf an, dass man auf der gesamtdeutschen Ebene mit den gleichgesinnten Freunden [...] ein politisches Bündnis in Form einer gemeinsamen Fraktion eingegangen hat, wenn auch innerhalb dieser Fraktion die Landesgruppe der CSU ihre eigene Stellung einnim[m]t, ihre eigenen Sitzungen abhält und notfalls ihre gesonderten bayerischen Interessen auf ihre Weise vertritt. [. . . W Wäre die CSU [. . .] diesen Weg nicht gegangen, dann wäre die stärkste Partei im Bundestag heute nicht die CDU/ CSU, sondern die SPD. Es würde das Gesicht der ersten deutschen Volksvertetung nach dem [Z]weiten Weltkrieg, das jeweils durch den Präsidenten der Volksvertretung dargestellt wird, von einem Sozialisten dargestellt werden. Das mögen diejenigen bedenken, die unseren Zusammenschluss mit der CDU in einer gemeinsamen Fraktion immer zum Anlass von Vorwürfen nehmen, als ob wir damit die bayerische Hand[lungs]freiheit verloren hätten. Man darf nämlich Handlungsfreiheit nicht verwechseln mit Handlungsunfähigkeit, was für diese Kritiker zutrifft. “317

314 Zum Stellenwert des Finanzministeriums in Ehards föderalistischem Kalkül vgl. ACSP, CSU-LTF I, 15-14, Protokoll der Fraktionssitzung am 26. 8. 1949. Ehard hatte aber zunächst nicht an Schäffer, sondern an Richard Ringelmann, den einflußreichen - aber parteilosen!- Ministerialdirektor im bayerischen Staatsministerium der Finanzen, gedacht. Vgl. Gelberg, Hans Ehard, S. 290.

315 Zur Ressortverteilung, die erst am 20.9. 1949 endgültig feststand, vgl. Auftakt zur Ära Adenauer, S. XLVII-LII. Ritter von Lex, ein Kampfgefährte Schäffers aus BVP-Zeiten, zögerte zunächst, das Amt des Staatssekretärs im Innenministerium zu übernehmen, stimmte aber schließlich doch zu. BAK, NL Schäffer 35, Bl. 17, Telegramm Hans Ritter von Lex' an Fritz Schäffer vom 21. 9. 1949, und Bl. 18f., Fritz Schäffer an Hans Ritter von Lex vom 16. 9. 1949.

316 Schäffer blieb auch nach seiner Ernennung zum Bundesfinanzminister nominell Vorsitzender der Landesgruppe. De facto führte aber Strauß die Landesgruppe, dem mit Max Solleder im Laufe des Jahres 1950 ein Stellvertreter zur Seite gestellt wurde, um die Kontinuität der Geschäftsführung sicherzustellen. Archiv der CSU-Landesgruppe, Protokolle der Landesgruppensitzungen am 23. 2. und 19. 10. 1950.

317 ACSP, CSU-LL, Protokoll der Landesversammlung der CSU am 17./18. 6. 1950 in Kempten. 
Um ihre selbstgesteckten Ziele zu erreichen und wirklich zu einem Faktor zu werden, den man trotz seiner zahlenmäßigen Schwäche nicht einfach außer acht lassen konnte, mußte die Landesgruppe eine Reihe von grundlegenden politisch-organisatorischen Problemen lösen. Zunächst galt es, die eigene Rolle auf der bundespolitischen Bühne zu definieren und auszugestalten. Dabei stand von vornherein fest, daß die Landesgruppe nur dann erfolgreich arbeiten konnte, wenn sie - vor allem in der gemeinsamen Fraktion - geschlossen auftrat und dem größeren Partner keinen Ansatzpunkt für eine Politik des divide et impera bot. Daß die Geschlossenheit der Landesgruppe nach einigen Anlaufschwierigkeiten ${ }^{318}$ schon bald geradezu sprichwörtlich wurde ${ }^{319}$, war nicht zuletzt der energischen und zupackenden Führung von Fritz Schäffer und Franz Josef Strauß zu verdanken. Den Obleuten kam es allerdings auch entgegen, daß ihre Parteifreunde durch die doppelte Frontstellung gegen die Bayernpartei und gegen allzu heftige Umarmungsversuche aus den Reihen der CDU zusammengerückt waren und daß die Flügelkämpfe, die etwa die Landtagsfraktion fast paralysiert hatten, offensichtlich nicht nach Bonn exportiert worden waren. Zudem war eine Gruppe von 24 Abgeordneten überschaubar und ließ sich durch geschickte Regie oder harsche Kritik an „Abweichlern" vergleichsweise leicht disziplinieren. Der Tirschenreuther Bundestagsabgeordnete Hans Bodensteiner beispielsweise, der wegen seiner wirtschafts- und sozialpolitischen Überzeugungen und seiner Skepsis gegen die Politik der Wiederbewaffnung ins Kreuzfeuer der innerparteilichen Kritik geraten war, wurde von der Landesgruppe wiederholt schwer unter Druck gesetzt ${ }^{320}$. Als Bodensteiner von Fritz Schäffer wegen einer öffentlichen Kundgebung, in der er den Finanzminister für die halbherzige Sozialpolitik der Bundesregierung verantwortlich gemacht hatte, zur Rede gestellt wurde, verteidigte er sich mit dem bezeichnenden Argument, es bliebe ihm ja gar nichts anderes übrig, als seine Ansichten in der Öffentlichkeit zu vertreten, da es unmöglich sei, in der Landes-

318 Spätestens 1951 hatte die Landesgruppe ihre Rolle gefunden; zu Startschwierigkeiten, Reibungsflächen und Konfliktpunkten vgl. Archiv der CSU-Landesgruppe, Protokolle der Landesgruppensitzungen am 1. 12. und 19. 12. 1949, 12.1., 23. 2., 27.4., 19.10. 1950 und 31. 8./1. 9. 1951.

$319 \mathrm{Vgl}$. Müchler, CDU/CSU, S. 81. Schon der Landtagsabgeordnete Anton Maier, der seinen Fraktionskollegen über die Vorgänge in Bonn Bericht erstattete, stellte im September 1949 erstaunt fest, „dass die Haltung der CSU-Fraktion in Bonn ausserordentlich geschlossen " sei (ACSP, CSU-LTF I, 15-14, Protokoll der Fraktionssitzung am 14. 9. 1949). Franz Josef Strauß betonte gegenüber Ehard Anfang 1950, in der Landesgruppe herrsche ,in den wesentlichen Fragen eine geschlossene Einheit" (Archiv der CSU-Landesgruppe, Protokoll der Landesgruppensitzung am 1. 3. 1950). Strauß dankte im Januar 1954 in seinem Rechenschaftsbericht den Mitgliedern der alten und neuen Landesgruppe für die „beinahe traditionell gewordene Geschlossenheit“. Wenn diese Geschlossenheit, „sei es aus politischen "Flügeleien", sei es aus persönlichem Ehrgeiz, einmal zerreissen würde“, fuhr Strauß fort, „so wird das niemand mehr freuen als diejenigen, die Bayern als eigene historische Kraft ausschalten wollen" (ACSP, CSU-LL, Protokoll der Sitzung des Landesausschusses der CSU am 15. 1. 1954 in Rothenburg ob der Tauber). Hermann Höcherl schrieb am 20.12. 1959 an seinen ehemaligen Kollegen Karl Kihn (ACSP, CSU-LG III): „Sie werden auch verfolgt und es gar nicht anders erwartet haben, dass in diesem Jahr, dessen erster Teil einen recht stürmischen politischen Verlauf nahm, die Landesgruppe ihre Eigenständigkeit und Geschlossenheit wie eh und je wahren konnte."

${ }^{320}$ Zum Fall Bodensteiner, der für die programmatische Reorientierung der CSU nach Müllers Sturz nicht ohne Bedeutung ist, vgl. BSB, NL Schwend 55, programmatische Leitsätze Hans Bodensteiners „zur Neuordnung unseres sozialen (gemeinschaftlichen) Lebens“, undatiert, Hans Bodensteiner an Hans Ehard vom 18. 9. 1950, Hans Ehard an Hans Bodensteiner vom 3. 10. 1950 und dessen Antwortschreiben an Hans Ehard vom 9. 10. 1950; NL Schwend 18, Berichte Wilhelm Kopfs über die Landesgruppensitzungen am 4. 9. 1950, 9. 1. 1951 und 13.3. 1952, und NL Schwend 13, Hans Bodensteiner an Hans Ehard vom 10. 11. 1952; Archiv der CSU-Landesgruppe, Protokoll der Landesgruppensitzung am 9.5.1951. Im November 1952 trat Bodensteiner aus der CSU aus. 
gruppe oder im Plenum der CDU/CSU-Fraktion Gehör zu finden. „Die Landesgruppe werde nach seiner Meinung von einigen geschickten Managern beherrscht, die es verstünden, abweichende Meinungen niemals hochkommen zu lassen. “ ${ }^{\text {321 }}$

Hand in Hand mit der Festigung der inneren Struktur der Landesgruppe ging das zeitweise zähe Ringen mit der CDU um die Anerkennung als eigenständige Kraft in der gemeinsamen Fraktion. Dieses Streben nach politischer, aber auch organisatorisch-technischer Eigenständigkeit war allein deshalb notwendig, weil die Autonomie der CSU auf der Bonner Bühne unter Beweis gestellt und abgesichert werden muß$\mathrm{te}^{322}$. Schon 1949 errichtete die Landesgruppe ein eigenes Büro, das in den folgenden Jahren Zug um Zug zu einer kleinen Geschäftsstelle ausgebaut wurde ${ }^{323}$. Zugleich versuchten die Bundestagsabgeordneten der bayerischen Unionspartei, möglichst auch in den Medien präsent zu sein. Zu diesem Zweck rief der Landesgruppenvorstand einen Presseausschuß ins Leben, der Rundfunk und Presse über die Arbeit der CSU in Bonn informieren, die Parteizentrale in München mit Material versorgen und eng mit der von der Landtagsfraktion herausgegebenen CSU-Correspondenz kooperieren sollte. Zudem forderte die Landesgruppenführung alle Abgeordneten auf, „in ihren Heimatzeitungen möglichst viele Artikel zu veröffentlichen, um mit der Bevölkerung Fühlung zu halten “324.

Der auf Eigenständigkeit und Gleichberechtigung zielende Kurs der Landesgruppe führte zwangsläufig zu Auseinandersetzungen mit der CDU. Im Januar 1950 konnte man zwar noch zufrieden feststellen, daß es in der gemeinsamen Fraktion nur in Einzelfällen Animositäten gegenüber der Landesgruppe gegeben habe, die jedoch kein wirklicher Grund für Beschwerden seien ${ }^{325}$. Aber schon sechs Monate später hatte sich diese Situation geändert, und es wurde erstmals massive Kritik laut. Der Landesgruppe fehle es an Durchsetzungskraft und an Möglichkeiten zur Darstellung eigener Positionen im Bundestag, hieß es. Um Abhilfe zu schaffen, müsse man unter Umständen "sogar ultimative Forderungen an die CDU-Fraktion" stellen ${ }^{326}$. Franz Josef Strauß, Michael Horlacher und Max Solleder konfrontierten Bundeskanzler Adenauer mit den weitgehenden Vorstellungen und Wünschen der Landesgruppe. Sie verlangten nichts anderes als die "praktische Gleichberechtigung der CSU auf Fraktionsebene" und die „Miteinladung eines CSU-Vertreters bei den Informationsbesprechungen, die der Kanzler mit den Fraktionsführern der Koalitionsparteien abhält“. Adenauer erklärte sich damit einverstanden, sofern sich die Landesgruppe mit Heinrich von Brentano,

${ }^{321}$ BSB, NL Schwend 18, Bericht Wilhelm Kopfs über die Landesgruppensitzung am 4. 9. 1950.

322 Vgl. Mintzel, Geschichte der CSU, S. 354.

323 Vgl. Müchler, CDU/CSU, S. 64-68. Mit Karl Donat leitete zwischen 1951 und 1966 ein Vertrauensmann von Franz Josef Strauß das Landesgruppenbüro; Donat war zuvor Strauß` Privatsekretär in Schongau gewesen. Vgl. ebenda, S. 67.

${ }^{324}$ Archiv der CSU-Landesgruppe, Protokoll der Landesgruppensitzung am 1. 12. 1949. Die Präsenz der Landesgruppe in den Medien - auch in der Parteipresse - war jedoch vor allem in der ersten Legislaturperiode unbefriedigend; Protokolle der Landesgruppensitzungen am 3.3. 1950 und 11.9. 1951. Zum publizistischen Apparat der Landesgruppe in späteren Jahren vgl. Mintzel, Geschichte der CSU, S. $354 \mathrm{f}$.

${ }^{325}$ Archiv der CSU-Landesgruppe, Protokoll der Landesgruppensitzung am 12. 1. 1950.

${ }^{326}$ Archiv der CSU-Landesgruppe, Protokoll der Landesgruppensitzung am 14. 6. 1950; Hervorhebungen im Original. Die Landesgruppe war auch darauf bedacht, ihr Gewicht im Vorstand der gemeinsamen Fraktion zur Geltung zu bringen, und forderte neben dem Amt des zweiten Fraktionsvorsitzenden eine entsprechende Anzahl von Sitzen im Fraktionsvorstand. Archiv der CSU-Landesgruppe, Protokolle der Landesgruppensitzungen am 12.1. und 19. 10. 1950 und 11.1. 1951. 
dem Vorsitzenden der CDU/CSU-Bundestagsfraktion, auf ein entsprechendes Procedere einigen könne ${ }^{327}$.

Adenauer war vielleicht deshalb so kompromißbereit, weil er einen anderen Konflikt nicht weiter schüren wollte, der sich 1950 an Fragen der inneren und äußeren Sicherheit entzündet hatte. Die Bundesregierung plante mit Zustimmung der Westmächte den Aufbau einer kasernierten Bundesbereitschaftspolizei in der Stärke von 25000 bis 30000 Mann und strebte zu diesem Zweck eine Änderung des Grundgesetzes an, um die Kompetenzen des Bundes auf Kosten der Polizeihoheit der Länder zu erwei$\operatorname{tern}^{328}$. Ehard und die bayerische Staatsregierung lehnten diesen Weg aus föderalistischen Gründen ebenso ab wie die CSU-Landesgruppe, die am 28. Februar 1951 über ihr weiteres Vorgehen in der Polizeifrage beriet ${ }^{329}$. Richard Jaeger, der seine Kollegen über die neuesten Entwicklungen informierte, verschloß sich keineswegs sicherheitspolitischen Notwendigkeiten, aber er forderte Konzepte, die dem föderalistischen Aufbau der Bundesrepublik Rechnung trugen. Jede Verfassungsänderung verstoße „gegen den Geist“ der gemeinsamen Fraktion, denn die CSU sei 1949 nur unter der Voraussetzung eine Fraktionsgemeinschaft mit der CDU eingegangen, daß ihre „föderalistischen Grundsätze [...] geachtet würden“. Die Landesgruppe schloß sich Jaegers Haltung an und stimmte bei einer Enthaltung gegen eine Änderung des Grundgesetzes, wie sie vor allem von Bundesinnenminister Lehr propagiert wurde ${ }^{330}$. Doch was sollte man tun, um diesen Standpunkt in der gemeinsamen Fraktion oder gegebenenfalls im Bundestag durchzusetzen? Jaeger hatte bereits angedeutet, welcher Weg erfolgreich sein könnte: Die Drohung mit der Auflösung der Fraktionsgemeinschaft, dem Ausscheiden aus der Koalition und mit dem Sturz der Regierung. Einigen führenden Mitgliedern der Landesgruppe, etwa Fritz Schäffer oder Michael Horlacher, ging das zu weit, und sie rieten zur Mäßigung. Nach einer langen Debatte fand sich jedoch eine Mehrheit für die Meinung Jaegers, „dass die Landesgruppe nicht nur gegen eine [Grundgesetzänderung] stimmen müsse, sondern auch bereit sein müsse, ihre Haltung gegenüber der CDU im Falle einer Niederstimmung zu überprüfen und g[egebenen]falls weitere Konsequenzen zu ziehen". Die Resolution, die schließlich einstimmig gefaßt wurde, war entsprechend scharf formuliert, ließ den Verhandlungsführern Horlacher, Jaeger, Solleder und Strauß bei ihren Gesprächen mit dem Bundeskanzler jedoch genügend Raum für Kompromisse ${ }^{331}$. Auch wenn die Landesgruppe die Aufkün-

327 BSB, NL Schwend 18, Bericht Wilhelm Kopfs über eine Besprechung der Landesgruppenführung mit Konrad Adenauer am 25. 1. 1951 und über die Landesgruppensitzung am 26. 1. 1951.

${ }^{328} \mathrm{Zu}$ den Auseinandersetzungen zwischen Bayern und dem Bund über den Aufbau der Bereitschaftspolizei, des Bundesgrenzschutzes und des Bundeskriminalamts vgl. Gelberg, Hans Ehard, S. 324-333. Die wichtige Rolle der CSU-Landesgruppe in diesem Konflikt wird jedoch nur ansatzweise deutlich.

${ }^{329}$ Archiv der CSU-Landesgruppe, Protokoll der Landesgruppensitzung am 28. 2. 1951; das folgende nach dem Protokoll dieser Sitzung. Schon am 13.2. 1951 hatte dieses Thema auf der Tagesordung gestanden; dabei hatten sich nur vier Mitglieder der Landesgruppe für eine Bundesbereitschaftspolizei bzw. für die vorgeschlagene Verfassungsänderung ausgesprochen. BSB, NL Schwend 18, Bericht Wilhelm Kopfs über die Sitzungen der CDU/CSU-Fraktion am 12. 2. und 13. 2. 1951 und über die Landesgruppensitzung am 13. 2. 1951.

${ }^{330}$ Franz Josef Strauß hatte sich schon in der Landesgruppensitzung am 13. 2. 1951 "mit aller Entschiedenheit für eine Ablehnung jeglicher Beeinträchtigung der Polizeihoheit der Länder" eingesetzt. Ebenda.

331 BSB, NL Schwend 18, Bericht Wilhelm Kopfs über eine Besprechung der Landesgruppenführung mit Konrad Adenauer vom 9. 3. 1951. 
digung der Fraktionsgemeinschaft mit all ihren Folgen mehr als Druckmittel einsetzte, als daß sie sie ernsthaft erwogen hätte ${ }^{332}$, war es doch nicht zuletzt ihrem harten Auftreten zu verdanken, daß die Bundesregierung einen Rückzieher machte und die Pläne zur Errichtung einer Bundesbereitschaftspolizei in der Versenkung verschwanden.

Spätestens nach diesem Erfolg hatte die Landesgruppe erkannt, welche Waffe sie mit der expliziten oder impliziten Drohung, die Fraktionsgemeinschaft aufzulösen, in der Hand hatte. Schon als sich die Bundestagsabgeordneten der bayerischen Unionspartei wenige Monate später im Schloß ihres Kollegen Josef Ernst Fürst Fugger von Glött zu ihrer ersten Klausurtagung trafen, stand die folgenschwere Frage „Trennung von der gemeinsamen Fraktion CDU/CSU oder grössere Selbständigkeit der Landesgr[uppe] innerhalb der Fraktion“ auf der Tagesordnung ${ }^{333}$. Die Abgeordneten votierten zwar dafür, die Fraktionsgemeinschaft mit der CDU aufrechtzuerhalten, aber sie verlangten dafür einen hohen Preis: finanzielle Selbständigkeit der Landesgruppe, räumliche Trennung von der CDU, Teilnahme an den Sitzungen der gemeinsamen Fraktion nur bei besonderen Anlässen, eigene Redezeiten im Plenum des Bundestags und die Gleichstellung der Landesgruppe mit den anderen Fraktionen der Koalition bei Verhandlungen mit dem Bundeskanzler oder seinen Ministern. Als Begründung dieser weitgehenden Forderungen vermerkt das Protokoll:

„Die aus koalitionstechnischen Gründen angestrebte und verwirklichte Fraktionsgemeinschaft mit der CDU [ . . ] hat sich in staatsrechtlicher (Föderalismus) und wirtschaftspolitischer Hinsicht für Bayern und damit für die Landesgr[uppe] CSU nicht immer bewährt. Der Kanzler nahm Erklärungen von CDU-Politikern entgegen und behandelte sie als Erklärungen der Gesamtfraktion, obwohl von der CSU niemand gehört worden war; auch wurde und wird die CDU besser vom Bundeskanzler informiert als die CSU. In wirtschaftspolitischer Hinsicht besteht bei der CDU angesichts des zahlenmässigen Übergewichts von Nordrhein-Westfalen das Bestreben, die Verhältnisse in diesem grössten Bundesland als Richtschnur für die gesamte Wirtschaftspolitik des Bundes zu erklären und Randgebiete, wie Bayern, zu vernachlässigen. Eine stärkere Betonung der bayerischen Wirtschaftsinteressen erschien daher der CSU geradezu wie ein Akt der Selbsterhaltung."

Als am 9. September 1951 eine Delegation der Landesgruppe bei Heinrich von Brentano erschien, um ihn von den Entscheidungen der Klausurtagung zu unterrichten, gab der Vorsitzende der CDU/CSU-Fraktion in fast allen Punkten nach. Lediglich in der Frage der Fraktionssitzungen konnte sich die Landesgruppe nicht durchsetzen, und so tagten die Bundestagsabgeordneten von CDU und CSU weiterhin gemeinsam. Allerdings beschloß die Landesgruppe, künftig grundsätzlich vor den Sitzungen der Gesamtfraktion zusammenzutreten und eine gemeinsame Marschroute festzulegen, um die eigenen Positionen effektiver als bisher vertreten zu können ${ }^{334}$. Damit war die Lan-

332 In einem vertraulichen Bericht der bayerischen Vertretung in Bonn hieß es: „Bei der Frage, in welcher Weise die CSU einen Druck auf die CDU ausüben könne, wurde der Gedanke eines Austritts aus der Koalition allgemein abgelehnt, dagegen billigte man nach längeren, eindringlichen Ausführungen des Abg. Strauss den Plan, gegebenenfalls mit dem Austritt aus der Fraktionsgemeinschaft zu drohen." BSB, NL Schwend 18, Bericht Wilhelm Kopfs über die Sitzungen der CDU/CSU-Fraktion am 12. 2. und 13. 2. 1951 und über die Landesgruppensitzung am 13. 2. 1951.

333 Archiv der CSU-Landesgruppe, Protokoll der Landesgruppensitzung am 31. 8./1. 9. 1951; das folgende nach dem Protokoll dieser Sitzung. Diese Klausurtagungen erwiesen sich als probates Mittel zur Abstimmung und Konzeption der eigenen Politik abseits vom Tagesgeschehen. Bis 1965 fanden die Klausurtagungen der Landesgruppe auf dem Fugger-Schloß Kirchheim statt. Vgl. Müchler, CDU/CSU, S. 69.

334 BSB, NL Schwend 19, Bericht Ernst Rattenhubers über die Sitzungen der Landesgruppe und der 
desgruppe auf dem Weg zur Emanzipation von der CDU und zur Etablierung als eigenständige Kraft einen großen Schritt vorangekommen - und weitere Schritte folgten bald.

Nach dem überraschend hohen Sieg der CSU bei den Bundestagswahlen im September 1953 stellte sich die Frage nach dem bundespolitischen Kurs erneut ${ }^{335}$. Die bayerische Unionspartei hatte die Zahl ihrer Mandate mehr als verdoppeln können und entsandte nicht mehr nur 24, sondern 52 Abgeordnete nach Bonn. Damit wurde die CSU im neuen Bundestag hinter der CDU und der SPD zur drittstärksten Kraft und - nach dem Ausscheiden der Bayernpartei, die an der Fünf-Prozent-Hürde gescheitert war - zur einzigen Vertreterin bayerischer Interessen auf Bundesebene. Schon am 13. September 1953 trafen sich die Bundestagsabgeordneten der CSU auf Schloß Kirchheim, um über die anstehenden Entscheidungen zu beraten; auch Ministerpräsident Ehard und Karl Schwend, sein Stabschef in der Staatskanzlei, waren anwesend ${ }^{336}$. Franz Josef Strauß eröffnete die Tagung mit einem kurzen Überblick über die gegenwärtige Situation und kam dann auf eine der entscheidenden Fragen zu sprechen: Welche Organisationsform sollte die CSU in Bonn für die kommenden vier Jahre wählen? Strauß nannte vier Alternativen: die Verschmelzung von CDU und CSU zu einer Fraktion ohne wenn und aber, die Aufrechterhaltung der Fraktionsgemeinschaft in der bisherigen Form, eine Fraktionsgemeinschaft unter der Voraussetzung, daß die CSU „im Bundestag geschäftsordnungsmäßig als eigene Fraktion geführt und [...] auch in der Regierungskoalition so behandelt [wird], als ob sie eine eigene Fraktion wäre“, die Bildung einer eigenen Fraktion. Erwartungsgemäß sprach sich keiner von den Anwesenden dafür aus, eine Fraktionsgemeinschaft ohne Vorbedingungen einzugehen; außer Richard Jaeger plädierte aber auch niemand für eine eigene CSU-Fraktion. Die CSU-Abgeordneten entschieden sich auf Vorschlag von Strauß schließlich für die dritte Option, das heißt, sie konstituierten sich erneut als Landesgruppe und boten der CDU unter bestimmten Bedingungen eine Fortsetzung der Fraktionsgemeinschaft an. Strauß selbst hatte diese Bedingungen formuliert:

„1. Die CSU ist innerhalb der Regierungskoalition, auch wenn sie eine Fraktionsgemeinschaft mit der CDU eingeht, als eigene Partei zu behandeln. 2. Die CSU stellt den ersten stellvertretenden Fraktionsvorsitzenden der Gesamtfraktion. 3. [Die CSU] fordert eine Beteiligung [...] im Verhältnis 2:7 in allen Ausschüssen des Bundestages und sonstigen parlamentarischen Einrichtungen wie Europarat und Montanunion usw. 4. Die CSU stellt im Bundestag den Vizepräsidenten. 5. Eine schriftliche Verpflichtung des Vorstandes der CDU, keine verfassungsänder[nd]en Gesetze einzureichen oder solchen Gesetzen zuzustimmen, die gegen die Minorität der CSU gerichtet sind.“

Den Verhandlungsführern der bayerischen Unionspartei gelang es tatsächlich, diese Forderungen als Preis für die Neuauflage der Fraktionsgemeinschaft durchzusetzen ${ }^{337}$, auch wenn es noch eine Zeitlang dauern sollte, bis die CSU politisch wie protokolla-

CDU/CSU-Fraktion am 18. 9. 1951; Archiv der CSU-Landesgruppe, Pressemitteilung der Landesgruppe vom 12. 9. 1951; zum Presseecho vgl. SZ vom 8./9. 9. 1951: „CSU lockert Fraktionsverbindung mit CDU“, Neue Zeitung vom 10. 9. 1951: „Brentano dementiert Unstimmigkeiten in CDU/ CSU“.

335 Eine detaillierte - auf Bayern bezogene - Analyse des Wahlergebnisses in: Zweite Bundestagswahl in Bayern am 6. September 1953, hrsg. vom Bayerischen Statistischen Landesamt, München 1954, S. 5-21.

336 Archiv der CSU-Landesgruppe, Protokoll der Landesgruppensitzung am 13. 9. 1953; das folgende nach dem Protokoll dieser Sitzung.

337 Vgl. Müchler, CDU/CSU, S. 112-122. 
risch endgültig als eigenständige Partei behandelt wurde ${ }^{338}$. Damit befand sich die Bonner Landesgruppe schon fast in einer „strategisch-operativen Schlüsselstellung “339.

Bei der Wahl der Mittel zur Durchsetzung der eigenen Ziele war die Landesgruppenführung nicht gerade zimperlich. Konrad Adenauer klagte schon im März 1951, man könne ja mit den Gewerkschaften noch leichter verhandeln als mit der bayerischen $\mathrm{CSU}^{340}$. Die streckenweise kompromißlose, herausfordernde Art, mit der vor allem der von Heinrich Krone nach leidvollen Erfahrungen als „rücksichtslos“ und „gefährlich“ charakterisierte Franz Josef Strauß gegenüber der CDU auftrat ${ }^{341}$, schlug tiefe Wunden und schürte Revanchegelüste gegen die bayerische Schwesterpartei oder ihre Spitzenpolitiker. Es war daher kein Wunder, daß der Bundeskanzler selbst wiederholt versuchte, „die Front der CSU aufzubrechen“, deren Anspruch auf Autonomie ihm ein Dorn im Auge war ${ }^{342}$. Vor allem nach der Bildung seines zweiten Kabinetts im Herbst 1953, die für die CSU nicht gerade wunschgemäß verlaufen war ${ }^{343}$, kam es immer wieder zu handfesten Auseinandersetzungen. Schon nach den ersten Enttäuschungen erklärte Fritz Schäffer vor dem geschäftsführenden Landesvorstand der CSU:

„Wir dürfen uns nicht im Gedanken wiegen, dass die Fraktionsgemeinschaft unbedingt aufrecht erhalten werden muss, einmal muss eine Grenze sein. Wir werden dazu kommen müssen, dass wir als Landesgruppe viel mehr zusammenwirken. In der gemeinsamen Fraktion ist eine wirkliche Meinungsbildung nicht mehr möglich, weil sie viel zu gross ist. Die Landesgruppe wird das Gremium sein, in dem die Leute wirklichen Meinungsaustausch haben, in dem es eine wirkliche Meinungsbildung gibt. Ich halte es für unbedingt notwendig, dass die Landesgruppe ein möglichst starkes, geschlossenes Eigenleben behält. [. . . Es ist eine Tradition, dass alle Mitglieder des Kabinetts für einen Mehrheitsbeschluss des Kabinetts auch nach aussen eintreten, selbst wenn sie persönlich gegen diesen Beschluss gestimmt hatten. Das kann für uns unter Umständen dazu führen, dass wir einen zentralistischen Gedanken unseren Wählern hier klar machen sollen, den wir selbst mit gutem Gewissen nicht vertreten könnten. Es würde uns in einem solchen Fall nichts anderes übrig bleiben, als eben das Kabinett zu verlassen. [. . .] Wir haben 1949 die Fraktionsgemeinschaft eingegangen, aber nur unter der Voraussetzung, dass unser Charakter als selbständige Partei gewahrt bleibt. Hier beginnt die Grenze, wo wir uns zu einem inneren Entschluss durchringen müssen, ob wir uns freimachen von der inneren Angst, wir müssten alles schlucken, selbst wenn die Partei in Scherben geht." ${ }^{3+4}$

Tatsächlich versuchte die CSU in den folgenden Monaten, ihre Unzufriedenheit mit bestimmten Sach- und Personalentscheidungen durch Aggressivität zu kompensieren $^{345}$. So sah sich Adenauer beispielsweise im Oktober 1954 gezwungen, die unbeque-

338 Vgl. ebenda, S. 70-73.

${ }^{339}$ Mintzel, Franz Josef Strauß und die CSU-Landesgruppe, in: Zimmermann (Hrsg.), Anspruch und Leistung, S. 291.

${ }^{3+0}$ BSB, NL Schwend 18, Bericht Wilhelm Kopfs über eine Besprechung der Landesgruppenführung mit Konrad Adenauer vom 9. 3. 1951.

341 Eintragungen vom 9. 2. 1955 und 19. 3. 1961, in: Krone, Tagebücher, Bd. 1, S. 158f. bzw. S. 474 f.

342 Vgl. Köhler, Adenauer, S. 797-805, das Zitat findet sich auf S. 805.

${ }^{343}$ Vgl. dazu Jürgen Domes, Mehrheitsfraktion und Bundesregierung. Aspekte des Verhältnisses der Fraktion der CDU/CSU im 2. und 3. Deutschen Bundestag zum Kabinett Adenauer, Köln 1964, S. 49-61; Müchler, CDU/CSU, S. 105-122; Gelberg, Hans Ehard, S. 469-484. Bislang unbekannte Dokumente zur Regierungsbildung finden sich im ACSP, CSU-LTF II/2, 6-45, Protokolle der Fraktionssitzungen am 22.9., 23. 9., 12. 10., 15. 10. und 21. 10. 1953, sowie im Archiv der CSU-Landesgruppe, Protokolle der Landesgruppensitzungen am 15. 9., 6.10., 8. 10., 14.10., 20.10., 26. 10., 11. 11., 16. 11. und 2. 12. 1953.

${ }^{3+4}$ ACSP, CSU-LL, Protokoll der Sitzung des geschäftsführenden Landesvorstands am 24. 9. 1953.

${ }^{345}$ Franz Josef Strauß erklärte im Januar 1954 kämpferisch vor dem Landesausschuß: „Wir lassen uns von der CDU nicht zermalmen, wir lassen uns von ihr nicht eingemeinden. “ ACSP, CSU-LL, Pro- 
men Bayern zu disziplinieren, nachdem allzu harsche Äußerungen von Schäffer und Strauß fast zu einer Regierungskrise geführt hätten ${ }^{346}$. Die Konflikte eskalierten sogar soweit, daß der Bundeskanzler seinen getreuen Mitstreiter Heinrich Krone 1956 offen zum „Kampf“" gegen Strauß aufrief ${ }^{347}$, der die Landesgruppe immer mehr als seine politische Hausmacht ansah.

Abgrenzung von der CDU war für die Bundestagsabgeordneten der CSU freilich nur die eine Seite; nicht weniger wichtig war es, sich in der eigenen Partei zu etablieren und zu einem einflußreichen, möglichst autonomen Faktor der innerparteilichen Willensbildung zu werden. Eine solche Entwicklung konnte freilich nicht im Sinne des Ministerpräsidenten und seiner Strategen in der Staatskanzlei sein. In der Konzeption Hans Ehards spielte die Landesgruppe lediglich als de facto weisungsgebundenes, über die Dienststelle des bayerischen Bevollmächtigten beim Bund gesteuertes, föderalistisches Sprachrohr und Vollzugsorgan von Staatsregierung und Parteiführung eine Rolle $^{348}$. Ähnlich war es vor 1933 gewesen, als sich die Reichstagsfraktion der BVP in allen entscheidenden Fragen den Kommandos aus München zu beugen hatte ${ }^{349}$, ähnlich war es auch im Frankfurter Wirtschaftsrat und im Parlamentarischen Rat gewesen, wo die Abgeordneten der CSU in hohem Maße von Josef Müller und Hans Ehard beeinflußt worden waren ${ }^{350}$. Der CDU-Politiker Paul de Chapeaurouge etwa sah sich deshalb zu der Bemerkung veranlaßt, „daß man gelegentlich sich dem Eindrucke nicht ganz entziehen konnte, daß die bayerischen Abgeordneten [im Parlamentarischen Rat] in ihren Entschließungen nicht frei waren und sich mehr als es der Stellung eines unabhängigen Abgeordneten eigentlich entspricht, von Weisungen und Anschauungen der bayerischen Staatsregierung abhängig zeigten" ${ }^{351}$.

In der Landesgruppe war man jedoch von Anfang an nicht bereit, sich in ein solches Korsett zwängen zu lassen. Dafür waren Franz Josef Strauß und Fritz Schäffer, die unter den Bundestagsabgeordenten der CSU den Ton angaben, zu dynamisch, zu machtbewußt und zu ehrgeizig, während Hans Ehard weder über die Härte noch über die Hausmacht eines Georg Heim verfügte, der 1920 die Auflösung der Fraktionsgemeinschaft mit dem Zentrum erzwungen und die BVP so auf einen isolationistischen, radikal föderalistischen Kurs gebracht hatte ${ }^{352}$. Die Landesgruppe wachte im Gegenteil eifersüchtig über ihre Selbständigkeit, verbat sich allzu weitgehende Einmischungsversu-

tokoll der Sitzung des Landesausschusses der CSU am 15. 1. 1954 in Rothenburg ob der Tauber. Vgl. auch die streckenweise sehr aggressive Berichterstattung im Bayern-Kurier vom 26.9., 10. 10., 17. 10., 24. 10., 7. 11. und 14. 11. 1953.

346 Protokoll der Sitzung des Bundesvorstands der CDU am 11. 10. 1954, in: Adenauer: „Wir haben wirklich etwas geschaffen." Die Protokolle des CDU-Bundesvorstands 1953-1957, bearb. von Günter Buchstab, Düsseldorf 1990, S. 247, S. 263-266 und S. 292-330.

347 Am 27. 9. 1956 vermerkte der Fraktionsvorsitzende Heinrich Krone in seinem Tagebuch: „Der Bundeskanzler ließ mich kommen. [...] Ein Gespräch, in seiner Diktion und in seinen Forderungen so ernst geführt wie heute morgen, habe ich mit dem Kanzler noch nicht gehabt. [...] Mir und der Fraktion warf er vor, daß wir nicht hart genug seien. Wir müßten den Kampf mit Strauß aufnehmen; wenn es dabei zu einem Bruch zwischen der CDU und CSU käme, müsse das in Kauf genommen werden." Krone, Tagebücher, Bd. 1, S. 230.

348 Vgl. Gelberg, Hans Ehard, S. 98, S. 195-199 und S. 205-208.

349 Vgl. - mit teilweise unterschiedlicher Gewichtung - Schönhoven, BVP, S. 78 ff. und S. 281 f.; Maga, Johann Leicht, S. 299 f.

350 Vgl. Gelberg, Hans Ehard, S. 98 und S. 195-199.

351 Zit. nach Die CDU/CSU im Parlamentarischen Rat. Sitzungsprotokolle der Unionsfraktion, bearb. von Rainer Salzmann, Stuttgart 1981, S. XXIV; vgl. auch Gelberg, Hans Ehard, S. 196.

352 Vgl. Maga, Johann Leicht, S. 69-77. 
che ${ }^{353}$ und gestattete sich das Recht auf eine eigene Meinung, auch wenn diese den $\mathrm{Pa}$ rolen zuwiderlief, die in München ausgegeben wurden. Als es im Januar 1950 zu Unstimmigkeiten über kultur- und hochschulpolitische Fragen kam, stellte die Landesgruppe entschieden und einmütig fest:

„Um die Frage der 4. Landesuniversität ist eine Meinungsverschiedenheit über die Zweckmäßigkeit einer Einschaltung der Landesgruppe [der ] CSU im Bundestag in die innerbayer[is]che Partei- und Landespolitik entstanden. Für die Landespolitik ist zweifellos die bayer. Landesregierung und die Landtagsfraktion sowie die Landesleitung der CSU zuständig. Für die Politik im Bundestag und in der Bundesregierung besteht die Zuständigkeit von Landesgruppe und Bundesministern aus der CSU. Beide zusammen aber stellen die CSU-Politik insgesamt dar. Eine Einschaltung der einen Gruppe in die Zuständigkeit der anderen ist grundsätzlich nicht erwünscht, jedoch muß sich jede Gruppe das Recht vorbehalten, dann, wenn die Politik der anderen Seite die gesamte Unionspolitik zu gefährden droht, in entsprechender Weise ihre Meinung und ihre Wünsche zu äußern." ${ }^{354}$

Ihren Grund hatten solche Meinungsverschiedenheiten in der Tatsache, daß die Mehrheit der CSU-Abgeordneten unter dem Eindruck der Bonner Verhältnisse ein anderes Föderalismusverständnis entwickelte als ihre Münchner Parteifreunde, die fast jede Entscheidung auf die föderalistische Goldwaage legten. Um kein Mißverständnis aufkommen zu lassen: Auch die Landesgruppe sah in der CSU den organisatorischen „Kristallisationskern für den föderativen Gedanken“, dessen „wahrlich dornenvolle Aufgabe“ es sei, in Verbindung mit der CDU „das föderalistische Prinzip als das zweckmäßigste durchzusetzen “355. Allerdings waren die Bundestagsabgeordneten der CSU dennoch bereit, aus koalitionspolitischen Zwängen, übergeordneten Interessen oder nationaler Verantwortung heraus Entscheidungen mitzutragen, die aus bayerischer Sicht unpopulär, wenn nicht gar gefährlich waren. Franz Josef Strauß, dessen föderalistische Gesinnung für Ehard nicht über jeden Zweifel erhaben war ${ }^{356}$, umschrieb die Position der Landesgruppe in einem Rechenschaftsbericht so:

„Meine sehr verehrten Anwesenden! Ich bitte, dieses Wort, das ich jetzt sage, nicht übel zu nehmen oder nicht falsch zu verstehen. Man würde den Ruf des bayerischen Föderalismus, als dessen Vorkämpfer in Bonn die CSU [... .] bekannt ist, zerstören, wollte man von unseren Freunden in dieser Position eine einseitige, auf Bayern orientierte Politik verlangen, die das Ansehen des Föderalismus im übrigen Deutschland zerstören würde. [...] Ein Mann, der als Finanzminister, als Wirtschaftsminister oder als Ernährungsminister für die Schicksale der Bundesrepublik verantwortlich ist, ist für alle Länder und ist für den Bund da. Wenn er diese Aufgabe als Bayer, als CSU-Mann, als Föderalist wahrnimmt, dann wahrt er damit die Bedeutung und das Ansehen, das Bayern im gesamtdeutschen Ablauf zukommt. Man darf nicht verwechseln, dass ein Bundesminister nicht ein [b]ayerischer Oberinspektor ist, der dort kleinliche Interessen zu vertreten hat, ein Bundesminister ist ein Mann, der als Bayer ges[am]tdeutsche Aufgaben im Rahmen der föderalistischen Zielsetzung zu vertreten hat. ${ }^{3357}$

353 Z. B. Archiv der CSU-Landesgruppe, Protokoll der Landesgruppensitzung am 11. 9. 1951.

354 Archiv der CSU-Landesgruppe, Protokoll der Landesgruppensitzung am 20. 1. 1950.

355 ACSP, CSU-LL, Rede Franz Josef Strauß" "Gefahren und Aussichten des Föderalismus in Bonn" vor dem Landesausschuß der CSU am 15. 1. 1954 in Rothenburg ob der Tauber.

356 Vgl. Gelberg, Hans Ehard, S. 404.

357 ACSP, CSU-LL, Protokoll der Landesversammlung der CSU am 17./18. 6. 1950 in Kempten. Zweieinhalb Jahre später erklärte Strauß: „Die CSU wird Landespartei bleiben. Die Verantwortung besteht aber nicht nur dem Land gegenüber. Wir müssen die Bundesverantwortung nicht nur dem Schein nach, sondern im Ernst bejahen." ACSP, CSU-LTF II/2, 6-45, Protokoll der Koordinierungssitzung von Landtagsfraktion und Landesgruppe am 14. 1. 1953. 
Da die Landesgruppenführung die Münchner Animositäten kannte, bemühte sie sich, ihre Politik mit der Landtagsfraktion und der Staatskanzlei abzustimmen und zugleich um Verständnis für umstrittene Maßnahmen zu werben. Daß es bis 1954 dennoch nicht zu einer effektiven Koordinierung von Bundes- und Landespolitik kam, lag neben den ungenügenden Kommunikationsstrukturen hauptsächlich am fehlenden Fingerspitzengefühl der Landesgruppe und am Desinteresse der Parteifreunde in Bayern. Richard Jaeger sah sich noch im Oktober 1954 genötigt zu erklären:

„Mir hat heute ein maßgeblicher Parteifreund gesagt, er habe Stimmen gehört, die lauteten: Was geht es eine[n] Bundestagsabgeordneten an, was in der Landespolitik geschieht? - Darüber soll er sozusagen seinen Mund halten. Ich glaube, daß dafür weniger die Reden, die Bundesminister Strauß und ich gehalten haben, der Grund waren als vielmehr eine Resolution, die die Landesgruppe als solche in Kirchheim auch zu gewissen bayerischen Fragen einmütig gefaßt hat. Dazu möchte ich doch einmal als zweiter Vorsitzender dieser Landesgruppe sagen: Die Politik ist nun einmal unteilbar, und auch die Politik der CSU ist unteilbar. Sie wird nicht immer völlig einheitlich sein; denn es ist ein zwangsläufiger Unterschied, ob in Bonn gegen die Sozialisten regiert wird oder ob in Bayern [...] mit den Sozialisten regiert werden muß. [.. .] Aber es gibt nur einen Abgeordneten - ob er im Landtag oder im Bundestag sitzt, ist eine Frage zweiter Ordnung -, es gibt nur eine CSU-Politik, die wir alle zu vertreten haben." ${ }^{358}$

Das war jedoch pures Wunschdenken. Über die Inhalte der von Jaeger als „unteilbar“ beschworenen Politik kam es immer wieder zu teilweise heftigen Meinungsverschiedenheiten zwischen den Bundes- und den Landespolitikern der bayerischen Unionspartei. Dabei erwies sich die Steuer- und Finanzpolitik als zentrales Konfliktfeld, das nicht nur für Hans Ehard aus föderalistischer Sicht von überragender Bedeutung war. Der Ministerpräsident hatte nicht zuletzt aus Furcht vor einer Aushungerungs- und Aushöhlungspolitik gegenüber den Ländern 1949 das Finanzressort für die CSU beansprucht, auch wenn er sich der damit verbundenen Probleme durchaus bewußt war. Ein „Bayer als Finanzminister“, erklärte Ehard im September 1949 vor der Landtags-

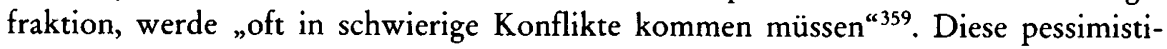
schen Worte erwiesen sich als geradezu prophetisch. Denn Fritz Schäffer, der nicht nur ein anerkannter Fachmann war, sondern auch als in der Wolle gefärbter Föderalist galt, trat zum Schrecken seiner Münchner Parteifreunde schon nach kurzer Zeit wie „selbstverständlich“ als „Anwalt der Bundesfinanzen“ auf und verfocht die Interessen des Bundes „erstaunlich hartnäckig“360.

Auseinandersetzungen zwischen dem Bundesfinanzminister und den Ländern - und damit auch zwischen Schäffer und seinen Parteifreunden in der bayerischen Staatsregierung - waren vor allem in der Frage, wie das Steueraufkommen zwischen dem

358 ACSP, CSU-LL, Protokoll der Landesversammlung der CSU am 9./10. 10. 1954 in Nürnberg. Aber auch Landtagsabgeordnete wie der Finanzexperte Rudolf Eberhard beklagten sich darüber, daß die Bundesminister der CSU und die Landesgruppe "mit der Landtagsfraktion politisch kaum mehr Fühlung“ hielten. ACSP, CSU-LTF II/1, 15-14, Protokoll der Fraktionssitzung am 3. 12. 1952.

359 ACSP, CSU-LTF I, 15-14, Protokoll der Fraktionssitzung am 14. 9. 1949.

360 Henzler, Fritz Schäffer, S. 350. Dieter Grosser, Die Rolle Fritz Schäffers als Finanzminister in den ersten beiden Kabinetten Konrad Adenauers, in: Mückl (Hrsg.), Föderalismus und Finanzpolitik, S. 67-80, hier S. 67, hat zutreffend bilanziert: „Das Etikett des bayerisch-katholischen Partikularisten, das ihm 1948 manche gern angeheftet hätten und das sich angesichts seiner Nähe zur Bayernpartei und seiner Missetaten in der CSU damals auch anbot, stand in krassem Widerspruch zu dem, was er nach seiner Wahl in den Ersten Deutschen Bundestag und erst recht nach seiner Berufung zum Bundesfinanzminister tat und äußerte." 
Bund und den Ländern verteilt werden sollte, geradezu vorprogrammiert. Die im Grundgesetz verankerte Finanzverfassung kam den Ländern entgegen, da sie die Einkommen- und Körperschaftsteuer den Ländern zusprach, während beim Bund lediglich die Zölle und die Umsatzsteuer verblieben. Der Bund konnte allerdings mit Zustimmung des Bundesrats einen Teil der Einkommen- und Körperschaftsteuer für sich beanspruchen, wobei über die Höhe des Bundesanteils immer wieder neu verhandelt werden mußte ${ }^{361}$. Die damit verbundenen Konflikte belasteten nicht nur die Beziehungen Schäffers zu seinen Kollegen in den Ländern, sondern markierten auch „einen Einschnitt im Verhältnis des Finanzministers zu seiner Partei“362. Schon 1951 hatte es ein unerfreuliches Tauziehen über die Höhe des Bundesanteils an der Einkommenund Körperschaftsteuer gegeben. Der Kompromiß, der am 30. Oktober endlich beschlossen worden war, setzte den Bundesanteil für das laufende Rechnungsjahr auf 27 Prozent fest ${ }^{363}$. Die neue Verhandlungsrunde eröffnete Schäffer im Februar 1952 mit einem Paukenschlag. Der Finanzminister forderte mit Blick auf den deutschen Verteidigungsbeitrag, den Anteil des Bundes an der Einkommen- und Körperschaftsteuer auf 40 Prozent zu erhöhen ${ }^{364}$.

Dieser Vorstoß stieß bei den Ländern auf einhellige Ablehnung und löste im steuerschwachen Bayern blankes Entsetzen aus. Schäffer konnte jedoch aus einer starken Position heraus agieren; er war eine wichtige Figur im Kabinett, hatte die Mehrheit der Landesgruppe hinter sich ${ }^{365}$ und war auch in der CSU überaus populär. Auf der Landesversammlung in Bad Reichenhall, die erst wenige Monate zurücklag, war es nicht Ehard gewesen, der in einer vielbeachteten Grundsatzrede den Standort der Partei bestimmt hatte, sondern Schäffer ${ }^{366}$. Der Bundesfinanzminister zögerte nicht, seine Trümpfe auch gegenüber den eigenen Parteifreunden auszuspielen. Schließlich war es für ihn besonders wichtig, Bayern aus der Ablehnungsfront herauszubrechen und die CSU auf seine Linie einzuschwören, um im Konflikt mit den anderen Ländern den Rücken frei zu haben. Schäffer konnte es zwar nicht verhindern, daß Bayern in einer ersten Abstimmung im Bundesrat gegen seine Forderungen stimmte, aber als der Landtag am 3. April 1952 auf Antrag von CSU, SPD und BP über eine Entschließung beriet, in der die Staatsregierung ersucht wurde, die Erhöhung des Bundesanteils auf 40 Prozent auch weiterhin abzulehnen, sah sich der Finanzminister zum Handeln gezwungen. Sollte sich die CSU tatsächlich gegen die Erhöhung des Bundesanteils aussprechen, telegraphierte er an Ministerpräsident Ehard, dann hätte dies seinen sofortigen Rücktritt zur Folge ${ }^{367}$. Diese Drohung blieb nicht ohne Wirkung, und die CSU-

${ }^{361}$ Vgl. Gelberg, Hans Ehard, S. 398f., und Grosser, Fritz Schäffer als Finanzminister, in: Mückl (Hrsg.), Föderalismus und Finanzpolitik, S. 69 f.

362 Henzler, Fritz Schäffer, S. 354.

363 Vgl. Gelberg, Hans Ehard, S. 399, und Henzler, Fritz Schäffer, S. 355. Schäffer hatte im März 1951 gefordert, der Bundesanteil müsse 33 Prozent betragen. BSB, NL Schwend 7, Bericht Wilhelm Kopfs über die Sitzung der CDU/CSU-Fraktion am 8. 3. 1951.

364 BSB, NL Schwend 55, Fritz Schäffer an Hans Ehard vom 23. 2. 1952. Zu den Auseinandersetzungen um die Höhe des Bundesanteils im Jahre 1952 vgl. Gelberg, Hans Ehard, S. 399-410, und Henzler, Fritz Schäffer, S. 355-360.

365 BSB, NL Schwend 55, Fritż Schäffer an Hans Ehard vom 23. 2. 1952; ACSP, CSU-LTF II/1, 15-14, Protokoll der gemeinsamen Sitzung von Landtagsfraktion, Landesgruppe und Landesvorstand am 21. 4. 1952.

366 ACSP, CSU-LL, Protokoll der Landesversammlung der CSU am 24. 6. 1951 in Bad Reichenhall.

367 Vgl. Gelberg, Hans Ehard, S. 401, und Henzler, Fritz Schäffer, S. 358. 
Fraktion enthielt sich der Stimme, als im Landtag über die fragliche Interpellation entschieden wurde. Auch wenn man sich in der CSU-Fraktion der Verdienste des Finanzministers um den Freistaat durchaus bewußt war und anerkannte, daß seine Aktionen nicht gegen Bayern gerichtet waren ${ }^{368}$, machten Schäffers forsches Auftreten und seine in den Augen vieler Abgeordneter geradezu maßlosen Forderungen viel böses Blut. Rudolf Eberhard, der Finanzexperte der Fraktion, fürchtete um die Zukunft des föderativen Systems, „wenn das unsere Leute jetzt [schon] so machen“ ${ }^{369}$, und Fritz von Haniel-Niethammer bemerkte hellsichtig, das „Schwergewicht der Parteipolitik“ verlagere sich immer mehr von München nach Bonn ${ }^{370}$.

Da der Konflikt um die Verteilung des Steueraufkommens immer weitere Kreise zog, war eine klärende Aussprache zwischen den Bundes- und den Landespolitikern der CSU dringend notwendig. Am 21. April 1952 trafen sich die Mitglieder der Landtagsfraktion, der Landesgruppe und des Landesvorstands zu einer gemeinsamen Sitzung ${ }^{371}$. Der Bundestagsabgeordnete Elimar von Fürstenberg erklärte gleich zu Beginn, daß die Landesgruppe geschlossen für eine Erhöhung des Bundesanteils an der Einkommenund Körperschaftsteuer auf 40 Prozent stimmen werde. Schäffer selbst begründete die sachliche Notwendigkeit dieser Maßnahme und appellierte an die Landtagsabgeordneten:

„Ihr könnt den Bund nicht zu einer Zeit verlassen, wo einer Eu[rer] Parteifreunde die Finanzpolitik des Bundes leitet in der Absicht, gerade seiner steuerschwachen Heimat zu dienen. Ihr solltet allmählich merken, daß gewisse Länder wieder eine Hegemonie im Bund errichten wollen. Daß sich die steuerstarken Länder gegen die $40 \%$ wehren, müsst Ihr kapieren. Daß sich die steuerschwachen Länder dagegen wenden, ist freilich unverständlich. Bayern braucht den Bund als Ausgleichsmoment gegenüber den finanzstarken Ländern."

Schäffer hatte Ehard schon Wochen zuvor erklärt, daß für ihn ein enger Konnex zwischen der Erhöhung des Bundesanteils und dem Gesetzentwurf über den Finanzausgleich bestehe, mit dem der Bund den steuerschwachen Ländern einen Teil ihrer Last abnehmen wolle ${ }^{372}$. Der Finanzminister ließ aber auch keinen Zweifel daran, daß diese Zahlungen nur geleistet werden könnten, wenn der Anteil des Bundes an der Einkommen- und Körperschaftsteuer auf 40 Prozent erhöht werde ${ }^{373}$. Aus finanzpolitischer und fiskalischer Sicht mochte diese Argumentation folgerichtig sein, aus der Perspektive konsequenter Föderalisten war sie verhängnisvoll ${ }^{374}$. Schließlich war es ein Eckpfeiler des föderativen Systems, daß die Länder einen Teil des Steueraufkommens in eigener Regie verwalten konnten. Gestand man nun dem Bund einen größeren Anteil zu, so war eine generelle Stärkung der Zentralgewalt auf Kosten der Länder zu befürchten, und genau dies lehnten viele Abgeordnete der CSU im bayerischen Landtag ab, auch

${ }^{368}$ ACSP, CSU-LTF II/1, 15-14, Protokoll der Fraktionssitzung am 16. 7. 1952 (Hans Ehard und Alois Schlögl).

369 ACSP, CSU-LTF II/1, 15-14, Protokoll der Fraktionssitzung am 2. 4. 1952.

370 ACSP, CSU-LTF II/1, 15-14, Protokoll der Fraktionssitzung am 16. 7. 1952.

${ }^{371}$ ACSP, CSU-LTF II/1, 15-14, Protokoll der gemeinsamen Sitzung von Landtagsfraktion, Landesgruppe und Landesvorstand am 21.4. 1952; das folgende - soweit nicht anders belegt - nach dem Protokoll dieser Sitzung.

${ }^{372}$ BSB, NL Schwend 55, Fritz Schäffer an Hans Ehard vom 4. 3. 1952.

373 Das Dotationssystem des Bundes war allerdings vielen Mitgliedern der CSU-Fraktion im bayerischen Landtag aus föderalistischen Gründen ein Dorn im Auge. ACSP, CSU-LTF II/1, 15-14, Protokolle der Fraktionssitzungen am 2. 4. und 16. 7. 1952.

${ }^{374}$ Vgl. Gelberg, Hans Ehard, S. 401. 
wenn ihnen klar war, daß sie unter diesen Umständen auf willkommene Zuschüsse aus der Bundeskasse würden verzichten müssen ${ }^{375}$. Für Franz Josef Strauß zählten solche Bedenken angesichts der gesamtpolitischen Situation nicht. Er unterstützte Schäffers Forderungen und mahnte seine Parteifreunde in der Krisensitzung vom 21. April 1952 zur Geschlossenheit:

„Ich wollte verhindern, daß die [Landesgruppe] mit ja stimmt, während die Landtagsfraktion an einer Interpellation beteiligt ist, deren Sinn ein nein ist. Wenn die [Landesgruppe] nein sagt, ist der Rücktritt des Finanzministers unvermeidlich. Sachlich müssen wir uns im klaren sein, daß diese Frage nicht isoliert gesehen werden kann, etwa als Auseinandersetzung zwischen Bayern und [dem] Bund. Diese Frage ist ein Bestandteil der gesamten Regierungspolitik. Hier schlägt der Lastenausgleich sowie der Verteidigungsbeitrag herein. Die einzige Lösungsmöglichkeit ist, daß Landtagsfraktion und Landesvorstandschaft ihr Einverständnis geben, [daß] die Bundestagsabgeordneten [...] dem Gesetzentwurf Schäffer[s] im Bundestag zustimmen können. Anschliessend beschäftigt sich der Bundesrat mit dem Gesetz. Vermieden werden muß, daß ein Riß in unserer Partei aufscheint, etwa so, daß wir in Bonn nicht als die guten Föderalisten erscheinen. Unsere Gesamtpolitik muß entweder durchgeführt werden zu einem sicheren Erfolg oder wir brechen ab und die SPD bekommt recht."

Die Argumente und latenten Drohungen von Schäffer und Strauß blieben nicht ohne Wirkung. In der Landtagsfraktion war nun immerhin die Bereitschaft erkennbar, einer Erhöhung des Bundesanteils an der Einkommen- und Körperschaftsteuer zuzustimmen. Ein Bundesanteil von 40 Prozent wurde jedoch ebenso abgelehnt wie die von Strauß geforderte „Blankovollmacht“ für die Landesgruppe. Die Landtagsabgeordneten erklärten sich allerdings damit einverstanden, „dem Bund die Mittel zu geben, die er unbedingt“ brauche. Voraussetzung dafür müsse „jedoch die Möglichkeit der Überprüfung dieser Notwendigkeiten durch die Länder sein“. Landesvorstand und Landesgruppe billigten diesen Standpunkt am 21. April bei fünf Gegenstimmen und fünf Enthaltungen.

Damit waren die Weichen für eine Erhöhung des Bundesanteils an der Einkommenund Körperschaftsteuer gestellt. Doch die Auseinandersetzungen über den Verteilungsschlüssel hatten vor allem bei den Landespolitikern der CSU tiefe Wunden hinterlassen. Das ohnehin gespannte Verhältnis von Ehard und Schäffer hatte einen absoluten Tiefpunkt erreicht ${ }^{376}$, und auch die politische Freundschaft von Schäffer und Hundhammer drohte an den umstrittenen steuer- und finanzpolitischen Problemen zu zerbrechen. Als die beiden gemeinsam in Tuntenhausen vor dem Katholischen Männerverein auftraten, konnte ein offener Streit nur mit Mühe vermieden werden ${ }^{377}$. Während die bundespolitische Verantwortung so unterschiedliche Persönlichkeiten wie Schäffer und Strauß zusammenrücken ließ, entzweiten sich auch alte Kampfgefährten über der Frage nach dem Primat der Bundes- oder der Landespolitik. Die Konflik-

375 So erklärte Alois Hundhammer vor der Landtagsfraktion: „Dazu kommt, dass wir in Bayern selbst unseren eigenen Haushalt nicht ausgleichen können und daß die Länder im Geldaufbringen vor Bonn stehen. Von den Ländern her wird der Bund getragen. Zunächst müssen also die Bedürfnisse der Länder befriedigt werden, soweit es nicht ganz lebenswichtige allgemeine Bedürfnisse beim Bund sind. Es ist das das Subsidiaritätsprinzip. Freilich kann Bonn mit Repressalien drohen. Was man prinzipiell als richtig erkannt hat, darf man aber nicht deshalb aufgeben, weil gedroht wird." ACSP, CSU-LTF II/1, 15-14, Protokoll der Fraktionssitzung am 16. 7. 1952.

${ }^{376}$ Vgl. Gelberg, Hans Ehard, S. 401-410, und BayHStA, NL Ehard 268, Notiz Hans Ehards für Karl Schwend vom 11.8. 1952.

377 BSB, NL Schwend 55, Fritz Schäffer an Hans Ehard vom 5. 5. 1952 und Fritz Schäffer an Alois Hundhammer vom 5. 5. 1952; ACSP, CSU-LTF II/1, 15-14, Protokoll der Fraktionssitzung am 16. 7. 1952. 
te aus der noch nicht lange zurückliegenden Ära Müller wurden mehr und mehr durch neue Problemkreise überlagert.

In den Wochen nach der Krisensitzung von Landtagsfraktion, Landesgruppe und Parteivorstand wurde weiter zäh um die Höhe des Bundesanteils gerungen. Nachdem der Bundestag Schäffers Gesetzentwurf zugestimmt hatte, rief der Bundesrat den Vermittlungsausschuß an, um doch noch zu einer für alle Seiten tragbaren Übereinkunft zu kommen. Die Vertreter der bayerischen Staatsregierung sprachen sich im Vermittlungsausschuß dafür aus, den Bundesanteil an der Einkommen- und Körperschaftsteuer auf 35 Prozent zu erhöhen und nicht, wie von Schäffer gefordert, auf 40 Prozent. Der Kompromiß, der schließlich ausgehandelt und am 9. Juli 1952 auch vom Bundestag akzeptiert wurde, sah eine Erhöhung des Bundesanteils auf 37 Prozent vor ${ }^{378}$. Ob der Bundesrat aber diesem Vorschlag zustimmen würde, war ebenso unklar wie die Haltung der bayerischen Staatsregierung. Am 16. Juli 1952, zwei Tage vor der entscheidenden Abstimmung im Bundesrat, bat Hans Ehard die CSU-Fraktion um ihre Stellungnahme ${ }^{379}$. Der Ministerpräsident, von seinem Parteifreund Schäffer menschlich und politisch enttäuscht, zeigte sich einmal mehr führungsschwach und unentschlossen, auch wenn er im Ministerrat eine kompromißbereite Haltung hatte erkennen las$\operatorname{sen}^{380}$. Die Landtagsfraktion war ebenfalls hin- und her gerissen. Einige Abgeordnete, allen voran Alois Hundhammer, waren dafür, den mühsam ausgehandelten Kompromiß um des föderalistischen Prinzips willen abzulehnen, andere signalisierten ihre $\mathrm{Zu}$ stimmung, weil sie ihre Bonner Parteifreunde nicht im Stich lassen wollten, Schäffers Argumente anerkannten oder um die Bundeszuschüsse für Bayern fürchteten. Als sich ein Fraktionsmitglied erlaubte, diesen Gesichtspunkt in die Debatte zu werfen, rief Hundhammer voller Zorn: „Um ein Butterbrot gibt man Bayern her!“ Doch der ehemalige Kultusminister hatte in der Landtagsfraktion nicht mehr denselben Rückhalt wie noch zwei oder drei Jahre zuvor. Als es zur Abstimmung kam, votierten bei vier Enthaltungen 26 Abgeordnete für den Vorschlag des Vermittlungsausschusses und nur zehn dagegen. Ministerpräsident Ehard folgte dieser Linie und setzte sich auch im Kabinett durch. Am 18. Juli 1952 entschied sich der Bundesrat mit den Stimmen Bayerns für eine Erhöhung des Bundesanteils auf 37 Prozent.

Doch nicht nur die Finanz- und Steuerpolitik trieb einen immer größeren Keil zwischen die Bundes- und die Landespolitiker in der CSU ${ }^{381} .1954$ kam es auch über kulturpolitische Fragen zu einer hitzigen Kontroverse, die ein bezeichnendes Schlaglicht auf den inneren Zustand der CSU warf. Die nur halb zugeschütteten Gräben zwischen den seit den Gründungstagen der Partei existierenden Flügeln wurden dabei ebenso sichtbar wie die neuen Fronten, die sich zwischen der Bonner Landesgruppe und der Landtagsfraktion herausgebildet hatten, oder die Rivalitäten zwischen älteren Entscheidungsträgern, die sich ihre ersten politischen Sporen noch in der Weimarer Republik verdient hatten, und einer Reihe von Nachwuchspolitikern, die für die altbayeri-

\footnotetext{
378 Vgl. Gelberg, Hans Ehard, S. 402 f. und S. 406 f.

379 ACSP, CSU-LTF II/1, 15-14, Protokoll der Fraktionssitzung am 16. 7. 1952; das folgende - soweit nicht anders belegt - nach dem Protokoll dieser Sitzung.

${ }^{380}$ Zur Entscheidung im bayerischen Ministerrat und im Bundesrat vgl. Gelberg, Hans Ehard, S. $407 \mathrm{f}$.

$381 \mathrm{Zu}$ den steuer- und finanzpolitischen Konflikten der folgenden Jahre vgl. Henzler, Fritz Schäffer, S. 360-363; zur wachsenden Entfremdung zwischen den Bundes- und Landespolitikern in der CSU im Laufe des Jahres 1954 vgl. Gelberg, Hans Ehard, S. 513-516.
} 
sche Ideologie eines Alois Hundhammer kein Verständnis mehr aufbringen konnten. Die Auseinandersetzung entzündete sich an der Diskussion um die richtige Strategie für den bevorstehenden Landtagswahlkampf. Die katholisch-konservativen Kräfte um den noch immer einflußreichen Hundhammer und seinen kongenialen Mitstreiter Georg Meixner, der als Vorsitzender der Landtagsfraktion ${ }^{382}$ und als Vorsitzender des kulturpolitischen Ausschusses im Maximilianeum zu den Schlüsselfiguren der CSU zähl$\mathrm{te}^{383}$, drängten darauf, kulturpolitische Themen in den Mittelpunkt des Wahlkampfes zu stellen. Die christliche Kulturpolitik, erklärte Prälat Meixner 1954 wiederholt, sei seit jeher das „Herzstück“ der Politik der CSU gewesen und müsse es auch immer bleiben ${ }^{384}$. Meixner verstand unter christlicher Kulturpolitik dreierlei: zunächst die „Frage der Beziehungen zwischen Staat und Kirche“, dann eine dem Christentum verpflichtete Familienpolitik und schließlich und vor allem Schulpolitik ${ }^{385}$, die eines der heißesten Eisen der bayerischen Landespolitik war. Während die CSU - allen voran Meixner und Hundhammer - die Bekenntnisschule als Regelschule mit Klauen und Zähnen verteidigte und für eine nichtakademische, konfessionell streng getrennte Ausbildung der Volksschullehrer eintrat ${ }^{386}$, verfocht der Koalitionspartner SPD die nahezu entgegengesetzten Positionen ${ }^{387}$. Dieser Konflikt erwies sich nicht nur als dauerhafte Belastung der Regierungsarbeit, sondern drohte auch die CSU im Landtag zu isolieren, da auch die anderen Parteien mehrheitlich gegen die von den Kulturpolitikern der CSU immer wieder vorgebrachten Maximalforderungen standen.

In Bonn betrachtete man diese Entwicklung mit Sorge. Für Franz Josef Strauß und viele andere Mitglieder der Landesgruppe war es zunächst einmal wichtig, die Landtagswahlen zu gewinnen. Dafür mußten aber Wähler aus dem evangelischen und liberalen Lager angesprochen werden, die erfahrungsgemäß allergisch auf eine Schul- und Kulturpolitik reagierten, die im Verdacht stand, allzu konservativ und einseitig konfes-

${ }^{382}$ Georg Meixner war im August 1951 zum Fraktionsvorsitzenden gewählt worden, nachdem Alois Hundhammer das Amt des Landtagspräsidenten übernommen hatte. ACSP, CSU-LTF II/1, 15-14, Protokoll der Fraktionssitzung am 8. 8. 1951.

383 Eine Beschäftigung mit der politischen Biographie Georg Meixners wäre ebenso interessant wie lohnend. Zwar existiert nach Auskunft des Archivs des Erzbistums Bamberg kein Nachlaß des Prälaten, sein politisches Wirken nach 1945 läßt sich jedoch aus den Akten der CSU-Landtagsfraktion, aus den Sitzungsprotokollen des Landtags und seiner Ausschüsse und aus den - allerdings nur schwer zugänglichen - Akten in den Archiven der sieben bayerischen Bistümer rekonstruieren. Eine Sammlung von Zeitungsausschnitten und Materialien zu Meixner findet sich im ACSP, CSU-LTF II/2, 6-43, und in der BSB, NL Schwend 7; vgl. vor allem Die Zeit vom 4. 2. 1954: "Prälat und Politiker“, und Bamberger Volksblatt vom 25. 7. 1957: „Unser Prälat. Georg Meixner zu seinem 70. Geburtstag am 26. Juli 1957“. Vgl. auch Werner K. Blessing, Georg Meixner (1887-1960), in: Fränkische Lebensbilder 16 (1996), S. 213-240.

384 ACSP, CSU-LL, Protokoll der Sitzung des Landesausschusses der CSU am 15. 1. 1954 in Rothenburg ob der Tauber, Protokoll der Sitzung des Landesausschusses der CSU am 3. 7. 1954 in Landshut und Rechenschaftsbericht Georg Meixners vor der Landesversammlung der CSU am 9./10. 10. 1954 in Nürnberg.

385 Vgl. ACSP, CSU-LL, Rede Georg Meixners vor dem Landesausschuß der CSU am 15. 1. 1954 in Rothenburg ob der Tauber.

386 Zur wesentlich von Meixner bestimmten Diskussion in der CSU-Fraktion vgl. exemplarisch ACSP, CSU-LTF II/2, Protokoll der Arbeitstagung vom 30. 11.-2. 12. 1953.

387 Vgl. dazu ausführlich Müller, Schulpolitik; Franz Sonnenberger, Die Rekonfessionalisierung der bayerischen Volksschule 1945-1950, in: ZfBLG 45 (1982), S. 87-155; Hubert Buchinger, Volksschule und Lehrerbildung im Spannungsfeld politischer Entscheidungen 1945-1970, München 1975, und Jana Richter, Eine Schule für Bayern. Die schulpolitischen Auseinandersetzungen um die Einführung der Christlichen Gemeinschaftsschule in Bayern nach 1945, München 1997. 
sionell geprägt zu sein ${ }^{388}$. Während es für Hundhammer und Meixner in dieser Frage keine Kompromisse geben konnte, war die Landesgruppe größtenteils zu Zugeständnissen bereit, wenn dadurch der politische Erfolg sichergestellt werden konnte. Selbst Richard Jaeger, ein politischer Ziehsohn Hundhammers, und der katholische Jugendfunktionär Emil Kemmer taten sich schwer, den kulturpolitischen und wahltaktischen Kurs der Parteifreunde in München zu rechtfertigen. Im Protokoll der Landesgruppensitzung vom 30. April 1954 heißt es:

„Der Vorsitzende [Franz Josef Strauß] weist auf die Gefahren hin, die aus einer Überbetonung kulturpolitischer Ziele für die Einheit der CDU/CSU entstehen können, und auf die Verluste, die bei einer zu starken Propagierung dieser Ziele im Wahlkampf zu erwarten wären. Die CSU sollte sich darüber im klaren sein, daß sie von einem großen Teil ihrer Wähler nicht um ihrer Kulturpolitik, sondern vielmehr um ihrer wirtschaftlichen und außenpolitischen Ziele willen gewählt worden sei. Es sei dazu erwiesen, daß evangelische Kreise alle kulturpolitischen Vorstöße mit größtem Mißtrauen betrachten. [...] Die CSU müßte deshalb, ohne auf ihre weltanschaulichen Grundlagen zu verzichten, kulturpolitische Ziele nicht zum Mittelpunkt ihres Wahlprogrammes machen. Abg. Dr. Jaeger warnt umgekehrt davor, durch Vernachlässigung der Kulturpolitik die Stammwähler der CSU vor den Kopf zu stoßen und zu glauben, daß die liberalen Wähler [...] überhaupt zu halten wären. Außerdem könnte der Landtagswahlkampf im wesentlichen nur mit kulturpolitischen Fragen bestritten werden, weil Kulturpolitik das einzige Gebiet sei, in dem Bayern die alleinige Zuständigkeit hätte. Abgesehen davon, $m[\ddot{u}]$ Bte einer Weltanschauungspartei wie der CSU die Kulturpolitik besonders am Herzen liegen, ja sie sei dazu vom Gewissen her verpflichtet. Abg. Kemmer stimmt dem letzten Satz des Abg. Dr. Jaeger zu und stellt fest, daß man Grundsätze nicht verleugnen darf, auch wenn man dabei Wähler verlieren sollte. [...] Abg. Wacher bedauert, daß in Bayern die Frage der Lehrerbildung jetzt an den Schluß der Wahlperiode gestellt worden sei und damit überhaupt eine so heikle Frage in den Wahlkampf komme. Er unterstreicht im übrigen die Ausführungen des Vorsitzenden. [...] Abg. Dr. Horlacher warnt davor, den Fehler der früheren Bayerischen Volkspartei zu wiederholen. [...] Der Vorsitzende stellt nochmals richtig, daß es keineswegs darum gehe, die christlichen Grundsätze aufzugeben, sondern sich einer solchen Mehrheit zu [ver]sichern, daß sie auch verteidigt werden könn[ten]. Man brauche Bundesgenossen, um die christlichen Staatsideale verwirklichen zu können. Kulturpolitik sei außerdem schwer zu verteidigen, da, wie es in Bayern der Fall ist, auf kulturpolitische[m] Gebiet viel zu wenig geschehen sei. Abg. Dr. Dollinger warnt auch ebenso wie der Abg. Unertl davor, kulturpolitische Fragen als Hauptwahlkampfparole zu benutzen. Abg. Dr. Jaeger gibt zu, $\mathrm{da} ß$ auf kulturpolitischem Gebiet in Bayern viel zu wenig geschehen sei, als daß man es erfolgreich verteidigen könne. Das dürfe aber nicht daran hindern, über die Grundsätze einer christlichen Kulturpolitik zu sprechen. [...] Abg. Kemmer stellt abschließend fest, daß der Landtagswahlkampf wohl nur mit den Erfolgen der Bundespolitik geführt werden kann. ${ }^{\text {“389 }}$

Auf der Tagung des Landesausschusses am 3. Juli 1954 in Landshut prallten die gegensätzlichen Positionen hart aufeinander. Nachdem auch Ministerpräsident Ehard vorsichtig davor gewarnt hatte, sich zu sehr auf kulturpolitische Fragen zu konzentrieren, und statt dessen gefordert hatte, die Bevölkerung über die ganze Bandbreite der Politik der CSU zu informieren, trat Georg Meixner ans Rednerpult ${ }^{390}$. Obwohl es nicht gerade üblich war, dem Landesvorsitzenden coram publico zu widersprechen, trat der Prä-

${ }^{388}$ Zur Position der katholischen Kirche, die im wesentlichen mit den von Hundhammer und Meixner formulierten Positionen übereinstimmte, vgl. Archiv des Erzbistums Bamberg, Rep. 4/3, 111/20.6, Rundschreiben der Diözesanleitung der Katholischen Aktion Bamberg, gez. Georg Meixner und Dr. Mehling, an die Pfarrer vom 12.11. 1954.

${ }^{389}$ Archiv der CSU-Landesgruppe, Protokoll der Landesgruppensitzung am 30. 3. 1954; vgl. auch BSB, NL Schwend 19, Bericht Heinz Brencks über die Landesgruppensitzung am 30. 3. 1954.

390 ACSP, CSU-LL, Protokoll der Sitzung des Landesausschusses der CSU am 3. 7. 1954 in Landshut; das folgende nach dem Protokoll dieser Sitzung. 
lat offen dafür ein, „die Kulturpolitik beim kommenden Wahlkampf in den Vordergrund“ zu stellen. Schließlich sei der Kulturpolitik „im Rahmen der gesamten Politik der Christlich-Sozialen Union immer eine gewisse zentrale Stellung eingeräumt worden“ und der Großteil der Wähler der CSU habe der Partei „über alle Wandlungen der Zeit hinweg die Treue gehalten, weil sie eben Vertrauen in diese Partei wegen ihrer klaren christlichen Kulturpolitik immer gesetzt haben“. Überdies müsse man berücksichtigen, daß auch die SPD beschlossen habe, den Wahlkampf vor allem mit kulturpolitischen Themen zu bestreiten. Als katholischer Geistlicher war Meixner zwar über jede öffentliche Kritik erhaben, aber seine Ausführungen über die Rolle der Kulturpolitik gingen einigen unerschrockenen Vertretern der jungen Generation doch zu weit. Unterstützt vom bayerischen JU-Vorsitzenden Franz Sackmann, dem enfant terrible der CSU und Schrecken der alten Garde, führte Fritz Zimmermann aus:

„Ich glaube, meine lieben Freunde, daß wir diesmal vielleicht schon in einem zu frühen Zeitpunkt, mitunter ungewollt, einen etwas extremen Standpunkt ab und an vertreten haben, nicht in der Zielsetzung, aber ab und zu im Ton. Wir haben mitunter die Dinge überbetont, und ich glaube, das sollten wir in den nächsten Monaten nicht mehr tun. [. . .] Wir müssen im Wahlkampf in diesen Fragen die Grenze finden zwischen unserer eigenen festen und unverrückbaren Überzeugung, zwischen unseren unverzichtbaren kulturpolitischen Grundsätzen auf der einen Seite und einer politisch-taktischen Linie auf der anderen Seite. [...] Meine lieben Freunde, es ist nicht notwen$\mathrm{dig}, \mathrm{da}$ wir immer und immer wieder zu forciert, etwas überzogen und überbetont einen Kreis ansprechen, der sowieso keine andere Möglichkeit hat, als uns in diesem Wahlkampf zu wählen. Es kommt aber mehr als in jedem anderen Wahlkampf darauf an, daß wir den letzten Nichtwähler und den letzten schwankenden Wähler [...] gewinnen. Lassen wir die weise Mäßigung [...] auch hier walten! Unterlassen wir alles [. . . ], was Gräben zwischen den Bekenntnissen ziehen könnte. [...] Wir dürfen uns auch nicht den leisesten Anschein geben, als ob wir irgendeinen geistlichen Totalitätsanspruch verfechten wollten."

Diese Worte des späteren CSU-Generalsekretärs, der durch die Schule Josef Müllers gegangen war, waren Franz Josef Strauß aus dem Herzen gesprochen. Der Landesgruppenchef wiederholte - von Zwischenrufen Meixners unterbrochen - seine Bedenken, die er intern bereits in Bonn geäußert hatte. Zugleich warnte er geradezu prophetisch davor, SPD, FDP, BHE und Bayernpartei „durch eine falsch propagierte und in der Öffentlichkeit böswillig ausgelegte Politik“" in eine Koalition gegen die CSU zu treiben.

Doch die liberal-konservativen Kräfte in der bayerischen Unionspartei waren noch zu schwach, um das Blatt zu wenden, und auch die einflußreiche Bonner Landesgruppe unter der Führung von Strauß verfügte nicht über die notwendigen Mittel zur Beeinflussung eines Landtagswahlkampfes ${ }^{391}$. Der Wahlkampf vom Herbst 1954, der von allen Seiten aggressiv und polemisch geführt wurde ${ }^{392}$, war mit Sicherheit eine der größten strategischen Fehlleistungen der Parteiführung um Hans Ehard, die nicht willens oder nicht in der Lage war, die überspitzten kulturpolitischen Forderungen von Meixner und Co. zu unterbinden ${ }^{393}$, obwohl sie über die Gefahren genau infor-

391 Zum Landtagswahlkampf und zur inneren Situation der CSU vgl. Heike Bretschneider, Die Bildung der Viererkoalition. Die parteipolitische Konstellation in Bayern in der ersten Hälfte der fünfziger Jahre, in: ZfBLG 41 (1978), S. 999-1038, hier S. 1000-1012.

392 Exemplarisch IfZ-Archiv, ED 120 NL Hoegner 231, SPD - Die Landtagswahl Nr. 1, 4, 7, 10-13, Mai bis November 1954.

393 Dies zeigen etwa die entsprechenden Artikel in der von der Landtagsfraktion herausgegebenen CSU-Correspondenz Nr. 31 vom 26.1., Nr. 49 vom 30.3., Nr. 50 vom 2.4., Nr. 3 vom 8. 10., 
miert war. Nicht zuletzt machten die Ergebnisse einer von der Landesleitung bei Emnid in Auftrag gegebenen Spezialstudie über die „Voraussetzungen der Landtagswahlen 1954 in Bayern“ deutlich, daß der kulturpolitische Dogmatismus des katholischkonservativen Parteiflügels nicht mehr zeitgemäß war und wie berechtigt die Bedenken aus den Reihen der Landesgruppe und der Jungen Union waren. Auf die Frage „An welcher Massnahme bzw. an welchem Gesetz hatten Sie etwas auszusetzen?“ nannten die Befragten an zweiter Stelle die Schulpolitik der Staatsregierung und des von der CSU gestellten Kultusministers, und auf die Frage, welche Form der Volksschule die Befragten für ihre Kinder wählen würden, wenn sie frei darüber entscheiden könnten, nannten nur 24 Prozent die von der CSU im Wahlkampf so kompromißlos verfochtene Konfessionsschule, während sich 69 Prozent für die christliche Gemeinschaftsschule oder die Gemeinschaftsschule mit Religionsunterricht aussprachen ${ }^{394}$. Auch andere Umfrageergebnisse waren alarmierend. Danach waren 48 Prozent der Befragten der Meinung, die CSU sei „zu sehr von der Kirche beeinflußt“, und nur 15 Prozent hielten es für gut, „wenn es in Bayern noch mehr Männer wie den Hundhammer geben würde“ 395 .

So führte die CSU den Landtagswahlkampf an den Interessen eines großen Teils der bayerischen Wählerinnen und Wähler vorbei - und die Quittung dafür sollte nicht lange auf sich warten lassen. Die bayerische Unionspartei gewann zwar gegenüber 1950 mehr als zehn Prozent der Stimmen und wurde mit 38 Prozent stärkste politische Kraft, nach dem grandiosen Sieg bei den Bundestagswahlen vom September 1953, wo man im Sog des Adenauer-Effekts die absolute Mehrheit nur knapp verfehlt hatte, war dieses Ergebnis jedoch eine Enttäuschung ${ }^{396}$. Nun trat genau das ein, was Franz Josef Strauß von Bonn aus vergeblich zu verhindern versucht hatte: Eine Koalition unter Führung der SPD, die auch durch die kulturpolitischen Maximalforderungen aus den Reihen der CSU zusammengeschweißt worden war, verdrängte die siegreiche CSU auf die harten Bänke der Opposition.

\section{Die Partei verändert ihr Gesicht}

\section{a) Verdrängung, Resignation, Isolation: Josef Müller und seine Mitstreiter nach 1949}

Bis 1949 hatten Josef Müller und seine Getreuen die politische, programmatische und organisatorische Entwicklung der CSU entscheidend geprägt. Doch wieviel Einfluß blieb ihnen nach der Landesversammlung in Straubing und dem Sturz des Ochsensepp? Rein zahlenmäßig war der Müller-Flügel noch immer eine Macht. Im Mai 1949 hatte der scheidende Landesvorsitzende immerhin noch ein Viertel der Stimmen erhal-

Nr. 3 k vom 9. 10., Nr. 6 vom 19.10., Nr. 7 vom 22. 10., Nr. 9 vom 29. 10., Nr. 9 a vom 29. 10., Nr. 13 vom 12.11., Nr. 14 vom 16. 11., und Nr. 16 vom 23.11. 1954.

394 Voraussetzungen der Landtagswahlen 1954 in Bayern. Eine Spezialstudie im Auftrage der Landesgeschäftsführung der CSU Bayern, durchgeführt vom Emnid-Institut für Meinungsforschung, Bielefeld 1954, S. 53 f. und S. 109 f. Zu ähnlichen Ergebnissen kam auch die Studie: Vor den Landtagswahlen. Bericht über die Bevölkerungsumfragen in Hessen und Bayern, durchgeführt vom Institut für Demoskopie, Allensbach 1954, S. $36 \mathrm{f}$.

395 Ebenda, S. 61 und S. 95.

396 Angaben nach Zweite Bundestagswahl, S. 10, und Ritter/Niehuss, Wahlen in Deutschland, S. 174. 
ten, und neben den „150 von Straubing“ ${ }^{397}$ waren es vor allem Teile der fränkischen Bezirksverbände und der Arbeitsgemeinschaften, die Müller die Treue hielten. Die große Frage war, ob der gestürzte Parteichef und seine Mitstreiter bereit waren, ihre Niederlage zu akzeptieren, oder ob sie auf Rache sinnen und versuchen würden, nach dem Vorbild der Anti-Müller-Fronde um Alois Hundhammer die Politik der neuen Parteiführung systematisch zu torpedieren. Schließlich war Hans Ehard nur für ein Jahr gewählt, so daß sich spätestens im Sommer 1950 die Chance bot, das Ergebnis von Straubing zu revidieren.

Doch die Befürchtungen, die Führungs- und Flügelkämpfe könnten unter umgekehrten Vorzeichen weitergehen, waren überzogen. Viele Anhänger Josef Müllers waren erschöpft und der ständigen Streitigkeiten müde. Lediglich in Franken gab es noch eine Fraktion, die sich kampfbereit zeigte, und nur auf das Signal wartete, die alten Bataillone wieder zu sammeln. Otto Graf nahm im Juli 1949 an, der Ochsensepp sei „in Unterfranken immer noch der ungekrönte Prinzregent “ ${ }^{398}$, und ein Würzburger Parteifreund ermunterte Müller, mit neuem Elan daran zu gehen, die alten Ideale doch noch zu verwirklichen:

„Ich brauche nicht erst zu betonen, daß ich nach wie vor der alte bin, der nicht gewillt ist, eventuelle Veränderungen der Parteipolitik im Sinne [o]berbayerische[r] Rückschrittlichkeit mitzumachen. Wenn wir hier alle [...] weiterhin auf dem Posten bleiben und mit verstärkter Aktivität in den Wahlkampf gehen, so deshalb, weil wir die Hoffnung haben, daß es Ihnen [...] gelingen wird, in Kürze oder erst in Monaten doch noch eine klare Linie in die Partei zu bringen. [...] Sie sehen, Dr. Müller, Sie haben nicht nur Freunde, sondern Ihre Freundeszahl wächst, das aber nur, wenn Sie uns die Gewissheit geben, nicht umsonst zu arbeiten, bzw. uns ein Ziel geben." ${ }^{399}$

Die Mehrheit von Müllers Anhängern dachte jedoch anders. Eine Fortsetzung des Machtkampfes, so fürchteten sie, könne die CSU irreparabel schädigen. Daher baten Freunde und Mitstreiter den Ochsensepp inständig darum, sich zumindest vorerst mit den Tatsachen abzufinden und nicht zu denselben Waffen zu greifen wie seine Gegner. Auch Hans Schwägerl, ein CSU-Politiker aus dem oberfränkischen Marktredwitz, gehörte zu denen, die den Wechsel an der Parteispitze zutiefst bedauerten. Nachdem Ehard aber nun einmal gewählt worden sei, schrieb er unmittelbar nach der Straubinger Landesversammlung an Josef Müller, „wird es an uns liegen, ihm unsere Gefolgschaft nicht zu verweigern, sondern ihn $100 \%$ zu unterstützen, damit die Oberbayern sehen, daß wir nicht einer Person, sondern der CSU. dienen“. Schwägerl fuhr fort:

„Es ist allerdings hart, wenn man gesehen hat, wie sich die Minderheit bei Deiner Wahl benommen hat, heute gerade das Gegenteil zu tun. Aber im Interesse unserer Union und auf Grund unserer christlichen Weltanschauung müssen wir diesen Weg gehen und beweisen, daß wir, trotzdem wir nicht so viel von den klerikalen Dingen verstehen, doch unser Christentum $100 \%$ ig ernst nehmen. ${ }^{400}$

397 ACSP, NL Müller 198, CSU-Kreisverband Würzburg-Stadt an Josef Müller vom 14. 6. 1949.

398 ACSP, NL Müller 325, Otto Graf an Josef Müller vom 11. 7. 1949.

${ }^{399}$ ACSP, NL Müller 198, CSU-Kreisverband Würzburg-Stadt an Josef Müller vom 14. 6. 1949; ähnlich auch NL Müller 184, Albin Niklaus an Josef Müller vom 2. 6. 1949.

400 ACSP, NL Müller 149, Hans Schwägerl an Josef Müller vom 30. 5. 1949; am 31.5. 1949 schricb Heinz Fischer an seinen gestürzten Mentor (NL Müller 144): "So sehr man bei uns den Ausgang der Wahl bedauert, so erwartet man aber unbedingt von Dir, daß Du Dich dieser Mehrheit fügst, nur so können wir Aussicht haben, Dich wieder zu wählen." 
Wie groß Müllers Chancen, das Rad der Geschichte zurückzudrehen, überhaupt waren, läßt sich nur schwer sagen. Sicher ist, daß man den Einfluß des ehemaligen Landesvorsitzenden in der CSU bis 1952 nicht unterschätzen darf. Der Ochsensepp meldete sich wiederholt in den Führungsgremien der Partei zu Wort, denen er nach wie vor angehörte ${ }^{401}$, und hatte im Dezember 1950 als Verbündeter Hans Ehards maßgeblichen Anteil an der Ausschaltung der Bayernpartei bei der Regierungsbildung und am Zustandekommen einer großen Koalition. Müller zählte auch nach seinem Sturz zu den bekanntesten Politikern der CSU und wußte sich mit dem geheimnisvollen Flair der großen Politik zu umgeben. Die gewohnte Dynamik ließ er allerdings vermissen. Die jahrelangen Auseinandersetzungen unter den Augen der Öffentlichkeit waren nicht spurlos an ihm vorübergegangen. Gesundheitlich und finanziell angeschlagen, zog sich Müller zeitweise aus der Parteiarbeit zurück und ließ seine Anhänger in den Kreisen und Bezirken über seine Pläne und Ziele im unklaren. Es hat fast den Anschein, als hätten sich die Treuesten der Treuen mehr Gedanken über sein Comeback gemacht als Müller selbst ${ }^{402}$, der nur halbherzig versucht $e^{403}$, alte Kontakte aufrechtzuerhalten, verlorene Positionen zurückzugewinnen und bewährte Mitstreiter in einflußreiche Positionen zu bringen ${ }^{404}$. Zudem saß der Stachel der Enttäuschung tief, und noch Jahre später war die Verbitterung spürbar, die Josef Müller empfand, wenn er an die Methoden dachte, mit denen seine Gegner den Kampf gegen ihn geführt hatten. Als Karl Sigmund Mayr, dem es der Ochsensepp niemals verzieh, daß er sich 1949 gegen ihn gestellt hatte, Müller wiederholt darum bat, die Reorganisation der CSU finanziell zu unterstützen, hüllte er sich zunächst in Schweigen, um dann mit dem Hinweis auf die Vergangenheit abzulehnen ${ }^{405}$. Inhalt und Diktion von Müllers Antwort veranlaßten Mayr zu einer deutlichen Replik:

„Es ist mir innerlich schon eine Beruhigung, daß Du mir überhaupt Antwort gibst und daß Du mir selbst schreibst. Weißt Du, das Ausbleiben einer Antwort auf verschiedene Briefe ha[t] den Groll in mir, den ich seit langem gegen Dich habe, verstärkt. Nun wird er langsam schwinden, aber er kann erst ganz beseitigt werden, wenn ich weiß, daß Du Dich endlich einmal von der Vorstellung freimachst, daß Du das Recht hättest, genau so zu handeln, wie Deine Gegner von ehemals. Du bist völlig im Recht, wenn Du fragst, wo sind die Geldmittel, von denen in Straubing die Rede war. Aber Du darfst nicht die Arbeit der Vorstandschaft und Landesleitung sabotieren, weil Hundhammer mit dieser Waffe gegen Dich gekämpft hat. Es geht hier um eine Sache und nicht um eine Person, und wenn man gegen Dich unanständige Waffen gebraucht hat, dann darfst Du der Sache wegen nicht mit den gleichen Waffen kämpfen. Gerade dadurch müßtest Du Dich von Deinen früheren Ge[gn]ern unterscheiden. [...] Ich habe immer anerkannt, daß Du ein Politiker bist, dem eine besondere Begabung mitgegeben ist, aber was hilft Dir diese Begabung, wenn sie nicht einer großen Sache uneingeschränkt dient. ${ }^{*}{ }^{406}$

Doch es waren nicht nur der alte Groll und die offensichtlich fehlende Motivation, die Müller mit der Zeit zu einem Außenseiter in der CSU werden ließen. Auch

401 ACSP, CSU-LL, Protokolle der Sitzungen des geschäftsführenden Landesvorstands am 17. 6., 28. 6. und 3. 10. 1949, und Protokoll der Sitzung des Landesausschusses der CSU am 15. 1. 1950 in Fürth.

402 ACSP, NL Müller 52, Horst Erny an Josef Müller vom 26. 4. und 1. 9. 1950.

${ }^{403}$ Main-Echo vom 24. 3. 1950: „Dr. Müller will nach Canossa gehen. Die Amerikaner und die russischen Lockvögel“; Neue Zeitung vom 24. 5. 1950: „Problematik der bürgerlichen Regierungskoalition. Kulmbacher Wahlkampf als Beispiel - Kulturpolitik zur Zeit das heißeste Eisen“.

404 ACSP, NL Müller 150, Aktennotiz über eine Besprechung mit Georg Gamperl am 16. 11. 1949.

405 ACSP, NL Müller 21, Karl Sigmund Mayr an Josef Müller vom 16. 11. und 14. 12.1951 und dessen Antwortschreiben an Karl Sigmund Mayr vom 17. 12. 1951.

406 ACSP, NL Müller 21, Karl Sigmund Mayr an Josef Müller vom 27. 12. 1951. 
programmatisch geriet der Ochsensepp immer mehr ins Abseits. Seine gesamtdeutsche Konzeption paßte ebensowenig in das eisige Klima des Kalten Krieges wie seine von neutralistischen Äußerungen begleitete Forderung nach einem Dialog zwischen Ost und West ${ }^{407}$. Als Müller im Herbst 1949 den Vorschlag machte, ein Gremium zur „Koordinierung der ostdeutschen und westdeutschen Wirtschaft als Ausgangsbasis der Wiedergewinnung der deutschen staatlichen Einheit" einzurichten ${ }^{408}$, und bemerkte, das Christentum „kenne keinen eisernen Vorhang“, erntete er in seiner eigenen Partei wütende Proteste ${ }^{409}$. Georg Meixner und Franz Josef Strauß lehnten diese Gedanken öffentlich und mit teils scharfen Worten ab, andere CSUPolitiker forderten von Hans Ehard, gegen diese „Unglückspolitik“ seines Justizministers einzuschreiten und Müller „für seine Anknüpfung zum Bolschewismus“ zur Rechenschaft zu ziehen ${ }^{410}$. Alois Hundhammer schrieb nach einer Rede Müllers, in der er sich für einen Ausgleich zwischen den Westmächten und der Sowjetunion ausgesprochen und die Politik der Wiederbewaffnung kritisiert hatte, an Ministerpräsident Ehard:

„Wenn Leute aus den eigenen Reihen die heutige Menschheitsgefahr in dieser Weise bagatellisieren, dann erscheint die Abwehrstellung gegen den Bolschewismus, die wir übrigen Anhänger der CSU vertreten und für eine Gewissenspflicht erachten, aus dem eigenen Lager untergraben. “411

Auch wegen seiner Aktivitäten im Widerstand gegen das NS- Regime geriet Müller zunehmend ins Kreuzfeuer der Kritik. 1945 hatten ihm sein mutiges Eintreten für den Frieden und seine mehrjährige Odyssee durch die Gefängnisse und Konzentrationslager des Dritten Reiches noch den Weg in die Politik geebnet. Nach 1949 wurde der Ochsensepp jedoch von politischen Gegnern wie von Mitgliedern seiner eigenen Partei als Landesverräter diffamiert, der das Leben tausender deutscher Soldaten auf dem Gewissen habe ${ }^{412}$.

Trotz allem konnte Müller noch einmal einen Erfolg verbuchen, der bei seinen verbliebenen Anhängern neue Hoffnung und bei seinen Gegnern wohlbekannte Ängste auslöste. Die Bezirksversammlung wählte Müller im März 1951 zum Vorsitzenden der Münchner CSU; der Ochsensepp erhielt 81 Stimmen, sein Gegenkandidat, der amtierende Bezirksvorsitzende Franz Heubl, nur $71^{413}$. Müller rückte damit zwar in den

407 ACSP, CSU-LL, Protokoll der Sitzung des Landesausschusses der CSU am 15. 1. 1950 in Fürth (Reden Josef Müllers und Friedrich Wilhelm von Prittwitz und Gaffrons); zur Reaktion auf die beiden Reden, in denen Kritik an einer Politik der einseitigen Westorientierung geübt wurde, vgl. ACSP, CSU-LTF I, 15-20/0, Hans Hermann von Eicken an Herrn Schäfer vom 31. 1. 1950.

${ }^{408}$ Münchner Merkur vom 5. 12. 1949: „Dr. Müller: Ost-West eine Familie“.

${ }^{409}$ Main-Echo vom 7. 12. 1949: „Gegensätze auf Burg Feuerstein. Dr. Josef Müller contra Prälat Meixner"; zur Kritik von Meixner und Strauß an Müller vgl. ebenda.

+10 ACSP, CSU-LTF I, 15-20/0, Ludwig Sporer an Hugo Geiger vom 5. 12. 1949; BayHStA, NL Ehard 1363, Bericht über eine Rede Josef Müllers auf einer CSU-Versammlung in Hersbruck am 29.10. 1950.

411 ACSP, CSU-LTF II/1, 15-12/1, Alois Hundhammer an Hans Ehard vom 4. 6. 1951.

412 ACSP, CSU-LTF 11/1, 15-14, Protokolle der Fraktionssitzungen am 18.12. 1950 und 14.5. 1952; vgl. auch Stenographischer Bericht über die 85. Sitzung des Landtags am 8.5. 1952, S. 2040f.; Lenz, Tagebuch, Eintragung vom 12. 5. 1952, S. 327; Hans Kapfinger, Um das Datum des 10. Mai 1940. Justizminister wird des dreifachen Landesverrats beschuldigt, in: Passauer Neue Presse vom 15. 5. 1952; BSB, NL Schwend 52, Pressenotiz „Dr. Müller weist Vorwurf des Verrats zurück“ vom 23. 11. 1954.

${ }^{413}$ SZ vom 22. 3. 1951: „Dr. Müller CSU-Bezirksvorsitzender in München“; ACSP, NL Müller 52, Horst Erny an Josef Müller vom 1. 4. 1951; die Datierung der Wahl Müllers zum Münchner Bezirks- 
erlauchten Kreis der einflußreichen „Bezirksfürsten“ auf, aber er hatte seine Wahl weniger der eigenen Person als dem rastlosen Einsatz einiger Nachwuchspolitiker aus den Reihen der Jungen Union zu verdanken ${ }^{414}$. Diese „Kampfgruppe Müller“, der an führender Stelle Fritz Zimmermann angehörte, versuchte in einer konzertierten Aktion, so viele Delegierte wie möglich im persönlichen Gespräch für den Ochsensepp zu gewinnen. Dieser Coup, Müller zum Vorsitzenden eines Bezirksverbands küren zu lassen, der ihm bis 1949 mit schärfster Opposition begegnet war, zeigt, daß es wenigstens eine kleine Chance für ein Comeback gegeben hätte. Doch langfristig geplante, mühselige Kleinarbeit war etwas, was Müller ganz und gar nicht lag, ganz abgesehen davon, daß seine Widersacher hellhörig geworden waren und jede Aktion argwöhnisch verfolgten ${ }^{415}$.

Der Erfolg in München war aber nur ein Strohfeuer, das schnell wieder erlosch, und schon ein Jahr später mußte Müller einen entscheidenden Rückschlag hinnehmen, von dem er sich nicht mehr erholte. Die Rede ist von der Affäre um Philipp Auerbach, den kommissarischen Leiter des bayerischen Landesentschädigungsamts, die Josef Müller sein Amt als Justizminister kostete. Auerbach, ein Intimfeind Müllers, wurde im März 1951 verhaftet und wegen unberechtigter Führung eines Doktortitels, Unterschlagung öffentlicher Gelder, Nötigung, versuchter Erpressung und anderer Delikte angeklagt $^{416}$. Im Zuge des Verfahrens gegen Auerbach, in dem auch der bayerische Landesrabbiner Aaron Ohrenstein zu den Angeklagten gehörte, wurden Vorwürfe laut, Justizminister Müller habe aus einem zwielichtigen Sonderfonds des Landesentschädigungsamts $40000 \mathrm{DM}$ erhalten und sei somit in eine Affäre verstrickt, die die ihm unterstellten Behörden aufklären sollten ${ }^{417}$. Müller dementierte, jemals von Auerbach Geld aus Mitteln des Landesentschädigungsamtes bekommen zu haben, gab aber zu, 1950 von Ohrenstein eine Spende von 20000 DM angenommen zu haben, von denen er $15000 \mathrm{DM}$ für politische und 5000 für caritative Zwecke verwendet habe. $15000 \mathrm{DM}$ habe er jedoch an Ohrenstein zurückgegeben, nachdem die Vorwürfe gegen ihn bekannt geworden seien.

Diese - wenn man so will - frühe Parteispendenaffäre war für Alois Hundhammer ein willkommener Anlaß, erneut zur Attacke gegen den Ochsensepp zu blasen. Hundhammer verfolgte dabei allerdings nicht nur persönliche Ziele. Wenn es ihm gelang, den Justizminister zu stürzen, der als eine der Schlüsselfiguren der großen Koalition galt, dann zerbrach vielleicht auch das ungeliebte Regierungsbündnis von CSU und

vorsitzenden auf das Jahr 1952, die sich bei Mintzel, Anatomie, S. 540 f. Anm. 2, Hettler, Josef Müller, S. 426, und Geschichte einer Volkspartei, S. 682, findet, ist falsch.

${ }^{414}$ Erinnerungsinterview mit Friedrich Zimmermann, in: Geschichte einer Volkspartei, S. 622; das folgende Zitat ebenda.

415 ACSP, CSU-LTF II/1, 15-20, Rundschreiben der JU Oberbayern, gez. Ludwig Huber, an alle Kreisvorsitzenden im Bezirk vom 13. 9. 1952.

416 Vgl. Constantin Goschler, Der Fall Philipp Auerbach. Wiedergutmachung in Bayern, in: Ludolf Herbst, Constantin Goschler (Hrsg.), Wiedergutmachung in der Bundesrepublik Deutschland, München 1989, S. 77-98, hier S. 90 und S. 96 f.

417 ACSP, CSU-LTF II/1, 15-14, Protokolle der Fraktionssitzungen am 18. 2., 5. 4. und 14. 5.1952 sowie Protokoll der gemeinsamen Sitzung von Landtagsfraktion, Landesgruppe und Landesvorstand am 21. 4. 1952; Stenographischer Bericht über die 84. Sitzung des Landtags am 7. 5. 1952, S. 20032007. Zur Verwendung des Geldes durch Müller vgl. ACSP, CSU-LSG, Ordner Müller - Hundhammer 1952, Bericht einer Prüfungskommission des CSU-Bezirksverbands München vom 27. 6. 1952. Ein Aufsatz über Josef Müller und die Affäre Auerbach ist in Vorbereitung. 
SPD und machte einer Koalition von CSU und Bayernpartei Platz ${ }^{418}$. Hundhammer sorgte durch gezielte Indiskretionen dafür, daß Müller nicht aus den Schlagzeilen kam, und forderte öffentlich seinen Rücktritt ${ }^{419}$. Für kurze Zeit schien es so, als würden die mühsam eingedämmten Machtkämpfe zwischen den verschiedenen Lagern in der CSU wieder ausbrechen und Ehards halbwegs erfolgreiche Politik der Befriedung und Konsolidierung zunichte machen ${ }^{420}$. Doch der Unmut der Parteibasis richtete sich rasch gegen die beiden Kampfhähne ${ }^{421}$. Hundhammer isolierte sich durch sein rücksichtsloses Vorgehen selbst ${ }^{422}$, und auch Müller hatte - bei allem Verständnis, das man ihm entgegenbrachte ${ }^{423}$ - nicht mehr viele Freunde in der CSU, die vorbehaltlos für ihn in die Bresche gesprungen wären. Offensichtlich war es den meisten Politikern der bayerischen Unionspartei wichtiger, den instabilen Burgfrieden aufrechtzuerhalten, als noch einmal die Schlachten der Vergangenheit zu schlagen. Franz Josef Strauß verlieh dieser Stimmung Ausdruck, als er in einer gemeinsamen Sitzung von Landesvorstand, Landtagsfraktion und Landesgruppe zornig ausrief: „Wir wollen einmal unsere Ruhe haben von diesem Dreck in unserer Partei, daß man entweder im Sog von Hundhammer und Müller oder von Juden in solche Drecksgeschichten gezogen wird. “424 Der mittelfränkische Landtagsabgeordnete Georg Mack hieb in dieselbe Kerbe: „Ich bedauere nur“, erklärte er seinen Fraktionskollegen, „daß die Brandstifter noch so ungehindert wirken“ können. Auch Müller werde „einsehen müssen, dass er nicht mehr das ist, was er einmal war" ${ }^{425}$.

Der Druck auf den Justizminister wuchs. Zu den Anfeindungen aus der eigenen Partei kamen parlamentarische Interpellationen der Oppositionsparteien und schließlich Rücktrittsforderungen aus den Reihen der Koalitionspartner ${ }^{426}$. Nachdem sich Müller im Landtag und im Untersuchungsausschuß zu den Vorgängen im Landesentschädigungsamt nicht gerade klug verhalten hatte ${ }^{427}$, blieb Ehard nichts anderes mehr übrig,

418 Vgl. Gelberg, Hans Ehard, S. $403 \mathrm{f}$.

419 Münchner Merkur vom 5./6. 4. 1952: „Hundhammer fordert Rücktritt Müllers. ,Im Interesse der Unantastbarkeit der Staatsführung" - Schreiben an Dr. Ehard veröffentlicht“; SZ vom 8. 4. 1952; „Im Dschungel der bayerischen Politik. Josef Müllers dunkle Geldquellen - Alois Hundhammers Verschwörung gegen die Große Koalition. Ein chronologischer Bericht in Dokumenten“.

420 ACSP, CSU-LTF II/1, 15-14, Protokoll der gemeinsamen Sitzung von Landtagsfraktion, Landesgruppe und Landesvorstand am 21. 4. 1952.

421 ACSP, CSU-LSG, Ordner Müller - Hundhammer 1952, Resolutionen der CSU-Kreisverbände Landshut-Stadt, Weilheim und Schongau vom 9. 4., 27. 4. und 19. 5. 1952.

422 Sogar Georg Meixner bemerkte: „Ich halte es für absolut unmöglich, daß solche parteiinternen Dinge an die Öffentlichkeit getragen werden. Der Landtagspräsident [Alois Hundhammer] täusche sich darüber nicht, die Reaktion im Land draussen ist verheerend für die Partei und für ihn persönlich. Ich sage das nicht leichthin, von allen Seiten kommt nur Empörung und Entrüstung. " ACSP, CSULTF II/1, 15-14, Protokoll der gemeinsamen Sitzung von Landtagsfraktion, Landesgruppe und Landesvorstand am 21. 4. 1952.

423 ACSP, CSU-LSG, Ordner Müller - Hundhammer 1952, Erklärung der CSU-Landtagsfraktion vom 5. 4.1952.

424 ACSP, CSU-LTF II/1, 15-14, Protokoll der gemeinsamen Sitzung von Landtagsfraktion, Landesgruppe und Landesvorstand am 21. 4. 1952.

425 ACSP, CSU-LTF II/1, 15-14, Protokoll der Fraktionssitzung am 14. 5. 1952.

+26 Stenographischer Bericht über die 84. Sitzung des Landtags am 7. 5. 1952, S. 2003-2027; Stenographischer Bericht über die 85. Sitzung des Landtags am 8.5. 1952, S. 2029-2042; ACSP, CSU-LTF II/1, 15-14, Protokoll der Fraktionssitzung am 14. 5. 1952.

427 Der Spiegel vom 7. 5. 1952: „Den Fußtritt geben“, vom 14. 5. 1952: „Christliche Nächstenliebe“, vom 4. 6. 1952: „Ochsen-Sepp: Amt zur Verfügung“. Zur Tätigkeit des parlamentarischen Untersuchungsausschusses vgl. Plöhn, Untersuchungsausschüsse, S. 246-257. ACSP, NL Seidel 19, Hanns Seidel an Hildegunde Feilner vom 20.5. und 30.5. 1952. Am 30. 5. schrieb der Wirtschaftsminister 
als seinen Justizminister zur Demission aufzufordern, wollte er eine Regierungskrise vermeiden. Müller kam diesem Ersuchen nach und bat den Ministerpräsidenten am 26. Mai 1952 um seine Entlassung, die Ehard einen Tag später vollzog ${ }^{428}$.

Nach seinem Ausscheiden aus dem Kabinett wurde Müller in der CSU endgültig zu einer Randfigur. Er gehörte zwar weiterhin dem Landtag und dem Landesvorstand an, die wichtigen Entscheidungen aber wurden ohne ihn getroffen. Dennoch ließen ihn seine Gegner nicht aus den Augen. In der Staatskanzlei wurden die Aktivitäten und öffentlichen Auftritte des geheimnisumwitterten Ochsensepp mit Argusaugen beobachtet $^{429}$, und es gibt sogar Hinweise darauf, daß Innenminister Hoegner seinen ehemaligen Ministerkollegen zeitweise vom Verfassungsschutz observieren ließ ${ }^{430}$. Noch 1954 berichtete die Presse über Müllers politischen Salon in der Gedonstraße, in dem sich angeblich illustre Gäste trafen und von dem „weit gesponnene Fäden“ ausgingen, die „dem ehemaligen Abwehrmann ein politisches Spiel mit hohem Einsatz" erlaubten ${ }^{431}$. Doch da war Müllers große Zeit vorbei. Als er 1955 noch einmal seine Ambitionen auf den Parteivorsitz anmeldete, mußte er erkennen, daß in der Partei, die er einst aus der Taufe gehoben hatte, längst andere den Ton angaben.

Seit 1949 war es um Müller immer einsamer geworden. Von dem einst gefürchteten Müller-Flügel der CSU, dessen Zerfall schon 1948 begonnen hatte, waren bald nur noch isolierte Zirkel übrig, denen profilierte Führungsfiguren fehlten und die kaum Einfluß auf die Entwicklung der Partei nehmen konnten. Alois Hundhammer konnte bereits Ende 1949 zufrieden feststellen, die „sogenannten ,Kreise und Grüppchen in der CSU“ hätten ein für alle Mal ausgespielt und auch der Gautinger Kreis um den Müller-treuen Karl Köhler sei inzwischen „zur Bedeutungslosigkeit herabgesunken “432. Wie rasch die Partei in der Ära Ehard ihr Gesicht zu verändern begann, zeigt ein Blick auf die Zusammensetzung des Landesvorstands. Unter den 48 Personen, die 1951 den Parteivorstand bildeten, waren lediglich 21 - also nicht einmal 44 Prozent -, die diesem Gremium schon 1948 angehört hatten ${ }^{433}$. Es fällt auf, daß es vor allem prominente Mitstreiter Josef Müllers wie Georg Barth, Georg Gamperl, Franz Liedig oder Eugen Rindt waren, die ihren Platz im Landesvorstand räumen mußten, ein Indiz da-

kopfschüttelnd an seine Vertraute: „Müller ist nicht gestürzt worden; er hat sich selbst gestürzt. Die Presse ist tief enttäuscht, nicht über die Dinge, die man Müller vorwirft, sondern über die Ungeschicklichkeit, mit der er taktiert hat. Sie war wirklich nicht zu übertreffen. Es rührt daher, dass er, wie so oft, die Realität falsch beurteilt hat."

${ }^{428}$ ACSP, CSU-LTF II/1, 15-14, Protokoll der Fraktionssitzung am 28. 5. 1951; Stenographischer Bericht über die 90. Sitzung des Landtags am 5. 6. 1952, S. 2203. Die Angelegenheit wurde in den folgenden Wochen vor dem Landesschiedsgericht der CSU verhandelt. Das Verfahren endete mit einer Verwarnung für die beiden Kontrahenten Müller und Hundhammer. ACSP, CSU-LSG, Ordner Müller - Hundhammer 1952, Protokoll der Sitzung des Landesschiedsgerichts der CSU am 7.6. 1952 und Schiedsspruch des Landesschiedsgerichts der CSU vom 1. 7. 1952.

429 Beispielsweise BayHStA, NL Ehard 139, Aktennotiz Ernst Deuerleins für Hans Ehard vom 14. 1. 1953.

${ }^{430}$ BayHStA, NL Ehard 139, Bayerisches Landesamt für Verfassungsschutz, gez. Regierungsdirektor Kurz, an Wilhelm Hoegner vom 20. 2. 1953.

431 Sonntagspost vom 29. 4. 1954: „Hinter geschlossenen Gardinen... Der Salon in der Gedonstraße ist Treffpunkt der Freunde Dr. Josef Müllers - Ein Blick in das Kulissenspiel des großen Taktikers“ (Zeitungsausschnitt im ACSP, CSU-LTF II/2, 6-41).

432 NA, RG 466, OLCB, Land Commissioner's Central Files, Box 11- Political Movements 1949-28. 2. 1950, „Subject: Bezirksversammlung der CSU-Oberbayern“ vom 3.11. 1949.

${ }^{433}$ BayHStA, NL Ehard 64, Liste der Mitglieder des Landesvorstands der CSU vom 10. 3. 1951; Mintzel, Anatomie, S. 686-720; die Zahlenangaben beruhen auf einer eigenen Auszählung. 
für, wieviele Anhänger Müllers nach 1949 resignierten oder ohne Perspektive an den Rand gedrängt wurden. Wenn sie nicht aus der CSU austraten, so verloren sie meist schnell ihre Ämter und blieben einfache Mitglieder, die keine größeren Aktivitäten entfalteten. Der Verlust der liberalen, protestantischen oder nationalkonservativen Kräfte, die 1945/1946 mühsam für die CSU hatten gewonnen werden müssen, löste aber nicht nur Bedauern aus, im Gegenteil. Hundhammer stellte wiederholt mit „Befriedigung “ fest, daß die „innere Kraft" von Partei und Fraktion gewachsen sei, nachdem „sehr viele Randfiguren abgestossen worden“ $\operatorname{seien}^{434}$.

$\mathrm{Zu}$ diesen Randfiguren zählte Hundhammer beispielsweise August Haußleiter, der seinen katholisch-konservativen Parteifreunden als Sprecher der Protestanten, als „Gehirn“ des Müller-Flügels ${ }^{435}$ und als "Giftbeule“ der CSU ${ }^{436}$ besonders verhaßt war. Obwohl Haußleiter 1946 das Aktionsprogramm der Partei verfaßt hatte und seit Februar 1948 das Amt eines stellvertretenden Landesvorsitzenden bekleidete, blieb er in der CSU im Grunde genommen ein Außenseiter. Seine gesamtdeutsch-nationalistischen, neutralistischen und teilweise sozial-revolutionären Überzeugungen hatten in der CSU keinen Platz ${ }^{437}$, zudem überwarf er sich im Herbst 1948 mit Josef Müller, der ihn lange gefördert hatte. Nach dem Sturz des Ochsensepp war es so nur noch eine Frage der Zeit, wann Haußleiter der CSU den Rücken kehren würde, zumal er in der neu gegründeten Deutschen Union ein Sprungbrett für eine Fortsetzung seiner politischen Karriere gefunden zu haben schien. Haußleiter versuchte zwar nach der Straubinger Landesversammlung noch einmal, die Entwicklung der CSU in seinem Sinne zu beeinflussen und eine Ablösung von Alois Hundhammer als Fraktionschef zu erzwingen ${ }^{438}$. Als dieser Vorstoß scheiterte, legte er zunächst sein Amt als stellvertretender Parteivorsitzender nieder und trat am 20. September 1949 endgültig aus der CSU aus ${ }^{439}$.

August Haußleiter war aber beileibe nicht der einzige, der nach der Entscheidung von Straubing in der Union keine Perspektive mehr sah, aus Führungspositionen ausschied oder rasch in Vergessenheit geriet. Elisabeth Meyer-Spreckels etwa, die bekannte evangelische Politikerin aus Fürth, zog sich Ende August 1949 aus Protest gegen den Führungsstil des neuen Landesvorsitzenden und die Behandlung der Protestanten in der CSU aus dem geschäftsführenden Landesvorstand zurück ${ }^{440}$. Eugen Rindt, als Vorsitzender der Bezirksverbände Augsburg und Schwaben und Stellvertreter Hundhammers in der Landtagsfraktion einst überaus einflußreich, wurde mehr oder weniger gezwungen, aus der CSU auszutreten, als er dubioser Geschäfte und zweifelhafter finan-

434 BSB, NL Schwend 48, „Niederschrift über Dr. Hundhammers Erklärungen vor der Arbeitsgemeinschaft der Katholischen Publizisten in München (19. Januar 1952)“; ACSP, CSU-LL, Protokoll der Landesversammlung der CSU am 17./18.6. 1950 in Kempten.

${ }^{435}$ Münchner Merkur vom 22. 9. 1949: "Haußleiters Ausscheiden ohne Folgen?“.

${ }^{436}$ ACSP, CSU-LTF I, 15-14, Protokoll der Fraktionssitzung am 14. 9. 1949 (Hans Hagn).

437 Vgl. Stöss, Vom Nationalismus zum Umweltschutz, S. 65-93.

438 Vgl. S. 335-339.

439 BayHStA, NL Ehard 1019, August Haußleiter an Hans Ehard vom 22. 6., 12. 9. und 20. 9.1949 und Hans Ehard an August Haußleiter vom 23. 6. und 30. 9. 1949; ACSP, CSU-LL, Protokolle der Sitzungen des geschäftsführenden Landesvorstands am 28.6. und 5.12. 1949; BayHStA, NL Ehard 102, Protokoll der Sitzung des geschäftsführenden Landesvorstands am 3. 10. 1949.

440 ACSP, CSU-LTF I, 2-30, Elisabeth Meyer-Spreckels an Alois Hundhammer vom 23. 8. 1949; ACSP, NL Müller 168, Elisabeth Meyer-Spreckels an Hans Ehard vom 29. 8. 1949 und Elisabeth MeyerSpreckels an Josef Müller vom 16. 9. 1949; vgl. auch Kühnel, Fränkischer Protestantismus, S. 54 ff. 
zieller Transaktionen beschuldigt wurde ${ }^{441}$. Der Fall Rindt, so erklärte Karl Sigmund Mayr im Juni 1950 vor dem Landesvorstand, beweise die „Notwendigkeit“ der rechtzeitigen „Säuberung der Partei von unehrenhaften Elementen“"442. Es gab sicherlich Fälle, in denen ein solches Vorgehen berechtigt war; in anderen Fällen kann man sich jedoch des Eindrucks nicht erwehren, daß unter dem Deckmantel der politischen Moral nach 1949 alte Rechnungen beglichen wurden, die aus der Zeit der Führungs- und Flügelkämpfe offengeblieben waren.

\section{b) Konfessionelle Konflikte und die Gründung des Evangelischen Arbeitskreises $\operatorname{der} \mathrm{CSU}$}

Der Exodus prominenter evangelischer Mitbegründer der CSU stellte die Partei vor besondere Probleme. Nach August Haußleiter und Elisabeth Meyer-Spreckels verschwanden auch andere bekannte Protestanten aus den Gründungstagen mehr und mehr in der Versenkung. Friedrich Wilhelm von Prittwitz und Gaffron legte 1951 sein Amt als stellvertretender Vorsitzender der Landtagsfraktion nieder, als sich die Abgeordneten für den katholischen Geistlichen Georg Meixner als neuen Fraktionschef entschieden ${ }^{443}$. Johannes Semler war zwar 1950 bei einer Nachwahl im Bundeswahlkreis Kulmbach erfolgreich ${ }^{44}$, konnte aber den Kurs der CSU nicht wesentlich beeinflussen und zog sich 1953 aus der Politik zurück. Der Theologe Hermann Strathmann verlor 1950 sein Landtagsmandat und trat 1954 nach enervierenden Querelen aus der CSU aus ${ }^{445}$.

Der Abgang protestantischer Symbolfiguren führte bei den evangelischen Anhängern der CSU ebenso zu Verunsicherung und Mißtrauen wie die Tatsache, daß Josef Müller, der Bannerträger des interkonfessionellen Gedankens, nach der Wahl Hans Ehards zum Landesvorsitzenden Zug um Zug an Einfluß verlor und mit Alois Hundhammer, Georg Meixner oder Josef Schwalber Politiker in den Vordergrund traten, die eindeutig auf eine katholisch-konfessionelle Linie festgelegt zu sein schienen ${ }^{446}$. Das Gros der Protestanten Frankens sei „stark von dem Gedanken bewegt, daß nun die CSU völlig in die Abhängigkeit des Herrn Dr. Hundhammer geraten" sei, schrieb Julius Zirkelbach vom Politischen Arbeitskreis evangelischer Christen Ende Mai 1949 an Hans Ehard. Die CSU werde in Franken große Verluste erleiden, so Zirkelbach weiter, „wenn nicht der gegenreformatorische Kurs des Herrn Dr. Hundhammer [...] sein Ende findet “447. Im Kreuzfeuer der Kritik stand insbesondere die Personalpolitik

44i Materialien zum Fall Rindt in: BayHStA, NL Ehard 115, NL Ehard 850, NL Ehard 1362, NL Ehard 1363; BSB, NL Schwend 2; ACSP, CSU-LL, Protokolle der Sitzungen des geschäftsführenden Landesvorstands am 4. 2. und 25. 7. 1950 und Protokoll der Sitzung des Landesvorstands am 9. 6. 1950; ACSP, CSU-LTF II/1, 15-14, Protokoll der Fraktionssitzung am 5. 12. 1951.

442 ACSP, CSU-LL, Protokoll der Sitzung des Landesvorstands am 9. 6. 1950.

443 ACSP, CSU-LTF II/1, 15-14, Protokoll der Fraktionssitzung am 8. 8. 1951.

${ }^{444}$ Semler trat als gemeinsamer Kandidat von CSU, FDP und BP an und eroberte diesen Wahlkreis, der 1949 noch einen SPD-Politiker nach Bonn entsandt hatte. BSB, NL Schwend 2, Bericht der CSULandesgeschäftsstelle über die Nachwahl im Bundeswahlkreis Kulmbach vom 18. 5. 1950.

445 Zeitungsausschnitte, Korrespondenzen und Informationsmaterialien zum Fall Strathmann finden sich in: BSB, NL Schwend 15; ACSP, CSU-LTF II/2, 5-50; ACDP, NL Ehlers 10/1. Vgl. auch Anzeneder/Götz, 50 Jahre CSU in Erlangen, S. 106-112.

446 ACSP, NL Müller 52, Schreiben des Kirchenrats Adolf Kaeppel vom 26. 8. 1950.

447 BSB, NL Schwend 2, Politischer Arbeitskreis evangelischer Christen, gez. Julius Zirkelbach, an Hans Ehard vom 31. 5. 1949. 
der bayerischen Staatsregierung und ihres Kultusministers, der bis Ende 1950 Hundhammer hieß. So sah sich Hermann Strathmann im November 1950, wenige Tage vor den Landtagswahlen, gezwungen, Hundhammer ins Gewissen zu reden und auf die Folgen seiner umstrittenen Personalentscheidungen aufmerksam zu machen:

„Ich würde etwas versäumen, wenn ich Sie nicht noch einmal mit allem Ernst auf diese Fragen hinwiese. Ich stosse immer wieder auf eine Erbitterung Ihnen gegenüber [. . .], die mich bisweilen tief erschreckt. Vor einigen Tagen erzählte mir [Gerhard] Kroll von einer Auseinandersetzung mit dem Jugendforum an der T. H. in München. Er war geradezu erschlagen. Vor einigen Tagen schüttete mir hier ein bis dahin Unbekannter sein Herz aus. Weissglut! Lieber Herr Minister, Sie wissen gar nicht, was sie anrichten! Alles Mißtrauen, aller Grimm hier in Franken richtet sich nur gegen Sie. Das ist so. Und zwar, weil man überall unter Hinweis auf Einzelerlebnisse überzeugt ist, dass Sie in Ihren personalpolitischen Entscheidungen von konfessioneller Voreingenommenheit nicht frei sind. “448

Es war jedoch nicht nur der Unmut über die tatsächliche oder angebliche Benachteiligung der evangelischen Seite bei der Besetzung von Staats-, Verwaltungs- und Parteiämtern ${ }^{49}$, der in den frühen fünfziger Jahren das Verhältnis der Konfessionen zunehmend belastete und das historisch gewachsene Mißtrauen zwischen Katholiken und Protestanten schürte. Auch die politischen, gesellschaftlichen und ökonomischen Rahmenbedingungen, die auf die Beziehung der Kirchen und der Gläubigen nicht ohne Einfluß blieben, hatten sich gegenüber 1945 erheblich verändert. Als die CSU wenige Monate nach Kriegsende gegründet worden war, war das Klima für eine Zusammenarbeit von katholischen und evangelischen Christen günstig gewesen. Die Schreckensherrschaft des Nationalsozialismus hatte auch bei den Kirchen tiefe Spuren hinterlassen und trug entscheidend dazu bei, daß die Sprachlosigkeit zwischen den Konfessionen zumindest teilweise überwunden werden konnte. Die Wirren der unmittelbaren Nachkriegszeit, die Not der Heimatvertriebenen und Ausgebombten und die verbreitete geistige Orientierungslosigkeit taten ein übriges, um die Gegensätze zwischen $\mathrm{Ka}$ tholiken und Protestanten zurücktreten zu lassen. Nach der Gründung der Bundesrepublik begann sich die Situation jedoch allmählich zu normalisieren, und damit gab es wieder Raum für Auseinandersetzungen in Sach- und Personalfragen, die man schon fast für obsolet gehalten hatte ${ }^{450}$. Der Kölner Erzbischof Josef Kardinal Frings hatte dies klar erkannt, als er im August 1953 nach einer Reihe von unerfreulichen konfessionellen Zwischenfällen Bilanz zog:

„Das brüderliche Verhältnis, das der Kirchenkampf des Nationalsozialismus heraufgeführt hatte, ist entstanden in einer in mancher Hinsicht anormalen Situation, die heute weitgehend geschwunden ist. Beide Konfessionen waren möglichst aus dem Raum der Öffentlichkeit verdrängt, so daß manche Reibungsflächen weggefallen waren. [.. .] Die Freude über die im Kirchenkampf gefundene und erfahrene Gemeinsamkeit hatte Erwartungen lebendig werden lassen, die unwirklich waren und sich

448 ACSP, CSU-LTF I, 15-12/1, Hermann Strathmann an Alois Hundhammer vom 12. 11. 1950.

449 Beispielsweise BayHStA, StK 114082, Entschließung der evangelischen Kirchenvorsteher des Dekanats Uffenheim vom 26. 6. 1949, Dekanat Uffenheim an das Landratsamt Uffenheim vom 27.6. 1949 und Schreiben des Dekanats Uffenheim, im Abdruck an Hans Ehard, vom 27. 6. 1949.

450 Einen gerafften Überlick über die Situation des Katholizismus und des Protestantismus in den fünfziger Jahren bieten die Aufsätze von Karl Gabriel, Die Katholiken in den 50er Jahren: Restauration, Modernisierung und beginnende Auflösung eines konfessionellen Milieus, in: Axel Schildt, Arnold Sywottek (Hrsg.), Modernisierung im Wiederaufbau. Die westdeutsche Gesellschaft der 50er Jahre, Bonn 1993, S. 418-430, und von Christoph Kleßmann, Kontinuitäten und Veränderungen im protestantischen Milieu, in: ebenda, S. 403-417. 
über Verschiedenheiten in Grundanschauungen und in konkreten Anliegen hinwegtäuschten, die sofort aufbrechen mußten, wo wieder die Gelegenheit sich bot, Grundanschauungen und Anliegen zu verwirklichen. Die sichtbar gewordenen Spannungen sind in mancher Hinsicht nur Ausdruck einer Desillusionierung, die nach Ende des Kirchenkampfes notwendig eintreten mußte. “451

Auch in Bayern begann sich das Verhältnis der beiden großen christlichen Konfessionen merklich abzukühlen, und die Evangelische Landeskirche ging dementsprechend auf größere Distanz zur katholisch dominierten $\mathrm{CSU}^{452}$. Die Spannungen und Meinungsverschiedenheiten zwischen der Kirchenleitung und Spitzenpolitikern der bayerischen Unionspartei wirkten sich jedoch unmittelbar negativ auf das Verhältnis von katholischen und evangelischen Christen in der CSU aus. Schließlich waren gerade die aktivsten Protestanten in der CSU eng mit der Landeskirche verbunden, und es ist kaum denkbar, daß sie sich bei einem Veto des Landesbischofs oder des Landeskirchenrats weiter für die Union hätten einsetzen können. Die führenden evangelischen CSU-Politiker befanden sich zweifellos in einem Dilemma. Einerseits mußten sie die Unionsidee glaubwürdig nach außen vertreten und ihre Partei gegen Angriffe verteidigen, andererseits wußten sie um die Berechtigung mancher Vorwürfe und um die Schwäche ihrer eigenen Position. Wie schwer sich das Häuflein protestantischer Politiker nach dem Sturz Josef Müllers tat, zwischen ihrer Partei und der Landeskirche zu vermitteln, zeigte sich in einem Gespräch zwischen zwölf evangelischen CSU-Mitgliedern und Bischof Hans Meiser, an dem unter anderem Alfred Euerl, Elisabeth MeyerSpreckels und Karl Sigmund Mayr teilnahmen. Mayr, 1950 als Nachfolger des ausgetretenen August Haußleiter zum stellvertretenden Landesvorsitzenden gewählt ${ }^{453}$, war von Meisers Ausführungen so schockiert, daß er fast zwei Wochen verstreichen ließ, bis er den Mut fand, Hans Ehard über die Aussprache zu informieren:

„Der Herr Landesbischof erteilte mir das Wort, und so war es zunächst meine Aufgabe, die Wünsche und Anregungen der evangelischen Freunde der CSU vorzutragen. Nach einem Bekenntnis zum Unionsgedanken bat ich den Herrn Landesbischof, uns in der Schaffung einer geschlossenen evangelischen Front zu unterstützen [. . .]. Ein Zerbrechen der Union in Bayern würde die christliche Front in der Bundesrepublik erschüttern zum Schaden der Politik auf christlicher Grundlage. Ich beklagte mich u. a., dass wir evangelischen Politiker nicht nur keine Unterstützung erhielten, sondern wiederholt uns gegen Angriffe aus kirchlichen Kreisen [...] wehren $m[\ddot{u}]$ ssten, und ich beklagte mich über die zunehmende Intoleranz in evangelischen Gegenden, die so weit gehe, dass man einem evangelischen Kandidaten nur deshalb seine Stimme versage, weil er sich zum Unionsgedanken bekenne (Bundestagswahl). Nach diesen und ähnlichen Ausführungen gab der Herr Landesbischof zum Teil mit sehr harten und heftigen Worten dem Sinne nach folgende Erwiderung: Sie, die evangelischen Politiker in der CSU, verkennen Ursache und Wirkung. Während die evang. luth. Kirche unter dem Haus Wittelsbach wirklich königlich und unter der Regierung der [B]ayerischen Volkspartei gut behandelt wurde, fühlt sie sich von der Regierung, welche die Christlich-Soziale Union bildet, fortgesetzt zurückgesetzt, vernachlässigt und übergangen. [...] Der Herr Landesbischof und seine Mitarbeiter versicherten, dass der überwiegende Teil der

451 Rede Josef Kardinal Frings' auf der Fuldaer Bischofskonferenz im August 1953, abgedruckt als Quellenanhang zu: Norbert Trippen, Interkonfessionelle Irritationen in den ersten Jahren der Bundesrepublik Deutschland, in: Karl Dietrich Bracher u. a. (Hrsg.), Staat und Parteien. Festschrift für Rudolf Morsey zum 65. Geburtstag, Berlin 1992, S. 345-377, hier S. 361.

452 Zum Verhältnis von Evangelischer Landeskirche und CSU in der Ära Ehard vgl. Renner, Nachkriegsprotestantismus, S. 33-52; Kühnel, Fränkischer Protestantismus, S. 25-83; Müller, Schulpolitik, S. $281 \mathrm{ff}$.

453 Karl Sigmund Mayr wurde während der Tagung des Landesausschusses am 14./15. 1. 1950 in Fürth zum stellvertretenden Landesvorsitzenden gewählt. SZ vom 16.1. 1950: „Ost-West-Problem in Fürth betrachtet. Tagung des CSU-Landesausschusses/,Orientierung nach der Mitte““. 
evangelischen Bevölkerung sich im Jahre 1946 im guten Glauben zur Union bekannt habe. Die Zusammensetzung der Regierung [...] war die erste Enttäuschung. Und die einseitige und kurzsichtige Politik des Herrn Dr. Hundhammer und seiner Freunde, die in allen Ministerien in seinem Sinne gearbeitet haben, hat eine bittere Enttäuschung hervorgerufen. ,Die gegen uns gerichtete Politik ist unaufrichtig und verfolge eine planmässige Zurücksetzung', sagte der Herr Landesbischof wörtlich. Zu Frau Dr. Meyer-Spreckels und mir sprach er unter 6 Augen Vorwürfe und Anklagen aus von einer nie gehörten Bitterkeit, die Frau Dr. Meyer-Spreckels und mich zutiefst erschreckte. “454

Der Unmut des Landesbischofs und seine Unzufriedenheit mit der CSU kam nicht von ungefähr, denn die Partei war in der Ära Ehard weit von einer wirklichen Union katholischer und evangelischer Christen entfernt. Wie sehr die Protestanten in der Minderheit waren, zeigt ein Blick auf die konfessionelle Zusammensetzung der Landesgruppe im Bundestag, der Landtagsfraktion und der Regierungsmitglieder, die der CSU angehörten. Von den 24 Abgeordneten der CSU, die 1949 in den Bundestag gewählt worden waren, bekannten sich lediglich zwei zum evangelischen Glauben; mit Johannes Semler wurde 1950 noch ein dritter Protestant für die CSU in den Bundestag gewählt ${ }^{455}$. Unter den 1950 gewählten 64 Landtagsabgeordneten befanden sich lediglich sieben Protestanten; damit war der prozentuale Anteil der evangelischen Abgeordneten gegenüber dem ohnehin mageren Ergebnis von 1946 noch einmal zurückgegangen ${ }^{456}$. Von den Bundesministern der CSU in der ersten Legislaturperiode war keiner evangelisch, von den Regierungsmitgliedern der Union im zweiten und dritten Kabinett Ehard bekannte sich wenigstens je ein Staatssekretär zum evangelischen Glauben ${ }^{457}$.

Daß von der angestrebten konfessionellen Parität keine Rede sein konnte, lag jedoch nicht nur am bösen Willen der Katholiken in der CSU. Zwar lassen sich in den Quellen immer wieder Beispiele für die Benachteiligung der Protestanten bei Stellenbesetzungen und Kandidatenaufstellungen finden, oft blieb den zuständigen Gremien aber auch nichts anderes übrig, als sich für einen katholischen Bewerber zu entscheiden, $\mathrm{da}$ es einfach zu wenige evangelische Christen gab, die zu einer aktiven Mitarbeit in der CSU bereit gewesen wären. In den 18 Kreisverbänden der CSU im mehrheitlich protestantischen Regierungsbezirk Mittelfranken waren im Dezember 1953 keine 2200 zahlenden Mitglieder registriert. Der Bezirksverband Nürnberg-Fürth hatte nicht einmal 1000 Mitglieder, die ihre Beiträge an die Partei abführten, wobei die Kreisverbände Fürth-Stadt und Fürth-Land gerade einmal 56 bzw. 29 Mitglieder aufweisen konnten ${ }^{458}$.

Das Häuflein der evangelischen Christen in der CSU erlebte wiederholt unangenehme Überraschungen, die Zweifel am guten Willen der katholischen Parteifreunde auf-

${ }^{454}$ BayHStA, NL Pfeiffer 535, Karl Sigmund Mayr an Hans Ehard vom 23. 2. 1950.

455 Von den 24 CSU-Abgeordneten, die 1949 in den Bundestag gewählt worden waren, bekannten sich 18 zum katholischen und zwei zum evangelischen Glauben; die Konfessionszugehörigkeit von vier Abgeordneten ließ sich nicht ermitteln. Aufgrund eindeutiger Quellenbelege steht jedoch fest, daß kein weiterer Protestant darunter war.

456 Von den 64 CSU-Abgeordneten, die 1950 in den Landtag gewählt worden waren, bekannten sich 49 zum katholischen und sieben zum evangelischen Glauben; die Konfessionszugehörigkeit von acht Abgeordneten ist unbekannt. In den Quellen ist jedoch wiederholt nur von sieben Protestanten in der CSU-Fraktion die Rede.

457 Adam Sühler, 1947-1950 Staatssekretär im Staatsministerium für Ernährung, Landwirtschaft und Forsten, und Paul Nerreter, 1950-1954 Staatssekretär im Staatsministerium des Innern.

458 BayHStA, NL Ehard 646, Aufstellung über den Mitgliederstand der Bezirksverbände Mittelfranken und Nürnberg-Fürth (nur zahlende Mitglieder), Stand vom 31. 12. 1953. 
kommen ließen. So predigte Stadtpfarrer Karl Boeckl, der der CSU nahestand, in Vilshofen ex cathedra gegen eine Zusammenarbeit von Katholiken und Protestanten. Interkonfessionell, so verkündete er den Gläubigen, sei „soviel wie antichristlich“459. Für Hans Wutzlhofer, einen katholischen Mitbegründer der CSU, der vor 1933 zu den führenden BVP-Funktionären in der Oberpfalz gehört hatte, waren die Protestanten gar unzuverlässige „Stiefbrüder in Christo Jesu“460. Derartige Aussagen, die stets für Aufruhr sorgten, wenn sie bekannt wurden, ließen die Bekenntnisse führender CSU-Politiker zum Unionsgedanken nicht unbedingt glaubwürdiger erscheinen, schürten das ohnehin vorhandene Mißtrauen bei den evangelischen Anhängern und trieben nicht wenige in die Resignation. Man habe es „allmählich vollkommen satt, daß man uns immer mit ,christlich' kommt und nur ,katholisch' meint - nicht einen idealen und versöhnlichen Katholizismus, sondern den massiven Parteikatholizismus, der über alle unsere Leichen geht", schrieb der CSU-nahe evangelische Stadtpfarrer von Erlangen ebenso verbittert wie erzürnt an Hans Ehard ${ }^{461}$.

Die konfessionellen Spannungen drohten die Einheit der CSU zeitweise ernstlich zu gefährden. In Nürnberg beispielsweise kam es 1952 zu schweren Auseinandersetzungen, als nach dem Tod des evangelischen Bezirksvorsitzenden Hans Hassel mit Karl Schäfer ein Katholik an die Spitze des Bezirksverbands trat, der im Verdacht stand, einseitig für katholische Interessen einzutreten und „mit allen Mitteln" auf eine katholische Partei hinzuarbeiten. Die evangelischen und katholischen Stadträte der CSU kamen bereits zu getrennten Sitzungen zusammen, und beide Seiten drohten mehrfach damit, die CSU zu verlassen ${ }^{462}$. Eine weitere Eskalation des Konflikts konnte zwar verhindert werden, aber die Bilanz, die Karl Sigmund Mayr im September 1952 zog, war trotzdem niederschmetternd. Im Protokoll einer Aussprache von führenden evangelischen Politikern der Unionsparteien heißt es dazu:

„Was sich in Bayern auf dem Gebiet der Personalpolitik abspielt, bezeichnet Herr Mayr als tragisch. Das evangelische Franken würde planmäßig wirtschaftlich und politisch so abgeschnürt, daß es auf Dauer gesehen unerträglich würde, in der CSU zu arbeiten. [...] Herr Mayr habe mit Dr. Hans Ehard (der ev. verheiratet ist) ganz offen über diese Dinge gesprochen. Er gibt ihm mehr oder weniger recht, tut aber dann nichts, da er das Hundhammer gegenüber nicht wagt. Die ganze Lage in Bayern kann in dem Satz zusammengefaßt werden: ,In Bayern marschiert die Gegenreformation'. Vor 8 Wochen mußte mit größter Mühe verhindert werden, daß die evang. Stadträte von Nürnberg, Erlangen und Bayreuth sich von der CSU lösten, um nach außen hin noch die Union aufrechtzuerhalten. Wahrscheinlich wird die Union aber in Bayern zerbrechen. Das darf nicht vor der Bundestagswahl geschehen, weil es bis dahin nicht möglich wäre, sich zu sammeln und die finanziellen Mittel zu beschaffen, um einen eigenen Weg zu gehen. (Es besteht die Neigung, in Nordbayern die CDU mit evangelischem Kern aufzumachen.) «463

Eine Schlüsselfigur in den konfessionellen Streitigkeiten war zweifellos der Parteivorsitzende Hans Ehard, auf den die evangelischen CSU-Mitglieder vor allem deshalb zählten, weil er über den Verdacht erhaben war, ein klerikaler Katholik zu sein, und

459 ACSP, CSU-LTF I, 9-70, Karl Boeckl an Alois Hundhammer vom 21. 2. 1950.

${ }_{460}^{4}$ ACSP, CSU-LTF II/1, 15-20, Hans Wutzlhofer an Wilhelm Röhrl vom 18. 6. 1952.

461 BayHStA, NL Ehard 190, Evangelisches Pfarramt der Stadt Erlangen an Hans Ehard vom 11. 12. 1950.

${ }^{462}$ BSB, NL Schwend 13, Aktennotiz Ernst Deuerleins für Karl Schwend vom 9. 9. 1952 über eine Aussprache mit führenden CSU-Politikern aus Mittelfranken.

463 ACDP, NL Ehlers 02/1, Protokoll der Sitzung des geschäftsführenden Ausschusses des EAK der CDU/CSU am 29. 9. 1952. 
sich wiederholt öffentlich zum Unionsgedanken bekannt hatte ${ }^{464}$. Die Hoffnung der Protestanten, Ehard würde ihren besonderen Problemen wirkliches Verständnis entgegenbringen und ihre Anliegen fördern, wurde jedoch bald enttäuscht. „Die Art des Herrn Landesvors[itzenden], sich der Dinge anzunehmen, ist für uns untragbar und kann nicht hingenommen werden", hieß es in einem Schreiben, das an Pfarrer Alfons Kreußel ${ }^{465}$, einen führenden Repräsentanten der fränkisch-protestantischen Gruppe in der CSU, gerichtet war ${ }^{466}$. Und nach einer Konferenz, an der neben den wichtigsten Vertretern der Parteiführung vor allem evangelische CSU-Politiker teilgenommen hatten, berichtete Karl Gabler an Baron Georg von Manteuffel-Szoege, das Ergebnis sei nicht nennenswert gewesen, man habe sich aber des Eindrucks nicht erwehren können, daß Ehard die Probleme der Partei im protestantischen Franken einfach nicht sehe ${ }^{467}$.

Tatsächlich bemühte sich der Landesvorsitzende nicht nachdrücklich darum, das Klima zwischen katholischen und evangelischen Christen nachhaltig zu verbessern. Anstatt eine entschlossene Reformpolitik mit dem Ziel zu betreiben, die protestantische Bevölkerung für die Union zu gewinnen, begnügte er sich zumeist mit Lippenbekenntnissen. Wenn die schwelenden konfessionellen Streitigkeiten dann eskalierten, setzte Ehard auf Krisenmanagement und kurzfristige Zugeständnisse. Damit konnte die Parteiführung zwar immer wieder lokale Konfliktherde beseitigen, an den Grundproblemen änderte sich jedoch nichts. Karl Sigmund Mayr erklärte seinen evangelischen Parteifreunden im Mai 1953 deprimiert, es gebe offensichtlich eine Tendenz, „nur soviel oder gerade soviel“ für die Protestanten zu tun, „als notwendig sei, um sie gerade noch in der CSU zu halten ${ }^{\star 468}$.

Es kann kein Zweifel daran bestehen, daß viele bekenntnistreue evangelische Christen, die an und für sich dem bürgerlich-konservativen Lager zuneigten, von der CSU bitter enttäuscht waren und das Gefühl hatten, dem katholisch-konfessionellen Flügel der Union hilflos ausgeliefert zu sein. Aber gab es Alternativen? Neben Splittergruppen wie Haußleiters nationalistischer Deutscher Gemeinschaft versuchte vor allem die FDP, sich als Partei der Protestanten Frankens zu profilieren ${ }^{469}$. Diese Bemühungen waren jedoch nur teilweise erfolgreich, da bei der Evangelischen Landeskirche erhebliche Bedenken gegen die kultur- und schulpolitischen Vorstellungen der Liberalen

${ }^{464}$ Beispielsweise ACSP, CSU-LTF II/1, 15-12/3, Rede Hans Ehards vor der Evangelischen Akademie in Tutzing am 25. 1. 1952. Vgl. - mit anderer Akzentsetzung - auch Gelberg, Hans Ehard, S. $463 \mathrm{ff}$.

${ }^{465}$ Alfons Kreußel, geb. 7. 4. 1910 in Nürnberg, gest. 3. 4. 1963, ev., 1930 Abitur, anschließend Studium der evangelischen Theologie, Philosophie, Germanistik und Geschichte in Bonn, Leipzig und Erlangen, legte 1935 und 1937 beide landeskirchlichen Examina ab, zunächst Vikar, dann seit 1938 Religionslehrer in Regensburg, seit 1946 Pfarrer in Dinkelsbühl, seit 1954 Dozent für Religionslehre und Religionspädagogik an der Pädagogischen Hochschule in München-Pasing, Mitbegründer der CSU in Regensburg, Mitbegründer und 1952-1962 Vorsitzender des EAK der CSU, 1951-1963 Mitglied des Landesvorstands und 1952-1963 Mitglied des geschäftsführenden Landesvorstands der CSU, 1958-1963 MdL (CSU).

${ }^{466}$ ACSP, CSU-EAK 2, Mappe: Kreußel - allgemeine Korrespondenz 1953-1959, Karl Gabler an Alfons Kreußel vom 15.7. 1954; ähnlich auch das Schreiben Karl Gablers an Alfons Kreußel vom 29. 7. 1954 im selben Bestand.

467 ACSP, CSU-EAK 2, Mappe: Kreußel - allgemeine Korrespondenz 1953-1959, Karl Gabler an Georg von Manteuffel-Szoege vom 2. 8. 1954.

468 ACSP, CSU-EAK 6, Mappe: Kreußel - allgemeine Korrespondenz 1953-1958, Protokoll der Sitzung des EAK der CSU am 30. 5. 1953.

${ }^{469}$ Vgl. Kühnel, Fränkischer Protestantismus, S. 68, und Thränhardt, Wahlen und politische Strukturen, S. 316 und S. 320. 
bestanden ${ }^{470}$. In Anbetracht dieser unbefriedigenden Situation fand sich immer wieder eine Gruppe von Protestanten, die in der Gründung einer evangelischen Partei nach dem Muster des Christlich-Sozialen Volksdienstes der Weimarer Republik ${ }^{471}$ den einzigen Ausweg sahen. Im März 1949 wurde beispielsweise in Nürnberg ein Flugblatt verteilt, in dem die Gründung eines Evangelischen Volksdienstes mit folgenden Worten angekündigt wurde:

„Seit 1945 gibt es eine Partei für christliche Wähler, die CSU. Aber die letzten Jahre haben gezeigt, daß die CSU nicht das wurde, was man von ihr erhoffte, nämlich eine Partei für alle Christen. Vielmehr ist sie eine katholische Weltanschauungspartei geworden. Es ist das gute Recht des katholischen Volksteiles in Bayern, [seine] Interessen politisch zu vertreten. Aber bei dem Übergewicht desselben müssen die Evangelischen in Bayern dasselbe Recht für sich in Anspruch nehmen. Die Folge davon ist, daß die evangelischen Wähler der CSU [.. .] von ihr abwandern und durch die Gründung einer evangelischen Partei künftig zwei Parteien für die christlichen Wähler vorhanden sind, eine für den katholischen - und eine für den evangelischen Volksteil [...].“472

Verlief diese Initiative noch im Sande, so unternahmen die Protagonisten einer evangelischen Partei nach den Bundestagswahlen vom August 1949 einen neuen Anlauf. Diesmal riefen sie Evangelische Wählergemeinschaften ins Leben, die vor allem in Nürnberg und Umgebung, aber auch in Regensburg aktiv waren, Wahlempfehlungen für evangelische Kandidaten auf den Listen der etablierten Parteien abgaben und sich 1952 stellenweise selbst an den Kommunalwahlen beteiligten ${ }^{473}$. Im September 1952 wurde dann noch einmal versucht, einen Evangelischen Volksdienst als evangelischkonfessionell, sozial, deutsch und national ausgerichtete Partei aufzubauen ${ }^{474}$, wie es ihn schon in Teilen Hessens und Nordrhein-Westfalens gab ${ }^{475}$.

In der CSU nahm man solche Initiativen durchaus ernst ${ }^{476}$. Eine eigenständige evangelische Partei hätte den Unionsgedanken permanent und weithin sichtbar in Frage gestellt, von einer zu erwartenden Verschärfung der konfessionellen Spannungen ganz zu schweigen. Die Eröffnung einer neuen Front in Franken konnte sich die CSU jedoch keinesfalls leisten, hatte sie doch schon genug mit der BP in Altbayern zu tun. So ist es nicht verwunderlich, daß Hans Ehard schon wenige Wochen nach der Gründung des Evangelischen Volksdienstes vor dem Landesausschuß der CSU entschieden gegen die neue Partei Stellung nahm:

470 Vgl. Renner, Nachkriegsprotestantismus, S. 75-79.

471 Vgl. Günter Opitz, Der Christlich-soziale Volksdienst. Versuch einer protestantischen Partei in der Weimarer Republik, Düsseldorf 1969.

${ }^{472}$ Zit. nach Kühnel, Fränkischer Protestantismus, S. $57 \mathrm{f}$.

${ }^{473}$ BSB, NL Schwend 13, Aktennotiz Ernst Deuerleins für Karl Schwend vom 9. 9. 1952 über eine Aussprache mit führenden CSU-Politikern aus Mittelfranken; vgl. auch Kühnel, Fränkischer Protestantismus, S. 65-69.

474 BSB, NL Schwend 13, Julius Zirkelbach an Hans Ehard vom 22. 11. 1952.

475 Vgl. Kühnel, Fränkischer Protestantismus, S. 69-75.

${ }^{476}$ In einer Notiz für Ehards Stabschef Karl Schwend heißt es: „Der wieder gegründete [E]vangelische Volksdienst, der sich mit der Absicht trägt, evtl. als eigene Gruppe an den Bundestagswahlen 1953 teilzunehmen, entfaltet eine umfangreiche Aufklärungs- und Werbetätigkeit im westlichen Mittelfranken [.. .] Durch Broschüren und Flugblätter versucht er, vor allem in den evangelischen Pfarrhäusern und in den kirchlichen Organisationen den Gedanken zu verbreiten, dass eine Zusammenarbeit mit Katholiken auf die Dauer unmöglich ist. [.. . ] Angesichts der schwierigen Situation in Mittelfranken und einer sehr ernsten Resignation und Verstimmung in evangelischen CSU-Kreisen wird dem Gedanken des [E]vangelischen Volksdienstes ausserordentliche Beachtung geschenkt." BSB, NL Schwend 13, Aktennotiz Ernst Deuerleins für Karl Schwend vom 9. 9. 1952 über eine Aussprache mit führenden CSU-Politikern aus Mittelfranken. 
„Es erscheint [. . .] fraglich, ob der [.. .] Evangelische Volksdienst in der Lage ist, den politischen Zielen gerecht zu werden, die er sich selbst gestellt hat. Seine Gründung bedeutet zunächst eine Vermehrung der ohnedies vorhandenen Spannungen durch die Betonung konfessioneller Gegensätze. Es ist nicht notwendig, daran zu erinnern, daß die Christen in Deutschland in verschiedenen Kirchen beten. Als sie von einem terroristischen System des Nationalsozialismus bekämpft wurden, sprachen sie gemeinsam ihr Gebet und fanden, daß zwischen ihnen nicht nur Gräben der Verschiedenheit, sondern auch Brücken der Zusammengehörigkeit vorhanden sind. Aus dieser Erkenntnis erwuchs unsere politische Bewegung, die den ebenso kühnen wie geistig fortschrittlichen Versuch unternahm, im politischen Bereich alle zusammenzuführen, die sich ihrem christlichen Glauben verpflichtet fühlen und die in ihm eine entscheidende geistige Kraft für das deutsche Volk und die tragende Grundlage der europäischen Völk[er]gemeinschaft sehen. [...] Was allen im erhebenden Aufbruch des Jahres 1945 eigen war, war die tiefe Überzeugung, konfessionelle Gegensätze nicht zum Gegenstand politischer Auseinandersetzung zu machen und alle Fragen, über die auf Grund der konfessionellen Verschiedenheit Meinungsunterschiede auftreten könnten, im brüderlichen Geiste zu lösen. An diesem müssen wir festhalten, wenn wir uns weiterhin als christliche Demokraten bezeichnen wollen. [.. . ] Nicht nur vom parteipolitischen, sondern vor allem vom staatspolitischen Standpunkte aus ist es bedenklich, daß durch die Gründung des Evangelischen Volksdienstes der konfessionelle Gegensatz im Politischen erneut aufgerissen zu werden droht. [...] Unser Vertrauen zu unseren evangelischen Freunden in der CDU/CSU ist groß und uneingeschränkt. Wir zweifeln deshalb nicht, daß sie die Gefährlichkeit des mit der neuen Spaltung beschrittenen Weges erkennen und in gleicher Verbundenheit und Treue, wie bisher, festhalten an dem Gemeinsamen, das zu verwirklichen wir uns in der CSU vorgenommen haben. [...] Der Rückfall in Konfessionsparteien könnte zu einem politischen Erdrutsch führen, der den kirchlichen Bereich nicht unberührt lassen würde. Diese Feststellung trifft nicht nur für die inne[n]politischen Verhältnisse und für die Fragen der Kulturpolitik zu. Sie ist vor allem notwendig im Hinblick auf die außenpolitische Entscheidung, vornehmlich auf die außenpolitische Gefährdung. ${ }^{4}{ }^{777}$

Es waren jedoch weniger solche warnenden, beschwichtigenden und beschönigenden Worte aus der CSU als die Haltung der Landeskirche, die wesentlich dazu beitrug, daß die evangelischen Parteien nicht reüssierten. Bischof Meiser hatte wohl vorübergehend mit dem Gedanken an eine evangelische Partei gespielt, sich aber letztlich doch dagegen entschieden ${ }^{478}$. Er setzte vielmehr auf die parteipolitische Neutralität der Amtskirche und hoffte darauf, daß sich die spezifischen Interessen der Protestanten durch die Einflußnahme auf die bestehenden Parteien durchsetzen ließen. Meiser setzte dabei vor allem auf die CSU, mit der seiner Meinung nach „die bürgerlich-konservativen Vorstellungen der Kirchenleitung am effektivsten" verwirklicht werden konnten, „auch wenn sie ihm immer das Bild einer BVP im neuen Gewand zu bieten schien“. So war es nur folgerichtig, daß sich Meiser im September 1952 gegen den Evangelischen Volksdienst aussprach. In einer Aktennotiz für Karl Schwend, den Leiter der bayerischen Staatskanzlei, heißt es:

„Der Bischof bedauert die Gründung des EVD. Er gibt ihm auch keine Chance und glaubt, dass niemand kirchenamtlicherseits ihn in Bayern unterstützen wird. Er hält es für ausgeschlossen, dass diese Partei etwas erreichen wird. Der EVD. sei im Grunde abzulehnen, da er als Splitterpartei nur eine [s]innlose Aufspaltung der Kräfte bringe. “479

477 ACSP, CSU-LL, Rechenschaftsbericht Hans Ehards vor dem Landesausschuß der CSU am 25./ 26. 10. 1952 in Dinkelsbühl; zur Auseinandersetzung zwischen der CSU und dem Evangelischen Volksdienst vgl. BSB, NL Schwend 13, Julius Zirkelbach an Hans Ehard vom 22. 11. 1952, dessen Antwortschreiben an Julius Zirkelbach vom 27. 11. 1952, sowie NL Schwend 14, Julius Zirkelbach an Hans Ehard vom 7. 7. 1953.

${ }^{478}$ Vgl. Renner, Nachkriegsprotestantismus, S. 52-58; das folgende Zitat findet sich ebenda, S. 54.

479 BSB, NL Schwend 13, Aktennotiz über die Gründung des Evangelischen Volksdienstes in Bayern und über ein Gespräch mit Landesbischof Hans Meiser, ungezeichnet, undatiert. 
Tatsächlich erhielt der Evangelische Volksdienst von der Kirchenleitung nicht den erhofften Beistand, im Gegenteil. Bischof Meiser und seine Mitarbeiter konnten die Führung des Volksdienstes um Julius Zirkelbach im März 1953 sogar dazu bewegen, alle parteipolitischen Aktivitäten einzustellen und lediglich die beratende Tätigkeit der Evangelischen Wählergemeinschaft fortzusetzen ${ }^{480}$. Trotz dieser Schützenhilfe blieb Meiser gegenüber der CSU überaus mißtrauisch. Im Juli 1953 schrieb er an Eugen Gerstenmaier, die Konzeption der Union, „auf der die CSU so verheißungsvoll aufgebaut" worden sei, sei an ihr Ende gekommen, wenn die katholische Kirche ihren gegenwärtigen Kurs beibehalte und sich die CSU „zur Trägerin dieses Kurses machen sollte“481.

Um einer solchen Entwicklung entgegenzusteuern, hielt es Meiser für wünschenswert, den Zusammenhalt der evangelischen CSU-Abgeordneten zum Zwecke größerer Konfliktfähigkeit in irgendeiner Form zu stärken ${ }^{482}$. Mit der Gründung des Evangelischen Arbeitskreises der CDU/CSU als institutionalisierter Interessenvertretung der Protestanten in der Union hatte sich im Frühjahr 1952 tatsächlich etwas ähnliches angebahnt. Obwohl die CSU offiziell nicht an der Gründung des EAK beteiligt war, konnte es keinen Zweifel daran geben, daß sich die neue Gruppierung auch verpflichtet fühlte, die Angelegenheiten der evangelischen Christen in der bayerischen Unionspartei zu vertreten ${ }^{483}$. An der ersten Tagung des EAK im März 1952 nahmen sieben evangelische CSU-Mitglieder teil, allen voran die beiden Bundestagsabgeordneten Friedrich Jakob Funk und Johannes Semler, und mit Karl Sigmund Mayr und Georg von Manteuffel-Szoege waren auch im geschäftsführenden Ausschuß des EAK zwei CSU-Politiker präsent.

Die Mitbegründer des Evangelischen Arbeitskreises befanden sich in keiner beneidenswerten Lage, gleichgültig, ob sie nun der CDU oder der CSU angehörten. In ihren Parteien mußten sie versuchen, konfessionelle Parität durchzusetzen, um den Wählern die Tragfähigkeit der interkonfessionellen Idee zu beweisen und um den immer wieder gehörten Vorwurf zu entkräften, die Union sei nichts anderes als eine verkappte katholische Partei. Zudem galt es, die Auseinandersetzung mit den Bruderräten der Bekennenden Kirche zu führen, die "mit theologisch-ethischen Argumenten“ eine Partei ablehnten, „die den Namen ,christlich“ in ihrem Signet führte" ${ }^{\text {“484 }}$.

Nach der von einer Gruppe evangelischer CDU-Politiker um Hermann Ehlers und Robert Tillmanns ausgehenden Gründung des EAK war es nur eine Frage der Zeit, wann sich in Bayern eine ähnliche Organisation etablieren würde, zumal es mit dem Ansbacher Kreis einen idealen Anknüpfungspunkt gab ${ }^{485}$. Dieser Diskussionszirkel,

480 BSB, NL Schwend 14, Julius Zirkelbach an Hans Ehard vom 7. 7. 1953; vgl. auch Kühnel, Fränkischer Protestantismus, S. $73 \mathrm{f}$.

481 Hans Meiser an Eugen Gerstenmaier vom 13. 7. 1953; zit. nach Renner, Nachkriegsprotestantismus, S. 57.

482 BSB, NL Schwend 13, Aktennotiz über die Gründung des Evangelischen Volksdienstes in Bayern und über ein Gespräch mit Landesbischof Hans Meiser, ungezeichnet, undatiert.

483 Zur Gründung des EAK und zur organisatorischen Einbeziehung der evangelischen CSU-Mitglieder vgl. Peter Egen, Die Entstehung des evangelischen Arbeitskreises der CDU/CSU, Diss., Bochum 1971, S. XXXII f. und S. XLV.

484 Gerhard Besier, "Christliche Parteipolitik“ und Konfession. Zur Entstehung des Evangelischen Arbeitskreises der CDU/CSU, in: KZG 3 (1990/1991), S. 166-187, hier S. 167.

485 Zum Ansbacher Kreis und zur Frühgeschichte des EAK der CSU vgl. ACSP, CSU-EAK 6, Mappe: Kreußel - allgemeine Korrespondenz 1953-1955, Bericht Karl Gablers „Der Evangelische Arbeits- 
dem neben Vertretern der Landeskirche vor allem evangelische CSU-Mitglieder wie Friedrich Bauereisen, Alfons Kreußel, Hans Küßwetter ${ }^{486}$, Karl Sigmund Mayr oder Paul Nerreter angehörten, kam seit Jahren zu Gesprächen darüber zusammen, wie sich die mißtrauischen Protestanten Frankens für die Union gewinnen ließen und wie die spezifischen Interessen des evangelischen Bevölkerungsteils in der CSU am effektivsten durchgesetzt werden konnten. Der Ansbacher Kreis war die eigentliche Keimzelle der Evangelischen Arbeitsgemeinschaft der CSU, die um die Jahreswende 1952/ 1953 ihre Arbeit aufnahm ${ }^{487}$. Am 1. April 1953 wurde eine Geschäftsstelle unter der Leitung von Karl Gabler eröffnet, die ihren Sitz zunächst in Dinkelsbühl hatte, und mit der Tagung in den Räumen der evangelischen Volkshochschule auf dem Hesselberg trat die Evangelische Arbeitsgemeinschaft im Mai erstmals ins Licht der Öffentlichkeit. Sechs Monate später beschloß die Mitgliederversammlung, die Evangelische Arbeitsgemeinschaft nach dem Vorbild der CDU in Evangelischen Arbeitskreis umzubenennen. Im Januar 1954 wurde auf einer Jahreshauptversammlung eine Satzung verabschiedet und ein ordentlicher Vorstand gewählt ${ }^{488}$. Das Amt des ersten Vorsitzenden übernahm Alfons Kreußel, ein ebenso ehrgeiziger wie umtriebiger Mann, der als evangelischer Pfarrer eine wichtige Rolle in der Selbstdarstellung des EAK spielte und qua Amt die Verbindung zur Kirchenleitung aufrechterhielt ${ }^{489}$. Zu Kreußels Stellvertretern wählte die Mitgliederversammlung Hans Küßwetter, den Dinkelsbühler Landrat und Vorsitzenden des CSU-Bezirksverbands Mittelfranken, und den Bamberger Amtsgerichtsrat Siegfried Hofmann.

Nach außen gab sich der EAK moderat. Man fand lobende Worte für den Unionsgedanken, bekräftigte die Zusammenarbeit der Konfessionen in der CSU und erinnerte die katholischen Parteifreunde mit sanftem Nachdruck daran, daß es die „Christenpflicht einer Ma[j]orität sei“, die „Minorität zu pflegen“490. Intern nahmen die führenden Vertreter des EAK jedoch kein Blatt vor den Mund. Sie ließen keinen Zweifel daran, daß die neue Gruppierung „als Bollwerk der evangelischen Seite der CSU gegen-

kreis der Christlich-Sozialen Union in Bayern!", undatiert; Renner, Nachkriegsprotestantismus, S. 39-44; Kühnel, Fränkischer Protestantismus, S. 76f.; Egen, Entstehung, S. 133 f.

${ }^{486}$ Hans Küßwetter, geb. 14. 1. 1909 in Ehingen/Mfr., gest. 19.11. 1965 in Dinkelsbühl, ev., Studium der Geschichte, Politik, Germanistik und alten Sprachen in München und Berlin, 1936 Promotion zum Dr. phil., seit 1937 Studienassessor und Studienrat in München, 1941-1945 Teilnahme am Zweiten Weltkrieg, 1948-1965 Landrat in Dinkelsbühl, 1952-1965 Mitglied des Bezirkstags von Mittelfranken (CSU), 1962-1965 dessen Präsident, 1958-1965 MdS, 1952-1965 Vorsitzender des CSU-Bezirksverbands Mittelfranken, 1952-1965 Mitglied des Landesvorstands der CSU.

487 Das genaue Gründungsdatum konnte nicht ermittelt werden. Renner, Nachkriegsprotestantismus, S. 42, nennt den November 1952, Egen, Entstehung, S. 133, den April 1953, Kühnel, Fränkischer Protestantismus, S. 77, gibt gar Mitte 1950 an. Der Geschäftsführer des EAK selbst hat vom April 1953 als Monat der Gründung des EAK gesprochen (ACSP, CSU-EAK 6, Mappe: Kreußel - allgemeine Korrespondenz 1953-1955, Bericht Karl Gablers „Der Evangelische Arbeitskreis der Christlich-Sozialen Union in Bayern!“, undatiert), Tatsache ist jedoch, daß bereits im März 1953 Tagungen der „Evangelische[n] Arbeitsgemeinschaft innerhalb der CSU“ stattfanden.

488 ACSP, CSU-EAK 6, Mappe: Kreußel - allgemeine Korrespondenz 1953-1955, Bericht Karl Gablers „Der Evangelische Arbeitskreis der Christlich-Sozialen Union in Bayern!“, undatiert.

489 Die Kirchenleitung begrüßte die Gründung des EAK und erhob zunächst auch keinen Einspruch gegen die Arbeit Kreußels an der Spitze der neuen Gruppierung, um das Experiment nicht zu gefährden. Erst später legte der Landeskirchenrat sein Veto ein. Kreußel legte daraufhin sein Pfarramt nieder, um eine Dozentur an der Pädagogischen Hochschule in München anzunehmen. Vgl. Renner, Nachkriegsprotestantismus, S. 43.

490 ACSP, CSU-EAK 6, Mappe: Kreußel - allgemeine Korrespondenz 1953-1958, Presseerklärung zur "Tagung der Evangelischen Arbeitsgemeinschaft i. d. CSU auf dem Hesselberg" vom 15. 5. 1953. 
über dem Katholizismus in der eigenen Partei“ gedacht war ${ }^{491}$. Am 24. April 1953 schrieb Alfons Kreußel an Paul Nerreter:

„Die Lage innerhalb der CSU verschärft sich zusehends. Nicht nur insofern, daß manche unserer katholischen Parteifreunde immer unbekümmerter einen ausgesprochen katholischen Kurs steuern, sondern auch deswegen, weil unsere evangelischen Mandatsträger im Landtag in durchaus ungenügender Weise sich selbst und unser evangelisches Anliegen zur Geltung bringen. [...] Die Gefahren einer Aufsplitterung der CSU liegen nahe. [...] Ohne den evangelischen Faktor wird die CSU eine so klerikale Partei, daß eine äusserst bittere Reaktion seitens der Bevölkerung beider Konfessionen, nicht ausbleiben wird. [. . . ] Ich bin der Meinung, daß unserer [E]vangelischen Arbeitsgemeinschaft die Aufgabe zufält, noch einmal den evangelischen Bevölkerungsteil zu sammeln und zu integrieren. ${ }^{.492}$

Doch ob es dem Evangelischen Arbeitskreis gelingen würde, diese selbstgestellte Mission zu erfüllen, war auch für führende Persönlichkeiten des EAK zweifelhaft. Der Ansbacher Kreisdekan, Oberkirchenrat Koch, war sich nicht mehr sicher, ob die katholische Seite überhaupt noch den Willen hätte, die CSU zu einer wirklichen Union zu machen ${ }^{493}$. Werner Dollinger, der 1945 die CSU im Landkreis Neustadt an der Aisch mitgegründet hatte, ging noch weiter. Die CSU sei eine katholische Partei geworden, erklärte er verbittert während einer Tagung des EAK im Mai 1953, wobei er nicht zuletzt das parteischädigende, rücksichtslose und taktlose Verhalten des Parteivorsitzenden für diese negative Entwicklung verantwortlich machte. Die evangelischen Christen, so schloß Dollinger seinen kämpferischen Redebeitrag, dürften auf die Dauer nicht nur "Stimmvieh“ bleiben. Georg Riedel, ein Mann der ersten Stunde aus dem schwäbischen Nördlingen, warf gar die Frage auf, ob die Protestanten ,überhaupt noch mit gutem Gewissen in der CSU sein" könnten ${ }^{494}$. Die Führung des EAK war jedoch im Frühjahr 1953 übereinstimmend der Meinung, man müsse es trotz der konfessionell bestimmten Politik von Männern wie Hundhammer noch einmal versuchen, die Unionsidee zu verwirklichen, wenn dies auch für alle Beteiligten ein mühevolles Unterfangen werden würde. Alfons Kreußel faßte am Ende einer Grundsatzdebatte, die am 21. März 1953 auf einer der ersten größeren Tagungen des EAK geführt wurde, die Ergebnisse zusammen:

„Ehrlich und treu unserer Sache dienend gelte es, in mühevoller Kleinarbeit und rastlosem Einsatz unsere wertvollen ev. Freunde zur Mitarbeit zu gewinnen. Der Unionsgedanke müsse heilig gehalten werden, und die Parteifreunde aus dem kath. Lager müßten durch überzeugende Argumente dazu gebracht werden, in wirklicher Unionstreue mit uns gemeinsam der Zukunft entgegenzugehen. Die echte Parität gelte es zu erreichen, und dazu müsse erst einmal bei uns gesammelt werden, um dann durch unsere Geschlossenheit auch mit Nachdruck für unsere gemeinsamen Interessen eintreten zu können. “495

Im Kern läßt sich die Arbeit des Evangelischen Arbeitskreises auf zwei zentrale Ziele reduzieren: Zum einen galt es, die Idee der interkonfessionellen Kooperation im politi-

491 Renner, Nachkriegsprotestantismus, S. 43.

492 ACSP, CSU-EAK 2, Mappe: Kreußel - allgemeine Korrespondenz 1953-1959, Alfons Kreußel an Paul Nerreter vom 24. 4. 1953; Hervorhebung im Original.

493 ACSP, CSU-EAK 6, Mappe: Kreußel - allgemeine Korrespondenz 1953-1958, Protokoll der Zusammenkunft des EAK der CSU am 21.3. 1953.

494 ACSP, CSU-EAK 6, Mappe: Kreußel - allgemeine Korrespondenz 1953-1958, Protokoll der Zusammenkunft des EAK der CSU am 30.5. 1953.

495 ACSP, CSU-EAK 6, Mappe: Kreußel - allgemeine Korrespondenz 1953-1958, Protokoll der Zusammenkunft des EAK der CSU am 21. 3. 1953. 
schen Raum gegen alle Angriffe von außen zu verteidigen, durch gezielte Werbetätigkeit die protestantischen Wähler anzusprechen und neue, gut qualifizierte Aktivisten zu gewinnen, um so die eigene Basis zu verbreitern ${ }^{496}$. Zum anderen setzte der EAK alles daran, möglichst viele evangelische Parteimitglieder in wichtige Positionen zu bringen. Personalentscheidungen, sei es bei der Aufstellung künftiger Mandatsträger oder bei der Auswahl von Ministern, Staatssekretären und Parteifunktionären, standen für den EAK stets unter dem Primat der konfessionellen Parität, d. h. man beanspruchte einen Anteil an allen Ämtern und Mandaten für die evangelische Seite, der in etwa dem Anteil der Protestanten an der bayerischen Bevölkerung entsprach ${ }^{497}$. Zugleich versuchte der EAK, sich als alleinige Interessenvertretung der evangelischen Christen in der CSU zu etablieren und das Vorschlagsrecht für evangelische Kandidaten gleichsam zu monopolisieren ${ }^{498}$.

Um diese Ziele verwirklichen zu können, mußte der Evangelische Arbeitskreis bestrebt sein, eine von der Parteiführung möglichst unabhängige Stellung und damit größtmögliche Handlungsfreiheit nach innen und nach außen zu erreichen. Aus diesem Grund konstituierte sich die neue Gruppierung nicht als Arbeitsgemeinschaft der CSU - ein Status, wie ihn beispielsweise die Junge Union oder die Frauen-Union hatten -, sondern firmierte als nicht rechtsfähiger Verein ${ }^{499}$. Damit verzichtete der EAK zwar schweren Herzens auf von der Parteisatzung garantierte Ämter in den Führungsgremien der bayerischen Unionspartei, vermied aber den Eindruck, der Evangelische Arbeitskreis sei so etwas wie ein getarnter Agent der katholisch dominierten CSU. Ein solches Negativ-Image hätte es von vornherein schier unmöglich gemacht, den Teil der evangelischen Bevölkerung an die Union heranzuführen, der zwar konservativ geprägt war, aber in der CSU lediglich den verlängerten Arm der katholischen Kirche sah. So begnügte sich der EAK damit, als Diskussionsforum und „Bindeglied zwischen der CSU und evangelischen Christen " $z u$ dienen ${ }^{500}$. Überdies fürchtete man die Reaktion der katholischen Parteifreunde. Wollte man den EAK als offizielle Arbeitsgemeinschaft in die CSU einbauen, bestände die Gefahr, daß auch eine katholische Arbeitsgemeinschaft ins Leben gerufen würde. Damit wäre aber die „Grundlage für die Auflö-

496 Hans Küßwetter erklärte in diesem Zusammenhang: „[W]ir Evangelischen müssen durch Qualität ersetzen, was die andere Seite an Quantität hat." ACSP, CSU-EAK 6, Mappe: Kreußel - allgemeine Korrespondenz 1953-1958, Protokoll der Zusammenkunft des EAK der CSU am 30. 5. 1953, und CSU-EAK 1, Mappe: Kreußel - allgemeine Korrespondenz 1956-1958, Satzung des EAK der CSU vom 2. 1. 1954.

497 Der Anteil der Protestanten an der bayerischen Bevölkerung betrug etwa 26 Prozent. Zur Diskussion um die konfessionelle Parität in der CSU und zur Position der Landeskirche vgl. Renner, Nachkriegsprotestantismus, S. 16-34.

498 Karl Schäfer (kath.) und Georg Stiller (ev.) vom Vorstand des CSU-Bezirksverbands NürnbergFürth standen Teilen des EAK mehr als kritisch gegenüber: „Man kann ja jetzt schon eine Teilung der Arbeitsgemeinschaft in 2 Richtungen beobachten, von denen die eine die Interessen der Union aus wirklichem Unionsgeist im Auge hat, während die andere nur die Erreichung von Machtpositionen anstrebt." BayHStA, NL Ehard 75, CSU-Bezirksverband Nürnberg-Fürth, gez. Karl Schäfer und Georg Stiller, an Fritz Schäffer vom 9. 11. 1953.

499 ACSP, CSU-EAK 1, Mappe: Kreußel - allgemeine Korrespondenz 1956-1958, Satzung des EAK der CSU vom 2. 1. 1954; CSU-EAK 4, Mappe: Satzungen, Entschließungen, interne Referate, Korrespondenz 1954-1960, Satzungsentwurf für den EAK der CSU, undatiert; ACDP, NL Ehlers 02/1, Alfons Kreußel an Hermann Ehlers vom 5. 1. 1954.

500 ACSP, CSU-EAK 6, Mappe: Kreußel - allgemeine Korrespondenz 1953-1958, Satzungsentwurf Karl Gablers für den EAK der CSU, undatiert (1953). 
sung der CSU“ als interkonfessioneller Partei geschaffen, hieß es 1953 in einem Strategiepapier zu aktuellen Satzungsfragen ${ }^{501}$.

Der Evangelische Arbeitskreis tat sich überaus schwer, den Aufgaben gerecht zu werden, die er sich selbst gestellt hatte. Ein Jahr nach seiner Gründung hatte er lediglich 200 Mitglieder ${ }^{502}$ - ein viel zu schmales Fundament, um personelle Alternativen anbieten und die Parteiführung wirksam unter Druck setzen zu können. Neben der organisatorischen und finanziellen Schwäche ${ }^{503}$ waren es vor allem die Auseinandersetzungen unter den führenden evangelischen CSU-Politikern, die ein geschlossenes Auftreten und eine effektive Arbeit des EAK verhinderten und es immer wieder möglich machten, die wenigen Protestanten in der bayerischen Unionspartei gegeneinander auszuspielen ${ }^{504}$. Dennoch fiel die erste $Z$ wischenbilanz positiv aus. Der stellvertretende CSU-Vorsitzende Karl Sigmund Mayr schrieb Anfang Februar 1953 an Hermann Ehlers:

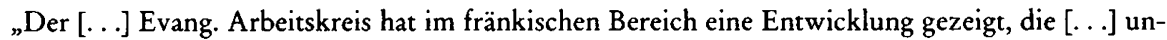
seren katholischen Freunden offenbar Bedenken verursachte; denn unsere führenden Freunde, unter [i]hnen Herr Ministerpräsident Dr. Hans Ehard, sein Mitarbeiter, Herr Ministerialdirektor Dr. Schwen[d], Herr Prälat Meixner u. a., zeigten für unsere Wünsche und Sorgen eine Aufgeschlossenheit und ein Verständnis wie nie zuvor. [...] Es hat sich auch herumgesprochen, dass Sie den bayerischen Vertreter zu den jeweiligen Sitzungen des Evang. Arbeitskreises in Bonn einladen, und da man vielleicht fürchtet, der evangelische Teil der Union könnte selbständig werden, zeigt man mir ein Entgegenkommen und eine Unterstützung, dass ich mich entgegen meiner ursprünglichen Neigung wieder zum stellvertretenden Landesvorsitzenden wählen ließ. Meine Freunde und ich wollen die für uns günstige Situation ausnützen und uns bemühen, auf dem Wege einer freundlichen Aussprache das zu erreichen, was dem evang. Teil in der CSU häufig nicht gegeben wurde, nämlich: Gleichstellung überall dort, wo wir es auf Grund der konfessionellen Verhältnisse verlangen können. “505

Im Juni 1953 teilte Mayr seinem Parteivorsitzenden optimistisch mit, die Arbeit des EAK trage nun „sichtbare Früchte“ und viele Anzeichen deuteten darauf hin, „daß wir wieder die Zuneigung unserer Kirche und große Teile des evangelischen Kirchen-

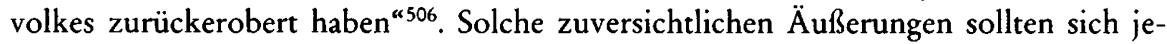
doch schnell als verfrüht erweisen. Keine drei Wochen nach Mayrs hoffnungsvollem Lagebericht belastete ein gravierender Zwischenfall das Verhältnis von Katholiken und Protestanten schwer und drohte auch die CSU vor eine neue Zerreißprobe zu stellen. Stein des Anstoßes war die Einweihung einer Zuckerfabrik im unterfränkischen Ochsenfurt, die am 28. Juni 1953 unter den Augen von so prominenten Gästen wie

501 ACSP, CSU-EAK 1, Mappe: Kreußel - allgemeine Korrespondenz 1956-1958, Bemerkungen zu einem Satzungsentwurf für den EAK der CSU, ungezeichnet, undatiert (1953).

502 ACSP, CSU-EAK 6, Mappe: Kreußel - allgemeine Korrespondenz 1953-1955, Bericht Karl Gablers „Der Evangelische Arbeitskreis der Christlich-Sozialen Union in Bayern!“, undatiert.

503 ACDP, IV-001-003/3, Tätigkeitsbericht der Geschäftsstelle des EAK der CSU für den Zeitraum vom 1.4.-30. 5. 1953; ACSP, CSU-EAK 6, Mappe: Kreußel - allgemeine Korrespondenz 1953-1958, Protokoll der Zusammenkunft des EAK der CSU am 30. 5. 1953, und CSU-EAK 2, Mappe: Kreußel allgemeine Korrespondenz 1953-1959, Karl Gabler an Karl Sigmund Mayr vom 24. 7. 1953.

50t ACSP, CSU-EAK 2, Mappe: Kreußel - allgemeine Korrespondenz 1953-1959, Alfons Kreußel an Karl Sigmund Mayr vom 4. 7. 1953 und Karl Gabler an Alfons Kreußel vom 1.8. 1953; ACDP, NL Ehlers 02/1, Karl Sigmund Mayr an Hermann Ehlers vom 18. 8. und 26. 10. 1953.

505 ACDP, IV-001-003/3, Karl Sigmund Mayr an Hermann Ehlers vom 2. 2. 1953. Ähnlich äußerte sich Mayr einen Tag später in Bonn; ACDP, NL Ehlers 02/1, Protokoll der Sitzung des geschäftsführenden Ausschusses des EAK der CDU/CSU am 3. 2. 1953.

506 BayHStA, NL Ehard 115, Karl Sigmund Mayr an Hans Ehard vom 4. 6. 1953. 
Landwirtschaftsminister Alois Schlögl ihrer Bestimmung übergeben werden sollte ${ }^{507}$. Ochsenfurt selbst war katholisch geprägt, die umliegenden Dörfer dagegen evangelisch. Aus diesem Grund beabsichtigte die Werksleitung, neben dem katholischen Bischof von Würzburg, Julius Döpfner, auch einen Vertreter der evangelischen Kirche zu bitten, ein Weihegebet zu sprechen. Was unter den Vorzeichen der Ökumene heute selbstverständlich ist, war 1953 vom katholischen Kirchenrecht als „communicatio in sacris" verboten ${ }^{508}$. Bischof Döpfner erfuhr erst unmittelbar vor der Zeremonie davon, daß der evangelische Kreisdekan Schwinn nicht nur im Talar an der Einweihung teilnehmen, sondern auch selbst eine liturgische Handlung vornehmen sollte. Er drohte daraufhin, unter diesen Umständen nicht an den Feierlichkeiten teilzunehmen. Da sich kein Kompromiß finden ließ, blieben Dekan Schwinn und seine Helfer der Zeremonie schließlich fern, so daß Döpfner die Weihehandlung alleine vornehmen konnte.

Als die Angelegenheit bekannt wurde - und die Nachricht verbreitete sich wie ein Lauffeuer -, war der Eklat perfekt. Evangelische Gäste protestierten und verließen die Feier demonstrativ, Bischof Döpfner wurde mit Pfui-Rufen und Drohungen wie "Zieht ihn raus, schlagt ihn tot" überschüttet ${ }^{509}$. Wie ernst dieser Vorfall genommen wurde, zeigt ein Schreiben von Landesbischof Meiser an Bundeskanzler Adenauer, der sich besorgt in die hitzige Diskussion eingeschaltet hatte:

„Die Sorge, aus der heraus Sie ihren Brief geschrieben haben, daß die Angelegenheit über den kirchlichen Raum hinaus auch im politischen Bereich unerfreuliche Wirkungen zur Folge haben könnte, ist keineswegs unbegründet. Ich wüßte aus jüngerer Zeit, abgesehen von den Zeiten des Kirchenkampfes, kein Ereignis zu nennen, das eine so tiefgreifende Erregung, ja elementare Empörung in weitesten Kreisen unserer Gemeinden hervorgerufen hat, als den Ochsenfurter Zwischenfall." 510

Tatsächlich waren die Folgen dieser Affäre gar nicht abzusehen. Schließlich ging der Bundestagswahlkampf in die heiße Phase, und die Union mußte um die Stimmen des evangelischen Bevölkerungsteils bangen, zumal der politische Gegner - allen voran die FDP - nicht zögerte, die konfessionellen Irritationen für Wahlkampfzwecke auszunutzen $^{511}$. Es war also kein Wunder, daß die CSU um Schadensbegrenzung bemüht war. Schon am 1. Juli 1953 kam die Landtagsfraktion zu einer Krisensitzung zusammen, an der auch die wichtigsten Repräsentanten des Evangelischen Arbeitskreises teilnahmen $^{512}$. Pfarrer Kreußel hatte eine Erklärung vorbereitet, in der die Vorfälle in Ochsenfurt und die damit verbundene Brüskierung der Protestanten bedauert wurden. Doch Alois Hundhammer stellte sofort fest, daß die „CSU keine vorgesetzte Stelle der Kirchen“ sei. Die CSU müsse „in ihrem eigene[n] Raum das gute Einver-

507 Eine Vielzahl von Briefen, Resolutionen, Berichten und Stellungnahmen zur Affäre um die Einweihung der Ochsenfurter Zuckerfabrik findet sich in: ACDP, NL Ehlers 10/2; ACDP, IV-001-003/3; BSB, NL Schwend 38; ACSP, CSU-EAK 2, Mappe: Kreußel - allgemeine Korrespondenz 1953-1959, und CSU-EAK 6, Mappe: Kreußel - allgemeine Korrespondenz 1953-1955. Vgl. auch Kühnel, Fränkischer Protestantismus, S. 79 ff., und Renner, Nachkriegsprotestantismus, S. 48-52.

508 Vgl. Trippen, Interkonfessionelle Irritationen, in: Bracher u. a. (Hrsg.), Staat und Parteien, S. 350.

509 ACDP, IV-001-003/3, Bericht der Geschäftsstelle des EAK der CSU über die „Vorkommnisse bei der Weihe der Zuckerfabrik Ochsenfurt" vom 29. 6. 1953.

510 BSB, NL Schwend 38, Hans Meiser an Konrad Adenauer vom 22. 7. 1953; Adenauers Brief an den Landesbisch of (im selben Bestand) datiert vom 3. 7. 1953.

511 ACDP, NL Ehlers 10/2, Karl Sigmund Mayr an Hermann Ehlers vom 29. 6. 1953; vgl. auch Kühnel, Fränkischer Protestantismus, S. $79 \mathrm{f}$.

512 ACSP, CSU-LTF II/2, 6-45, Protokoll der Fraktionssitzung am 1. 7. 1953. 
nehmen der Konfessionen wahren, eine Kritik an unseren Bischöfen“ sei dagegen unmöglich. Der Wortführer des katholisch-konservativen Flügels der CSU konnte sich mit dieser Ansicht durchsetzen, und so fehlte in der Resolution, die schließlich einstimmig angenommen wurde, jedes Wort der Mißbilligung gegenüber kirchlichen Würdenträgern. Die Abgeordneten vermieden es überhaupt, eindeutig Stellung zu beziehen. Sie begnügten sich mit einem Bekenntnis zur Unionsidee und zogen sich ansonsten auf den Standpunkt zurück, diese bedauerliche Angelegenheit sei Sache der Kirchen.

„Die Vorkommnisse von Ochsenfurt liegen ausschliesslich im kirchlichen, nicht im politischen Raum. Auch die Klärung und Bereinigung des Vorfalls ist ausschliesslich Sache der kirchlichen Stellen. Die CSU-Fraktion erbittet ihre baldige Durchführung und die grundsätzliche Verständigung der beiden Kirchen über ähnlich gelagerte Fälle. Die CSU-Fraktion und insbesondere ihre evangelischen Mitglieder sind entschlossen, an ihrer politischen Konzeption der Zusammenarbeit der beiden christlichen Konfessionen auf dem Boden voller Parität im politischen Raum unbedingt festzuhalten. Sie halten diese Zusammenarbeit zum Wohl des bayerischen und des deutschen Volkes mehr als je für geboten. Die CSU-Fraktion bedauert, dass infolge mangelnder Vorbereitung der Eindruck der Zurücksetzung des evangelischen Bevölkerungsteils entstehen konnte. Die CSU-Fraktion wendet sich entschieden gegen das sichtbar gewordene Bestreben, diesen Vorfall zu parteipolitischen Zwecken zu missbrauchen. ${ }^{~} 513$

In evangelischen Kreisen war man mit dieser Erklärung freilich nicht zufrieden; selbst die Bayernpartei hatte eindeutiger zum Ochsenfurter Zwischenfall Stellung genommen $^{514}$. Hermann Ehlers und der Nürnberger Kreisdekan, Oberkirchenrat Schieder, fanden nur ein Wort für die Resolution der CSU-Fraktion: „kümmerlich“515. Auch beim Evangelischen Arbeitskreis machte sich - ungeachtet der Tatsache, daß Karl Sigmund Mayr und Alfons Kreußel an der Abfassung der Entschließung beteiligt waren - Enttäuschung darüber breit, wie die Angelegenheit von Partei- und Fraktionsführung behandelt wurde ${ }^{516}$. Doch anstatt in fruchtlose Resignation zu verfallen, versuchte der EAK, aus der Entrüstung über die Vorkommnisse in Ochsenfurt und die laue Resolution der CSU-Fraktion politisches Kapital zu schlagen. Die CSU müsse „ihren Willen zu einer echten Parität dadurch sichtbar unter Beweis stellen, daß in den überwiegend evangelischen Gebieten Nordbayerns und auf der Landesliste mehr evangelische Kandidaten an aussichtsreicher Stelle nominiert werden“, hieß es in einer Anfang Juli 1953 veröffentlichten Erklärung. Die Chancen für die Durchsetzung dieser Forderung waren nicht schlecht, denn die Parteiführung um Hans Ehard stand von verschiedenen Seiten unter Druck und war zum Handeln gezwungen. Die evangelischen Wähler und die Landeskirche, deren Einfluß auf die Wahlentscheidung der Gläubigen nicht zu unterschätzen war, erwarteten ganz einfach ein großzügiges Entgegenkommen in

513 BSB, NL Schwend 38, Resolution der CSU-Landtagsfraktion vom 1. 7. 1953 zum Zwischenfall in Ochsenfurt.

514 Vgl. Kühnel, Fränkischer Protestantismus, S. 79.

515 ACDP, NL Ehlers 10/2, Oberkirchenrat Schieder an Hermann Ehlers vom 4. 7. 1953 und dessen Antwortschreiben an Schieder vom 8. 7. 1953. Im Schreiben des Oberkirchenrats hieß es: „Es muß ein ,Zeichen aufgerichtet' werden. Es muß klar ausgesprochen werden, daß die CSU das Vorgehen des Bischofs bedauert, ja mißbilligt. Die Erklärung, die die bayer. CSU in dieser Woche herausgegeben hat, ist derartig kümmerlich, daß sie höchstens das Gegenteil anrichtet."

516 ACSP, CSU-EAK 6, Mappe: Kreußel - allgemeine Korrespondenz 1953-1955, „Informationsdienst der Evangelischen Arbeitsgemeinschaft innerhalb der CSU“, undatiert (Juli 1953); das folgende Zitat findet sich ebenda. 
der Kandidatenfrage ${ }^{517}$, und für die CSU bot sich die Möglichkeit, die Glaubwürdigkeit der Bekenntnisse zur Zusammenarbeit der Konfessionen auf paritätischer Grundlage durch einen beherzten Schritt unter Beweis zu stellen. Zudem gab es Befürchtungen, der Evangelische Arbeitskreis könnte sich zur Keimzelle einer evangelischen Partei oder - noch schlimmer! - einer bayerischen CDU entwickeln ${ }^{518}$, und dies galt es unter allen Umständen zu verhindern.

Hans Ehard selbst setzte sich - unterstützt von Bundespolitikern wie Strauß und Stücklen - mit Erfolg für die Nominierung evangelischer Kandidaten ein ${ }^{519}$. Unter den 47 Direktkandidaten waren mindestens acht Protestanten; vier traten in Mittelfranken an, zwei in Oberfranken und je einer in Unterfranken und Schwaben ${ }^{520}$. Von den 50 Bewerbern auf der Landesliste bekannten sich immerhin elf zum evangelischen Glauben, wobei anzumerken ist, daß von den ersten 20 Listenplätzen sechs (30 Prozent) mit Protestanten besetzt waren und Friedrich Bauereisen nach den Zugpferden Fritz Schäffer und Franz Josef Strauß auf die dritte Stelle gesetzt worden war ${ }^{521}$. Im Evangelischen Arbeitskreis war man schon mit diesem Ergebnis sehr zufrieden, besondere Freude löste jedoch das Ergebnis der Bundestagswahlen am 6. September 1953 aus. Die CSU errang mit 47,8 Prozent der Stimmen einen überzeugenden Wahlsieg, der nicht zuletzt auf das gute Abschneiden der Union in den protestantischen Regionen Frankens zurückzuführen war. In Oberfranken gewann die CSU gegenüber 1949 15,1 Prozent hinzu und kam auf 38,1 Prozent, in Mittelfranken konnte sie sogar einen Stimmengewinn von 17,2 Prozent verbuchen und ihren Stimmenanteil auf 41,2 Prozent steigern $^{522}$. Von den sechs oberfränkischen Wahlkreisen gingen drei an die CSU, zwei an die FDP und einer an die SPD, in den sechs mittelfränkischen Wahlkreisen konnten sich sogar vier Bewerber der Union und nur zwei Kandidaten der SPD durchsetzen ${ }^{523}$. Von den 50 Bundestagsabgeordneten der CSU waren 41 (82,0 Prozent) katholisch ${ }^{524}$

517 ACDP, NL Ehlers 10/2, Karl Sigmund Mayr an Hermann Ehlers vom 29.6. 1953 und Oberkirchenrat Schieder an Hermann Ehlers vom 4. 7. 1953; BSB, NL Schwend 38, Hans Meiser an Konrad Adenauer vom 22. 7. 1953.

${ }^{518}$ Diesbezügliche Gerüchte und Befürchtungen gab es seit längerer Zeit: ACSP, NL Müller 410/4, Walter Langenfass an Josef Müller vom 13. 7. 1950; BSB, NL Schwend 13, Aktennotiz Ernst Deuerleins für Karl Schwend vom 9. 9. 1952 über eine Aussprache mit führenden CSU-Politikern aus Mittelfranken; ACDP, IV-001-003/3, Karl Sigmund Mayr an Hermann Ehlers vom 2. 2. 1953.

${ }^{519}$ BayHStA, NL Ehard 170, Hans Ehard an Fritz Schäffer vom 6. 8. 1953; ACSP, CSU-EAK 6, Mappe: Kreußel - allgemeine Korrespondenz 1953-1955, „Informationsdienst der Evangelischen Arbeitsgemeinschaft innerhalb der CSU“, undatiert (Juli 1953). Zu Dissonanzen im EAK vgl. ACDP, NL Ehlers 02/1, Karl Sigmund Mayr an Hermann Ehlers vom 18. 8. 1953, und ACSP, CSU-EAK 2, Mappe: Kreußel - allgemeine Korrespondenz 1953-1959, Karl Gabler an Alfons Kreußel vom 1. 8. 1953.

520 Diese und die folgenden Angaben beruhen auf einer eigenen Auszählung und auf den (teils fehlerhaften) Zahlen im Schreiben von Karl Sigmund Mayr an Hermann Ehlers vom 18. 8. 1953; ACDP, NL Ehlers 02/1.

${ }^{521}$ ACSP, CSU-LL, Protokoll der Sitzung des Landesausschusses der CSU am 10. 8. 1953 in München.

${ }_{522}$ Angaben nach Zweite Bundestagswahl, S. 10 und S 12.

${ }^{523}$ Zur regionalen Verteilung und Parteizugehörgkeit der direkt gewählten Kandidaten vgl. das Schaubild "Die zweite Bundestagswahl in Bayern am 6. September 1953“.

${ }^{524}$ Unter den neugewählten katholischen CSU-Abgeordneten war auch Hermann Höcherl, der in den nächsten Jahren eine steile Karriere vor sich haben sollte. Hermann Höcherl, geb. 31. 3. 1912 in Brennberg/Opf., gest. 18. 5. 1989, kath., Jurastudium, anschließend 1938 Eintritt in den juristischen Staatsdienst, seit 1935 NSDAP-Mitglied, 1940-1945 Teilnahme am Zweiten Weltkrieg, amerikanische Kriegsgefangenschaft, nach 1945 zunächst Bauarbeiter, dann Rechtsanwalt und bis 1953 wieder im juristischen Staatsdienst tätig (zuletzt Amtsrichter), 1945 Mitbegründer der CSU in Brennberg, seit 1955 Mitglied des Landesvorstands und 1959-1961 Mitglied des geschäftsführenden Landesvorstands der CSU, seit 1952 Kreisrat (CSU) in Regensburg, 1953-1976 MdB (CSU), 1955-1957 und 


\section{Die zweite Bundestagswahl in Bayern am 6. September 1953 \\ Parteizrgehörigkeit der in den Wahlkreisen mit Mehrheit gewählten Abgeordneten}

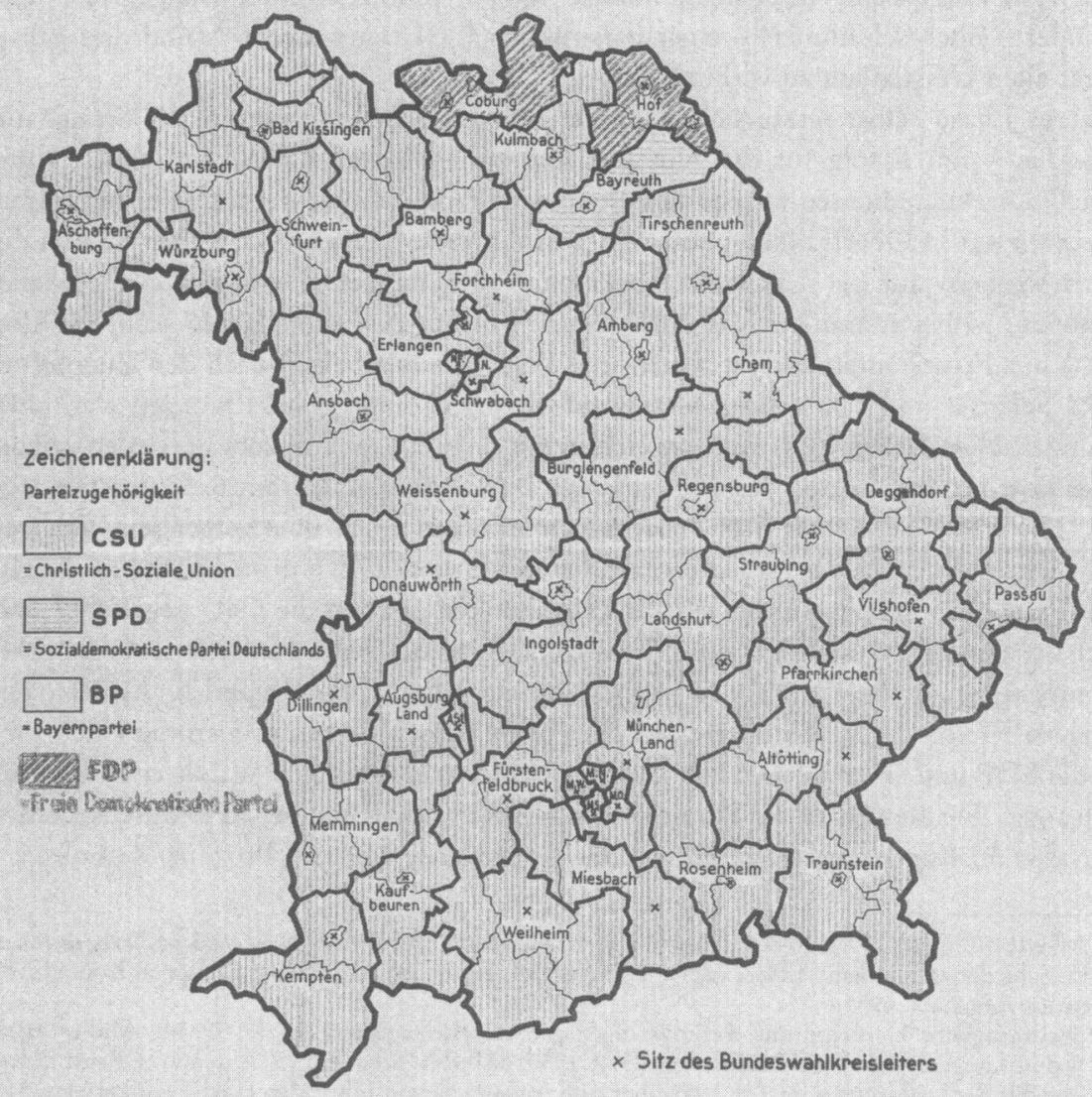

Barerisches Statistisches Landesamt

und neun (18,0 Prozent) evangelisch; 1949 hatten sich unter den 24 Abgeordneten der bayerischen Unionspartei lediglich zwei Protestanten (8,3 Prozent) befunden ${ }^{525}$.

Damit war die Forderung nach konfessioneller Parität zwar noch nicht erfüllt, aber man war diesem Ziel ein gutes Stück nähergekommen. Es bestand allerdings kein

seit 1961 Mitglied des Landesgruppenvorstands, 1957-1961 Vorsitzender der CSU-Landesgruppe und stellvertretender Vorsitzender der CDU/CSU-Fraktion, 1969-1972 Vorsitzender des Vermittlungsausschusses von Bundestag und Bundesrat, 1961-1965 Bundesinnenminister, 1965-1969 Bundeslandwirtschaftsminister.

525 Die Zahlenangaben beruhen auf einer eigenen Auszählung. Die beiden Bayernpartei-Mitglieder Benno Graf und Otto Gumrum, die gemäß dem Wahlabkommen zwischen CSU und BP in den Bundestag gewählt worden waren, wurden dabei nicht berücksichtigt. 
Grund zur Euphorie, denn ein großer Teil der evangelischen Wähler hatte nicht die CSU als solche gewählt, sondern Konrad Adenauer, die Politik der sozialen Marktwirtschaft und der Westintegration ${ }^{526}$.

Führende Persönlichkeiten des EAK waren sich durchaus darüber im klaren, daß der Wahlerfolg der CSU in den protestantischen Regionen Bayerns auf wackligen Beinen stand ${ }^{527}$. Dennoch waren die Ziele des Evangelischen Arbeitskreises für das Jahr 1954, das ganz im Zeichen der Landtagswahlen stand, hoch gesteckt. Von den 80 bis 85 CSU-Abgeordneten im neuen Landtag sollten mindestens 20 "bewußte evangelische Christen" sein, die aber nur zur Hälfte in Ober- und Mittelfranken aufgestellt werden sollten. Zehn Protestanten hoffte man dagegen in den katholisch dominierten Regierungsbezirken unterbringen zu können ${ }^{528}$. Die Hoffnung, den Anteil der evangelischen Abgeordneten von knapp elf Prozent im Jahre 1950 auf 24 Prozent steigern zu können, erwies sich jedoch schnell als illusionär, und der Evangelische Arbeitskreis mußte schmerzhaft erfahren, daß Bundestags- und Landtagswahlen anderen Gesetzen unterlagen.

In der Tat brachten die Bundestagswahlen nur eine kurze Atempause in den konfessionellen Auseinandersetzungen. Schon bei der Regierungsbildung kam es zu neuen Konflikten, als Konrad Adenauer den von der CSU für das Amt des Postministers vorgeschlagenen Katholiken Hans Schuberth ablehnte und aus Gründen der Konfessionsarithmetik forderte, dieses Ministerium mit einem Protestanten zu besetzen ${ }^{529}$. Der Kandidat, mit dem Adenauer hinter dem Rücken der CSU-Führung verhandelte, hieß Karl Sigmund Mayr. Der Stellvertreter Hans Ehards, einer der prominentesten evangelischen Christen in der CSU, signalisierte zunächst sein Einverständnis, wurde dann aber von seinen eigenen Parteifreunden gezwungen, seine Zusage zurückzunehmen. Wenig später legte Mayr auch tief enttäuscht das Amt des stellvertretenden Landesvorsitzenden nieder ${ }^{530}$.

Doch nicht nur die Affäre Schuberth/Mayr sorgte für Spannungen zwischen den katholischen und evangelischen Anhängern der CSU. Das Verhältnis der Konfessionen wurde 1954 auch durch immer neue Zwischenfälle à la Ochsenfurt schwer belastet. Für eine gewisse Zeit drohte von der Einweihung von Brücken, Schulen und Friedhöfen ganz allgemein eine Gefahr für den konfessionellen Frieden ${ }^{531}$. Gerüchte, der Vatikan betreibe die Spaltung der Union in eine evangelische und eine katholische Partei ${ }^{532}$, und die anhaltende Diskussion über die Frage der Lehrerbildung, die für Alfons Kreußel mit der Zeit zu einem „Al[p]druck“ wurde ${ }^{533}$, trugen weiter zur Verhärtung der Fronten bei. „Gegenreformation“, „Klerikalisierung“ und „Kulturkampf" waren Schlagworte, die man immer wieder hören und lesen konnte ${ }^{534}$. So ist

\footnotetext{
526 So beispielhaft ACDP, NL Ehlers 10/1, Oberkirchenrat Oscar Daumiller an Hermann Ehlers vom 13.10. 1953.

527 ACDP, NL Ehlers 02/1, Alfons Kreußel an Hermann Ehlers vom 14. 9. 1953.

528 ACDP, NL Ehlers 02/1, Alfons Kreußel an Hermann Ehlers vom 5. 1. 1954.

529 Vgl. Gelberg, Hans Ehard, S. 476-484; Köhler, Adenauer, S. 802-805; Kühnel, Fränkischer Protestantismus, $\mathrm{S} .82 \mathrm{f}$.

530 BayHStA, NL Ehard 115, Hans Ehard an Karl Sigmund Mayr vom 11. 2. 1954.

${ }^{531}$ Eine ganze Reihe von Zwischenfällen ist dokumentiert in: ACDP, NL Ehlers 10/1 und 2; BSB, NL Schwend 17 und NL Schwend 38.

532 BayHStA, NL Ehard 1343, Bericht Ernst Deuerleins über seine Romreise vom 31. 5. 1954.

${ }_{533}$ ACDP, NL Ehlers 02/1, Alfons Kreußel an Hermann Ehlers vom 5. 1. 1954.

${ }^{534}$ ACSP, CSU-EAK 6, Mappe: Kreußel - allgemeine Korrespondenz 1953-1958, Protokoll der Zu-
} 
es nicht verwunderlich, daß im Sommer 1954 wieder einmal eine evangelische Partei gegründet wurde. Der wichtigste Initiator war ausgerechnet der Theologe Hermann Strathmann, der aus der CSU austrat, um einen Deutschen Volksdienst ins Leben zu rufen ${ }^{535}$. Es ist bezeichnend, daß Strathmann mit diesem Schritt auch bei Aktivisten des Evangelischen Arbeitskreises Verständnis erntete ${ }^{536}$, obwohl man den Deutschen Volksdienst als bedrohliche Konkurrenz einstufte.

Der EAK hatte aber auch in der CSU keinen leichten Stand, und der Versuch, den Evangelischen Arbeitskreis als alleinige Interessenvertretung der Protestanten zu etablieren, mißlang gründlich. Dies zeigte sich besonders deutlich während der Tagung des Landesausschusses am 3. Juli 1954 in Landshut, in der ein Nachfolger für den zurückgetretenen Karl Sigmund Mayr gewählt werden sollte. Der Kandidat des EAK war Staatssekretär Paul Nerreter, doch es war Alfons Kreußel und Hans Küßwetter nicht gelungen, alle evangelischen Delegierten auf ihre Linie einzuschwören. So kam es zu einer Kampfabstimmung zwischen Nerreter und Rudolf Eberhard, dem stellvertretenden Vorsitzenden der Landtagsfraktion, die knapp zugunsten Eberhards ausfiel. Der neue Stellvertreter Ehards war zwar Protestant, aber kein Freund des EAK, dem er schon in seiner kurzen Antrittsrede eine klare Absage erteilte:

„Ich möchte dieses Ergebnis nicht anders werten, [. . .] weil wir gerade jetzt im Jahr 1954 vor einem sehr schweren Wahlkampf stehen, einem Wahlkampf, der besonders unsere evangelischen Freunde in der Union in Anspruch nehmen wird und der von uns mehr denn je unsere ganze Einsatzbereitschaft für die CSU und damit zu dem Gedanken der Christlich Sozialen Union erfordert. Wenn die evangelischen Freunde in der CSU diese Arbeit erfolgreich durchführen können, dann nur - das lassen Sie mich auf der anderen Seite sagen - zusammen mit unseren katholischen Parteifreunden und an der Seite unserer katholischen Parteifreunde, die ja in der Union, das wollen wir gern feststellen, in der Überzahl sind. Ich glaube, daß die Christlich-Soziale Union ihre Arbeit nicht durchführen kann etwa im Sinn eines katholischen Kreises und eines evangelischen Flügels." ${ }^{\text {"537 }}$

Eine „deutlichere Ohrfeige konnte der EAK nicht erhalten“, stellte Geschäftsführer Gabler ernüchtert fest ${ }^{538}$. Krisenstimmung machte sich breit. Die führenden Repräsentanten des Evangelischen Arbeitskreises waren zutiefst deprimiert, und Alfons Kreußel spielte sogar mit dem Gedanken, den Vorsitz niederzulegen. Das gespannte Verhältnis der Konfessionen und die Brüskierung des EAK waren denkbar schlechte Vorzeichen für die kommenden Landtagswahlen. Der Nimbus Konrad Adenauers würde der CSU in Ober- und Mittelfranken diesmal nicht zum Sieg verhelfen! Auch Bundestagspräsident Ehlers sah keinen Grund zum Optimismus. „In Bayern habe sich die Lage verschlechtert, und zwar durch die Parteileitung (CSU)“, erklärte er im Oktober 1954. „Hier stehe die Politik tatsächlich unter dem Vorzeichen des Klerikalismus und

sammenkunft des EAK der CSU am 30. 5. 1953; ACDP, NL Ehlers 10/1, Helmut Weyland an Hermann Ehlers vom 16. 4. 1954.

535 Materialien zum Austritt Strathmanns aus der CSU und zur Gründung des Deutschen Volksdienstes finden sich in: BayHStA, NL Ehard 75 und NL Ehard 328; BSB, NL Schwend 15; ACSP, CSU-LTF II/2, 5-50; ACDP, NL Ehlers 10/1; Archiv des Erzbistums Bamberg, Rep. 4/3-111/20.6.

536 ACSP, CSU-EAK 2, Mappe: Kreußel - allgemeine Korrespondenz 1953-1959, Karl Gabler an Alfons Kreußel vom 15. 7. 1954.

537 ACSP, CSU-LL, Protokoll der Sitzung des Landesausschusses der CSU am 3. 7. 1954 in Landshut. Zu Eberhards Credo vgl. seinen Artikel im Main-Echo vom 18. 8. 1951: „Vom Sinn der Union“.

538 ACSP, CSU-EAK 2, Mappe: Kreußel - allgemeine Korrespondenz 1953-1959, Karl Gabler an Siegfried Hofmann vom 7. 7. 1954. 
Konfessionalismus. Man habe sich hier kaum mit Erfolg gegenüber der anderen Seite durchzusetzen vermocht. “539

\section{c) Konservative Fassade und blockiertes Reformpotential}

Die innere Entwicklung der CSU in der Ära Ehard war gekennzeichnet von einem schleichenden Verfall der Parteiorganisation. Die Führungsgremien, der geschäftsführende Landesvorstand und der Landesvorstand, büßten einen großen Teil ihrer Bedeutung ein, die Tagungen des Landesausschusses und der Landesversammlung drohten zur bloßen Bühne zu degenerieren, auf der sich die Parteiprominenz selbst darstellte. Laut Satzung stand den Delegierten zwar das Recht zu, die Richtlinien der Politik zu bestimmen, doch dieses Recht stand zumeist nur auf dem Papier ${ }^{540}$. Tatsächlich fielen beinahe alle wichtigen Entscheidungen anderswo, und die Parteibasis wurde mit mehr oder weniger inhaltsleeren Rechenschaftsberichten abgespeist.

Der stille Verfassungswandel, der sich in der CSU nach der Wahl Hans Ehards vollzog, begann bereits im Sommer 1949. Der Landesvorsitzende hielt es nicht für nötig, den Landesvorstand oder gar den Landesausschuß einzuberufen, um über das Ergebnis der Bundestagswahlen und die Regierungsbildung zu beraten. Lediglich der geschäftsführende Landesvorstand wurde von Ehard informiert, als alles vorüber war ${ }^{541}$. Der Parteichef fand nicht einmal Zeit, Briefe von Vorstandsmitgliedern zu beantworten, die sich verunsichert nach dem Stand der Dinge erkundigten ${ }^{542}$. Elisabeth MeyerSpreckels zog sich aus Protest gegen die in ihren Augen untragbare „Ausschaltung des Landesvorstands“ aus der Parteiführung zurück ${ }^{543}$, aber an der Situation änderte sich deshalb wenig. Ehard war nun einmal kein Mann der Partei, und er war auch kein Mann der Parteigremien. Von Mai 1949 bis Dezember 1954 tagte der Landesausschuß lediglich neunmal ${ }^{544}$. Dabei waren in der Satzung pro Jahr mindestens zwei Landesausschußsitzungen vorgesehen ${ }^{545}$, doch diese Quote wurde nur 1950 und 1954 erreicht, als es galt, die CSU für einen Landtagswahlkampf zu mobilisieren. Zwischen der Landesausschußsitzung im April 1951 und der im Oktober 1952 vergingen sogar 18 Monate. Josef Müller hatte den Landesausschuß, nominell das höchste Gremium zwischen den Parteitagen, wesentlich häufiger zusammengerufen, nämlich zwischen Mai 1946 und Mai 1949 insgesamt zwölfmal ${ }^{546}$. Auch der geschäftsführende Landes-

539 ACDP, IV-001-002/1, Protokoll der Sitzung des geschäftsführenden Ausschusses des EAK der CDU/CSU am 6. 10. 1954.

540 Satzung der CSU in der Fassung vom 4. 10. 1946, abgedruckt in: Protokolle und Materialien, S. 1783-1803; ACSP, CSU-LTF III/1, 6-10, gedruckte Fassung der Satzung der CSU von 1952; in der Fassung vom 11. 10. 1958 findet sich die Satzung von 1952 abgedruckt in: Dokumente zur parteipolitischen Entwicklung in Deutschland seit 1945, hrsg. von Ossip K. Flechtheim, Bd. 1, Berlin 1962, S. 279-302.

541 BayHStA, NL Ehard 102, Protokoll der Sitzung des geschäftsführenden Landesvorstands am 3. 10. 1949 (Emil Muhler).

${ }^{542}$ ACSP, NL Müller 43, Rundschreiben Karl Köhlers an die Mitglieder des Gautinger Kreises vom 22. 9.1949.

${ }^{543}$ ACSP, NL Müller 168, Elisabeth Meyer-Spreckels an Hans Ehard vom 29. 8. 1949.

544 Eigene Zählung nach den Findmitteln im ACSP.

545 Satzung der CSU in der Fassung vom 4. 10. 1946, abgedruckt in: Protokolle und Materialien, S. 1783-1803; ACSP, CSU-LTF III/1, 6-10, gedruckte Fassung der Satzung der CSU von 1952.

${ }^{546}$ Eigene Zählung nach BayHStA, NL Ehard 1421, Disposition für die Besprechung mit den Bezirksvorsitzenden am 7. 1. 1950 und Manuskript des Rechenschaftsberichts Hans Ehards vor dem Lan- 
vorstand und der Landesvorstand traten relativ selten zusammen, der etwa fünfzigköpfige Landesvorstand von Juni 1949 bis Juni 1950 gar nur zweimal ${ }^{547}$ !

Die großen zeitlichen Abstände zwischen den Tagungen und der fehlende Rhythmus machten eine effektive Kontrolle der Parteiführung ebenso unmöglich wie eine geregelte Kommunikation zwischen Parteiführung und Parteibasis, von einer wirklichen Mitwirkung der gewählten Delegierten bei wichtigen Entscheidungen ganz zu schweigen. Kein Wunder, daß angesichts dieser unbefriedigenden Situation immer wieder die Forderung laut wurde, die Parteileitung möge doch in Zukunft die Gremien vor allem den Landesausschuß - wieder öfter einberufen ${ }^{548}$. Ein Delegierter aus München machte seinem Herzen auf dem Regensburger Parteitag der CSU im Juli 1952 mit folgenden Worten Luft:

"Als bisheriges Landesausschußmitglied habe ich einmal zuerst zu beanstanden, daß seit Mai vorigen Jahres [. . . ] bis heute keine einzige Landesausschußsitzung stattgefunden hat. (Sehr richtig!) Ich habe so das Empfinden, wie wenn der Landesausschuß die Fassade der Partei darstellen würde, so daß man sagen kann: Bitte, bei uns sind die Arbeiter, die Angestellten und die Beamten und die Geschäftsleute auch vertreten. Aber man frägt sie das ganze Jahr nie. Ich stehe auf dem Standpunkt: Der Landesausschuß bestimmt die Politik der Partei mit und ist mitverantwortlich. [...] Wir verlangen, daß bei wichtigen Fragen der Landesausschuß einberufen wird. [...] Das Mitbestimmungsrecht, das sogenannte Betriebsverfassungsgesetz hat sehr viel Staub aufgewirbelt. Die Parteileitung hat es nicht der Mühe wert gefunden, hierzu den Landesausschuß einzuberufen, auch nicht zum Schuman-Plan, zum Generalvertrag und all diesen Dingen. Meine Herren, wir müssen ja draußen die Verantwortung dafür tragen. Denn wenn der eine oder andere darüber etwas sagt, dann heißt es ja: Die CSU hat das besprochen. Das stimmt ja nicht, das ist doch die persönliche Meinung eines Parteifreundes. Wir verlangen, daß bei diesen Fragen der Landesausschuß gehört wird. ${ }^{\text {S49 }}$

Um die Meinung der Basis zu hören, wäre es aber nicht nur notwendig gewesen, Gremien wie den Landesausschuß öfter einzuberufen, sondern die Delegierten auch wirklich zu Wort kommen zu lassen. Offene Diskussionen waren jedoch nicht nach dem Geschmack der Parteiführung um Hans Ehard, die nichts mehr fürchtete als eine Fortsetzung der Flügelkämpfe ${ }^{550}$. Aus diesem Grund wurden alle Tagesordnungspunkte, die im Landesausschuß oder in der Landesversammlung Kontroversen hätten auslösen können, entweder unter Ausschluß der Öffentlichkeit besprochen, nur kurz angerissen oder überhaupt dilatorisch behandelt ${ }^{551}$. Während in der Ära Müller keine größere Ta-

desausschuß der CSU am 14./15. 1. 1950; NL Ehard 2468, Material für den Rechenschaftsbericht Hans Ehards vor der Landesversammlung der CSU am 17./18. 6. 1950 in Kempten; NL Ehard 437, Material für den Rechenschaftsbericht Hans Ehards vor der Landesversammlung der CSU am 13. 6. 1953 in Augsburg; ACSP, CSU-LL, Entwurf für den Rechenschaftsbericht Hans Ehards vor dem Landesausschuß der CSU am 25.10. 1952 in Dinkelsbühl, und den Findmitteln im ACSP.

547 BayHStA, NL Ehard 2468, Material für den Rechenschaftsbericht Hans Ehards vor der Landesversammlung der CSU am 17./18. 6. 1950 in Kempten.

${ }^{548}$ BayHStA, NL Ehard 1362, Memorandum "Zur Frage der Reorganisation der CSU“ vom 21.9. 1949, oder NL Ehard 102, Protokoll der Sitzung des geschäftsführenden Landesvorstands am 3. 10. 1949 (Emil Muhler).

549 ACSP, CSU-LL, Protokoll der Landesversammlung der CSU am 5./6. 7. 1952 in Regensburg (Delegierter Huber, München).

550 ACSP, CSU-LL, Protokolle der Landesversammlungen der CSU vom 27.-29. 5. 1949 in Straubing und am 5./6. 7. 1952 in Regensburg.

551 ACSP, CSU-LL, Protokoll der Sitzung des Landesvorstands am 9. 6. 1950 oder Protokoll der Landesversammlung der CSU am 9./10. 10. 1954 in Nürnberg. Münchner Merkur vom 16. 1. 1950: "CSU-Minister geben Rechenschaft. Landesausschuß-Sitzung in Fürth - Ausschluß der Öffentlichkeit bei partei-politischen Fragen“. 
gung ohne lautstarke Debatten geendet hatte, bestimmten nach 1949 Rechenschaftsberichte aus Partei und Fraktion sowie politische Referate der Regierungsmitglieder das Bild. Die Delegierten wurden mit solchen Reden geradezu überschüttet, doch sie konnten sich nur selten dazu äußern, da bei der gedrängten Tagesordnung meist die Zeit dazu fehlte oder die Sitzungsleitung ihr Veto einlegte. Kritik an dieser Praxis konnte nicht ausbleiben. Doch als Heinrich Junker ${ }^{552} 1954$ im Landesvorstand mehr Zeit für Diskussionen einforderte, hielt ihm der Parteivorsitzende die schlechten Erfahrungen entgegen, die man damit gemacht habe, und Generalsekretär Josef Brunner erklärte mit Blick auf die anstehenden Landtagswahlen sogar, es sei "gefährlich“, eine „breite Diskussion zu führen“"553.

Bei aller Kritik scheinen sich die meisten Delegierten aber daran gewöhnt zu haben, daß die Monotonie der Tätigkeitsberichte und Grundsatzreden die innerparteiliche Demokratie zu ersticken drohte. Als am Ende der Landshuter Tagung des Landesausschusses am 3. Juli 1954 ausnahmsweise noch Zeit für eine allgemeine Aussprache war, machte sich nach einigen Redebeiträgen verlegene Stille breit. Franz Josef Strauß, der sich „für alle Fälle als Reserveredner" hatte auf die Liste setzen lassen, mußte „lange vor Ablauf der festgesetzten Diskussionszeit feststellen“, daß die Rednerliste erschöpft war. So sah er sich gezwungen, „sozusagen als Reserve, Landsturm oder Landesschütze“ mit einer mehr als einstündigen Rede „in das rhetorische Gefecht“ einzugreifen, das eigentlich gar nicht stattgefunden hatte ${ }^{554}$.

Während die Parteiorganisation mehr und mehr an Bedeutung verlor, verlagerten sich die Entscheidungsprozesse in Gremien, die in der Satzung nicht oder nicht in dieser Form vorgesehen waren. Unter dem Deckmantel der Demokratisierung der Parteiführung ${ }^{555}$ wurden Persönlichkeiten regelmäßig zu den Sitzungen des geschäftsführende Landesvorstands geladen, die dazu nicht legitimiert waren. Es gab in der Praxis kaum einen Unterschied zwischen den regulär gewählten Vorstandsmitgliedern und den Sitzungsteilnehmern, die von Ehard aus Gründen der Opportunität zu den Beratungen hinzugezogen wurden. Aber der geschäftsführende Landesvorstand mußte seine Funktion als wichtigstes Führungsgremium der CSU in den ersten Jahren der Ära Ehard ohnehin an die von der Satzung nicht gedeckte Konferenz der Bezirksvorsitzenden abtreten ${ }^{556}$. Die Vorsitzenden der zehn Bezirksverbände waren an der Wahl Ehards

552 Heinrich Junker, geb. 30.8. 1911 in München, gest. 6. 4. 1993 in Dachau, kath., Diplom-Vermessungsingenieur, nach kurzer Referendarzeit im bayerischen Vermessungsdienst Regierungsbaurat bei der Wehrmacht, Teilnahme am Zweiten Weltkrieg (zuletzt Major) und amerikanische Kriegsgefangenschaft, 1945-1947 Leiter des Vermessungsamts Dachau, Dozent an der Staatsbauschule und am Oskar-von-Miller-Polytechnikum in München, stellvertretender Landrat, 1948-1957 Landrat in Dachau, 1953/1954 Bezirksrat (CSU) für Oberbayern, 1950-1967 Mitglied des Landesvorstands der CSU, 1950-1970 MdL (CSU), 1950-1954 Mitglied des Fraktionsvorstands, 1957-1962 Staatssekretär im bayerischen Innenministerium, 1962-1966 bayerischer Innenminister, 1966-1972 Präsident der Bayerischen Landesbodenkreditanstalt, 1972-1976 Vizepräsident, 1976/1977 Präsident der Bayerischen Landesbank.

553 ACSP, CSU-LL, Protokoll der Sitzung des Landesvorstands am 8. 10. 1954.

554 ACSP, CSU-LL, Protokoll der Sitzung des Landesausschusses der CSU am 3. 7. 1954 in Landshut.

555 ACSP, CSU-LL, „Besprechungsprotokoll für die Sitzung des geschäftsführenden Vorstandes unserer Partei“ am 5.12. 1949 vom 3. 12. 1949 und Protokoll der Sitzung des Landesvorstands am 17. 12. 1949.

556 Zur Konferenz der Bezirksvorsitzenden: ACSP, CSU-LL, Protokoll und Notizen über die Sitzung des geschäftsführenden Landesvorstands am 5. 12. 1949 und Protokoll der Landesversammlung der CSU am 17./18. 6. 1950 in Kempten (Hans Ehard). 
maßgeblich beteiligt gewesen und erwarteten nun eine angemessene Beteiligung an der Macht ${ }^{557}$. Eine enge Zusammenarbeit mit den „Bezirksfürsten“ hatte für den Parteivorsitzenden durchaus Vorteile. Gespräche in kleiner Runde, die sich kurzfristig arrangieren ließen, waren ein probates Mittel, um anstehende organisatorische Fragen zu besprechen, Tagungen von Landesvorstand, Landesausschuß und Landesversammlung im Detail vorzubereiten oder Stimmungsberichte aus den Regionen einzuholen, auf die Hans Ehard und seine Strategen angewiesen waren, nachdem die Landesgeschäftsstelle nicht mehr in der Lage war, die Kommunikation mit den regionalen Suborganisationen aufrechtzuerhalten. Die Konferenz der Bezirksvorsitzenden konnte zwar keine bindenden Beschlüsse fassen, es war aber kaum denkbar, daß von den Bezirksvorsitzenden einhellig mitgetragene Entscheidungen nicht die Zustimmung der eigentlich zuständigen Parteigremien gefunden hätten.

Auch der 1948 gegründete Wirtschaftsbeirat der Union wurde zusehends einflußreicher. Der Wirtschaftsbeirat, ein eingetragener Verein außerhalb der eigentlichen Parteiorganisation, hatte es sich zur Aufgabe gemacht, die Repräsentanten der bayerischen Wirtschaft für die CSU zu gewinnen, Spenden zu sammeln und „der Partei in Wirtschaftsfragen beratend zur Seite zu stehen“558. Darüber hinaus kam dem Wirtschaftsbeirat als Vermittler zwischen der chronisch finanzschwachen CSU und dem Landesverband der Bayerischen Industrie, auf dessen Unterstützung die Partei dringend angewiesen war, eine wichtige Rolle $\mathrm{zu}^{559}$. Anders als die CSU hatte der Wirtschaftsbeirat eine gut funktionierende Geschäftsstelle und keine finanziellen Sorgen. So kam es, daß aufwendige Großveranstaltungen mit Rednern wie Konrad Adenauer, Fritz Schäffer oder Robert Pferdmenges nicht von der CSU, sondern vom Wirtschaftsbeirat organisiert wurden ${ }^{560}$. Bei dieser Konstellation konnte es nicht ausbleiben, daß der Wirtschaftsbeirat von der Peripherie immer mehr ins Zentrum der innerparteilichen Willensbildung rückte. Mit Franz Elsen ${ }^{561}$ wurde im Dezember 1949 der Generalsekretär des Wirtschaftsbeirats zum Landesschatzmeister der CSU ernannt ${ }^{562}$, und wichtige programmatische Impulse gingen nicht von den Gremien der Partei, sondern von den Arbeitsausschüssen des Wirtschaftsbeirats aus ${ }^{563}$.

557 BayHStA, NL Ehard 102, Protokoll der Tagung der Bezirksvorsitzenden am 28. 10. 1949 (Alois Hundhammer).

558 ACSP, CSU-LL, Protokoll der Sitzung des Landesvorstands am 17. 12. 1949.

559 BSB, NL Schwend 11, Aktennotiz über ein Gespräch mit Generaldirektor Otto Seeling am 20.6. 1950.

560 BayHStA, NL Ehard 2468, Material für den Rechenschaftsbericht Hans Ehards vor der Landesversammlung der CSU am 17./18. 6. 1950 in Kempten.

561 Franz Elsen, geb. 11. 7. 1906 in München, gest. 23. 2. 1980 in München, kath., nach Besuch der Realschule landwirtschaftliche Praktika und Besuch der Landwirtschaftsschule, Abitur, seit 1926 Studium der Agrarwissenschaft und Nationalökonomie in München und Erlangen, Diplom-Volkswirt, vor 1933 BVP-Mitglied, 1934-1937 bei der Bayerischen Staatsbank tätig, 1937-1943 Gutsverwalter in Wertheim, 1943-1945 Teilnahme am Zweiten Weltkrieg, 1945 Unterstützung der Freiheitsaktion Bayern, Mitbegründer der CSU, 1949-1952 Landesschatzmeister der CSU, 1949-1952 Mitglied des Landesvorstands und des geschäftsführenden Landesvorstands der CSU, 1948 Mitinitiator des Wirtschaftsbeirats der Union und dessen langjähriger Generalsekretär, 1948/1949 MdWR (CSU), 1949 Mitglied der Bundesversammlung (CSU), 1950-1966 MdL (CSU), langjähriger Direktor der Bayerischen Staatsbank, 1958-1966 Mitglied der deutschen Atomkommission, Ehrendoktorwürde der Universität München.

562 ACSP, CSU-LL, Protokoll der Sitzung des Landesvorstands am 17. 12.1949.

${ }^{563}$ ACSP, CSU-LTF II/2, 6-10/4, Heinz Lechmann an Wilhelm Röhrl vom 9. 7. 1953 und Entwurf für ein Agrarprogramm der CSU. 
Auch die Staatskanzlei griff wiederholt in die innerparteiliche Willensbildung ein und übernahm seit 1949 immer mehr Funktionen von der ineffizienten Landesgeschäftsstelle. Hans Ehard „ließ die Partei über CSU-nahe Kreise und Mitglieder in der bayerischen Staatsverwaltung gewissermaßen mitverwalten " ${ }^{464}$. Vor allem der ehemalige BVP-Politiker Karl Schwend, der seit 1950 an der Spitze der Staatskanzlei stand, und sein Mitarbeiter Ernst Deuerlein kümmerten sich um die drängendsten Probleme. Sie sammelten Informationen über die wichtigsten Vorgänge in der $\mathrm{CSU}^{565}$, entwarfen Konzepte für Wahlkämpfe ${ }^{566}$, bereiteten die Auftritte Ehards in den Parteigremien vor ${ }^{567}$ und hielten über den Bayerischen Bevollmächtigten beim Bund den Kontakt mit der Bonner Landesgruppe ${ }^{568}$. Die Landesgeschäftsstelle konnte dagegen nur mit Mühe die elementarsten Aufgaben einer Parteizentrale erfüllen und war so wenig autonom, daß sich der stellvertretende Vorsitzende des CSU-Kreisverbands Starnberg im September 1950 tief verunsichert zu der Frage gezwungen sah, ob man sich künftig auch „in parteilichen Angelegenheiten an die Staatskanzlei“ zu wenden habe ${ }^{569}$.

Die Staatskanzlei zeichnete auch für das Aktionsprogramm der CSU für den Landtagswahlkampf 1954 verantwortlich, das einzige offizielle programmatische Dokument der bayerischen Unionspartei in der ganzen Ära Ehard. Die Entstehungsgeschichte dieses Programms zeigt deutlich, wie wenig die Partei als solche mittlerweile zu sagen hatte. Die Regierungsmitglieder der CSU hatten auf Ersuchen der Staatskanzlei „ihre Gedanken über die künftige Arbeit" der bayerischen Unionspartei zu Papier gebracht $^{570}$. Die eingehenden Texte wurden in der Staatskanzlei redaktionell bearbeitet und ergänzt, bevor sie im Oktober 1954 dem Parteitag als Wahlkampfgrundlage präsentiert werden sollten. Selbst der Landesvorstand erfuhr erst einen Tag vor Beginn der Landesversammlung von diesem Vorhaben. Doch als der Bundestagsabgeordnete Gerhard Wacher „sein Erstaunen darüber“ ausdrückte, „daß das Aktionsprogramm heute vorgelegt werden und man sich dahinterstellen solle", erklärte Hans Ehard nur, dieses Dokument enthalte nichts, was für die CSU neu sei, und man käme zu keinem Ende, wollte "man das Aktionsprogramm im einzelnen diskutieren “571. Als die Landesversammlung am 9. Oktober 1954 zusammentrat, wurde die programmatische Plattform für die heiße Phase des Wahlkampfes nicht einmal in ihren Grundzügen vorgestellt, geschweige denn von den Delegierten diskutiert und verabschiedet. Ehard kündigte lediglich an, das Aktionsprogramm werde allen Teilnehmern in gedruckter Fassung zugehen und die Arbeit der Redner in den folgenden Wochen sicherlich wesentlich erleichtern ${ }^{572}$.

564 Mintzel, Anatomie, S. 223.

565 Vgl. die Vielzahl von Berichten für Ehard in: BSB, NL Schwend.

566 BSB, NL Schwend 44, Strategiepapier Ernst Deuerleins zur Vorbereitung der Landtagswahlen in Bayern vom 21. 10. 1953.

567 Diesbezügliche Ausarbeitungen beispielsweise in: BayHStA, NL Ehard 437, NL Ehard 1421 oder NL Ehard 2468.

568 Viele diesbezügliche Berichte aus der Bayerischen Vertretung in Bonn finden sich in: BSB, NL Schwend 18, NL Schwend 19 und NL Schwend 51.

569 ACSP, CSU-LTF I, 15-20/0, CSU-Kreisverband Starnberg an Alois Hundhammer vom 29. 9. 1950.

570 ACSP, CSU-LL, Protokoll der Sitzung des Landesvorstands am 8. 10. 1954; Textentwürfe und ein gedrucktes Exemplar des Aktionsprogramms finden sich in: BSB, NL Schwend 15.

571 ACSP, CSU-LL, Protokoll der Sitzung des Landesvorstands am 8. 10. 1954.

572 ACSP, CSU-LL, Protokoll der Landesversammlung der CSU am 9./10. 10. 1954 in Nürnberg. 
Während die Parteiorganisation „jegliche Eigendynamik im politischen Leben Bayerns" zu verlieren drohte ${ }^{573}$, entwickelten sich die Landtagsfraktion und die Bonner Landesgruppe zum eigentlichen Rückgrat der CSU. Die parlamentarischen Gremien waren organisatorisch intakt, konnten auf eigene Geschäftsstellen zurückgreifen und standen dank der Fraktionsbeiträge der Abgeordneten auch finanziell auf eigenen Füßen. Die Landtagsfraktion verfügte mit der CSU-Correspondenz seit Herbst 1949 sogar über ein eigenes Publikationsorgan, das vor allem die von den Anhängern der Union in den ländlichen Regionen Bayerns viel gelesene Lokal- und Heimatpresse mit Informationen versorgte ${ }^{574}$. Hatte sich der Dualismus von Partei und Landtagsfraktion bis 1949 immer wieder als eines der Grundprobleme der CSU erwiesen, so löste sich dieses Problem mit der Degeneration der Parteiorganisation gleichsam von selbst. Es fehlte jedoch nicht an Stimmen, die vor den negativen Folgen dieser Entwicklung warnten ${ }^{575}$. So erklärte der Augsburger Bezirksvorsitzende Josef Fischer, selbst ein ehemaliger Landtagsabgeordneter, im Januar 1954 vor dem Landesausschuß:

„Nun meine Damen und Herren, der Landesausschuß der CSU kommt verhältnismäßig so selten zusammen, daß er sich auch einmal Gedanken über die eigene Partei und über die Wege, die zur politischen Willensbildung innerhalb der Partei führen, machen sollte. Gerade für eine permanente Regierungspartei ist es außerordentlich schwierig, neben den Aufgaben der Staatspolitik und öffentlichen Politik auch an sich selbst zu denken; in etwa diesen Willen auch den Parlamentsmitgliedern und der Regierung nahezubringen und darzustellen, ist uns oft sehr wenig Gelegenheit gegeben. Diese Frage ist nicht dadurch gelöst, daß Parlament und Regierung eine ausgezeichnete Arbeit leisten und daß wir als Partei und auch als Parteiorgan beiden, Fraktions- wie Regierungsmitgliedern, den tiefsten Dank aussprechen, sondern es handelt sich darum, ob die Partei bei dieser Art unseres eigenen Gebarens die Lebendigkeit erhält und auch der Verantwortung, die sie für die Politik mit trägt, auf die Dauer gewachsen ist in der Stunde, in der sie es einmal braucht. Nicht dadurch also, daß unsere Abgeordneten gewissermaßen das von vornherein schon tun, was wir nachher gern billigen, und auch nicht dadurch, daß der Landesvorsitzende gleichzeitig Ministerpräsident ist, ist diese Frage gelöst. [...] Wir wollen gar nicht mit dem, was geschehen ist, unzufrieden sein. Aber wir wollen aus Systemgründen heraus nicht, daß uns Fraktion und Regierung allzu viel von der Verantwortung abnehmen, die dem Landesausschuß zusteht. “576

Doch trotz aller Mahnungen dominierten die Inhaber von Ämtern oder Mandaten auf allen Ebenen ${ }^{577}$. Die Parteiorganisation löste sich ,in ein diffuses Gebilde vieler kleiner übers Land verstreuter Honoratiorenzirkel auf, die sich um politische Mandatsträger und Exponenten der CSU im bayerischen Staatsapparat gruppierten“578. Viele Ortsund Kreisverbände waren nach dem Zusammenbruch des Parteiapparats in einen Dornröschenschlaf versunken, aus dem sie lediglich erwachten, wenn Wahlen anstanden. Belebende Impulse von der Landesleitung waren kaum zu erwarten. Die unterbesetzte Landesgeschäftsstelle unter der Leitung von Josef Brunner, der Dezember 1949 zum Stellvertreter des Generalsekretärs ernannt worden war und drei Jahre später

\footnotetext{
${ }^{573}$ Mintzel, Anatomie, S. 224.

${ }^{574}$ Eine Fülle von Material zur Entwicklung der CSU-Correspondenz - u. a. Kassenbücher, Abonnentenlisten und Geschäftsberichte - findet sich im Bestand Landtagsfraktion des ACSP.

575 Vgl. Müller, Festansprache, in: 10 Jahre CSU, S. $48 \mathrm{f}$.

${ }^{576}$ ACSP, CSU-LL, Protokoll der Sitzung des Landesausschusses der CSU am 15. 1. 1954 in Rothenburg ob der Tauber.

577 Beispiele dafür finden sich in: BayHStA, NL Ehard 370, Erfahrungsbericht Alois Engelhards über seine Inspektionsreise durch die Oberpfalz vom 26. 1.-29. 1. 1953.

578 Mintzel, Anatomie, S. 224.
} 
selbst zum Generalsekretär avancierte ${ }^{579}$, hatte praktisch keine Möglichkeit, steuernd in die Angelegenheiten der Suborganisationen einzugreifen. Was fehlte, war ein Netz funktionierender, hauptamtlich geführter Geschäftsstellen in den Kreisen, mochte es auch noch so weitmaschig sein.

Die CSU verkümmerte in der Ära Ehard mehr und mehr zu einer mitgliederschwachen Honoratiorenpartei und erinnerte - von außen betrachtet - an die Bayerische Volkspartei ${ }^{580}$. Hatten Josef Müller und sein Anhang in der Gründungsphase der CSU noch großen Wert darauf gelegt, daß prominente Mitglieder der BVP in der neuen Partei nicht allzu sehr herausgestellt wurden, so änderte sich dies spätestens nach dem Sturz des Ochsensepp. Mit Fritz Schäffer feierte der ehemalige BVP-Vorsitzende im Sommer 1949 auf der Bonner Bühne ein ebenso unerwartetes wie triumphales Comeback; Georg Stang, von 1919 bis 1929 stellvertretender Vorsitzender der BVP-Landtagsfraktion und von 1929 bis 1933 Präsident des bayerischen Landtags, wurde 1950 erneut zum Landtagspräsidenten gewählt ${ }^{581}$; Prälat Georg Meixner, ebenfalls ein früherer BVP-Parlamentarier, übernahm im August 1951 den Vorsitz der CSU-Landtagsfraktion und stieg damit zu einem der mächtigsten Männer in der bayerischen Unionspartei auf ${ }^{582}$; als Nachfolger des ehemaligen BVP-Generalsekretärs Anton Pfeiffer übernahm mit Karl Schwend ein Mitbegründer der BVP die Leitung der Staatskanzlei, der vor 1933 zu den einflußreichen Beratern von Prälat Wohlmuth, Ministerpräsident Held und Fritz Schäffer gehört hatte ${ }^{583}$. Auch die Landtagsfraktion und die Landesgruppe hatten einen unübersehbaren BVP-Touch. Von den 1949 gewählten 24 Bundestagsabgeordneten der CSU hatten mindestens zehn der BVP angehört, von den 1950 gewählten 64 Landtagsabgeordneten mindestens $25^{584}$. Doch die CSU knüpfte nicht nur personell wieder verstärkt an die BVP an. Als 1950 über eine neue Parteizeitung beraten wurde, stand sofort der Name des alten Zentralorgans der BVP im Raum: Bayerischer Kurier. Daß das Parteiblatt dann doch Bayern-Kurier hieß, lag nicht an den Bedenken Hans Ehards, der Hemmungen dagegen hatte, zu sehr ins Fahrwasser der BVP zu geraten ${ }^{585}$, sondern daran, daß man sich mit dem Rechtsnachfolger des alten Verlages nicht über die Urheberrechte einigen konnte ${ }^{586}$.

Hinter dieser Fassade aus BVP-Tradition und konservativer Rückschrittlichkeit formierten sich jedoch Kräfte, die „einen möglichen Kurs der CSU-Politik in Richtung

579 ACSP, CSU-LL, Protokoll der Sitzung des Landesvorstands am 17. 12. 1949; Bayern-Kurier vom 10. 1. 1953: „Interne Vorbereitung auf die Bundestagswahlen. Josef Brunner neuer Generalsekretär - Franz Strauß arbeitet weiter mit“. Josef Brunner, geb. 21.6. 1909 in München, gest. 1982, kath., bis 1929 Bankkaufmann in München, anschließend Studium der Wirtschaftswissenschaften in Berlin, bis 1933 Vorsitzender des Reichsverbands Deutscher Zentrumsstudenten in Berlin, Referent für hochschulpolitische und studentische Fragen im Generalsekretariat der Zentrumspartei, Mitbegründer der CSU, 1946-1948 Vorsitzender des Dienstag-Clubs, 1950-1954 Mitglied des Landesvorstands, 1952-1954 Mitglied des geschäftsführenden Landesvorstands der CSU, 1954 nach finanziellen Unregelmäßigkeiten in der Landesleitung als Generalsekretär suspendiert.

580 Vgl. Mintzel, Anatomie, S. 223.

581 ACSP, CSU-LTF I, 15-14, Protokoll der Fraktionssitzung am 7. 2. 1950.

582 ACSP, CSU-LTF II/1, 15-14, Protokoll der Fraktionssitzung am 8. 8. 1951.

583 Vgl. Gelberg, Hans Ehard, S. 548.

${ }^{584}$ Die Zahlenangaben beruhen auf einer eigenen Auszählung.

585 ACSP, CSU-LL, Protokoll der Sitzung des geschäftsführenden Landesvorstands am 4. 2. 1950.

586 BayHStA, NL Ehard 1363, Aktennotiz Lorenz Sedlmayrs über einen Besuch bei Kommerzienrat Haas, Augsburg, am 14. 2. 1950. 
auf die ehem. bayer. Volkspartei hin" ablehnten ${ }^{587}$ und eine umfassende Reform der CSU forderten. Dazu gehörten Teile der Landesgruppe, die meisten Repräsentanten der evangelischen Parteimitglieder und vor allem die Vertreter der jungen Generation. Franz Josef Strauß hatte schon früh gegen die „starke Überalterung" der Partei protestiert und ihre „Verjüngung und Radikalisierung im guten Sinne" angemahnt ${ }^{58}$. Auch Hanns Seidel gehörte zu den wenigen arrivierten CSU-Politikern, die offen dafür eintraten, die Häufung von Ämtern in der Partei zu bekämpfen und der jungen Generation eine Chance zu geben ${ }^{589}$. Die Junge Union machte sich diese Forderungen zu eigen, stieß damit aber bei den gesetzten Herren in der Parteiführung auf wenig Gegenliebe. Als es Franz Sackmann von der Jungen Union im Sommer 1951 vor der Landesversammlung wagte, den Führungstil Hans Ehards zu kritisieren, „verfärbte“ sich das Gesicht des Ministerpräsidenten sekundenlang, und als Sackmann weiter erklärte, „daß künftig wieder die Partei die Politik der CSU-Regierungsmitglieder bestimmen müsse“ und nicht wie bisher die Staatskanzlei, verlor Karl Schwend zornbebend die Fassung ${ }^{590}$. Im Kern ließen sich die Forderungen der Jungen Union auf zwei Punkte reduzieren: die stärkere Berücksichtigung des politischen Nachwuchses bei der Auswahl der Kandidaten für Wahlämter und die organisatorische und programmatische Wiederbelebung der Partei. In einer Entschließung, die Ende 1951 auf dem Landestag der Jungen Union in Eichstätt diskutiert wurde, hieß es:

„Eine echte Dynamik innerhalb der Partei kann nur aufrecht erhalten werden durch eine mutige und lebendige Auseinandersetzung zwischen den Führungsorganen und den Mitgliedern. Nur auf diese Weise ist Gewähr dafür geboten, daß das politische Wollen der Mitglieder durch die F[ü]hrungsorgane der Partei und ihre Mandatsträger verwirklicht wird. Die Politik der CSU darf nicht nur von den Fraktionen bestimmt, sondern muß vom politischen Willen der Partei getragen werden. “591

Unter der tatkräftigen Führung von Franz Sackmann und Fritz Pirkl setzte die Junge Union zunächst alles daran, um wenigstens in den eigenen Reihen die Voraussetzungen dafür zu schaffen, diese Forderungen praktisch umzusetzen. Zwischen 1952 und 1954 wurden zahlreiche Kreisverbände der Jungen Union neu gegründet, die damit - nach einer Angabe von Franz Sackmann - in ganz Bayern etwa 13000 Mitglieder aufzuweisen hatte ${ }^{592}$. Besonders intensiv bemühte man sich um die Schulung und den Einsatz geeigneter Redner, die schon im Bundestagswahlkampf 1953 auf sich aufmerksam machten. Ebenso aufsehenerregend wie erfolgreich waren die Versammlungswellen der Jungen Union, die schwerpunktmäßig in bestimmten Land- und Stadtkreisen abgehalten wurden und auch Gemeinden erreichten, in denen oft seit Jahren kein Redner

587 Archiv der CSU-Landesgruppe, Protokoll der Landesgruppensitzung am 20. 1. 1950.

588 BayHStA, NL Ehard 2468, Protokoll der Sitzung des geschäftsführenden Landesvorstands am 5.6. 1950.

589 ACSP, CSU-LTF II/1, 15-14, Protokoll der Fraktionssitzung am 30. 1. 1952.

590 SZ vom 25. 6. 1951: „Unter dem Himmel von Reichenhall. . . ein wohlgelungener Parteikongreß der CSU/Ochsensepp als Meister der Regie“; zur scharfen Reaktion Fritz Schäffers auf den Auftritt Sackmanns vgl. ACSP, CSU-LL, Protokoll der Landesversammlung der CSU am 24. 6. 1951 in Bad Reichenhall.

591 BSB, NL Schwend 3, Bericht Ernst Deuerleins über den Landestag der Jungen Union in Eichstätt vom 3. 12. 1951; die Resolutionen sind diesem Bericht als Anlage beigefügt.

$592 \mathrm{Vgl}$. Franz Sackmann, Rückblick, in: 40 Jahre Junge Union Bayern. 1947-1987, hrsg. von der Jungen Union Bayern, München 1987, S. 24-28. 
der CSU mehr aufgetreten war. Anders als die Führungsgremien der CSU in der Ära Ehard bemühte sich die Junge Union auch intensiv um die Diskussion programmatischer Grundsatz- und politischer Sachfragen, bezog dabei aber immer wieder Positionen, die in der Parteiführung nicht gerade Begeisterungsstürme auslösten. Das Ziel der Jungen Union war eindeutig: zum Motor der CSU zu werden. Bei öffentlichen Anlässen machte Hans Ehard gute Miene zum bösen Spiel und lobte die aktive Arbeit der jungen Parteifreunde ${ }^{593}$. Intern wußte man aber mit den meist von Sackmann temperamentvoll vorgetragenen Forderungen der JU nicht mehr anzufangen, als sie als "Anflegeleien" abzuqualifizieren ${ }^{594}$.

Das Mißtrauen gegen die Junge Union wurde nicht zuletzt von dem Verdacht geschürt, sie sei der verlängerte Arm Josef Müllers ${ }^{595}$. Tatsächlich hatte den ehemaligen Landesvorsitzenden stets ein besonderes Verhältnis mit der jungen Generation verbunden, und mit Franz Sackmann oder Friedrich Zimmermann hatten aufstrebende Nachwuchspolitiker wichtige Ämter in der JU inne, die bei ihm gleichsam in die Lehre gegangen waren. Zum eigentlichen Vorbild und Orientierungspunkt der Jungen Union wurde aber immer mehr Franz Josef Strauß. Dies wurde besonders auf der Regensburger Landesversammlung im Juli 1952 deutlich, als es nach einem offensichtlichen Regiefehler zu einem nicht vorgesehenen Schlagabtausch über die Person des Landesvorsitzenden kam. Wie 1950 und 1951 stellte sich Ehard zur Wiederwahl, doch diesmal hatte er in Franz Josef Strauß einen Konkurrenten, der vor allem von den jüngeren Delegierten favorisiert wurde. Strauß zog seine Kandidatur zwar in letzter Sekunde zurück, erhielt aber dennoch 93 von 472 abgegebenen Stimmen ${ }^{596}$. Hanns Seidel zeigte sich von der Vorstellung der Jungen Union in Regensburg durchaus angetan, als er am Tag nach der Landesversammlung an eine Vertraute schrieb:

„Am Nachmittag fand sodann die Aussprache über die Referate und gleichzeitig über die Wahl des Landesvorsitzenden statt. [...] Während Schäffer nicht nominiert wurde, schlug man neben Ehard auch Strauss zum Vorsitzenden vor. Die Befürworter seiner Kandidatur stammten ausschliesslich aus der Jungen Union'. Die jungen Leute taktierten ausserordentlich geschickt. Sie diskutierten ohne jede persönliche Schärfe, erkannten die Leistung von Dr. Ehard durchaus an, verlangten aber den lebendigen Strauss als den kompromisslosen Gegner der SPD zum Vorsitzenden. Hätte man die Regie nicht allzusehr gemerkt, dann wäre die Wirkung dieser Redner ohne Zweifel sehr stark gewesen. Weil sie sich [von] jeder persönlichen Auseinandersetzung fernhielten und ihre Argumente sehr geschickt vortrugen, hätten sie ganz ohne Zweifel eine viel stärkere Wirkung gehabt, wenn man nicht den Eindruck gehabt hätte, dass sich hier die Junge Union - mit Dr. Müller im Hintergrund - auf eine Taktik festgelegt hatte. [...] Es hat sich gezeigt, dass in der Jungen Union ein Reservoir von Leuten vorhanden ist, die zu denken und zu kämpfen verstehen. “597

\footnotetext{
593 Beispielsweise ACSP, CSU-LL, Protokoll der Sitzung des Landesausschusses der CSU am 15. 1. 1954 in Rothenburg ob der Tauber.

594 BSB, NL Schwend 13, streng vertrauliche Aktennotiz über die bevorstehende Landesversammlung vom 2.7. 1952.

595 SZ vom 25. 6. 1951: „Unter dem Himmel von Reichenhall. . . ein wohlgelungener Parteikongreß der CSU/Ochsensepp als Meister der Regie“; ACSP, NL Seidel 19, Hanns Seidel an Hildegunde Feilner vom 7.7. 1952.

596 ACSP, CSU-LL, Protokoll der Landesversammlung der CSU am 5./6. 7. 1952 in Regensburg; vgl. auch Gelberg, Hans Ehard, S. $404 \mathrm{ff}$.

597 ACSP, NL Seidel 19, Hanns Seidel an Hildegunde Feilner vom 7. 7. 1952.
} 
Doch dieses Potential war mehr oder weniger blockiert und wurde erst freigesetzt, als die CSU nach der Bildung der Viererkoalition in eine tiefe Krise stürzte.

\title{
5. Ungelöste Probleme: Satzungsfragen, Mitgliederentwicklung, Parteifinanzen und Parteiapparat in der Ära Ehard
}

\author{
a) Eröffnungsbilanz
}

Eine der größten Belastungen der CSU in der Ära Ehard war zweifellos der fortschreitende Zerfall des Parteiapparats. Die Parteiführung bemühte sich zwar immer wieder, die Parteiverwaltung zu reorganisieren und die Parteiorganisation zu aktivieren, aber keiner dieser Initiativen war ein dauerhafter Erfolg beschieden. Der trostlose Zustand des Parteiapparats war nicht zuletzt eine Folge des schweren Erbes der Organisationsund Pressepolitik Josef Müllers, die nach der Währungsreform in einem Finanzchaos ohnegleichen versunken war. Als Hans Ehard Ende Mai 1949 sein neues Amt antrat, hatten sich die Zahlungsverpflichtungen der Landesgeschäftsstelle auf mehr als 111000 DM summiert ${ }^{598}$, gar nicht zu reden von den Schulden des Parteiverlags, die mehr als 200000 DM betrugen ${ }^{599}$. Alle, die gehofft hatten, mit der Wahl Ehards würden auch die Parteifinanzen wieder in Ordnung kommen, sahen sich rasch getäuscht. Alois Hundhammer hatte auf der Straubinger Landesversammlung noch mit dem Argument für seinen Kandidaten geworben, die Mitgliederbeiträge würden wieder fließen, wenn nur erst Josef Müller als Landesvorsitzender abgelöst worden sei ${ }^{600}$. Doch die Kreisverbände machten nach der Entscheidung von Straubing keinerlei Anstalten, ihren Verpflichtungen nachzukommen und ihre Beitragsschulden zu begleichen, die allein für die Monate Januar bis Mai 1949 mehr als 67000 DM betrugen ${ }^{601}$. Im Gegenteil: Der Trend, Mitgliederbeiträge nicht nach München abzuführen oder sie überhaupt nicht zu kassieren, hielt an, und auch der galoppierende Mitgliederschwund ging weiter. Im Mai 1949 wurden noch 69444 CSU-Mitglieder gezählt, ein Jahr später nur noch $61763^{602}$, wobei fraglich ist, ob diese Zahlen nicht viel zu hoch angesetzt waren, da eine Reihe von Kreisverbänden gar nicht mehr in der Lage war, korrekte Angaben zu machen und daher gar keine oder nur fiktive Zahlen an die Landesgeschäftsstelle weiterleitete.

Die Reste des Parteiapparats - gleich ob auf Landes-, Bezirks- oder Kreisebene konnten trotz aller Anstrengungen oft nicht einmal das Notwendigste an organisatorischer Arbeit leisten. Dies mußte beispielsweise Fritz Schäffer erfahren, als er im Vorfeld des Landtagswahlkampfes 1950 eine seit langem geplante Veranstaltung in München abhielt. Solange Josef Müller die Partei geführt hatte, war Schäffer beileibe kein

\footnotetext{
${ }^{598}$ BayHStA, NL Ehard 115, Bericht Karl Sigmund Mayrs über die finanzielle und organisatorische Situation der Landesgeschäftsstelle nach dem Stand vom 31. 5. 1949.

${ }^{599}$ BayHStA, NL Ehard 1362, Aufstellung der Schulden des Verlags Der Gerade Weg vom 3. 10.1949.

600 ACSP, NL Müller 16, Protokoll der Landesversammlung der CSU vom 27.-29. 5. 1949 in Straubing.

${ }^{601}$ BayHStA, NL Ehard 115, Bericht Karl Sigmund Mayrs über die finanzielle und organisatorische Situation der Landesgeschäftsstelle nach dem Stand vom 31. 5. 1949.

602 IfZ-Archiv, RG 260, 13/150-1/9, Politischer Tätigkeitsbericht der CSU für den Monat Mai 1949 vom 20.6. 1949; ACSP, CSU-LL, Protokoll der Landesversammlung der CSU am 17./18.6. 1950 in Kempten.
} 
Freund intensiver Organisationspolitik gewesen, doch die Vorbereitung dieser Versammlung war so "ausgeprochen schlecht" gewesen, daß er sich gezwungen sah, bei Hans Ehard das „Versagen“ der CSU anzuprangern ${ }^{603}$. Der ehemalige BVP-Vorsitzende scheute sich nicht, Ehard mit dem kleinen Einmaleins der Parteiarbeit zu konfrontieren, als er schrieb:

„Die CSU kann in die Landtagswahlen [. . . ] nur eintreten, wenn sie ihre Organisation besser ausbaut. Ich möchte Sie daher als Landesvorsitzenden bitten, sich um die Organisation anzunehmen und das Generalsekretariat auch entsprechend anzuweisen. Es müssen den verschiedenen Bezirksund Kreisverbandssekretären Instruktionen erteilt werden, wie solche V[e]rsammlungen vorzubereiten sind, wie und in welcher Form zu plakatieren ist, wie die Versammlungen in der Presse anzukündigen sind, wie der Rundfunk zu verständigen ist, wie die Berichterstattung nach dem Vortrag zu beeinflussen ist und wie die Mitglieder der Parteiorganisation zum Besuch der öffentlichen Kundgebungen, die für die ganze Partei werben sollen, anzuhalten sind. Ich bitte, das Landessekretariat zu verständigen, dass es sich, wenn ein Minister des Kabinetts im Lande oder im Bunde spricht, darum kümmert, dass die entsprechenden organisatorischen Vorbereitungen von den örtlichen Stellen auch getroffen werden."

Was Schäffer erleben mußte, war beileibe kein Einzelfall. Das organisatorische Unvermögen von Teilen der CSU scheint in den ersten Jahren der Ära Ehard vielmehr eher die Regel als die Ausnahme gewesen zu sein. So wußte sich Rudolf Schießl, der altgediente Geschäftsführer der niederbayerischen CSU, im April 1950 nicht mehr anders zu helfen, als in einem Rundschreiben, das an Deutlichkeit nichts zu wünschen übrig ließ, das ganze Ausmaß des Desasters in Niederbayern offenzulegen:

„Von unseren 26 Kreisverbänden halten fast ein Dutzend keine Verbindung mehr mit dem Bezirksverband. Zum Teil seit mehr als Jahresfrist. Keine Anfrage wird beantwortet, auch wenn sie in wenigen Sätzen mittels Postkarte erledigt werden könnte. Wenn nicht einmal eine solche geringe Arbeit geleistet wird, ist kaum anzunehmen, daß Aufklärungsversammlungen vorbereitet oder durchgeführt werden. Wahrscheinlich ruht die gesamte Parteiarbeit und die Kreisvorstandschaft steht nur auf dem Papier. Es ist klar, daß der Kreisvorsitzende ohne Unterstützung in seiner Arbeit gelähmt ist. Es wurde schon wiederholt darauf hingewiesen, daß dann eben Persönlichkeiten, die zur Mitarbeit gewillt sind, gefunden werden müssen. Was nützt die Wahl eines Gremiums, wenn es bis zur nächsten Wahl die Hände untätig in den Schoß legt?! Die Kreisverbände klagen, sie hätten keine Mitarbeiter und keine Redner. Sie haben aber Mandatsträger, die ihr Mandat durch die Partei erhalten haben und wahrscheinlich wieder ein solches haben wollen. Wenn sie erst kurz vor der Wahl rührig werden und nach der Wahl wieder in die bisherige Untätigkeit verfallen, ist der Partei damit wenig gedient. Wie soll ein erfolgreicher Wahlkampf durchgeführt werden, wenn die Hälfte der Kreisverbände Niederbayerns nur ein papierenes Dasein führt?! [...] Von der Organisation untrennbar ist die Frage der Finanzierung. Es ist bekannt, wie schwer bei der derzeitigen Geldknappheit Mitgliederbeiträge und Spenden aufzubringen sind. Es ist auch kein Geheimnis, daß ein Großteil der Obleute unglaublich lau und interesselos geworden ist. Von einem Kreisvorsitzenden kann man nicht verlangen, daß er persönlich die Beiträge einkassiert. Wiederum aber gehen diese nicht von selbst ein. Mit einigem Organisationsgeschick lassen sich auch hier Erfolge erzielen. Es handelt sich nur darum, daß tatsächlich etwas geschieht. Wiederum müssen Kreisvorsitzende erwähnt werden, die es nicht unter ihrer Würde finden, von Geschäft zu Geschäft zu gehen und Spenden zu erbitten. Die Erfolge waren in jedem Falle sehr beachtlich. Die Abführung der Beitragsanteile an den Bezirksverband ist ein besonders trauriges Kapitel. Wir haben Kreisverbände, die seit der Währungsreform noch keinen Pfennig abgeführt haben. Daß sie überhaupt noch existieren, kann nur durch ihre Anwesenheit bei Bezirksversammlungen festgestellt werden, wenn eine prominente Persönlichkeit erscheint. Interessant ist, daß ausgerechnet von diesen Kreisverbänden Forderungen erhoben werden. Von unseren 26 Kreisver-

${ }^{603}$ BSB, NL Schwend 54, Fritz Schäffer an Hans Ehard vom 14. 5. 1950; das folgende Zitat ebenda. 
bänden sind im Geschäftsjahr 1950 bisher 3 Verbände ihren Verpflichtungen nachgekommen. Es sind Verbände, die laufend Anteile abführen. Einer dieser Kreisverbände hat jedoch Sperrung der Anteile in Aussicht gestellt, da er nicht einsieht, warum er ständig zahlen soll, während die anderen dies nicht tun. Wenn die Bezirks-Geschäftsstelle ihren Aufgaben gerecht werden soll, müssen ihr dazu auch die finanziellen Grundlagen gegeben werden. ${ }^{\text {604 }}$

Als Rudolf Schießl mit seinem Rundschreiben an die Parteiöffentlichkeit trat, war Hans Ehard, die Lichtgestalt der CSU, immerhin schon zehn Monate im Amt, doch erfolgversprechende Neuansätze zur Reorganisierung der Parteiverwaltung und zur Sanierung der Parteifinanzen ließen nach wie vor auf sich warten. Dabei waren Parteifreunde wie Hans Wutzlhofer schon wenige Wochen nach Ehards Wahl an den neuen Landesvorsitzenden herangetreten und hatten konkrete Vorschläge gemacht. Wutzlhofer, vor 1933 Geschäftsführer der BVP in der Oberpfalz, gehörte zu den traditionsorientierten CSU-Politikern, die sich ihre Partei nur als locker organisierte Honoratiorenpartei vorstellen konnten und das von Müller und seinen Mitstreitern propagierte Konzept eines nach „industriellen Grundsätzen“ aufgebauten Parteiapparats ${ }^{605}$ von Anfang an strikt abgelehnt hatten. Die gesamte Parteiorganisation, so Wutzlhofer, müsse auf eine „vollständig neue Basis“ gestellt werden ${ }^{606}$. Der Verwaltungsapparat der CSU sei unter Josef Müller „zu gross, zu kostspielig und zu wenig auf die eigentliche Arbeit der Organisation eingespielt“ gewesen. Statt ihre eigentliche Aufgabe zu erfüllen, hätten die hauptamtlichen Geschäftsführer „vielfach Personalpolitik getrieben und jeden, der nicht ihrer Meinung war, von den Parteiämtern fernegehalten“. Politik hätten aber nicht die Funktionäre zu machen, sondern die gewählten und den Mitgliedern verantwortlichen Parteigremien; die „bezahlten Parteifunktionäre“ müßten daher „auf die reine Organisationsarbeit zurückgedrängt werden“. In diesem Sinne lehnte Wutzlhofer auch hauptamtliche Kreisgeschäftsführer ab, da diese „nicht voll ausgelastet“ seien, „in ihrer Arbeit zu wenig kontrolliert“ werden könnten und die Partei zudem „finanziell schwer belasten“ würden. Statt dessen schwebte ihm eine Parteiverwaltung nach dem Muster der BVP vor: Ein kleines Generalsekretariat und acht hauptamtlich besetzte Bezirksgeschäftsstellen, in denen sich eine Handvoll Mitarbeiter Wutzhofer ging von höchstens 33 für ganz Bayern aus - um die wichtigsten organisatorischen Belange der CSU kümmern sollte. Auch hinsichtlich der Finanzierung dieses Apparats griff Wutzlhofer auf das Vorbild der BVP zurück. Da sich eine bürgerliche Partei niemals durch Mitgliederbeiträge finanzieren könne, müsse man versuchen, die nötigen Mittel anderweitig zu beschaffen, etwa durch die Gründung parteinaher Vereine, wie sie die BVP in ihrem Wirtschaftsbeirat gehabt habe.

Im Herbst 1949 wurden die Stimmen lauter, die auf Maßnahmen der Parteiführung zur Beendigung der organisatorischen Misere drängten. Auch enge Mitarbeiter Ehards in der Staatskanzlei sahen sich gezwungen, den Ministerpräsidenten und Landesvorsitzenden auf die „dringende Notwendigkeit einer sofortigen Inangriffnahme der Reor-

604 ACSP, CSU-LTF I, 15-20/0, Rundschreiben des CSU-Bezirksverbands Niederbayern, gez. Rudolf Schießl, vom 8. 4. 1950; Hervorhebungen im Original. Schon einige Tage zuvor hatte der ehemalige Bezirksvorsitzende Konrad Kübler den Landesvorsitzenden auf die Mißstände im Bezirksverband Niederbayern aufmerksam gemacht; BSB, NL Schwend 2, Konrad Kübler an Hans Ehard vom 3. 4. 1950.

605 ACSP, NL Müller 17, August Wilhelm Schmidt an Josef Müller vom 12. 8. 1946.

606 BayHStA, NL Ehard 1362, Hans Wutzlhofer an Hans Ehard vom 12. 7. 1949; die folgenden Zitate ebenda. 
ganisation der Partei“ aufmerksam zu machen "mit dem Ziel, sie aus der heutigen Situation eines reinen Rahmengebildes heraus zu führen und zu einem lebendigen Organismus zu gestalten ${ }^{4607}$. Im einzelnen schlug man Ehard vor, die prominenten CSUPolitiker wie Minister und Staatssekretäre systematisch in die Parteiarbeit einzubinden, eine aktive Pressepolitik zu betreiben, Landesvorstand und Landesausschuß so bald wie möglich einzuberufen, die auf Eis gelegte Satzungsreform zu beschleunigen, die Landesgeschäftsstelle neu zu organisieren, die Sanierung der Parteifinanzen in Angriff zu nehmen, eine Kampagne zur Werbung neuer Mitglieder zu initiieren sowie stärkeres Gewicht auf die Arbeit der Bezirks- und Kreisverbände zu legen.

Dieser umfangreiche Katalog, der zum Teil sofort, zum Teil aber nur in zäher Kleinarbeit umgesetzt werden konnte, zeigte schonungslos auf, was bei der CSU alles im Argen lag. Hans Ehard verstand die Zeichen der Zeit und nahm die Anregungen und Warnungen seiner Ratgeber auf. Am 3. Oktober 1949 befaßte sich der geschäftsführende Landesvorstand mit dem Zustand von Parteiorganisation und -apparat ${ }^{608}$, und für den 28. Oktober war eine Konferenz des Landesvorsitzenden mit den Bezirksvorsitzenden angesetzt, zu der auch die Spitzen des Generalsekretariats, die Bezirksgeschäftsführer und Vertreter der Arbeitsgemeinschaften eingeladen waren. Die Tagung sollte unter dem Motto stehen: „Finanzierung und Reorganisation der Partei und Vorbereitung für die Landtagswahlen 1950 “609.

Tatsächlich entspann sich am 28. Oktober eine lebhafte Diskussion über die Lage der Partei und ihre inneren Probleme. Bei den meisten Teilnehmern hatte sich offensichtlich die Erkenntnis durchgesetzt, daß die CSU einer grundlegenden Erneuerung bedürfe, und zwar auch auf dem Sektor der Parteiverwaltung. Es bestanden jedoch nach wie vor unübersehbare Meinungsverschiedenheiten darüber, wie groß der Parteiapparat sein müsse und wie er strukturiert sein sollte. Anton Hergenröder, der Vorsitzende der oberfränkischen CSU, nahm in etwa die Position ein, die die BVP-Traditionalisten in ihrem Kampf gegen Josef Müller vertreten hatten. Die Parteiverwaltung, so der Bamberger Oberbürgermeister, solle „am besten nicht durch hauptamtliche Geschäftsführer", sondern "nur durch ehrenamtliche Kräfte getragen“" werden. Da die „Lähmung der Partei“ durch eine Finanzkrise erfolgt sei, dürfe man nicht wieder einen teuren Parteiapparat aufbauen, dessen Finanzierung nicht gesichert werden könne. Hergenröder vertrat damit Prinzipien, die er in seinem Bezirksverband bereits verwirklicht hatte. Seit April 1949 gab es nicht einmal mehr einen hauptamtlichen Bezirksgeschäftsführer, nachdem Alexander Schönwiese endgültig entlassen worden war und Hergenröder die Geschäftsführung selbst übernommen hatte ${ }^{610}$.

Einen „föderativen Aufbau“ der CSU und damit verbunden "möglichst viel Freiheit" für die Bezirks- und Kreisverbände befürwortete auch Alois Hundhammer. Der Vorsitzende des Bezirksverbands Oberbayern, der die Frage der Parteiorganisati-

${ }^{607}$ BSB, NL Schwend 2, Notiz „Zur Frage der Reorganisation der CSU“ vom 21. 9. 1949.

${ }^{608}$ BayHStA, NL Ehard 102, Protokoll der Sitzung des geschäftsführenden Landesvorstands am 3. 10. 1949.

609 BayHStA, NL Ehard 102, Aktennotiz und Protokoll über die Tagung der Bezirksvorsitzenden am 28. 10. 1949 vom 11. 11. bzw. vom 7. 11. 1949; danach auch das folgende.

610 IfZ-Archiv, ED $720 \mathrm{Smlg}$. Mintzel 45, Anton Hergenröder an das Arbeitsgericht Bamberg vom 8. 9. 1949; welche Schwierigkeiten es dem Bezirksverband Oberfranken noch 1952/1953 bereitete, wieder eine funktionsfähige, hauptamtlich besetzte Geschäftsstelle aufzubauen, zeigen die diesbezüglichen Dokumente im BAK, NL Guttenberg 278 und 279. 
on aus einem anderen Blickwinkel betrachtete als der Kommunalpolitiker Hergenröder, war sich jedoch auch darüber klar, daß die CSU ohne ein einigermaßen stabiles organisatorisches Gerippe auf Dauer nicht erfolgreich sein konnte. Eine starke Parteizentrale paßte ihm zwar nach wie vor nicht ins Konzept, „hauptamtliche Geschäftsführer für die Bezirksverbände“ hielt er aber „für unbedingt nötig“. Unterstützt von seinem Geschäftsführer Alois Klughammer favorisierte dagegen Josef Fischer, der Bezirksvorsitzende Schwabens, eine Rückkehr zu den organisationspolitischen Verhältnissen, wie sie vor der Währungsreform bestanden hatten. Fischer sprach sich unmißverständlich für eine „Wiedereinführung eines Netzes hauptamtlicher Geschäftsführer" aus. Man dürfe Parteigremien und Parteiorganisation nicht verwechseln. Zur Zeit bestünden nur Gremien, aber keine Organisation. „Die CSU“, so Fischer weiter, „sei nur mehr eine Wählerorganisation, aber keine Partei mehr“. Die Kreisvorsitzenden seien meist „zu passiv, die Ortsverbände fast nicht mehr vorhanden“. Überdies sei es bemerkenswert, daß die Parteiorganisation dort am schwächsten sei, wo die CSU ihre größten Wahlerfolge erzielt hätte. Wenn es der SPD und der NSDAP gelungen sei, „Riesenorganisationen aufzubauen“, schloß Fischer seine Rede mit einem nicht ganz passenden Vergleich, dann „müsse die CSU wenigstens das Nötigste schaffen können".

Fast wie gewohnt versuchte Hans Ehard eine "gesunde Mittellinie“ zwischen „zentralistischer und völlig aufgelöster Organisation“ zu finden. Ein „Körper ohne Gerippe“, so faßte er seine Argumente in einer Sitzung des geschäftsführenden Landesvorstands am 5. Dezember 1949 nochmals zusammen, könne sich nicht selbst tragen ${ }^{611}$. Daher werde es notwendig sein, „zur Wiedererrichtung eines Netzes hauptamtlicher Bezirks- und Kreisgeschäftsführer überzugehen“. Der Parteichef hatte das im Zuge der Währungsreform entwickelte Modell der Kreishauptgeschäftsstellen im Auge, als er erklärte, drei bis vier kleinere oder zwei bis drei größere Kreisverbände sollten zukünftig eine hauptamtlich besetzte Geschäftsstelle erhalten, da ein dichteres Netz von Geschäftsstellen nicht finanzierbar sei. Weiter führte Ehard aus:

„Die trüben Erfahrungen, die wir seit der durch die Währungsreform erzwungenen Entlassung des grössten Teils der Kreisgeschäftsführer, besonders auf dem Gebiet des Beitragsaufkommens, gemacht haben, zeigen die Notwendigkeit dieser Maßnahme. Man kann sagen: ,Ohne hauptamtliche Geschäftsführer keine Beiträge und ohne Beiträge keine hauptamtlichen Geschäftsführer $[\ldots]^{c}$."

Der Parteivorsitzende hatte also in der Zwischenzeit die Lektion gelernt, die Müller und seine Mitstreiter schon im Herbst 1948 hatten lernen müssen. Ehard war sich jedoch völlig klar darüber, daß seine Haltung in diesen wichtigen organisationspolitischen Fragen nicht auf ungeteilte Zustimmung stieß, und er versicherte den traditionalistischen Skeptikern, die CSU sei weit davon entfernt, „eine Funktionärs-Hierarchie nach dem Muster der SPD zu züchten"612.

611 ACSP, CSU-LL, „Besprechungsprotokoll für die Sitzung des geschäftsführenden Vorstandes unserer Partei" am 5. 12. 1949 vom 3. 12. 1949; die folgenden Zitate ebenda. Bei diesem Dokument, das dem eigentlichen Sitzungsprotokoll beigefügt ist, handelt es sich vermutlich um die Disposition für den Bericht des Parteivorsitzenden. Generalsekretär Strauß hatte sechs Wochen zuvor einen ähnlichen Standpunkt vertreten. BayHStA, NL Ehard 102, Protokoll über die Tagung der Bezirksvorsitzenden am 28. 10. 1949.

${ }^{612} \mathrm{Zu}$ dieser Kontroverse vgl. den groben Überblick bei Mintzel, Anatomie, S. $142 \mathrm{ff}$. und S. 335. 
Eine Nagelprobe dafür, wie ernst solche Bekenntnisse gemeint waren, war stets die Haltung in der Frage gewesen, ob die Bezirks- und Kreisgeschäftsführer vom Landesverband angestellt und besoldet werden sollten oder von den Suborganisationen selbst. Josef Müller hatte sich 1946 zunächst mit einer Regelung durchsetzen können, die den Einfluß der Parteiführung stärkte ${ }^{613}$. Nach der Währungsreform blieb dem Ochsensepp und seinen Mitstreitern in der Parteizentrale jedoch nichts anderes übrig, als die verbliebenen Geschäftsstellen in die Verantwortung der Kreise und Bezirke zu entlassen. Die Satzung der CSU vom Dezember 1946 war jedoch nach wie vor gültig, so $\mathrm{daß}$ der Landesvorstand jederzeit in der Lage gewesen wäre, sein verbrieftes Recht zu aktivieren und das Personal der Geschäftsstellen in eigener Regie anzustellen und zu besolden $^{614}$. Franz Josef Strauß warf diese Frage schon in einer der ersten Sitzungen des geschäftsführenden Landesvorstands nach der Straubinger Landesversammlung auf $^{615}$, und Hans Ehard scheint dafür plädiert zu haben, das organisationspolitische Gewicht der Parteizentrale wieder zu stärken. Die hauptamtlichen Geschäftsführer, so erklärte er auf der Tagung mit den Bezirksvorsitzenden am 28. Oktober 1949, müßten angemessen bezahlt, „in ihrer Arbeit von der Landesleitung zusammengefasst “ und zu regelmäßigen Besprechungen nach München gerufen werden ${ }^{616}$. Das in dieser Frage nach wie vor enthaltene Konfliktpotential kam jedoch nicht zum Ausbruch. Das lag nicht nur daran, daß mit Hans Ehard nun ein Mann an der Spitze der CSU stand, dem nicht wie Josef Müller der Ruf vorauseilte, ein „Parteidiktator“ zu sein ${ }^{617}$. Die Gegner aller Ansätze für eine zentral gesteuerte Organisationspolitik konnten sich vor allem deshalb beruhigt zurücklehnen, weil es der Parteiführung noch nicht einmal gelang, das Generalsekretariat auf eine solide finanzielle Basis zu stellen.

Allerdings hatte schon die Tagung am 28. Oktober 1949 gezeigt, daß bei den führenden Politikern der CSU kein generelles Desinteresse an organisatorischen Fragen herrschte, auch nicht bei denjenigen, die sich der BVP-Tradition verpflichtet fühlten. Die bestehenden Probleme wurden auch nicht totgeschwiegen, wie es die Führung der CSU in der Ära Ehard gerne tat, um den inneren Frieden aufrechtzuerhalten; dafür war der Problemdruck auch einfach zu groß. Zumindest in den Jahren 1949 und 1950 gab es kaum eine Sitzung der engeren Führungsgremien der CSU, bei der nicht der Zustand des Parteiapparats oder der Parteifinanzen ganz oben auf der Tagesordnung gestanden hätte ${ }^{618}$. Daß alle Diskussionen, Pläne und gut gemeinten Initiativen jedoch letztlich nichts fruchteten, lag hauptsächlich an drei Gründen: Erstens gelang es der Parteiführung nicht, der finanziellen Misere ein Ende zu setzen und die Parteifinanzen

${ }^{613}$ Vgl. Fait, Einleitung zu: Protokolle und Materialien, S. LI-LVIII, und Mintzel, Anatomie, S. 144-149.

614 Satzung der CSU in der Fassung vom 4. 10. 1946, abgedruckt in: Protokolle und Materialien, S. 1783-1803.

615 ACSP, CSU-LL, Protokoll der Sitzung des geschäftsführenden Landesvorstands am 17.6. 1949.

616 BayHStA, NL Ehard 102, Protokoll über die Tagung der Bezirksvorsitzenden am 28. 10. 1949.

617 IfZ-Archiv, ED $132 \mathrm{NL}$ Baumgartner 3, Joseph Baumgartner an Alois Hundhammer vom 29.7. 1947.

618 ACSP, CSU-LL, Protokolle der Sitzungen des geschäftsführenden Landesvorstands am 17. 6., 28. 7. und 5. 12. 1949 und am 4. 2., 6.3. und 25.7. 1950 sowie Protokolle der Sitzungen des Landesvorstands am 17. 12. 1949 und 9.6. 1950; BayHStA, NL Ehard 102, Protokoll der Sitzung des geschäftsführenden Landesvorstands am 3. 10. 1949, NL Ehard 2468, Protokoll der Sitzung des geschäftsführenden Landesvorstands am 5.6. 1950, sowie NL Ehard 102, Aktennotiz und Protokoll über die Tagung der Bezirksvorsitzenden am 28. 10. 1949 vom 11. 11. bzw. vom 7. 11. 1949. 
durch konsequentes Eintreiben von Mitgliederbeiträgen und Erschließung neuer Geldquellen auf eine sichere Grundlage zu stellen. $\mathrm{Zu}$ einer Zeit, in der die staatliche Parteifinanzierung noch in den Kinderschuhen steckte ${ }^{619}$, lebte die CSU praktisch von der Hand in den Mund. Zweitens rangierte die Organisationspolitik auf der Prioritätenskala nicht gerade an erster Stelle und wurde immer wieder zugunsten anderer Fragen zurückgestellt. Hans Ehard war nun einmal kein Parteipolitiker im Sinne des Wortes, sondern griff lieber auf die Staatskanzlei zurück ${ }^{620}$, die er für effizienter hielt als die unterbesetzte und schlecht ausgestattete Landesgeschäftsstelle der CSU. Drittens fehlte es in der Parteiführung an durchdachten, realistischen Konzepten zur Reorganisation der Parteiverwaltung, die wenigstens mittelfristig praktikabel gewesen wären, und es gab unter den Vertrauten Ehards niemanden, der einflußreich und innovativ genug gewesen wäre, einen gangbaren Weg aus der Misere aufzuzeigen und in der Partei durchzusetzen $^{621}$. Die Beschlüsse zur Erneuerung von Parteiorganisation und -apparat standen meist nur auf dem Papier ${ }^{622}$. Die Parteiführung beschränkte sich darauf, die schlimmsten Mißstände zu beseitigen und die größten Löcher zu stopfen. Franz Xaver Fackler, Vorsitzender der CSU-Fraktion im Münchner Stadtrat und Inhaber einer Reklamefirma, konnte über diesen Zustand nur verständnislos den Kopf schütteln: „Mit der organisatorischen Praxis der Jahrhundertwende“, schrieb er im April 1950 an Hans Ehard, könne „bei den Menschen der Gegenwart [. . . nur bei wenigen der Opfersinn für eine bestimmte politische Idee geweckt und dauernd aufrecht erhalten werden ${ }^{\text {6623. }}$.

\section{b) Satzungsfragen und Satzungsreform}

Die Versuche, die CSU an Haupt und Gliedern zu reformieren, fanden ihren sichtbarsten Ausdruck in der neuen Satzung von 1952, die die seit 1946 geltenden, mehrfach modifizierten Statuten ablöste ${ }^{624}$. Mit der Verabschiedung einer neuen Satzung sollte nicht nur ein Signal für einen neuen Aufbruch der CSU gesetzt, sondern auch ein Konflikt endgültig beigelegt werden, der schon wenige Monate nach der Gründung der Partei begonnen hatte ${ }^{625}$.

Die Auseinandersetzungen um das statuarische Gerüst der CSU waren bis 1949 immer auch Teil der Auseinandersetzungen um die Macht in der bayerischen Unionspartei gewesen. Die Gegner Josef Müllers hatten sich vor allem gegen die Paragraphen zur

${ }^{619}$ Vgl. Ulrich Dübber, Parteifinanzierung in Deutschland. Eine Untersuchung über das Problem der Rechtslegung in einem künftigen Parteiengesetz, Köln, Opladen 1962, S. 1-44.

620 Vgl. Gelberg, Hans Ehard, S. 289.

${ }^{621}$ In einem Rundschreiben der unterfränkischen Bezirksgeschäftsstelle hieß es dazu nach den Landtagswahlen von 1950: „Mit unerbittlicher Härte hat diese Wahl aber auch gezeigt, daß die Organisation unserer Partei auf Landesbasis reformbedürftig ist und daß wir endlich eine Führung benötigen, die sich ausschließlich dieser schweren Aufgabe widmet." ACSP, NL Seidel 35 a, Rundschreiben $\mathrm{Nr}$. 12/50 des Bezirksverbands Unterfranken vom 29.11. 1950.

622 Vgl. z. B. den Maßnahmenkatalog, auf den man sich am 28. 10. 1949 geeinigt hatte; BayHStA, NL Ehard 102, Aktennotiz über die Tagung der Bezirksvorsitzenden am 28. 10. 1949.

623 BayHStA, NL Ehard 1363, Franz Xaver Fackler an Hans Ehard vom 21. 4. 1950.

${ }^{624}$ Zur großen Satzungsreform von 1952 vgl. die kurzen, aber unvollständigen Ausführungen von Mintzel, Anatomie, S. 248f.

${ }^{625}$ Vgl. dazu Fait, Anfänge, S. 126-142 und S. 230-238, und Mintzel, Anatomie, S. 99-118, S. 126-129 und S. 144-149. 
Wehr gesetzt, die den fränkischen Anhang des Parteivorsitzenden zu bevorzugen und der Parteiführung eine zu große Machtfülle einzuräumen schienen. Josef Müller hatte erst 1948 begonnen, dem Druck der Opposition nachzugeben, die unter dem Banner der innerparteilichen Demokratie für eine grundlegende Umgestaltung der Statuten eintrat. Eine kleine Satzungsreform im Januar 1948 hatte nicht genügt, um die Gegner Müllers zufriedenzustellen. So war im Juli 1948 ein Ausschuß eingesetzt worden, der den Entwurf für ein neues Satzungswerk ausarbeiten und alle bestehenden Streifragen schlichten sollte. Zwar hatten solche Kommissionen und Ausschüsse in der Ära Müller oft nur ein Schattendasein geführt, der Satzungskommission war es aber zwischen September 1948 und Mai 1949 gelungen, sich in mehreren Sitzungen auf die Rahmenrichtlinien für eine neue Satzung zu einigen. Wie die zwölf Leitsätze zur Satzungsreform für die Straubinger Landesversammlung zeigen, hatten sich die Vertreter der innerparteilichen Opposition in der Satzungskommission in wesentlichen - wenn auch nicht in allen - Punkten durchsetzen können:

„1.) In allen Gremien der Partei müssen die von den Mitgliedern unmittelbar gewählten Personen das Übergewicht über die automatischen Mitglieder besitzen, d. h. in der Regel zwei Drittel der Stimmen. 2.) Die Vorsitzenden eines unteren Gremiums sind jeweils gleichzeitig Delegierte zu den nächsthöheren Gremien. 3.) Grundsätzlich kann niemand mit mehr als mit einer Stimme ausgestattet werden. Schriftliche Stimmübertragung ist möglich, jedoch kann auch auf dem Wege der Stimmübertragung nur eine Stimme wahrgenommen werden. Für die Kreisvertreter in der Landesversammlung können Ausnahmen zugelassen werden. 4.) Zum Schutz der Minderheiten in der Partei muss auf Wunsch einer qualifizierten Minderheit bei den Wahlen innerhalb der Partei ein Punktsystem zur Anwendung gebracht werden, das auch den Minderheiten eine Vertretung sichert. 5.) Die Vorsitzenden der Arbeitsgemeinschaften gehören jeweils den erweiterten Vorständen an, sofern sie im betreffenden Bereich ein Mindestmaß an Organisation aufweisen. [...] 6.) Der erste Vorsitzende und seine beiden Stellvertreter werden von der Landesversammlung gewählt. 7.) Der Landesvorstand besteht aus dem Landesvorsitzenden und seinen beiden Stellvertretern, einem Vertreter der Bayerischen Staatsregierung, einem Vertreter der Bundesregierung, dem Landtagsfraktionsvorsitzenden, dem Bundestagsfraktionsvorsitzenden, dem Landtagspräsidenten (sofern er der Union angehört), den gewählten Vorsitzenden der Arbeitsgemeinschaften [...], dem Vorsitzenden des Wirtschaftsbeirates der Union, dem Generalsekretär der Union sowie je 3 Vertretern der Bezirksverbände. Dazu kann der Landesausschuß bis zu 5 Persönlichkeiten seiner Wahl berufen. 8.) Der engere Landesvorstand besteht aus dem 1. Vorsitzenden und seinen beiden Stellvertretern, einem Vertreter der Staatsregierung, einem Vertreter der Bundesregierung, dem Landtagsfraktions-Vorsitzenden, dem Bundestagsfraktionsvorsitzenden und den Vorsitzenden der Bezirksverb. (darunter muß eine Frau sein). 9.) Zur parteipolitischen Arbeit ist dem 1. Vorsitzenden und seinen beiden Stellvertretern ein Organisationsstab zur Seite zu stellen. 10.) Der Landesausschuss besteht aus dem Landesvorstand, sämtlichen Regierungsmitgliedern der CSU in der Bayerischen Staatsregierung und der Bundesregierung, aus 2 Vorsitzenden und 1 Vorstandschaftsmitglied der Landtagsfraktion, aus 2 Vorsitzenden der Bundestagsfraktion, aus den Vorsitzenden der wichtigen politischen Ausschüsse und je 5 weiteren Vertretern der Bezirksverbände, denen mindestens 1 Heimatvertriebener, 1 Frau und 1 Vertreter der Jugend angehören müssen. 11.) Die Delegierung der Kreisverbände zu der Landesversammlung erfolgt nach Massgabe der zablenden Mitglieder in den Kreisverbänden [...] Ausserdem gehören der Landesversammlung der Landesausschuß und die Landtags- und Bundestags-Fraktion der CSU an. 12.) Es wird versucht, zur ständigen Regeneration der leitenden Parteiorgane taugliche Wege zu finden." ${ }^{626}$

${ }^{626}$ ACSP, CSU-LTF II/1, 15-20/0, Der oberbayerische Informationsbrief 3/51 vom 12. 2. 1951; BayHStA, NL Ehard 1379, „Leitsätze für die neuen Satzungen der Christlich-Sozialen Union“, undatiert (1949). An diesen Richtlinien hatte der oberbayerische Vertreter in der Satzungskommission, Franz Ammann, maßgeblichen Anteil. 
Diese Richtlinien wurden zu einer wichtigen Grundlage für die Satzungsreform. Alle künftigen Initiativen knüpften in der einen oder anderen Form an die Straubinger Leitsätze an, und als die Delegierten der Regensburger Landesversammlung die neuen Statuten im Juli 1952 verabschiedeten, war eine Reihe von Grundsätzen darin verankert, auf die sich die Satzungskommission bereits 1948/1949 geeinigt hatte.

Es dauerte jedoch quälend lange, bis die neue Satzung unter Dach und Fach war, denn in Straubing wurde erst einmal nichts entschieden. Hans Ehard bat die Delegierten nach seiner Wahl zum Parteichef, den Tagesordnungspunkt Satzungsänderungen zurückzustellen, da er mit der Materie zu wenig vertraut sei, und die Vorschläge der Satzungskommission an den Landesausschuß weiterzuleiten ${ }^{627}$. Die Landesversammlung stimmte diesem Antrag zu, aber eine Diskussion über die Satzungsreform im Landesausschuß ließ auf sich warten, und da der Machtkampf in der Partei vorerst beendet war, sahen die bisherigen Protagonisten der Satzungsreform keinen Grund mehr dafür, die Prozedur zu beschleunigen. Überdies standen bald andere Fragen wie die Bundestagswahlen, die Bildung der ersten Bundesregierung oder die Vorbereitung der Landtagswahlen auf der Tagesordnung, so daß die einst so heiß umstrittenen Satzungsfragen mehr und mehr in den Hintergrund rückten. Ein baldiger Abschluß der Satzungsreform wurde zwar immer wieder angemahnt ${ }^{628}$, aber da sich keine wirklich einflußreichen Fürsprecher fanden, fehlte die treibende Kraft hinter diesen Bemühungen.

Auch Hans Ehard schien es mit einer neuen Satzung nicht allzu eilig zu haben ${ }^{629}$. Anstatt die Richtlinien der Satzungskommission dem Landesausschuß vorzulegen oder die Satzungskommission selbst mit den weiteren Arbeiten zu betrauen, wurde der Augsburger Stadtrechtsrat Otto Weinkamm damit beauftragt, eine neue Satzung zu konzipieren ${ }^{630}$. Der Satzungsausschuß hatte sich nämlich nach Ehards Meinung als höchst ineffektiv erwiesen, da er ,infolge seiner oft gewechselten Zusammensetzung und der Schwierigkeit der örtlich getrennten Mitglieder die Reform nur wenig gefördert" habe. Einem erfahrenen Kommunalpolitiker und Juristen wie Weinkamm diese Aufgabe zu übertragen, hielt Ehard für den erfolgversprechenderen Weg, um zu einem "raschen Abschluß der Reform zu kommen“631.

Weinkamm übernahm damit eine wahre "Sisiphusarbeit", die sich "viel schwieriger" gestaltete, als er ursprünglich angenommen hatte ${ }^{632}$. Das größte Problem bestand darin, die Vielzahl der zum Teil schon seit 1946 diskutierten Grundsätze, Richtlinien und Vorschläge zu einem in sich schlüssigen Satzungsentwurf zu verarbeiten und tragfähige Kompromisse zu finden, die in der Partei konsensfähig waren. Doch Weinkamm stellte

627 ACSP, NL Müller 16, Protokoll der Landesversammlung der CSU vom 27.-29. 5. 1949 in Straubing.

628 BayHStA, NL Ehard 102, Aktennotiz über die Tagung der Bezirksvorsitzenden am 28. 10. 1949, und BSB, NL Schwend 2, Notiz „Zur Frage der Reorganisation der CSU“ vom 21. 9. 1949.

629 ACSP, CSU-LL, „Besprechungsprotokoll für die Sitzung des geschäftsführenden Vorstandes unserer Partei“ am 5. 12. 1949 vom 3. 12. 1949.

630 ACSP, CSU-LL, Protokoll der Sitzung des geschäftsführenden Landesvorstands am 5. 12. 1949. Zu Weinkamm vgl. Otto Weinkamm - Politiker der ersten Stunde. Aufbau und Konsolidierung eines demokratischen Europas. Berichte eines Zeitzeugen, hrsg. von Peter Eisenmann, Frankfurt am Main 1993, S. 11-21.

631 ACSP, CSU-LL, Protokoll der Sitzung des Landesvorstands am 9.6. 1950. Der geschäftsführende Landesvorstand hatte sich schon am 5.6. 1950 mit der Satzungsreform beschäftigt und ein Referat Weinkamms zur Kenntnis genommen; BayHStA, NL Ehard 2468.

632 ACSP, CSU-LL, Protokoll der Landesversammlung der CSU am 17./18. 6. 1950 in Kempten (Hans Ehard). 
sich dieser Aufgabe und konnte dem Landesvorsitzenden im Mai 1950 einen fast 30seitigen Entwurf vorlegen ${ }^{633}$. Das wäre gerade noch rechtzeitig gewesen, um Weinkamms Papier mit dem Landesvorstand und der Satzungskommission abzustimmen und dann auf der Landesversammlung zur Diskussion zu stellen, die am 17. und 18. Juni 1950 in Kempten tagen sollte. Hans Ehard und seine Berater entschieden sich jedoch anders. Weinkamms Entwurf sollte zunächst an die Bezirksvorsitzenden weitergeleitet und anschließend in einem neugestalteten Satzungsausschuß diskutiert werden, dem die Aufgabe zufallen sollte, einen endgültigen Satzungsentwurf zu erarbeiten. Diese Beschlußvorlage sollte dann noch einmal im Landesausschuß besprochen werden, bevor die Delegierten der Landesversammlung endgültig darüber entscheiden sollten ${ }^{634}$. Ehard begründete dieses Verfahren, das de facto eine Vertagung der Satzungsreform auf unbestimmte Zeit bedeutete, auf dem Kemptener Parteitag nur mit wenigen Worten: „Ich glaube wir sollten uns heute nicht allzulange mit der Frage der Satzung beschäftigen“, erklärte er den Delegierten während seines Rechenschaftsberichts, denn es gebe wichtigere Probleme, mit denen sich die Landesvesammlung zu befassen habe. Überdies bestehe kein konkreter Handlungsbedarf, da die umstrittensten Punkte schon 1948 in Marktredwitz geregelt worden seien. Bei den Delegierten regte sich kein Widerspruch, im Gegenteil. Als Ehard die Delegierten mahnte, die Tagung nicht mit Satzungsfragen zu belasten, erntete er zustimmende Zurufe aus dem Auditorium.

Die Parteiführung hatte mit dem Abschluß der Satzungsreform nicht zuletzt deshalb keine Eile, weil sie mit dem status quo gut leben konnte. Die Satzung von 1946 war zwar nach wie vor gültig, wurde aber allenthalben als überholt angesehen, und da das neue Statut auf sich warten ließ, entstand ein Vakuum, das es Hans Ehard und seinen Gefolgsleuten ermöglichte, eine Reihe wichtiger organisatorischer Fragen provisorisch zu regeln, ohne sie den von der Satzung vorgesehenen Gremien zur Entscheidung vorzulegen. So verhielt es sich bei der Umgestaltung des geschäftsführenden Landesvorstand $s^{635}$, beim Einbau der Bonner Landesgruppe in die Parteiorganisation ${ }^{636}$ und bei der Lex Stang, die dem Landtagspräsidenten - sofern er der CSU angehörte - Sitz und Stimme im Landesvorstand einräumte ${ }^{637}$. All diese Entscheidungen hatten de facto

${ }^{633}$ BayHStA, NL Ehard 285, Otto Weinkamm an Hans Ehard vom 22. 5. 1950 und Entwurf Otto Weinkamms für eine neue Satzung der CSU, undatiert (Mai 1950); ein Exemplar dieses Satzungsentwurfs mit umfangreichen Randbemerkungen, eventuell von Alois Hundhammer oder Franz Ammann, dem Satzungsexperten des Bezirksverbands Oberbayern, findet sich im ACSP, CSU-LTF II/ 1, 15-20/1.

${ }^{634}$ ACSP, CSU-LL, Protokoll der Landesversammlung der CSU am 17./18. 6. 1950 in Kempten; die folgenden Zitate aus dem Rechenschaftsbericht Hans Ehards finden sich ebenda.

${ }^{635}$ Zur Aufgabe und Zusammensetzung des geschäftsführenden Landesvorstands (Paragraph 53 der Satzung von 1946 bzw. Paragraph 51 der Satzung von 1952), die bis 1954 nicht endgültig geklärt waren, vgl. BayHStA, NL Ehard 437, Antrag des Satzungsausschusses der CSU, gez. Max Gerstl, an die Landesversammlung vom 9.6. 1953, NL Ehard 810, Antrag auf Änderung des Paragraphen 51 der Satzung der CSU und ein diesbezüglicher Beschluß des Landesausschusses der CSU vom Januar 1954, und NL Ehard 1338, Rundschreiben des Generalsekretariats der CSU, gez. Josef Brunner, vom 10. 3. 1954; ACSP, CSU-LL, Protokoll der Sitzung des Landesausschusses der CSU am 15. 1. 1954 in Rothenburg ob der Tauber und Protokoll der Landesversammlung der CSU am 9./10. 10. 1954 in Nürnberg.

${ }^{636}$ Archiv der CSU-Landesgruppe, Protokoll der Landesgruppensitzung am 12. 1. 1950.

637 ACSP, CSU-LL, Ergebnisprotokoll der Sitzung des Landesausschusses der CSU am 14./15. 4. 1951 in Würzburg; da Landtagspräsident Georg Stang bereits im Mai 1951 starb, kam diese Regelung vor allem seinem Nachfolger Alois Hundhammer zugute. 
satzungsändernden Charakter, wurden bis 1952 aber nicht von der Landesversammlung abgesegnet.

$\mathrm{Da}$ die Satzungsreform im Sommer 1950 erneut vertagt wurde, lag aber vor allem daran, daß man die Einführung neuer Statuten vor den für November angesetzten Landtagswahlen für „unpraktisch“ hiel ${ }^{638}$, und daran, daß Weinkamms Entwurf offensichtlich noch nicht der Weisheit letzter Schluß war. Es fehlte ihm an inhaltlicher und konzeptioneller Geschlossenheit, Teile der alten Satzung standen neben neu eingefügten Bestimmungen, die sich mit der bestehenden Ordnung nur schwer vereinbaren ließen. Überdies hatte Weinkamm weitgehend die Grundsätze vernachlässigt, die 1948/ 1949 mühsam erarbeitet worden waren ${ }^{639}$. Kein Wunder, daß sich über diesen alles in allem unbefriedigenden Kompromiß schnell Unmut breitmachte. Der Protest gegen Weinkamms Entwurf kam vor allem aus den Bezirksverbänden, die an den scheinbar ad acta gelegten Grundsätzen der Satzungskommission großen Anteil gehabt hatten und sich nun übergangen fühlten. Speerspitze in der Diskussion um die Revision des Weinkamm-Entwurfs war der Bezirksverband Oberbayern, der schon in der Ära Müller für eine grundlegende Änderung der bestehenden Satzungsordnung eingetreten war. Hundhammer selbst, der nach wie vor eifersüchtig über die Autonomie der Bezirksverbände wachte und keine Gelegenheit ungenutzt ließ, um ihre Stellung in der Partei noch zu stärken ${ }^{640}$, hatte Ehard gedrängt, die Satzungsreform voranzutreiben ${ }^{641}$. Als Weinkamms Entwurf im März 1951 an die Bezirksverbände ging ${ }^{642}$, war die Enttäuschung bei den führenden Repräsentanten der oberbayerischen CSU jedoch groß. Für Franz Ammann, der Oberbayern 1948/1949 in der Satzungskommission vertreten hatte, war Weinkamms Satzungsentwurf ein klarer Schritt zurück hinter die Grundsätze, auf die man sich bereits im Vorfeld der Straubinger Landesversammlung geeinigt hatte. Entsprechend harsch fiel auch sein Fazit aus:

„Zusammenfassend kann gesagt werden, daß bedauerlicherweise bei dem vorliegenden Satzungsentwurf die Straubinger Anregungen der Satzungskommmission praktisch unberücksichtigt geblieben sind. Ebensowenig enthält der Entwurf neue konstruktive Vorschläge, durch welche die von den Bezirksverbänden wiederholt kritisierten Mängel der alten Satzungen beseitigt werden. Es wird einer eingehenden Durcharbeitung des Entwurfes sowohl durch die Bezirksverbände wie auch durch die Satzungskommission bedürfen, um den Willen der Mitglieder in dieser Angelegenheit endlich durchzusetzen und damit ein sicheres Fundament für die Arbeit der Partei zu schaffen." ${ }^{\text {" } 643}$

Der Bezirksverband Oberbayern beließ es nicht bei diesen Worten. Schon im Mai 1951 hatte Franz Ammann einen detaillierten Katalog mit Änderungsvorschlägen erarbeitet, der auf den Leitsätzen der Satzungskommission für die Straubinger Landesversammlung aufbaute. ${ }^{644}$

Otto Weinkamm war offensichtlich mit seinem Latein am Ende, und auch Hans Ehard schien zu der Einsicht gelangt zu sein, daß der Augsburger CSU-Politiker nicht

${ }^{638}$ ACSP, CSU-LL, Protokoll der Sitzung des Landesausschusses der CSU am 10.6. 1950 in München.

639 ACSP, CSU-LTF II/1, 15-20/1, Der oberbayerische Informationsbrief 5/51 vom 27. 3. 1951.

640 BayHStA, NL Ehard 2468, Protokoll der Sitzung des geschäftsführenden Landesvorstands am 5. 6. 1950.

641 ACSP, CSU-LTF II/1, 15-20/0, Der oberbayerische Informationsbrief 3/51 vom 12. 2. 1951.

${ }^{642}$ Bayern-Kurier vom 17. 3. 1951: „Reform der CSU-Satzung“.

643 ACSP, CSU-LTF II/1, 15-20/1, Der oberbayerische Informationsbrief 5/51 vom 27. 3. 1951.

644 ACSP, CSU-LTF II/1, 15-20/1, Der oberbayerische Informationsbrief 8/51 vom 21. 5. 1951. 
der Mann war, um die Satzungsreform zu einem guten Abschluß zu bringen. Anders ist seine Entscheidung nicht zu erklären, Weinkamm von seiner Aufgabe zu entbinden und im Juli 1951 Max Gerstl, einen Veteranen aus den Tagen der BVP und führenden Vertreter der kommunalpolitischen Vereinigung der CSU, mit der Ausarbeitung eines neuen Satzungsentwurfs zu beauftragen ${ }^{645}$. Gerstl stand vor dem schwierigen Problem, aus Teilen der gültigen Satzung, den Vorarbeiten Weinkamms und den Abänderungsvorschlägen der Bezirksverbände Oberbayern, Niederbayern, Oberpfalz, Schwaben und Unterfranken ein in sich schlüssiges Konzept zu machen und zugleich die Sonderwünsche von Landesgruppe und Landtagsfraktion zu berücksichtigen ${ }^{646}$. Gerstl tat gut daran, zunächst das Terrain zu sondieren und sich bei den Bezirksvorsitzenden über deren Wüsche und Vorstellungen zu informieren. Erst nachdem er sich auf diese Weise abgesichtert hatte, arbeitete er einen Satzungsentwurf aus, der im November 1951 fertiggestellt werden konnte ${ }^{647}$. Dieser Entwurf war die Grundlage für zwei Konferenzen in den ersten Wochen des Jahres $1952^{648}$. Am 7. Januar und 11. Februar diskutierten die Bezirksvorsitzenden, die Bezirksgeschäftsführer und Vertreter der Landesleitung und der Arbeitsgemeinschaften Gerstls Vorschläge in erster und zweiter Lesung, wobei weitgehende Einigung erzielt werden konnte. Auch die Vertreter Oberbayerns stimmten dem Ergebnis der Verhandlungen zu, obwohl nicht all ihre Wünsche und Vorschläge berücksichtigt worden waren ${ }^{649}$. Daraufhin arbeitete Gerstl einen zweiten Satzungsentwurf aus ${ }^{650}$, der nach einigen redaktionellen Änderungen am 20. Mai 1952 an den Landesvorstand weitergeleitet wurde. Gleichzeitig erfuhren die Vorstandsmitglieder, daß beabsichtigt sei, den Satzungsentwurf in einer für den 24. Mai anberaumten Sitzung "gegebenenfalls“ kurz durchzusprechen ${ }^{651}$. Wie so oft war aber „infolge der Beratung und Beschußfassung über wichtige innerparteiliche Fragen" keine Zeit dafür, eine so marginale Frage wie die des neuen Parteistatuts zu diskutieren ${ }^{652}$. Statt dessen wurden die Vorstandsmitglieder via Rundschreiben gebeten, ihre Änderungswünsche schriftlich einzureichen.

So waren es nicht die gewählten Gremien der Partei, die die neue Satzung erarbeiteten, sondern vom Parteivorsitzenden beauftragte Einzelpersonen und informelle Zirkel, die bestenfalls indirekt dazu legitimiert waren. Der Landesvorstand erhielt erst einen Tag vor der entscheidenden Landesversammlung Gelegenheit, Gerstls Entwurf zu diskutieren, und es ist kein Wunder, daß es nur noch zu wenigen - wenn auch nicht unwichtigen - Änderungen kam. Für grundlegende Einwände war es zu spät. Max Gerstl brachte seinen Entwurf am 5. Juli 1952 selbst in der Landesversammlung ein und mußte erfahren, daß sich viele Delegierte, denen der Entwurf schriftlich vorlag, für alles andere mehr interessierten als für die neue Satzung. Sicherlich, die Materie 645 BayHStA, NL Ehard 285, Bemerkungen Max Gerstls zu seinem Satzungsentwurf vom November

646 Archiv der CSU-Landesgruppe, Protokoll der Landesgruppensitzung am 12. 1. 1950; ACSP, CSULTF II/1, 15-14, Protokoll der Fraktionssitzung vom 5. 7. 1952.

647 BayHStA, NL Ehard 285, Satzungsentwurf Max Gerstls vom November 1951.

648 Bayern-Kurier vom 19. 1. 1952: „Die neue CSU-Satzung“.

649 ACSP, CSU-LTF II/1, 15-20/41, Der oberbayerische Informationsbrief 10/52 vom 27. 6. 1952.

${ }^{650}$ BayHStA, NL Ehard 98, Satzungsentwurf Max Gerstls vom Februar 1952.

651 ACSP, CSU-LTF II/1, 15-20/1, Rundschreiben der Landesgeschäftsstelle der CSU, gez. Josef Brunner, an die Mitglieder des Landesvorstands vom 20. 5. 1952.

652 ACSP, CSU-LL, Protokoll der Landesversammlung der CSU am 5./6. 7. 1952 in Regensburg; das folgende nach dem Protokoll dieses Parteitags. 
war höchst trocken, aber das war sie auch in den Jahren 1946 bis 1948 gewesen, als praktisch keine Sitzung des Landesausschusses und keine Landesversammlung verging, ohne daß erbittert und bis in die letzten Details über bestimmte Satzungsfragen gestritten worden wäre. Das offensichtliche Desinteresse an der neuen Satzung war ein Indikator dafür, wie sehr sich das Klima in der CSU seit 1949 verändert hatte. Kein Wunder, daß auf der Regensburger Landesversammlung keine rechte Diskussion in Gang kommen wollte. Nach einem kurzen Referat Gerstls wurden lediglich einige Stimmen laut, die redaktionelle Änderungswünsche in nicht gerade zentralen Artikeln anzumelden hatten, ansonsten gab es lediglich Nachfragen von Delegierten, die Gerstls Ausführungen nicht ganz verstanden oder verschlafen hatten. Bei der Abstimmung über das neue Satzungswerk stimmte nur eine Handvoll Delegierter dagegen.

Damit hatte die CSU nach jahrelangen Bemühungen eine neue Verfassung. Gerstl skizzierte die Ziele und Leitlinien der neuen Satzung so ${ }^{653}$ :

„Die Satzung einer Partei ist für sie dasselbe, was zum Beispiel das Grundgesetz für den Bund, was die Verfassung für das Land Bayern ist und was die neuen Kommunalgesetze für Gemeinden und Landkreise darstellen. Von einer guten Gestaltung der neuen Satzung der Partei hängt das gute Funktionieren der Parteiorganistion, der Erfolg der Parteiarbeit und damit letzten Endes weitgehend die Verwirklichung des Programms der Union ab. [...] Die Beratung von Satzungen ist zwar eine unangenehme Aufgabe, aber niemals eine langweilige. Das trifft besonders dann zu, wenn es sich um die Schaffung einer neuen Satzung für eine Partei wie die CSU handelt, die auf den Grundsätzen echter Demokratie aufgebaut ist, sein will und sein muß. Darum ist eine gute Satzung geradezu eine Vorbedingung für eine gute Arbeit in der Partei. (Beifall) Die Rechte und Pflichten der Mitglieder der einzelnen Organe müssen genau festgelegt werden, um ein reibungsloses Arbeiten möglich zu machen. Dies zu erreichen ist erste Aufgabe dieser Landesversammlung."

Mit der Entscheidung, den Satzungsentwurf Gerstls anzunehmen, zogen die Delegierten im Juli 1952 einen Schlußstrich unter eine Debatte, die sich mehr als vier Jahre dahingequält hatte. Schon die Tatsache, daß der Prozeß der Satzungsreform so lange gedauert hatte, läßt vermuten, daß die CSU eine grundsätzlich neue Verfassung bekommen hätte, und zwar um so mehr, wenn man bedenkt, wie intensiv sich die Gegner Josef Müllers bis 1949 um eine Revision des Parteistatuts bemüht hatten. Doch die Satzung von 1952 war kein Dokument des Sieges der katholisch-konservativen Kräfte in der CSU über ihre christlich-interkonfessionellen, liberal-konservativen Gegenspieler. Ein Vergleich der Satzungen von 1946 und 1952 zeigt im Gegenteil ein erstaunlich hohes $\mathrm{Maß}$ an Kontinuität, das angesichts der Rahmenbedingungen überraschen muß. Unverändert blieben vor allem allgemeine Bestimmungen und Richtlinien, beispielsweise der Teil über die Rechte und Pflichten der Parteimitglieder, die Ausführungen über die Aufgaben der verschiedenen Parteigremien sowie Regelungen technisch-organisatorischer Art wie Beitragszahlungen, Buchführung und Kassenprüfung oder Auflösung der $\mathrm{CSU}^{654}$. Die neue Satzung baute in diesen Teilen nicht nur auf der alten auf. Max Gerstl hatte vielmehr ganze Paragraphen aus der Satzung von 1946 übernom-

${ }^{653}$ Eine Zusammenfassung der Rede Max Gerstls auch im Bayern-Kurier vom 12. 7. 1952: „Das Grundgesetz der CSU“.

${ }^{654}$ Satzung der CSU in der Fassung vom 4.10. 1946, abgedruckt in: Protokolle und Materialien, S. 1783-1803; ACSP, CSU-LTF III/1, 6-10, gedruckte Fassung der Satzung der CSU von 1952; die angesprochenen Bestimmungen finden sich vor allem in den Teilen A, B und $\mathrm{E}$ der Texte, deren Grobgliederung gleich blieb. Die folgenden Ausführungen haben die hier zitierten Fassungen der Satzungen von 1946 und 1952 zur Grundlage. 
men, teils gänzlich unverändert, teils redaktionell überarbeitet, teils um einige Bestimmungen ergänzt, die auf Entwicklungen zurückgingen, die sich 1946 noch nicht hatten absehen lassen. Auch bei der in Paragraph 2 festgelegten Definition der Aufgaben und Ziele der CSU knüpfte die neue Satzung direkt an ihre Vorgängerin an. „Aufgabe der Christlich-Sozialen Union“, so hieß es in der Satzung von 1952, „ist der politische Zusammenschluß aller auf dem Boden der christlichen Kultur, der Demokratie und der sozialen Verantwortung stehenden Staatsbürger zu dem Zweck, die im Programm der Union festgelegten Ziele mit den Mitteln einer politischen Partei im öffentlichen Leben zu verwirklichen“. In der Satzung von 1946 hatte es lediglich anstatt Kultur Kulturauffassung, anstatt Verantwortung Verantwortungsbewußtsein, anstatt Zweck Aufgabe und anstatt verwirklichen zur Geltung bringen geheißen. Damit wurden wesentliche Prinzipien der Parteigründer von 1945/1946 ohne Veränderungen übernommen und nicht im Sinne der Kräfte modifiziert, die seit 1949 in der CSU den Ton angaben. Der vierstufige Aufbau der Parteiorganisation - vom Orts- über den Kreis- und Bezirksverband zum Landesverband - blieb ebenfalls unverändert, in der neuen Satzung wurden lediglich die berufsständisch gegliederten Orstverbands- und Kreisverbandsbeiräte, der Bezirksständerat und der berufsständische Rat der Landesvorstandschaft, die ohnehin fast nur auf dem Papier existent gewesen waren ${ }^{655}$, abgeschafft und durch Orts-, Kreis- und Bezirksverbandsausschüsse ersetzt, die wie der Landesausschuß auf gesamtbayerischer Ebene das Scharnier zwischen Vorstand und Mitgliederversammlung bilden sollten. Die Arbeitsgemeinschaften der CSU wurden erstmals umfassend und durchgängig in die Parteiorganisation eingebaut. Dieser Schritt war seit langem überfällig, da die Arbeitsgemeinschaften erst gegründet worden waren, nachdem die Militärregierung Ende Oktober 1946 die Satzung der CSU genehmigt hatte ${ }^{656}$, und die diesbezüglichen Reformbestrebungen trotz prinzipieller Einigkeit in den Führungsgremien der Partei offensichtlich nie konsequent umgesetzt worden waren ${ }^{657}$.

Wirklich neu waren dagegen die in der Satzung von 1952 festgelegte Zusammensetzung der Parteigremien und die entsprechenden Delegationsverfahren, die Landesvorstand und Landesausschuß zu großen und schwerfälligen Organen werden ließen, „charakterisiert durch Organverschachtelungen und Aggregierung unterschiedlicher Ämtergruppen mit jeweils verschiedenen Kreationsorganen “658. So gehörten etwa die

655 Vgl. Mintzel, Anatomie, S. 198-201.

656 Genehmigung der Satzung der CSU durch OMGBY vom 29. 10. 1946, abgedruckt in: Protokolle und Materialien, S. 1804.

${ }^{657}$ Die fehlende statuarische Verankerung der Arbeitsgemeinschaften war eines der Themen bei den Beratungen über eine Satzungsreform Anfang 1948. Da darüber im Prinzip Einigkeit bestand (vgl. Protokolle der Sitzungen des Landesausschusses am 3./4. 1. und 24. 1. 1948 in Erlangen bzw. in Marktredwitz, in: ebenda, S. 1300-1304 und S. 1379 ff.), nahm die Landesversammlung lediglich einen Antrag an, in dem die Bildung von Arbeitsgemeinschaften gut geheißen und Neugründungen von der Genehmigung durch den Landesausschuß abhängig gemacht wurden (Protokoll der Landesversammlung der CSU am 24./25. 1. 1948 in Marktredwitz, in: ebenda, S. 1419). In der synoptischen Darstellung der Satzungen von 1946 und 1948 (ebenda, S. 1783-1803) fehlen jedoch entsprechende Paragraphen. Ob die Satzung daher 1948 tatsächlich „auf die inzwischen gegründeten Arbeitsgemeinschaften abgestellt" wurde, wie Mintzel (Anatomie, S. 201 - mit wenig eindeutigen Belegen) annimmt, ist daher zweifelhaft. Noch im Dezember 1951 forderte beispielsweise die Junge Union, nicht nur schleunigst die Satzungsreform abzuschließen, sondern auch endlich die Arbeitsgemeinschaften statuarisch in der Partei zu verankern. BSB, NL Schwend 3, Bericht Ernst Deuerleins über den Landestag der Jungen Union in Eichstätt vom 3. 12. 1951.

${ }^{658}$ Mintzel, Anatomie, S. 248; man darf jedoch nicht übersehen, daß diese Entwicklung bereits in der Satzung von 1946 angelegt war. 
Ortsverbandsvorsitzenden automatisch der Kreisversammlung an, die Kreisverbandsvorsitzenden der Bezirksversammlung und die Bezirksvorsitzenden - einer alten Forderung des von Hundhammer geführten Bezirksverbands Oberbayern gemäß - der Landesversammlung und dem Landesvorstand. Zugleich enthielt die Satzung von 1952 eine Bestimmung, nach der in den Gremien der Partei auf allen Organisationsstufen die Anzahl der gewählten Mitglieder die der geborenen Mitglieder um das Doppelte übersteigen mußte. Diese Klausel sollte die innerparteiliche Demokratie ebenso sicherstellen wie der neu festgelegte Delegiertenschlüssel, nach dem sich die Zahl der Delegierten zur Kreis-, Bezirks- und Landesversammlung in Zukunft ausschließlich nach der Zahl der eingeschriebenen Mitglieder und ihrer Beitragsleistung richten sollte, um eine gerechte Mitgliederrepräsentation zu garantieren.

Alf Mintzel hat in der Satzungsreform von 1952 „keine echte Parteireform“ gesehen, sondern lediglich den statuarischen „Nachvollzug eines faktischen (Rück-)Entwicklungsverlaufes zur Honoratiorenpartei der BVP-Traditionalisten und föderalistischen Gouvernementalen“. An der strukturellen Entscheidung, die Suborganisationen in „eine weitgehende Finanzautonomie“ zu entlassen und das „Prinzip einer dezentralisierten, weitgehend ehrenamtlich getragenen Parteiverwaltung “ in der Satzung zu verankern, sei dies besonders deutlich geworden ${ }^{659}$. Ein Vergleich der Satzungen von 1946 und 1952 rechtfertigt Mintzels Urteil in dieser Eindeutigkeit jedoch nicht. So kann beispielsweise keine Rede davon sein, daß man 1952 in der neuen Satzung festgeschrieben hätte, der Parteiapparat müsse nach dem Vorbild einer Honoratiorenpartei aufgebaut werden. Die Geschäftsführerfrage war seit 1946 so geregelt gewesen, daß der Landesvorstand berechtigt war, in den Bezirks- und Kreisverbänden Geschäftsstellen einzurichten; das Personal der Geschäftsstellen sollte durch den Landesvorstand angestellt und bezahlt werden ${ }^{660}$. Paragraph 61 der neuen Satzung lautete:

"1.Zur Sicherung einer reibungslosen Geschäftsführung können neben der Landesgeschäftsstelle in den Bezirken und Kreisen Geschäftsstellen errichtet werden. Diese haben vor allem organisatorische und propagandistische Aufgaben. 2. Die Geschäftsführer sind satzungsmäßige Mitglieder der Vorstandschaft ihres Verbandes. Sie sind berechtigt, an allen Sitzungen und Versammlungen der Union und ihrer Organe innerhalb ihres Verbandes bzw. der Unterverbände beratend teilzunehmen. “661

Der Text der neuen Satzung ließ es damit offen, ob die Geschäftsstellen von ehrenamtlichen oder fest besoldeten Geschäftsführern geleitet werden sollten. Auch die Frage, welches Gremium für die Anstellung und Bezahlung etwaiger Parteiangestellter verantwortlich zeichnete, blieb unbeantwortet. Mit dieser Regelung war praktisch alles möglich; eine dezentralisierte, weitgehend ehrenamtlich getragene Parteiverwaltung in der Verantwortung der Bezirks- und Kreisverbände ebenso wie ein von der Parteizentrale aus gesteuerter Parteiapparat, der vor der Währungsreform bestanden hatte. Die neue Satzung ließ der Parteiführung die Möglichkeit, auf dem Feld der Organisationspolitik tätig zu werden, verpflichtete sie aber zu nichts. Es hing also wesentlich von der Interpretation der einschlägigen Satzungsbestimmungen, von der Lage der Parteifinanzen und von den Zielen der Parteiführung ab, ob sich die CSU zu einer Honoratioren-

659 Ebenda, S. $248 \mathrm{f}$.

660 Satzung der CSU in der Fassung vom 4. 10. 1946, abgedruckt in: Protokolle und Materialien, S. 1783-1803, hier S. 1800 (Paragraph 62).

661 ACSP, CSU-LTF III/1, 6-10, gedruckte Fassung der Satzung der CSU von 1952; das folgende Zitat findet sich ebenda. 
partei klassischen Zuschnitts oder zu einer modernen Apparatpartei entwickeln würde. Die Satzung von 1952 ließ beides zu, und als Hanns Seidel und Friedrich Zimmermann 1955 an die Reorganisation der Partei gingen, taten sie es auf der Basis dieser Satzung.

Zweifelsohne hätte die Satzung von 1952 auch Hans Ehard und seiner Führungsmannschaft die Möglichkeit geboten, die CSU aus ihrer organisatorischen Misere herauszuführen. Immerhin enthielt das neue Parteistatut eine Reihe von Bestimmungen, die die Stellung der Vorsitzenden auf allen Organisationsstufen der Partei, namentlich die des Landesvorsitzenden ${ }^{662}$, stärken sollten. In Paragraph 52 war etwa das Recht des Parteichefs festgeschrieben, „an allen Sitzungen der Organe der Union beratend teilzunehmen oder sich durch Beauftragte vertreten zu lassen“. Als Josef Müller 1946 versucht hatte, eine ähnliche Klausel in der Satzung zu verankern, hatten ihm seine Widersacher Diktaturgelüste unterstellt und im Verein mit der amerikanischen Militärregierung für ihre Streichung gesorgt ${ }^{63}$. Auch als der Ochsensepp vorgeschlagen hatte, die Amtszeit des Landesvorsitzenden und seiner Stellvertreter zu verlängern, war er 1948/1949 auf erbitterten Widerstand gestoßen ${ }^{664}$. Die neue Satzung sah dagegen wie selbstverständlich eine zweijährige Amtsperiode vor ${ }^{665}$. Nicht zuletzt fällt auf, daß die Delegierten die Einflußmöglichkeiten des Parteiapparats nicht etwa beschränkten, sondern den Spitzen der Parteiverwaltung - zumindest auf dem Papier - weitergehende Rechte als bisher einräumten. Der Abschnitt über die Rechte und Pflichten des Generalsekretärs blieb gegenüber der Satzung von $1946 \mathrm{zwar}$ unverändert, sieht man einmal davon $a b$, daß nun von einem Generalsekretär und nicht mehr von einem Landesgeschäftsführer die Rede war, aber Paragraph 61 machte die Geschäftsführer zu geborenen Mitgliedern ihrer Vorstandschaften und wies ihnen so nicht nur administrative, sondern auch politische Funktionen zu. Hatte es 1946 noch geheißen, die Geschäftsstellen hätten „rein verwaltungsmäßigen Charakter“ und seien nicht „berechtigt, sich in die politischen inneren Angelegenheiten der Verbände einzumischen"666, so war der entsprechende Passus im neuen Parteistatut wesentlich weniger apodiktisch gefaßt und ließ den Geschäftsführern mehr Spielraum.

662 So wurde der Landesvorsitzende in der Satzung von 1952 als eigenes Organ des Landesverbands genannt, und zwar an zweiter Stelle nach der Landesversammlung (Paragraph 42). Zudem wurde der Landesvorsitzende als einziger Vertreter der Parteispitze weiterhin von der Landesversammlung direkt gewählt, während die Wahl seiner Stellvertreter aller Kritik aus den Reihen des Bezirksverbands Oberbayern zum Trotz weiterhin dem Landesausschuß oblag. Der Landesvorsitzende verlor 1952 lediglich die Kompetenz, die Mitglieder des geschäftsführenden Landesvorstands in eigener Regie zu berufen; künftig sollten sie aus der Mitte des Landesvorstands gewählt werden. Angesichts der Entwicklung des geschäftsführenden Landesvorstands in der Ära Ehard wog dieser Kompetenzverlust jedoch nicht besonders schwer. Zur Forderung, auch die Stellvertreter des Landesvorsitzenden durch die Landesversammlung wählen zu lassen, vgl. ACSP, CSU-LTF II/1, 15-20/0, Der oberbayerische Informationsbrief 3/51 vom 12. 2. 1951, und CSU-LTF II/1, 15-20/1, Der oberbayerische Informationsbrief 8/51 vom 21.5. 1951.

663 Vgl. Fait, Anfänge, S. $137 \mathrm{f}$.

${ }^{664}$ IfZ-Archiv, RG 260, 10/90-3/1, „Subject: Situation of CSU“ (Gespräch mit Fritz Schäffer) vom 5. 2. 1949.

${ }^{665}$ Im Bayern-Kurier vom 14. 6. 1952 hieß es dazu unter der Überschrift „Mehr Rechte für die Mitglieder“: „Um Raum für diese organisatorische Arbeit und propagandistische Tätigkeit zu schaffen, soll eine grundsätzliche Änderung der Amtsdauer der gewählten Spitzen der einzelnen Organe der Union vorgenommen werden. Die bisherige einjährige Amtszeit soll von einer zweijährigen abgelöst werden."

666 Satzung der CSU in der Fassung vom 4. 10. 1946, abgedruckt in: Protokolle und Materialien, S. 1783-1803, hier S. 1800 (Paragraph 62). 
Dieser Befund paßt nicht recht zu Mintzels Bild einer Satzung, die der politischen Wirklichkeit einer Honoratiorenpartei angepaßt gewesen sei und einer zielgerichteten Organisationspolitik im Wege gestanden habe. Die von Max Gerstl konzipierten Statuten intendierten im Gegenteil eine Aktivierung und organisatorische Stärkung der CSU, auch wenn sie zweifellos nicht am Bild einer straff geführten Funktionärspartei orientiert waren ${ }^{667}$. Daß dieses Ziel nicht erreicht werden konnte und die CSU in Teilen Bayerns nur ein Schattendasein führte, lag aber weniger am statuarischen Rahmen als am fehlenden Willen der Verantwortlichen und an der desolaten Finanzlage der Partei.

\section{c) Mitgliederentwicklung, Parteifinanzen und Parteiapparat}

Der chronische Geldmangel der CSU seit 1948 resultierte vor allem aus der katastrophalen Entwicklung der Mitgliederzahlen und aus der ebenso schlechten Zahlungsmoral der verbliebenen Parteimitglieder. Im Juni 1948, dem Monat der Währungsreform, waren 85310 Frauen und Männer in den Mitgliederlisten der CSU eingeschrieben ${ }^{668}$, als Hans Ehard im Mai 1949 zum Landesvorsitzenden gewählt wurde, waren es nur noch 69444 und damit fast 16000 weniger als vor Jahresfrist ${ }^{669}$.

\section{Mitgliederentwicklung der CSU 1950 bis $1953^{670}$}

\begin{tabular}{|c|c|c|c|}
\hline Bezirksverband & $\begin{array}{l}\text { Mitgliederstand zum } \\
\text { 1. Mai } 1950\end{array}$ & $\begin{array}{l}\text { Mitgliederstand zum } \\
\text { 31.Dezember } 1953\end{array}$ & $\begin{array}{l}\text { Mitglied } \\
\text { und -ver }\end{array}$ \\
\hline Oberbayern & 13500 & 5477 & -8023 \\
\hline München & 1840 & keine Angaben & $\ldots$ \\
\hline Niederbayern & 9900 & 5194 & -4706 \\
\hline Oberpfalz & 11080 & 5765 & -5315 \\
\hline Schwaben & 8300 & 5727 & -2573 \\
\hline Augsburg & 492 & 557 & +65 \\
\hline Mittelfranken & 2600 & 2165 & -435 \\
\hline Nürnberg-Fürth & 1070 & 994 & -76 \\
\hline Oberfranken & 7015 & 3406 & -3609 \\
\hline Unterfranken & 5966 & 3700 & -2266 \\
\hline Gesamt & 61763 & 32985 & -28778 \\
\hline
\end{tabular}

667 ACSP, CSU-LL, Protokoll der Landesversammlung der CSU am 5./6. 7. 1952 in Regensburg. Gerst] weigerte sich auch, die weitgehenden Vorstellungen Hundhammers und seiner Gefolgsleute im Bezirksverband Oberbayern hinsichtlich der Rechte der Suborganisationen in seinen Entwurf aufzunehmen. Hundhammer hatte schon im Sommer 1950 vor dem geschäftsführenden Landesvorstand erklärt, die Satzung müsse so aufgebaut sein, daß der Bezirksverband die letztlich entscheidende Instanz sei. BayHStA, NL Ehard 2468, Protokoll der Sitzung des geschäftsführenden Landesvorstands am 5. 6. 1950 .

668 IfZ-Archiv, RG 260, 13/150-1/16, Politischer Tätigkeitsbericht der CSU für den Monat Juni 1948 vom 9.7.1948.

${ }^{669}$ IfZ-Archiv, RG 260, 13/150-1/9, Politischer Tätigkeitsbericht der CSU für den Monat Mai 1949 vom 20. 6. 1949.

${ }^{670}$ Zusammengestellt nach: ACSP, CSU-LL, Protokoll der Landesversammlung der CSU am 17./18. 6. 1950 in Kempten, und BayHStA, NL Ehard 646, Aufstellung über den Mitgliederstand der CSU nach Bezirks- und Kreisverbänden, Stand vom 31. 12. 1953. In der Aufstellung von 1953 wurden angeblich nur zahlende Mitglieder erfaßt; eine Reihe von Kreisverbänden meldete keine Mitgliederzahlen an die Landesleitung, Angaben zum Mitgliederstand im Bezirksverband München fehlen völlig. 
Auch dem großen Hoffnungsträger gelang es nicht, diese negative Entwicklung zu stoppen oder gar umzukehren. Im Juni 1950 mußte Josef Brunner der Landesversammlung Zahlen vorlegen, für die er selbst nur ein Wort fand: „erschreckend“671. Danach hatten der CSU zwischen Mai 1949 und Mai 1950 noch einmal mehr als 7600 Personen den Rücken gekehrt, und die Mitgliederzahl war auf 61763 gefallen. Doch es sollte noch schlimmer kommen. Nach einer Erhebung der Landesgeschäftsstelle zählte die CSU im Dezember 1953 gerade noch 32985 (zahlende) Mitglieder, gegenüber dem Mitgliederstand vom Mai 1950 ein Verlust von 28778 oder fast 47 Prozent.

\begin{tabular}{lc} 
Mitgliederzabl in den Kreisverbänden des Bezirks Oberbayern \\
\multicolumn{2}{c}{ Stand zum 31. Dezember $1953^{672}$} \\
Kreisverband & Mitglieder \\
Aichach & 140 \\
Altötting & 405 \\
Bad Aibling & 210 \\
Bad Reichenhall & 70 \\
Bad Tölz & 210 \\
Berchtesgaden & 176 \\
Dachau & 330 \\
Ebersberg & 290 \\
Erding & 123 \\
Freising & 160 \\
Fürstenfeldbruck & 105 \\
Garmisch-Partenkirchen & 277 \\
Ingolstadt-Stadt & 194 \\
Ingolstadt-Land & 76 \\
Landsberg & keine Meldung \\
Laufen & 145 \\
Miesbach & 250 \\
Mühldorf & keine Meldung \\
München-Land & keine Meldung \\
Pfaffenhofen & 140 \\
Rosenheim-Stadt & 130 \\
Rosenheim-Land & 340 \\
Schongau & 400 \\
Schrobenhausen & 50 \\
Starnberg & 250 \\
Traunstein & 501 \\
Wasserburg & 100 \\
Weilheim & 200 \\
Wolfratshausen & 205 \\
Oberbayern gesamt & 5477 \\
& \\
&
\end{tabular}

Diese Zahlen sind allerdings nicht unproblematisch. Eigentlich war es Aufgabe der Kreisverbände, Mitgliederlisten zu führen; eine zentrale Erfassung in der Landesgeschäftsstelle gab es nicht. Die Kreisverbände waren angesichts ihrer organisatorischen

671 ACSP, CSU-LL, Protokoll der Landesversammlung der CSU am 17./18. 6. 1950 in Kempten; die folgenden Zahlen für 1950 nach ebenda.

672 BayHStA, NL Ehard 646, Aufstellung über den Mitgliederstand der CSU nach Bezirks- und Kreisverbänden, Stand vom 31. 12. 1953; in dieser Aufstellung wurden angeblich nur zahlende Mitglieder erfaßt. Die folgenden Tabellen sind nach den Zahlen in diesem Dokument zusammengestellt. 
Schwäche aber vielfach nicht in der Lage, dieser Verpflichtung nachzukommen, so daß die Mitgliederzahlen, die sie an die Parteizentrale weitergaben, entweder veraltet waren oder auf Schätzungen beruhten.

\section{Mitgliederzabl in den Kreisverbänden des Bezirks Niederbayern Stand zum 31. Dezember 1953}

$\begin{array}{lr}\text { Kreisverband } & \text { Mitgl } \\ \text { Bogen } & 359 \\ \text { Deggendorf-Stadt } & 104 \\ \text { Deggendorf-Land } & 353 \\ \text { Dingolfing } & 106 \\ \text { Eggenfelden } & 230 \\ \text { Grafenau } & 108 \\ \text { Griesbach/Rottal } & 106 \\ \text { Kelheim/Abensberg } & 186 \\ \text { Kötzting } & 304 \\ \text { Landau an der Isar } & 88 \\ \text { Landshut-Stadt } & 134 \\ \text { Landshut-Land } & 78 \\ \text { Mainburg } & 68 \\ \text { Mallersdorf } & 204 \\ \text { Passau-Stadt } & 371 \\ \text { Passau-Land } & 379 \\ \text { Pfarrkirchen } & 257 \\ \text { Regen } & 186 \\ \text { Rottenburg an der Laaber } & 120 \\ \text { Straubing-Stadt } & 220 \\ \text { Straubing-Land } & 417 \\ \text { Viechtach } & 127 \\ \text { Vilshofen } & 208 \\ \text { Vilsbiburg } & 75 \\ \text { Wegscheid } & 201 \\ \text { Wolfstein } & 205 \\ \text { Niederbayern gesamt } & 5194\end{array}$

Eine Reihe von Kreisverbänden - 1952 fast 33 Prozent und 1953 mindestens 15 Prozent $^{673}$ - beantwortete diesbezügliche Anfragen der Landesgeschäftsstelle überhaupt nicht. Auch ob die Kreisverbände in der Lage waren, zwischen zahlenden und nichtzahlenden Parteimitgliedern zu unterscheiden, wie es 1952 und 1953 gefordert wurde, ist zweifelhaft ${ }^{674}$. Einige konnten sicherlich annähernd korrekte Angaben machen, an-

${ }^{673}$ BayHStA, NL Ehard 97, Aufstellung über den Mitgliederstand und die Mitgliederentwicklung der CSU, Stichtag 30. 3. 1952; Hans Ehard verwendete diese Angaben für seine Rechenschaftsberichte vor der Landesversammlung der CSU am 5./6. 7. 1952 in Regensburg und dem Landesausschuß der CSU am 25. 10. 1952 in Dinkelsbühl (ACSP, CSU-LL). Vor dem Landesausschuß gab er aber an, nicht 114 von 169 Kreisverbänden hätten Meldungen abgegeben, sondern 120. BayHStA, NL Ehard 646, Aufstellung über den Mitgliederstand der CSU nach Bezirks- und Kreisverbänden, Stand vom 31. 12. 1953; dazu kommt noch eine unbekannte Anzahl von Kreisverbänden aus München, da aus diesem Bezirksverband überhaupt keine Meldungen eingegangen waren.

674 Nach BayHStA, NL Ehard 97, Aufstellung über den Mitgliederstand und die Mitgliederentwicklung der CSU, Stichtag 30. 3. 1952, hatte die Partei 35356 eingeschriebene Mitglieder, von denen 27610 Beiträge zahlten. 
dere leiteten jedoch sichtlich überhöhte Zahlen an die Landesgeschäftsstelle weiter. Alle Mitgliederzahlen, die sich in den Quellen finden, sind daher mit einer gleichsam natürlichen Fehlerquote behaftet und müssen mit der gebotenen Vorsicht interpretiert werden. Für die Landesleitung waren die wenig verläßlichen Mitgliederzahlen ein großes Problem. Franz Josef Strauß erklärte schon 1949 in einer Sitzung des geschäftsführenden Landesvorstands, korrekte Mitgliederzahlen aus den Kreisverbänden seien eine unverzichtbare Voraussetzung für eine realistische Finanzplanung ${ }^{675}$, und Josef Brunner appellierte im Juni 1950 an die Verantwortlichen, mehr auf die Richtigkeit ihrer Angaben zu achten, da die Landesleitung mit „Potemkinschen Dörfern und Zahlen“ nichts anfangen könne ${ }^{676}$.

\section{Mitgliederzahl in den Kreisverbänden des Bezirks Oberpfalz Stand zum 31. Dezember 1953}

$\begin{array}{lc}\text { Kreisverband } & \text { Mitglieder } \\ \text { Amberg-Stadt } & 214 \\ \text { Amberg-Land } & 160 \\ \text { Beilngries } & \text { keine Meldung } \\ \text { Burglengenfeld } & 169 \\ \text { Cham } & 475 \\ \text { Eschenbach } & \text { keine Meldung } \\ \text { Kemnath } & \text { keine Meldung } \\ \text { Nabburg } & \text { keine Meldung } \\ \text { Neunburg vorm Wald } & \text { keine Meldung } \\ \text { Neumarkt-Stadt } & 216 \\ \text { Neumarkt-Land } & 504 \\ \text { Neustadt a. d. Waldnaab } & \text { keine Meldung } \\ \text { Oberviechtach } & 45 \\ \text { Parsberg } & 480 \\ \text { Regensburg-Stadt } & 530 \\ \text { Regensburg-Land } & 807 \\ \text { Riedenburg } & 213 \\ \text { Roding } & 380 \\ \text { Sulzbach-Rosenberg } & 74 \\ \text { Vohenstrauß } & 403 \\ \text { Waldmünchen } & \text { keine Meldung } \\ \text { Weiden } & 294 \\ \text { Tirschenreuth } & 757 \\ \text { Schwandorf } & 61 \\ \text { Oberpfalz gesamt } & 5765\end{array}$

Nichtsdestotrotz zeigt das vorhandene Zahlenmaterial, in welchen Teilen Bayerns die CSU ihre größten Einbrüche zu verzeichnen hatte und wo sie sich vergleichsweise gut halten konnte. Vergleicht man die Mitgliederzahlen aus den Jahren 1950 und 1953 auf Bezirksverbandsebene, fällt sofort der drastische Mitgliederschwund in den drei altbayerischen Bezirksverbänden Oberbayern, Niederbayern und Oberpfalz auf. In

675 ACSP, CSU-LL, Protokoll der Sitzung des geschäftsführenden Landesvorstands am 17. 6. 1949.

${ }^{676}$ ACSP, CSU-LL, Protokoll der Landesversammlung der CSU am 17./18. 6. 1950 in Kempten; ähnlich äußerte sich auch Hans Ehard in seinem Rechenschaftsbericht vor der Landesversammlung der CSU am 5./6. 7. 1952 in Regensburg; ACSP, CSU-LL. 
Oberbayern verlor die CSU sogar fast 60 Prozent ihrer Mitglieder! In Ober- und Niederbayern dürfte die heftige Konkurrenz durch die Bayernpartei für diese Entwicklung verantwortlich gewesen sein, deren Attraktivität für ehemalige Anhänger der CSU offensichtlich auch nach dem erzwungenen Stabwechsel von Müller auf Ehard vorerst kaum nachgelassen hatte. Die schlechten Zahlen aus der Oberpfalz dürften dagegen unter anderem auf fehlende Meldungen der Kreisverbände zurückzuführen sein. Immerhin sieben von 24 Kreisverbänden ließen die Landesgeschäftsstelle 1953 über die Zahl ihrer Mitglieder im unklaren. In Oberfranken, wo die Mitgliederzahl um mehr als 51 Prozent gesunken war, läßt sich eine ähnliche Entwicklung beobachten; dort gaben 1953 sogar nur 15 von 25 Kreisverbänden Mitgliederzahlen an die Parteizentrale weiter. Es ist allerdings fraglich, wieviele Mitglieder, vor allem zahlende Mitglieder, die CSU noch in Kreisverbänden hatte, die nicht einmal mehr Anfragen der Landesleitung beantworteten. Etwas besser lagen die Dinge in Unterfranken, Schwaben und - erstaunlicherweise - in Mittelfranken.

\section{Mitgliederzabl in den Kreisverbänden des Bezirks Oberfranken Stand zum 31. Dezember 1953}

$\begin{array}{lc}\text { Kreisverband } & \text { Mitglieder } \\ \text { Bamberg-Stadt } & 500 \\ \text { Bamberg-Land } & 604 \\ \text { Bayreuth-Stadt } & 64 \\ \text { Bayreuth-Land } & 120 \\ \text { Coburg-Stadt und -Land } & \text { keine Meldung } \\ \text { Ebermannstadt } & \text { keine Meldung } \\ \text { Forchheim-Stadt } & \text { keine Meldung } \\ \text { Forchheim-Land } & 284 \\ \text { Höchstadt an der Aisch } & 235 \\ \text { Hof-Stadt } & 118 \\ \text { Hof-Land } & 32 \\ \text { Kronach } & 524 \\ \text { Kulmbach-Stadt } & 35 \\ \text { Kulmbach-Land } & 42 \\ \text { Lichtenfels } & \text { keine Meldung } \\ \text { Münchberg } & 250 \\ \text { Naila } & \text { keine Meldung } \\ \text { Neustadt bei Coburg } & \text { keine Meldung } \\ \text { Pegnitz } & \text { keine Meldung } \\ \text { Rehau } & 104 \\ \text { Selb } & \text { keine Meldung } \\ \text { Staffelstein } & 170 \\ \text { Stadtsteinach } & 324 \\ \text { Wunsiedel } & \text { keine Meldung } \\ \text { Marktredwitz } & \text { keine Meldung } \\ \text { Oberfranken gesamt } & 3406 \\ & \end{array}$

Dort hatte die CSU zwischen 1950 und 1953 ihren kleinen Mitgliederstamm einigermaßen zusammenhalten können und lediglich 16,73 Prozent der Mitglieder verloren. Auch die Bilanz der mitgliederschwachen großstädtischen Bezirksverbände Augsburg und Nürnberg-Fürth war nicht so schlecht, wie man hätte befürchten können. Augsburg hatte als einziger Bezirksverband 1953 ein kleines Plus zu verzeichnen (13,21 
Prozent), und in Nürnberg und Fürth hielt sich der Mitgliederschwund wenigstens in Grenzen.

156 Kreisverbände hatten Mitgliederzahlen für Dezember 1953 an die Landesgeschäftsstelle weitergemeldet, und bei der Auswertung dieser Daten mußten die Verantwortlichen in der Parteizentrale erkennen, wie ausgezehrt die CSU wirklich war: In 35 Kreisverbänden waren weniger als 100 Mitglieder eingeschrieben. Solche Organisationen bestanden praktisch nur auf dem Papier. Im Kreisverband Fürth-Land zählte man gerade einmal 29 zahlende Mitglieder der CSU, von denen vermutlich jedes ein Amt oder Mandat bekleidete. Und das war kein Einzelfall, da Kreisverbände wie Hof-Land, Kulmbach-Stadt und Kulmbach-Land, Bad Brückenau, Kitzingen-Stadt, Hofheim oder Nördlingen-Stadt nicht viel besser dran waren. In den fränkischen Diasporagebieten - beispielsweise in Nordost-Oberfranken - fanden sich solche Feigenblätter besonders häufig, aber auch in Ober- und Niederbayern, in Schwaben, in Unterfranken oder in der Oberpfalz gab es Kreise, die in der Rangliste der mitgliederschwächsten Verbände ganz oben standen.

Ein solcher Kreisverband war Ingolstadt-Land, dem im Juni 1948, dem Monat der Währungsreform, noch 546 Mitglieder angehört hatten. Allerdings war der Organisationsgrad der CSU in diesem Landkreis schon damals nicht gerade überwältigend gewesen; bei 41 politischen Gemeinden hatte die Union gerade einmal fünf Ortsverbände aufbauen können ${ }^{677}$, und das in einem Landkreis, dessen Sozialstruktur - die Bevölkerung war überwiegend katholisch und in der Landwirtschaft beschäftigt - für die CSU nicht ungünstig war. Der landesweite Zusammenbruch des Parteiapparats ging auch am Kreisverband Ingolstadt-Land nicht spurlos vorüber, im Gegenteil. Bis Oktober 1949 verlor die CSU hier mehr als 400 Mitglieder $^{678}$, und auch in den folgenden Monaten kam diese Entwicklung nicht zum Stillstand. Im monatlichen Organisationsbericht des Kreisverbands für Dezember 1950 war der Mitgliederstand nur mehr mit 71 angegeben; gegenüber dem Vormonat, in dem immerhin Landtagswahlen stattgefunden hatten, die stets eine gewisse Mobilisierung der Parteibasis mit sich brachten, hatte die CSU im Landkreis Ingolstadt damit fast 45 Prozent ihrer verbliebenen Mitglieder verloren $^{679}$ ! In den folgenden Jahren störten abgesehen von Großveranstaltungen zu Wahlkampfzeiten lediglich einige Redner aus dem benachbarten Stadtkreis, die am Wochenende in halbleeren Gaststuben sprachen, den bleiernen Schlaf des Kreisverbands. Noch im Januar 1955 hatte die CSU im Landkreis Ingolstadt nur 67 Mitglieder, in den 41 Gemeinden des Landkreises existierte kein einziger Ortsverband mehr, lediglich in vier Gemeinden hatten sich Vertrauensleute halten können ${ }^{680}$. Die Situation änderte sich erst im Frühjahr 1956, als der neue Generalsekretär Friedrich Zimmermann versuchte, die CSU für die bevorstehenden Kommunalwahlen fit zu machen. Man gewinnt fast den Eindruck, als sei der CSU-Kreisverband Ingolstadt-Land in diesen Mo-

677 Stadtarchiv Ingolstadt, XXI/35, Bericht des CSU-Kreisverbands Ingolstadt-Land für Juni 1948 über Mitgliederstand und Organisation.

${ }^{678}$ Stadtarchiv Ingolstadt, XXI/35, Bericht des CSU-Kreisverbands Ingolstadt-Land für Oktober 1949 über Mitgliederstand und Organisation.

679 Stadtarchiv Ingolstadt, XXI/35, Bericht des CSU-Kreisverbands Ingolstadt-Land für Dezember 1950 über Mitgliederstand und Organisation.

680 Stadtarchiv Ingolstadt, XXI/35, Bericht des CSU-Kreisverbands Ingolstadt-Land für das zweite Quartal 1955 über Mitgliederstand und Organisation an den Bezirksverband Oberbayern und die Landesleitung. 
naten ein zweites Mal gegründet worden. Im Zuge einer organisationspolitischen Offensive wurden Versammlungen abgehalten, Mitglieder geworben, Vertrauensmänner eingesetzt und Ortsverbände gegründet. Von Januar bis April 1956 stieg die Zahl der CSU-Mitglieder von 86 auf 240; in den 41 Gemeinden des Landkreises gab es nun immerhin 19 Ortsverbände, die allesamt in den zurückliegenden Wochen neu ins Leben gerufen worden waren, und in den restlichen 22 Kommunen hatte man wenigstens einen Vertrauensmann installiert ${ }^{681}$.

\begin{tabular}{|c|c|}
\hline \multicolumn{2}{|c|}{$\begin{array}{c}\text { Mitgliederzabl in den Kreisverbänden der Bezirke Schwaben und Augsburg } \\
\text { Stand zum 31. Dezember } 1953\end{array}$} \\
\hline Kreisverband & Mitglieder \\
\hline Augsburg-Land & 339 \\
\hline Dillingen & 247 \\
\hline Donauwörth & 605 \\
\hline Friedberg & 298 \\
\hline Füssen & 60 \\
\hline Günzburg & 226 \\
\hline Illertissen & 152 \\
\hline Kaufbeuren-Stadt und -Land & 108 \\
\hline Kempten-Stadt & 261 \\
\hline Kempten-Land & 970 \\
\hline Krumbach & 102 \\
\hline Markt Oberdorf & 120 \\
\hline Memmingen-Stadt und -Land & 590 \\
\hline Lindau-Stadt und -Land & 635 \\
\hline Mindelheim & 235 \\
\hline Neuburg an der Donau & 105 \\
\hline Neu-Ulm-Stadt & 66 \\
\hline Neu-Ulm-Land & keine Meldung \\
\hline Nördlingen-Stadt & 30 \\
\hline Nördlingen-Land & 304 \\
\hline Schwabmünchen & 184 \\
\hline Sonthofen & keine Meldung \\
\hline Wertingen & 90 \\
\hline Schwaben gesamt & 5727 \\
\hline Augsburg I & 270 \\
\hline Augsburg II & 129 \\
\hline Augburg III & 158 \\
\hline Augsburg gesamt & 557 \\
\hline
\end{tabular}

Eine Reihe von Kreisverbänden hatte freilich auch 1953 schon erfreuliche Zahlen zu melden. Schongau in Oberbayern beispielsweise, das zum Bundeswahlkreis von Franz Josef Strauß gehörte, Passau-Stadt und Passau-Land in Niederbayern, die politische Heimat von Fritz Schäffer, oder Bamberg-Stadt und -Land. Diese Entwicklung kam freilich nicht von ungefähr. Während viele Kreisverbände richtungslos dahindümpelten

${ }^{681}$ Stadtarchiv Ingolstadt, XXI/35, Bericht des CSU-Kreisverbands Ingolstadt-Land für das erste Quartal 1956 über Mitgliederstand und Organisation an den Bezirksverband Oberbayern und die Landesleitung. 
und die ehrenamtlichen Kräfte hoffnungslos überfordert waren, hatten Strauß, Schäffer und die Bamberger Bundes- und Landtagsabgeordneten Emil Kemmer, Hans Ehard und Georg Meixner auf eigene Initiative Geschäftsstellen eingerichtet, die sich in kurzer Zeit zu wahren Aktivposten entwickelten ${ }^{682}$. Der unmittelbare Zusammenhang zwischen engagierten Geschäftsführern an der Parteibasis und erfolgreicher Mitgliederwerbung war auch der Parteiführung nicht verborgen geblieben ${ }^{683}$. Doch die CSU hatte in der Ära Ehard einfach nicht die finanziellen Mittel, um die notwendigen hauptamtlich besetzen Geschäftsstellen einzurichten.

\section{Mitgliederzabl in den Kreisverbänden der Bezirke Mittelfranken und Nürnberg-Fürth Stand zum 31. Dezember 1953}

$\begin{array}{lc}\text { Kreisverband } & \text { Mitglieder } \\ \text { Ansbach } & 133 \\ \text { Dinkelsbühl } & 250 \\ \text { Eichstätt-Stadt } & 102 \\ \text { Eichstätt-Land } & 125 \\ \text { Erlangen-Stadt } & 68 \\ \text { Erlangen-Land } & 60 \\ \text { Feuchtwangen } & 75 \\ \text { Gunzenhausen } & \text { keine Meldung } \\ \text { Hersbruck } & 65 \\ \text { Hilpoltstein } & 315 \\ \text { Lauf an der Pegnitz } & 236 \\ \text { Neustadt an der Aisch } & 70 \\ \text { Rothenburg o. d. Tauber } & 110 \\ \text { Scheinfeld } & 80 \\ \text { Schwabach-Stadt } & 50 \\ \text { Schwabach-Land } & 116 \\ \text { Uffenheim } & \text { keine Meldung } \\ \text { Weißenburg } & 310 \text { (200 zahlend) } \\ \text { Mittelfranken gesamt } & 2165 \\ & \\ \text { Fürth-Stadt } & 56 \\ \text { Fürth-Land } & 29 \\ \text { Nürnberg-Land } & 151 \\ \text { Kreisverband Nürnberg I-IV } & 758 \\ \text { Nürnberg-Fürth gesamt } & 994 \\ \end{array}$

Wie sollte die CSU bei der bekannt schlechten Zahlungsmoral ihrer wenigen Mitglieder auch über nennenswertes Kapital verfügen, mit dem sie sicher rechnen konnte? Für das Jahr 1950 hätten die Kreisverbände Mitgliederbeiträge in der Höhe von

${ }^{682}$ Zum Vorbildcharakter der Bundeswahlkreisgeschäftsstelle Schongau für den Bezirksverband Oberbayern vgl. ACSP, CSU-LTF II/1, 15-20/41, Der oberbayerische Informationsbrief 12/52 vom 10. 9. 1952. Bundeswahlkreisgeschäftsführer Wösner schrieb am 27. 2. 1950 an Fritz Schäffer (BAK, NL Schäffer 27, Bl. 268f.), mit Ausnahme von Passau und Straubing ruhe die Arbeit der CSU in ganz Niederbayern. Zum Abgeordneten-Büro in Bamberg vgl. Bayern-Kurier vom 10.6. 1950: "Volksnahe Abgeordnete".

683 ACSP, CSU-LL, Rechenschaftsbericht Hans Ehards vor der Landesversammlung der CSU am 5./ 6. 7. 1952 in Regensburg. 
$146934,80 \mathrm{DM}$ an den Landesverband abführen müssen ${ }^{684}$. Tatsächlich gingen in diesem Jahr aber gerade einmal 5436,18 DM bei der Landesgeschäftsstelle ein.

\section{Mitgliederzabl in den Kreisverbänden des Bezirks Unterfranken Stand zum 31. Dezember 1953}

$\begin{array}{lc}\text { Kreisverband } & \text { Mitglieder } \\ \text { Alzenau } & 90 \\ \text { Aschaffenburg-Stadt } & 264 \\ \text { Aschaffenburg-Land } & 252 \\ \text { Bad Brückenau } & 30 \\ \text { Bad Kissingen-Stadt } & 115 \\ \text { Bad Kissingen-Land } & 91 \\ \text { Bad Neustadt } & 210 \\ \text { Ebern } & 105 \\ \text { Gemünden } & 96 \\ \text { Gerolzhofen } & 144 \\ \text { Hammelburg } & 213 \\ \text { Haßfurt } & 137 \\ \text { Hofheim } & 42 \\ \text { Karlstadt } & \text { keine Meldung } \\ \text { Kitzingen-Stadt } & 31 \\ \text { Kitzingen-Land } & 80 \\ \text { Königshofen } & 50 \\ \text { Lohr am Main } & 178 \\ \text { Marktheidenfeld } & \text { keine Meldung } \\ \text { Mellrichstadt } & \text { keine Meldung } \\ \text { Miltenberg } & 131 \\ \text { Obernburg } & 202 \\ \text { Ochsenfurt } & \text { keine Meldung } \\ \text { Schweinfurt-Stadt } & 125 \\ \text { Schweinfurt-Land } & 170 \\ \text { Würzburg-Stadt } & 484 \\ \text { Würzburg-Land } & 460 \\ \text { Unterfranken gesamt } & 3700 \\ & \end{array}$

Von den 26 Kreisverbänden in Oberbayern fanden sich gerade einmal sechs bereit, Geld an die Parteizentrale zu überweisen, und in den anderen Bezirken sah es nicht besser aus. In Niederbayern waren es von 26 vier, die überhaupt etwas bezahlten, in der Oberpfalz von 22 nur zwei, in Oberfranken von 25 vier, in Mittelfranken von 17 drei und in Schwaben von 20 acht; die Kreisverbände in Nürnberg-Fürth und Augsburg ließen dem Landesverband keinen Pfennig zukommen, und der Bezirksverband München führte - welch eine Provokation! - bei einem Beitragssoll von 4388 DM für das Jahr 1950 gerade einmal acht DM an die Landesgeschäftsstelle ab. Lediglich in Unterfranken bot sich ein etwas erfreulicheres Bild. Dort kamen 13 von 26 Kreisverbänden ihren Zahlungsverpflichtungen zumindest ansatzweise nach. Aber auch die weni-

684 Zahlen nach BayHStA, NL Ehard 131, Aufstellung „Beiträge der Kreisverbände 1950“ für Hans Ehard, undatiert. 1949 hatte man sich im geschäftsführenden Landesvorstand darauf geeinigt, vom Mindestbeitrag von 50 Pfennig pro Monat 20 Pfennig dem Landesverband, 20 Pfennig dem Kreisverband und zehn Pfennig dem Bezirksverband zu überlassen. ACSP, CSU-LL, Protokoll der Sitzung des geschäftsführenden Landesvorstands am 17.6. 1949. 
gen zahlungswilligen Kreisverbände überwiesen meist nur einen Bruchteil ihrer Beitragsschuld nach München, meist Summen zwischen 25 und 250 DM. Mit SulzbachRosenberg gab es 1950 nur einen einzigen Kreisverband, der seine Verpflichtungen gegenüber dem Landesverband vollständig erfüllt hatte. Insgesamt betrugen die Beitragsschulden der Kreisverbände für das Jahr 1950 141498,62 DM!

Die Mitgliederentwicklung hatte jedoch nicht nur gravierende Auswirkungen auf die Parteifinanzen, sondern prägte auch die innerparteiliche Willensbildung in spezifischer Weise. Die Legitimationsbasis war stellenweise so schmal, „daß die demokratische Selektion der Personen für öffentliche und partiinterne Wahlämter wie die innerparteiliche Demokratie überhaupt zur Farce zu werden" drohten ${ }^{65}$.

\section{Beitragsleistungen der Kreisverbände 1950 (nach Bezirken) ${ }^{686}$}

$\begin{array}{lccc}\text { Bezirksverband } & \text { Beitragssoll 1950 } & \text { Zahlungen 1950 } & \begin{array}{c}\text { Beitragsschuld } \\ \text { (Stichtag: 15. 1. }\end{array} \\ \text { Oberbayern } & 31255,80 \mathrm{DM} & 1083,60 \mathrm{DM} & 30172,20 \mathrm{DM} \\ \text { München } & 4388 \mathrm{DM} & 8 \mathrm{DM} & 4380 \mathrm{DM} \\ \text { Niederbayern } & 23651,60 \mathrm{DM} & 476,80 \mathrm{DM} & 23174,80 \mathrm{DM} \\ \text { Oberpfalz } & 26541,40 \mathrm{DM} & 280,50 \mathrm{DM} & 26260,90 \mathrm{DM} \\ \text { Schwaben } & 19888 \mathrm{DM} & 1224 \mathrm{DM} & 18664 \mathrm{DM} \\ \text { Augsburg } & 1202,40 \mathrm{DM} & -\cdots & 1202,40 \mathrm{DM} \\ \text { Mittelfranken } & 6459,60 \mathrm{DM} & 363,78 \mathrm{DM} & 6095,82 \mathrm{DM} \\ \text { Nürnberg-Fürth } & 2569,80 \mathrm{DM} & -1 .- & 2569,80 \mathrm{DM} \\ \text { Oberfranken } & 16693,60 \mathrm{DM} & 896,60 \mathrm{DM} & 15797 \mathrm{DM} \\ \text { Unterfranken } & 14284,60 \mathrm{DM} & 1102,90 \mathrm{DM} & 13181,70 \mathrm{DM} \\ \text { Gesamt } & 146934,80 \mathrm{DM} & 5436,18 \mathrm{DM} & 141498,62 \mathrm{DM}\end{array}$

Diese gefährliche Entwicklung hatten zumindest einige Nachwuchspolitiker erkannt. Franz Sackmann von der Jungen Union erklärte im Januar 1954 ironisch, man habe heute einen ausgefeilten Delegiertenschlüssel zur Aufstellung der Kandidaten für die Landtagswahlen beschlossen, es werde aber in manchen Kreisverbänden sehr schwierig sein, die notwendige Anzahl an Delegierten überhaupt zusammenzubringen ${ }^{68}$. Dieser an und für sich unhaltbare Zustand war jedoch dem einen oder anderen Funktionär vor Ort nicht unrecht. Friedrich Zimmermann erinnerte sich sogar an Fälle, in denen der Kreisvorsitzende die Beiträge für den gesamten Verband aus der eigenen Tasche bezahlte und die Losung ausgab: „Es werden keine neuen Mitglieder aufgenommen. Das wäre ja noch schöner, wenn wir nicht mehr unter uns wären! “688

${ }^{685}$ Diesen Befund für den Bezirksverband Schwaben kann man getrost auf die anderen Bezirksverbände übertragen. Mintzel, Anatomie, S. 238. Vgl. z. B. die Schilderung der Zustände im Kreisverband Riedenburg: ACSP, NL Müller 162, Robert Weyh an Josef Müller vom 30.12. 1949.

686 Zusammengestellt nach: BayHStA, NL Ehard 131, Aufstellung „Beiträge der Kreisverbände 1950“ für Hans Ehard, undatiert.

${ }^{687}$ ACSP, CSU-LL, Protokoll der Sitzung des Landesausschusses der CSU am 15. 1. 1954 in Rothenburg ob der Tauber.

688 Erinnerungsinterview mit Friedrich Zimmermann, in: Geschichte einer Volkspartei, S. 623. In einem Strategiepapier der Jungen Union hieß es zu diesem Problem: „Manche Kreisverbände der CSU haben seit Jahren auf eine tatsächliche Parteiarbeit und auf eine Erweiterung des Mitgliederstandes keinen Wert gelegt. Denn nur so blieb die Kandidatenaufstellung die Angelegenheit eines kleinen Freundeskreises. “ BSB, NL Schwend 15, „Denkschrift über Wesen, Arbeit und Pläne der Arbeitsgemeinschaft Junge Union in der Christlich-Sozialen Union" vom 28. 3. 1954. 
Wie es in den einzelnen Kreisverbänden aussah, wußte man in der Landesleitung nicht mehr, seitdem die meisten Geschäftsführer im Zuge der Währungsreform entlassen worden waren. Um sich ein Bild von der Lage vor Ort zu machen, entsandte die Landesgeschäftsstelle von Zeit zu Zeit einen Beauftragten in die Provinz, um dort nach dem Rechten zu sehen. Im Frühjahr 1953 war es der kommissarische Landesgeschäftsführer Alois Engelhardt, der im Zuge der Vorbereitungen für die Bundestagswahlen eine Reihe von Kreisverbänden in Nord- und Ostbayern besuchte ${ }^{689}$. In der Oberpfalz, beispielsweise, traf Engelhardt auf viel guten Willen und erkannte im spürbaren Interesse jüngerer CSU-Mitglieder ein nicht zu unterschätzendes Potential für die Aktivierung der Partei. Ansonsten war das Bild aber eher trostlos. Der kommissarische Landesgeschäftsführer nahm an schlecht besuchten Mitgliederversammlungen und Vorstandssitzungen teil oder konferierte mit überforderten Funktionären. Die Personaldecke war vielfach so dünn, daß selbst einfachste Aufgaben zu einem Problem werden konnten. Auch das Desinteresse der Mandatsträger an der Parteiarbeit war immer wieder spürbar, mancherorts hatte sich sogar ein regelrechter Antagonismus zwischen Partei und Fraktion auf Gemeinde-, Stadt- oder Landkreisebene herausgebildet. So hatte die Kreisversammlung in Regensburg beschlossen, die Stadtratsfraktion durch „Anregungen und Weisungen“ stärker an die Partei zu binden. „Zuerst die Partei und dann die Fraktion“, war die Devise, die überwiegend von jüngeren CSU-Mitgliedern ausgegeben wurde. Doch die Stadtratsfraktion hatte dafür nur wenig Verständnis und quittierte derlei Initiativen mit der Aussage, der Kreisvorstand könne nicht als „Vormund des Stadtrates auftreten“. Die Energie, die noch in den Kreisverbänden steckte, wurde so des öfteren von internen Querelen aufgezehrt, die sich entweder an persönlichen Differenzen entzündet hatten oder noch aus der Zeit der Führungs- und Flügelkämpfe stammten. Besonders schwer wog aber die Tatsache, daß eine leistungsfähige Parteizentrale fehlte, die in der Lage gewesen wäre, die verbliebenen Kräfte zu bündeln, brachliegende Reserven zu mobilisieren, dem vielbeklagten Informationsdefizit an der Basis abzuhelfen und schlichtend in Konflikte einzugreifen, wenn diese die Parteiarbeit vor Ort zu gefährden drohten.

Es wäre interessant, über die quantitative Dimension der Mitgliederentwicklung hinaus etwas über das Sozialprofil der CSU-Mitglieder in der Ära Ehard zu erfahren. Doch in den Quellen lassen sich kaum Informationen zu dieser Frage finden. 1952 hat die Landesleitung offensichtlich versucht, eine Fragebogenaktion bei den Kreisverbänden zu starten, die entsprechende Analyse läßt jedoch sehr zu wünschen übrig. Hans Ehard gab in einem Rechenschaftsbericht lediglich einige Daten zur Altersstruktur bekannt. Danach waren ca. 22 Prozent der CSU-Mitglieder jünger als 40 Jahre, ca. 61 Prozent waren 40 bis 65 Jahre alt und ca. 17 Prozent waren älter als $65 \mathrm{Jahre}^{690}$. Alf Mintzel hat die CSU mit Blick auf ihre Mitgliederschaft als Partei "des alteingesessenen bäuerlichen, handwerklichen und kaufmännischen Besitzmittel-

689 BayHStA, NL Ehard 370, Erfahrungsberichte Alois Engelhardts über seine Inspektionsreisen durch die Oberpfalz vom 26. 1.-29. 1. 1953, durch Unterfranken vom 3. 2.-6. 2. 1953 und durch Oberfranken vom 13.3.-17. 3. 1953; das folgende nach dem Erfahrungsbericht über die Inspektionsreise durch die Oberpfalz.

690 BayHStA, NL Ehard 97, Aufstellung über den Mitgliederstand und die Mitgliederentwicklung der CSU, Stichtag 30. 3. 1952, und ACSP, CSU-LL, Rechenschaftsbericht Hans Ehards vor der Landesversammlung der CSU am 5./6. 7. 1952 in Regensburg. 
standes ländlicher und kleinstädtischer Gemeinden in überwiegend katholischen Gebieten" bezeichnet ${ }^{691}$. Da so gut wie keine Angaben zur Herkunft, Berufsgruppenschichtung oder konfessionellen Zusammensetzung der CSU-Mitglieder in der Ära Ehard vorliegen, läßt sich diese These nur schwer überprüfen. Eine Analyse der 1952 gewählten Mandatsträger der CSU auf kommunaler Ebene scheint Mintzels Aussage jedoch zu bestätigen. Danach waren 53 Prozent der Stadträte, 83 Prozent der Kreisräte, 93 Prozent der Gemeindebürgermeister und 83 Prozent der Gemeinderäte dem Mittelstand zuzurechnen ${ }^{692}$. Ein Blick auf das berufliche Profil der 79 Kreisvorsitzenden in den Bezirksverbänden Oberbayern, Oberpfalz und Unterfranken stützt Mintzels These ebenfalls, wenn man sie wohl auch in einem Punkt ergänzen muß: Auch Angehörige des öffentlichen Dienstes dürften in der CSU - gerade auf der Ebene der basisnahen Amts- und Mandatsträger - eine erhebliche Rolle gespielt haben. Nach den Vertretern des selbständigen Mittelstands (16) und den Landwirten (12) stellten die Angehörigen des öffentlichen Dienstes (acht) immerhin die drittgrößte Gruppe unter den hier untersuchten Kreisvorsitzenden, diejenigen gar nicht eingerechnet, die als Berufsbezeichnung Bürgermeister oder Landrat (17) angegeben haben ${ }^{693}$.

Daß die negative Entwicklung der Mitgliederzahlen, die Finanzmisere und der schleichende Zerfall von Parteiorganisation und -apparat Hand in Hand gingen, ist bereits gesagt worden. Doch was unternahm die CSU, um das Beitragsaufkommen zu steigern und wieder mehr Geld in die Kasse zu bekommen? Die wenigen hundert DM, die von den Kreisverbänden im Monatsdurchschnitt an die Landesgeschäftsstelle überwiesen wurden ${ }^{694}$, waren nur ein Tropfen auf den heißen Stein und deckten die anfallenden Kosten nicht einmal ansatzweise. Einen ordentlichen Haushalt aufzustellen und Geldquellen zu erschließen, auf die man regelmäßig rechnen konnte, erwies sich als vordringliches und nur schwer lösbares Problem ${ }^{695}$. "Wenn das Geld das Blut ist, das eine Parteiorganisation haben muß“, erklärte Landesschatzmeister Franz Elsen 1950 vor der Landesversammlung, „dann haben wir in den letzten Jahren an chronischer Blutarmut gelitten. ${ }^{696}$ Appelle an die Kreisverbände wie an die Parteimitglieder, ihren Zahlungsverpflichtungen endlich nachzukommen, um die Arbeit der CSU nicht zu gefährden, blieben ebenso ergebnislos wie unterschwellige Drohungen mit Sanktionen. „Es handle sich nicht nur um ein finanzielles, sondern auch um ein politisches und psychologisches Versagen der Mitglieder, denen die nötige Anteilnahme und der Mut zum Bekenntnis ihrer Überzeugung fehle“, stellte Elsen hellsichtig und resigniert zugleich fest ${ }^{697}$. Der

691 Mintzel, Anatomie, S. 283.

692 Bayern-Kurier vom 10. 1. 1953: „Der Mittelstand hat die Kommunalpolitik in der Hand“. Der Verfasser dieses Artikels, Regierungsrat Richard Schachtner vom Bayerischen Statistischen Landesamt, definierte als Mittelstand „die Gruppe der selbständigen Berufe“, d. h. die Handwerker, Gewerbetreibenden, Kaufleute, Landwirte und die Angehörigen der freien Berufe.

693 Angaben nach der Liste im Politischen Jahrbuch der CSU 1954, S. 270-276. Ein Teil der Kreisvorsitzenden machte keine Angaben über ihren Beruf.

694 Vgl. die detaillierten Kassenberichte für die Jahre 1950 und 1951, die dem Bericht des Helfers in Steuersachen Arnold Weber über die zwischen dem 22. 3. und 28. 4. 1954 vorgenommene Prüfung der CSU-Landesgeschäftsstelle als Anlage beigefügt sind; BayHStA, NL Ehard 1323.

695 ACSP, CSU-LL, Protokoll der Sitzung des geschäftsführenden Landesvorstands am 5. 12. 1949 und Protokoll der Sitzung des Landesvorstands am 17. 12. 1949.

6\%6 ACSP, CSU-LL, Protokoll der Landesversammlung der CSU am 17./18. 6. 1950 in Kempten.

697 ACSP, CSU-LL, Protokoll der Sitzung des Landesausschusses der CSU am 10.6. 1950 in München. 
Landesschatzmeister blieb mit dieser Einsicht nicht allein. Als in der Parteizentrale 1951 Bilanz gezogen wurde, schrieb man die Beitragsforderungen an die Kreisverbände für das vergangene Jahr in einer Höhe von mehr als $142000 \mathrm{DM}$ als „uneinbringlich“ $\mathrm{ab}^{698}$. Verschiedentlich waren sogar schon Stimmen laut geworden, auf Beiträge in toto zu verzichten, um den ständigen Reibereien ein Ende zu setzen und die Mitgliederzahlen wieder zu steigern ${ }^{699}$. Doch Hans Ehard weigerte sich, einen solchen Schritt zu vollziehen, und plädierte nachdrücklich dafür, die Mitgliederbeiträge trotz der völlig unbefriedigenden Situation als „äusseres Zeichen des Bekenntnisses zu einer Partei“ beizubehalten $^{700}$.

Statt dessen entschloß sich die Parteiführung zu einem anderen Schritt. Am 20. März 1951 einigte sich der geschäftsführende Landesvorstand darauf, die Verteilung des Beitragsaufkommens völlig neu zu regeln. Bisher waren die Mitgliederbeiträge von den Kreisverbänden erhoben und dann nach einem bestimmten Schlüssel zwischen dem Landesverband und den Kreis- und Bezirksverbänden aufgeteilt worden. Ab April 1951 wurden die Bezirksverbände verpflichtet, monatlich einen festgelegten, von der Mitgliederzahl unabhängigen Pauschalbetrag an die Landesgeschäftsstelle abzuführen $^{701}$. Die Kreisverbände hatten seitdem keine Leistungen mehr an den Landesverband zu erbringen, mußten jedoch damit rechnen, von den Bezirksverbänden belastet zu werden ${ }^{702}$. Da die festgelegten Beiträge der Bezirksverbände sehr gering waren, verzichtete der Landesverband nominell auf viel Geld, hatte aber andererseits die Chance, daß zumindest diese niedrigen Pauschalbeträge jeden Monat in der Landesgeschäftsstelle eingingen. Insgesamt begnügte sich der Landesverband mit 1400 DM monatlich $^{703}$; der Bezirksverband Oberbayern sollte davon 200 DM aufbringen, die Bezirksverbände München, Niederbayern, Schwaben, Mittelfranken, Oberfranken und Unterfranken je 150 DM und die Bezirksverbände Oberpfalz, Nürnberg-Fürth und Augsburg je $100 \mathrm{DM}^{704}$. Doch auch die Bezirksverbände konnten oder wollten ihren Zahlungsverpflichtungen vielfach nicht nachkommen. In den elf Monaten von Mai 1953 bis März 1954 fehlten in der Kasse der Landesgeschäftsstelle 7400 DM, also fast die Hälfte der zu erwartenden Gesamtsumme. Die Bezirksverbände Nürnberg-Fürth, München und Niederbayern hatten in diesem Zeitraum keine Mark an die Parteizentrale überwiesen; lediglich die Bezirksverbände Oberfranken und Oberpfalz hatten

${ }^{698}$ BayHStA, NL Ehard 64, Erläuterung zur Vermögensübersicht zum 31. 3. 1951, undatiert.

${ }^{699}$ BayHStA, NL Ehard 102, Protokoll der Tagung der Bezirksvorsitzenden am 28. 10. 1949 (Anton Hergenröder).

700 ACSP, CSU-LL, Protokoll der Landesversammlung der CSU am 17./18. 6. 1950 in Kempten.

701 Dieser Vorschlag stand seit 1949 im Raum. ACSP, CSU-LL, Protokoll der Sitzung des geschäftsführenden Landesvorstands am 5.12. 1949 und Protokolle der Sitzungen des Landesvorstands am 17. 12. 1949 und 9. 6. 1950; BayHStA, NL Ehard 2468, Protokoll der Sitzung des geschäftsführenden Landesvorstands am 5.6. 1950; ACSP, CSU-LL, Protokoll der Landesversammlung der CSU am 17./18. 6. 1950 in Kempten (Hans Ehard).

702 BayHStA, NL Ehard 64, Rundschreiben Karl Sigmund Mayrs an die Bezirksvorsitzenden der CSU vom 4. 4. 1951; BAK, NL Guttenberg 277, Bl. 12, Rundschreiben des CSU-Bezirksverbands Oberfranken, gez. Anton Hergenröder, vom 12. 4. 1951; ACSP, CSU-LTF II/1, 15-20/0, Der oberbayerische Informationsbrief 7/51 vom 16. 4. 1951.

703 Im Dezember 1949 hatte man noch mit Pauschalbeträgen in einer Höhe von 4500 DM gerechnet; ACSP, CSU-LL, Protokoll der Sitzung des geschäftsführenden Landesvorstands am 5. 12. 1949.

${ }^{204}$ BayHStA, NL Ehard 646, Aufstellung der Buchhaltung der CSU-Landesgeschäftsstelle über die monatlichen Beitragszahlungen der Bezirksverbände vom 9.4. 1954; die folgenden Zahlen finden sich ebenda. 
ihr Soll erfüllt, während alle anderen mit ihren Zahlungen mehr oder weniger stark im Rückstand waren.

Allerdings war man im Landesvorstand ohnehin davon überzeugt, daß das Beitragsaufkommen selbst im günstigsten Fall nicht ausreichen würde, um den Finanzbedarf der CSU zu decken ${ }^{705}$. Mit staatlichen Zuwendungen konnten die Parteien zu dieser Zeit noch nicht rechnen. Initiativen, die in diese Richtung gingen, waren in der CSU auch trotz der finanziellen Notlage nicht gerade populär. Als Richard Schachtner, zu dieser Zeit Landesschatzmeister, den Vorschlag aufgriff, die politischen Parteien durch eine „Wählersteuer“ zu unterstützen, mußte er zurücktreten, nachdem er in der Presse heftig angegriffen worden war ${ }^{706}$. Die Landtagsfraktion lehnte zwischen 1949 und 1951 wiederholt Anträge ab, die Fraktionsgeschäftsstellen der im Landtag vertretenen Parteien über den Staatshaushalt zu finanzieren ${ }^{707}$. Es gab zwar vereinzelte Stimmen, die zu bedenken gaben, „daß man sich schon überlegen“ müsse, „ob die Parteien nicht irgendwie in den Staat eingebaut werden" sollten, oder die darauf hinwiesen, daß es auch positive Folgen für die chronisch finanzschwache Parteiorganisation haben könnte, wenn die Fraktion mit Steuergeldern alimentiert würde. Hundhammer meldete jedoch stets größte Bedenken an und betonte, es sei nicht richtig, „daß das Parteiwesen über den Staat finanziert wird“.

\section{Einnabmen und Ausgaben der Landesgeschäftsstelle 1950-1954}

\begin{tabular}{|c|c|c|c|c|c|}
\hline & 1950 & 1951 & 1952 & 1953 & 1954 \\
\hline Einnahmen gesamt & 206688,38 & 100977,69 & 130477,77 & 402979,57 & 414685,02 \\
\hline $\begin{array}{l}\text { Beiträge der Kreis- } \\
\text { und Bezirksverbände }\end{array}$ & 7522,38 & 9795,20 & 12122 & 13181,30 & 9300 \\
\hline $\begin{array}{l}\text { Beiträge der Regierungsmit- } \\
\text { glieder und Abgeordneten }\end{array}$ & 21815 & 27084,72 & 28072,55 & 19542,70 & 42040 \\
\hline Spenden & 165437,95 & 53420,82 & 45504 & 345691,25 & 334636,06 \\
\hline Sonstiges & 11913,05 & 10676,95 & $44779,22^{709}$ & 24564,32 & 28708,96 \\
\hline Ausgaben gesamt & 205869,25 & 105602,13 & 124656,27 & 391767,69 & 414212,72 \\
\hline
\end{tabular}

Der Fraktionsvorsitzende konnte sich dabei auf eine breite Mehrheit in der Fraktion stützen, und auch Politiker wie Alfred Euerl, die ansonsten nicht zu seinen politischen

705 ACSP, CSU-LL, Protokoll der Sitzung des geschäftsführenden Landesvorstands am 5. 12. 1949 und Protokoll der Sitzung des Landesvorstands am 17. 12. 1949.

706 Archiv der CSU-Landesgruppe, Protokoll der Landesgruppensitzung am 19. 12. 1949; ACSP, CSULL, Protokoll der Sitzung des Landesvorstands am 17. 12. 1949.

707 ACSP, CSU-LTF I, 15-14, Protokolle der Fraktionssitzungen am 29.11. und 14. 12. 1949, sowie CSU-LTF II/1, 15-14, Protokoll der Fraktionssitzung am 22. 8. 1951; die folgenden Zitate von Josef Schwalber (29.11. 1949), Heinrich Emmert (14.12. 1949), Alois Hundhammer (29.11. 1949) und Alfred Euerl (14.12. 1949) ebenda. Franz Josef Strauß sprach sich in einer Fraktionssitzung am 4. 12. 1950 (CSU-LTF II/1, 15-14) für staatliche Zuschüsse an die Fraktionen aus.

708 Zusammengestellt nach BayHStA, NL Ehard 1323, Bericht des Helfers in Steuersachen Arnold Weber über die zwischen dem 22. 3. und 28. 4. 1954 vorgenommene Prüfung der CSU-Landesgeschäftsstelle (detaillierte Kassenberichte für die Jahre 1950 bis 1953 finden sich in der Anlage zu diesem Bericht), und NL Ehard 1711, Kassenbericht der CSU-Landesgeschäftsstelle für das Jahr 1954. Alle Angaben in DM.

709 Davon 16400 DM aus einem Darlehen und 21652 DM vom Bayern-Kurier. 
Freunden zählten, gaben ihm in dieser Frage recht. Staatliche Zuwendungen an die Fraktionsgeschäftsstellen, so meinte der Nürnberger Abgeordnete, seien „aus moralischen Gründen nicht zu verantworten“. Erst als sich der Koalitionspartner SPD im August 1951 dafür aussprach, den Fraktionen einen gewissen Betrag aus staatlichen Mitteln zukommen zu lassen, schwenkten die CSU-Abgeordneten zögernd auf diesen Kurs ein ${ }^{710}$.

Wie wollte die CSU dann ihren laufenden Finanzbedarf decken, der von den Mitgliedern des geschäftsführenden Landesvorstands im Dezember 1949 auf etwa $90000 \mathrm{DM}$ jährlich geschätzt wurde ${ }^{711}$ ? Von den $7500 \mathrm{DM}$, die monatlich notwendig waren, sollten $4500 \mathrm{DM}$ aus Mitgliederbeiträgen stammen und $3000 \mathrm{DM}$ von den Bundes- und Landtagsabgeordneten, den Regierungsmitgliedern in München und Bonn sowie den Mitgliedern der CSU im bayerischen Senat aufgebracht werden. In diesem Sinne beschloß der Landesausschuß auf Antrag des Landesvorstands am 14. Januar 1950, die Abgeordneten und Regierungsmitglieder in Bund und Land „zur Finanzierung der Partei heranzuziehen“. Die Mitglieder der Landesgruppe faßten daraufhin den Beschluß, monatlich 25 DM an die Landesgeschäftsstelle zu überweisen; die Bundesminister verpflichteten sich zur Zahlung von $35 \mathrm{DM}$, und wenn sie zugleich Bundestagsabgeordnete waren, von $50 \mathrm{DM}^{712}$. Die Abgeordneten der Landtagsfraktion erklärten sich bereit, der Landesgeschäftsstelle jeweils 15 DM monatlich zur Verfügung zu stellen ${ }^{713}$, und die Mitglieder der bayerischen Staatsregierung ließen der Parteizentrale jeweils $35 \mathrm{DM}$ pro Monat zukommen ${ }^{714}$. Auch wenn es vereinzelt zu Unstimmigkeiten kam und der eine oder andere Minister es mit der Zahlung seiner Beiträge nicht so genau nahm ${ }^{715}$, funktionierte dieses System im großen und ganzen gut. Bei Licht besehen waren die Abgaben der Mandatsträger und Regierungsmitglieder - zusammen mit den etwa 1000 DM, die der Wirtschaftsbeirat der CSU monatlich überwies ${ }^{716}$ die einzigen Geldmittel, mit denen die Landesgeschäftsstelle fest rechnen konnte. Es war nicht übertrieben, wenn Hans Ehard im Juni 1950 feststellte, zur Zeit werde die Partei - von Spenden abgesehen - durch die Beiträge der Abgeordneten und Kabinettsmitglieder finanziert ${ }^{717}$, und wenn der stellvertretende Parteivorsitzende Karl Sigmund Mayr murrte, es könne auf die Dauer doch nicht angehen, „dass nur ein sehr kleiner Kreis von Parteifreunden für die Finanzierung der Partei“ aufkomme ${ }^{718}$. Die Beiträge der Abgeordneten und Regierungsmitglieder überstiegen die Einnahmen der Landesgeschäftsstelle aus den Beiträgen der einfachen Parteimitglieder zwischen 1950 und 1954 bei weitem. 1950, 1951 und 1952 betrug das Mißverhältnis von Umlagen und

710 ACSP, CSU-LTF II/1, 15-14, Protokoll der Sitzung des Fraktionsvorstands am 27. 8. 1951.

71 ACSP, CSU-LL, Protokoll der Sitzung des geschäftsführenden Landesvorstands am 5. 12. 1949; das folgende nach dem Protokoll dieser Sitzung.

712 ACSP, CSU-LTF II/1, 15-11, Josef Brunner an Alois Hundhammer vom 7. 2. 1950.

713 ACSP, CSU-LTF II/1, 15-11, Alois Hundhammer an Josef Brunner vom 9. 3. 1950; in der Folgezeit wurden die Sätze aus verschiedenen Gründen immer wieder leicht verändert; Dokumente hierzu unter dieser Signatur und unter CSU-LTF II/2, 6-10/1, CSU-LTF II/2, 6-46 und CSU-LTF II/2, 6-47.

714 ACSP, NL Seidel 35 a, Franz Josef Strauß an Hanns Seidel vom 13. 6. 1951.

715 BayHStA, NL Ehard 646, Aufstellung der Buchhaltung der CSU-Landesgeschäftsstelle über die Beitragsrückstände der CSU-Mitglieder in der bayerischen Staatsregierung vom 24. 2. 1954.

716 BayHStA, NL Ehard 1323, Hugo Geiger an Hans Ehard vom 14. 11. 1953.

717 ACSP, CSU-LL, Protokoll der Sitzung des Landesvorstands am 9. 6. 1950.

718 BayHStA, NL Ehard 64, Rundschreiben Karl Sigmund Mayrs an die Bezirksvorsitzenden der CSU vom 4. 4. 1951. 
Mitgliederbeiträgen zwischen 2,9 und 2,3 zu 1, 1953 erreichte es mit 1,4 zu 1 seine günstigste Relation, während sich die Schere 1954 bei einem Verhältnis von 4,5 zu 1 weiter geöffnet hatte als jemals zuvor.

Es war Hans Ehard seit 1949 zwar gelungen, die Schulden der Landesgeschäftsstelle aus der Zeit der Währungsreform weitgehend abzubauen, so daß nur noch wenige Altlasten vorhanden waren ${ }^{719}$, die Beiträge der Abgeordneten und Regierungsmitglieder, die monatlichen Dotationen des Wirtschaftsbeirats und die spärlichen Mittel aus den Mitgliederbeiträgen reichten aber dennoch kaum aus, um den Etat der Landesgeschäftsstelle zu decken. Schon unvorhergesehene Ausgaben in vergleichsweise geringer Höhe reichten aus, um die Verantwortlichen in der Parteizentrale in Schwierigkeiten zu bringen, ob das nun Steuernachforderungen des Finanzamts waren ${ }^{720}$ oder Auslagen verdienter Funktionsträger. Die 71jährige Thusnelda Lang-Brumann, immerhin Mitglied des Landesvorstands und ehemalige BVP-Reichstagsabgeordnete, ersuchte die Landesgeschäftsstelle fünfmal vergeblich um die Erstattung von $150 \mathrm{DM}$, die sie für die Arbeitsgemeinschaft der Frauen in der CSU ausgelegt hatte, bevor sie an Josef Brunner schrieb:

„Ich habe schon letzten Monat Geld für mich selber aufnehmen müssen, wofür ich hohe Zinsen bezahle, und stehe jetzt vor dem letzten Fälligkeitstermin meiner Hypothekenzinsen, von denen ich nicht weiss, woher sie nehmen. Ich kann einfach nicht aus meiner kleinen Lehrerinnenpension, von der ich drei Menschen erhalte, auch noch die Auslagen für die Partei bestreiten. Jahrelang habe ich es ohnehin getan. [...] In meiner heutigen Lage ist es schlechterdings unmöglich. Sie kennen mich gut genug, Herr Generalsekretär, um zu wissen, dass ich, sähe ich irgend einen anderen Weg, uns die demütigenden Bittgänge [...] mit all dem kränkenden Drum und Dran nicht auferlegen würde. “721

Im Juli 1952 war die Landesgeschäftsstelle nicht in der Lage, die Gehälter auszuzahlen und die fälligen Rechnungen zu begleichen. Wieder einmal mußte die Landesleitung Löcher durch die Aufnahme von kurzfristigen Krediten stopfen, deren Rückzahlung fast jedesmal zu einem Vabanquespiel wurde ${ }^{722}$. Die Verbindlichkeiten der Landesgeschäftsstelle betrugen im September 1952 immerhin fast $35000 \mathrm{DM}^{723}$ !

Kein Wunder, daß die CSU - zumal in Wahlkampfzeiten - in hohem Maße von Spenden abhängig war. In den Wahljahren 1950, 1953 und 1954 machten die Spenden 80 bis 85 Prozent aller Einnahmen der Landesgeschäftsstelle aus, die ohne diese Mittel gar nicht kampagnenfähig gewesen wäre. Die eifrigsten Spendensammler der CSU waren Parteichef Ehard, Finanzminister Schäffer ${ }^{724}$ und Franz Josef Strauß. Strauß, der in Bonn ein „Wirtschaftsbüro“ unterhielt, trug allein 1952 und 1953 Spenden in einer Höhe von fast 98000 DM zusammen, die größtenteils der Landesleitung zugedacht waren, aber auch an verschiedene Kreisverbände oder einzelne Personen

719 ACSP, CSU-LL, Protokoll der Sitzung des geschäftsführenden Landesvorstands am 5. 12. 1949; diese Altlasten waren vor allem der Staatskredit aus dem Jahre 1948 und die Verbindlichkeiten des liquidierten Parteiverlags Der Gerade Weg.

720 AsD, SPD-Landesverband Bayern 288, Aufstellung des Finanzamts für Körperschaften über die Steuerrückstände politischer Parteien vom 8. 3. 1951.

721 ACSP, CSU-LTF II/1, 15-20, Thusnelda Lang-Brumann an Josef Brunner vom 22. 4. 1951; Hervorhebung im Original.

722 BSB, NL Schwend 13, Franz Josef Strauß an Hans Ehard vom 2. 7. 1952.

${ }^{723}$ BayHStA, NL Ehard 77, Hugo Geiger an Hans Ehard vom 23. 9. 1952.

724 Entsprechende Dokumente im BayHStA, NL Ehard 170. 
gingen $^{725}$. Daß man in der CSU munkelte, Strauß würde diese Mittel gezielt einsetzen, um seine Karriere in der Partei zu fördern, konnte kaum ausbleiben.

Das Sammeln von Spenden war jedoch mitunter ein mühsames Geschäft. Hinderlich war vor allem, daß Zuwendungen an politische Parteien zunächst nicht von der Einkommen- und Körperschaftsteuer abgesetzt werden konnten, was die Spendenfreudigkeit von Unternehmen ebenso dämpfte wie die von Privatpersonen. Das Steuerrecht ließ lediglich einige unbequeme Schlupflöcher ${ }^{726}$. Die Situation änderte sich erst, als der Bundestag im November 1954 beschloß, Spenden an politische Parteien als staatspolitische Aufwendungen künftig wie Spenden für kirchliche, caritative oder wissenschaftliche Zwecke zu behandeln und somit steuerlich zu begünstigen ${ }^{727}$. Da es kein Parteiengesetz gab, bewegten sich die Spendensammler gleichsam in einem Vakuum, und es mag vorgekommen sein, daß die finanziellen $Z$ wänge zu Transaktionen führten, die sich am Rande der Legalität bewegten ${ }^{728}$. Da Hans Ehard nicht die alleinige Verantwortung in dieser heiklen Angelegenheit tragen wollte, berief der Landesausschuß im Juni 1950 eine siebenköpfige Kontrollkommission ${ }^{729}$. Dieses Gremium, in dem einmal mehr die Bezirksvorsitzenden wie Karl Sigmund Mayr oder Hans Herrmann ${ }^{730}$ eine wichtige Rolle spielten, sollte dem Landesvorsitzenden und dem Landesvorstand „Entlastung für direkt gegebene Spenden“ erteilen. Die CSU blieb dennoch von Parteispendenaffären nicht verschont, auch wenn keine Mitglieder der engeren Parteiführung darin verstrickt waren. 1952 stolperte Josef Müller über die Affäre Auerbach, und 1954 war es der Landtagsabgeordnete und Memminger Landrat Karl Lenz, der im Zusammenhang mit der sogenannten Metex-Affäre ins Gerede kam ${ }^{731}$.

$\mathrm{Zu}$ den Gönnern der CSU gehörten der einflußreiche Landesverband der Bayerischen Industrie, Wirtschaftsverbände wie der Landesverband des Bayerischen Groß- und AuBenhandels oder Interessengruppen wie der Verband Bayerischer Grundbesitzer ${ }^{732}$. An-

725 BayHStA, NL Ehard 646, Franz Josef Strauß an Hans Ehard vom 5. 1. 1954; das folgende Gerücht wird ebenda kolportiert. Zum "Wirtschaftsbüro" von Strauß vgl. die Akten im ACDP, NL Balke 044/4.

726 Vgl. den diesbezüglichen Schriftwechsel im ACSP, NL Elsen 3. 2., und im BayHStA, NL Ehard 298; NL Ehard 1323, „Bericht über Einsparungsmöglichkeiten in der Landesgeschäftsstelle der CSU“ vom 2. 4. 1954.

727 Vgl. dazu Dübber, Parteifinanzierung, S. 15-44.

728 BayHStA, NL Ehard 1363, Franz Josef Strauß an Hans Ehard vom 25. 7. 1950.

729 ACSP, CSU-LL, Protokoll der Sitzung des Landesausschusses der CSU am 10. 6. 1950 in München. Der Kontrollkommission gehörten Franz Elsen, Karl Sigmund Mayr, Hans Herrmann, Fritz von Haniel-Niethammer, Josef Fischer, Direktor Steffan und Hans Schwägerl an.

730 Hans Herrmann, geb. 26. 1. 1889 in Regensburg, gest. 20. 8. 1959, kath., humanistisches Gymnasium in Metten und Regensburg, 1910 Abitur, Studium der Rechtswissenschaft und der Volkswirtschaft in Würzburg und München, nach dem Vorbereitungsdienst für Verwaltungsjuristen 1917-1919 juristischer Hilfsarbeiter bei der Stadtverwaltung Regensburg, 1920 Staatsprüfung für den höheren Justizund Verwaltungsdienst, anschließend rechtsanwaltschaftlicher Hilfsarbeiter in München, juristischer Hilfsarbeiter der Stadt Regensburg, Ratsassessor und Stadtsyndikus in Regensburg, seit 1922 berufsmäßiger Stadtrat (Rechtsrat), 1925-1945 rechtskundiger Bürgermeister von Regensburg, seit 1918 BVP-Mitglied, 1933 MdR (BVP), 1933 vorübergehend verhaftet, seit 1935 NSDAP-Mitglied, förderndes Mitglied der SS, 1945 von der amerikanischen Militärregierung zunächst mit der Leitung der Stadtverwaltung beauftragt, jedoch wegen seiner Tätigkeit während des Dritten Reiches nach wenigen Wochen wieder entlassen, Mitbegründer der CSU in Regensburg, 1950-1955 Vorsitzender des CSU-Bezirksverbands Oberpfalz, 1950-1955 Mitglied des Landesvorstands der CSU, 19521959 Oberbürgermeister von Regensburg, 1954-1958 MdL (CSU).

731 ACSP, CSU-LL, Protokoll der Sitzung des Landesvorstands am 8. 10. 1954; vgl. auch den entsprechenden Ordner im ACSP, LSG.

${ }^{732}$ BayHStA, NL Ehard 74, Rundschreiben des Landesverbands des Bayerischen Groß- und Außen- 
fang 1953 wurde unter maßgeblicher Mitwirkung des Landesverbands der Bayerischen Industrie die Volkswirtschaftliche Gesellschaft Bayern gegründet ${ }^{733}$, die in der Folgezeit eine maßgebliche Rolle bei der Finanzierung der CSU spielen sollte ${ }^{734}$. Mit August Wilhelm Schmidt und Siegfried Balke gehörten dem Vorstand der Volkswirtschaftlichen Gesellschaft Persönlichkeiten an, die - wie Schmidt - in der CSU bereits Ämter innehatten oder - wie Balke - in naher Zukunft in der Partei hervortreten sollten. Im Wahljahr 1954 vermittelte die Volkswirtschaftliche Gesellschaft der CSU allein $167000 \mathrm{DM}^{735}$.

Die Abhängigkeit der CSU von Spenden warf zweifellos die Frage auf, inwieweit die Partei von ihren Geldgebern beeinflußt werden konnte. Hans Ehard hatte im Dezember 1949 erklärt, die notwendige enge Zusammenarbeit mit den „uns nahestehenden Wirtschaftskreisen“ dürfe nicht dazu führen, daß die CSU ihre Grundsätze preisgebe ${ }^{736}$. Da mit den Spenden großer Wirtschaftsverbände auch Erwartungen verbunden waren ${ }^{737}$, kam es in der Praxis aber durchaus zu Rücksichtnahmen der Parteiführung auf deren Interessen. Im Juni 1950 wurde in einer Absprache mit Generaldirektor Otto Seeling vom Landesverband der Bayerischen Industrie sogar unter anderem vereinbart, die „Aufstellung der Landtagskandidaten [...] im gegenseitigen Einvernehmen und nach vorheriger Absprache“ durchzuführen ${ }^{738}$. Seeling scheute sich auch nicht, führenden CSU-Politikern offen mit dem Entzug der finanziellen Unterstützung zu drohen, um den Wünschen des Landesverbands Nachdruck zu verleihen ${ }^{739}$. Da sich die CSU dies keinesfalls leisten konnte, war man in der Führungsriege der Partei bemüht, Mißverständnisse oder tatsächliche Differenzen so schnell wie möglich beizulegen ${ }^{740}$.

Die kritische Finanzlage blieb in der gesamten Amtszeit von Hans Ehard ein Kardinalproblem der CSU und setzte jeder organisationspolitischen Initiative enge Grenzen. So war die Parteiführung im Zuge des Bundestagswahlkampfes 1953 daran gegangen, die Landesgeschäftsstelle auszubauen, mußte aber erkennen, daß sie sich übernommen hatte, als nach den Wahlen die Spenden ausblieben ${ }^{741}$. Wieder einmal schien es nur einen Ausweg zu geben: Einsparungen und Entlassungen - und das vor den bayerischen Landtagswahlen! Der Sieg bei den Bundestagswahlen, der der CSU 50 Mandate beschert hatte, öffnete jedoch die Aussicht, in nahezu allen bayerischen Bundeswahlkreisen hauptamtlich besetzte Abgeordnetenbüros oder Geschäftsstellen einzurichten und so auch die Parteiverwaltung auf eine neue Grundlage zu stellen ${ }^{742}$. Die Überlegungen

handels e. V. vom Januar 1953; ACSP, NL Elsen 3. 2., Landesverband des Bayerischen Groß- und Einzelhandels an Franz Elsen vom 4. 11. 1950; vgl. Dübber, Parteifinanzierung, S. 16.

733 BayHStA, NL Ehard 74, Aktennotiz "Wahlfinanzierung durch die Wirtschaft" für Karl Schwend vom 25. 2. 1953.

${ }^{734}$ Vgl. auch Dokumente zur parteipolitischen Entwicklung, Bd. 8, S. 19-22.

735 BayHStA, NL Ehard 1711, Aufstellung der CSU-Landesgeschäftsstelle über die 1954 eingegangenen Spenden vom 8.1.1955.

736 ACSP, CSU-LL, „Besprechungsprotokoll für die Sitzung des geschäftsführenden Vorstandes unserer Partei“ am 5. 12. 1949 vom 3. 12. 1949.

737 Vgl. den Spendenaufruf des Landesverbands der Bayerischen Industrie vom 17. 4. 1950, in: Dokumente zur parteipolitischen Entwicklung, Bd. 8, S. $23 \mathrm{f}$.

738 BSB, NL Schwend 11, Aktennotiz vom 20.6. 1950; ACSP, NL Elsen 3. 2., Aktennotiz vom 23. 6. 1950.

739 ACSP, NL Seidel 21, Otto Seeling an Georg Haindl vom 27.11. 1952.

$740 \mathrm{Vgl}$. den entsprechenden Schriftwechsel im ACSP, NL Seidel 20 und NL Seidel 21, BSB, NL Schwend 13, BayHStA, NL Ehard 115 und NL Ehard 170.

741 BayHStA, NL Ehard 1323, Hugo Geiger an Hans Ehard vom 14.11. 1953, und „Bericht über Einsparungsmöglichkeiten in der Landesgeschäftsstelle der CSU“ vom 2. 4. 1954; NL Ehard 73, Hans Stützle an Hans Ehard vom 10. 9. 1953.

${ }^{742}$ BSB, NL Schwend 19, Bericht Heinz Brencks über eine Landesgruppensitzung vom 18. 12. 1953; 
dazu waren 1954 schon relativ weit gediehen, als die CSU nach den Landtagswahlen überraschend in die Opposition gezwungen wurde. Nun, da die Regierungsmacht vorläufig verspielt war, gewann die Organisationspolitik eine neue Qualität. Der Vertriebenenpolitiker und Bundestagsabgeordnete Hans Schütz war es, der im Landesausschuß am 18. Dezember 1954 die Richtung für die Arbeit der kommenden Monate vorgab:

„Der größte Gegner muß dieser CSU in Bayern lassen, daß sie in all den Jahren, in denen sie regiert hat, eine gute Politik gemacht hat. Aber sie hat in all den Jahren eine schlechte Organisation gehabt. In der Opposition verlagert sich nun das parteipolitische Schwergewicht von der Politik zur Organisation; denn in der Opposition werden die Gedanken nur wirksam, wenn sie ein Echo in der Bevölkerung finden, und das geht nur über den Weg der Organisation. Soll es doch der Meier holen! 52 Bundestagsabgeordnete in Bonn, 84 Landtagsabgeordnete in Bayern - probieren wir es einmal und machen wir einen halbwegs vernünftigen Plan! [. . .] Das muß doch möglich sein. Haben wir bisher eine gute Politik gemacht, so wollen wir es jetzt auch mit einer guten Organisation als der Voraussetzung für eine wirksame Opposition versuchen. “743

Archiv der CSU-Landesgruppe, Protokolle der Landesgruppensitzungen am 13. 9. und 2. 12. 1953; ACSP, CSU-LL, Protokoll der Sitzung des Landesausschusses der CSU am 15. 1. 1954 in Rothenburg ob der Tauber (Franz Sackmann).

${ }^{743}$ ACSP, CSU-LL, Protokoll der Sitzung des Landesausschusses der CSU am 18. 12. 1954 in München. 